
THE UNIVERSITY

OF ILLINOIS

LIBRARY

q 913.798

J58a 
Return this book on or before the Latest Date stamped below. A charge is made on all overdue books.

University of Illinois Library

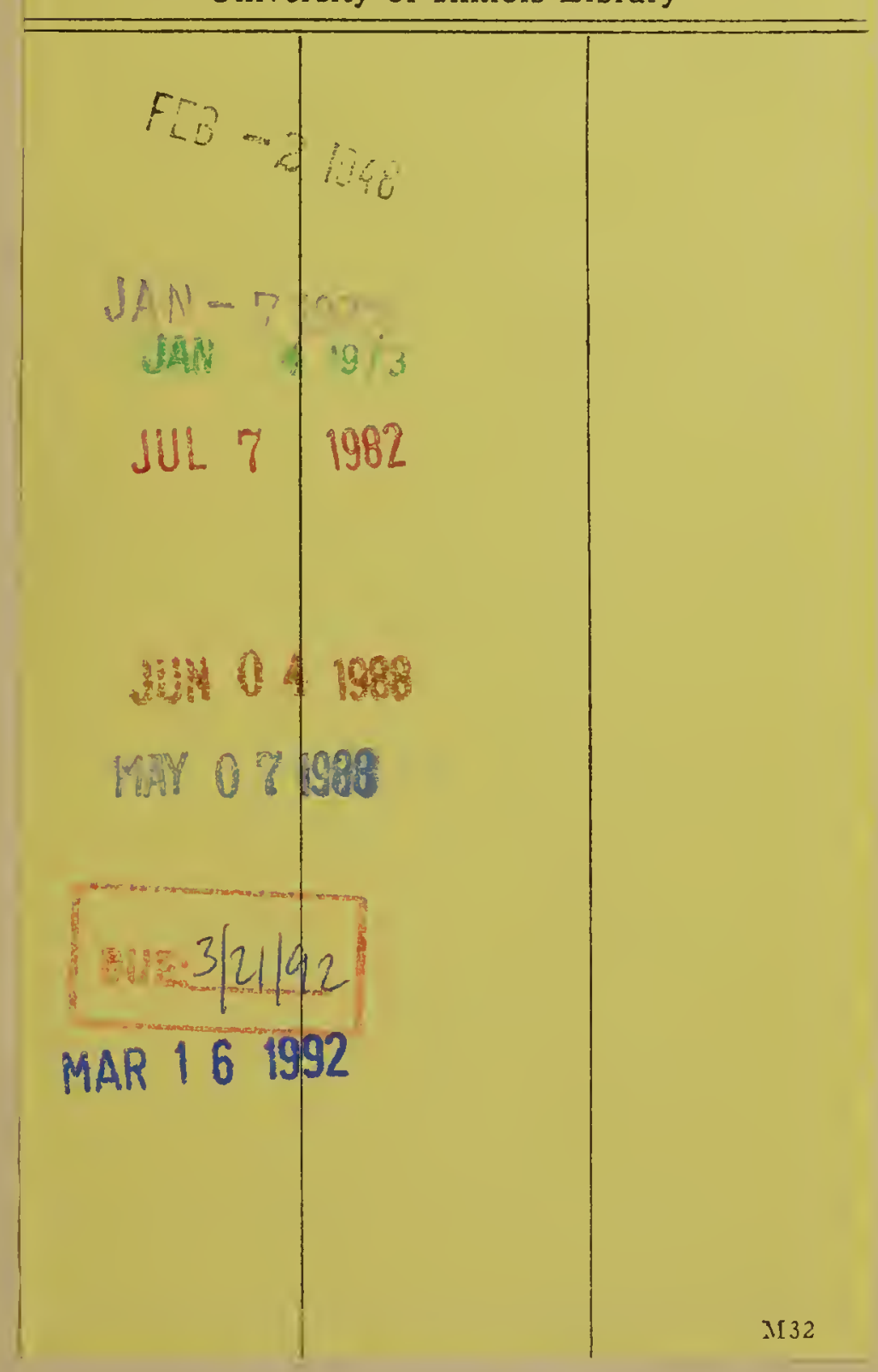





\title{
ARCHAEOLOGICAL INVESTIGATIONS IN THE \\ AlEuTian IsLANDS
}

\author{
$B Y$ \\ WALDEMAR JOCHELSON
}

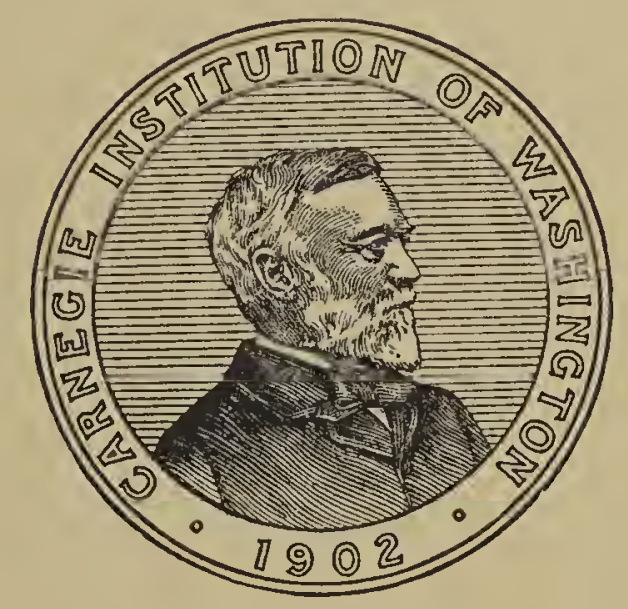

Published by the Carnegie Institution of Washington WASHington, October, 1925 
CARNEGIE INSTITUTION OF WASHINGTON Publication No. 367

Che Lord etzattimore Press BALTIMORE, MD., U. S. 


\section{$8 \begin{aligned} & 913.798 \\ & 558 \mathrm{a}\end{aligned}$}

CONTENTS.

PAGE

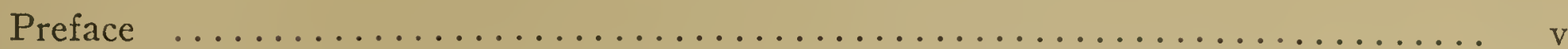

List of plates $\ldots \ldots \ldots \ldots \ldots \ldots \ldots \ldots \ldots \ldots \ldots \ldots \ldots \ldots \ldots \ldots \ldots \ldots \ldots \ldots \ldots \ldots$ vii

List of text-figures $\ldots \ldots \ldots \ldots \ldots \ldots \ldots \ldots \ldots \ldots \ldots \ldots \ldots \ldots \ldots \ldots \ldots$ viii

Chapter I.

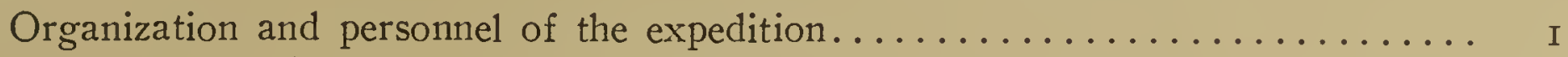

Reasons for an investigation of the Aleut......................... 2 Chapter II.

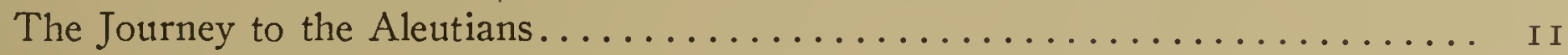

Preparations for the journey............................... I

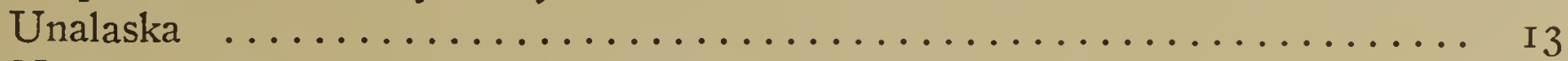

Natural features of the Aleutian Islands.................... I9

Chapter III.

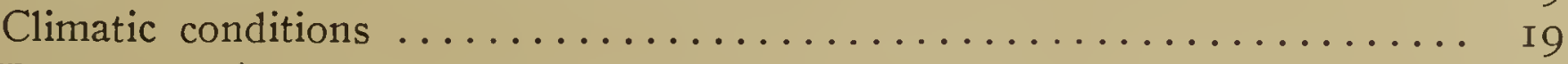

Excavation of ancient Aleut village sites....................... I

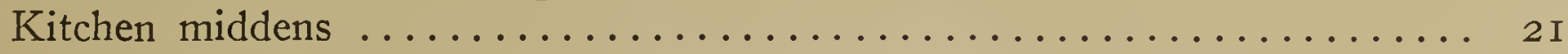

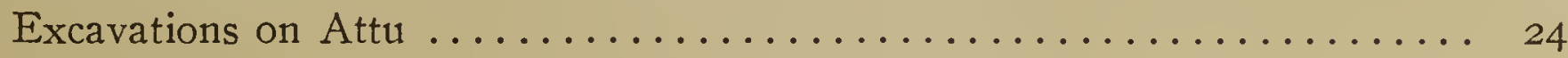

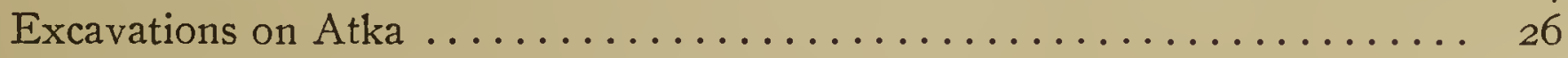

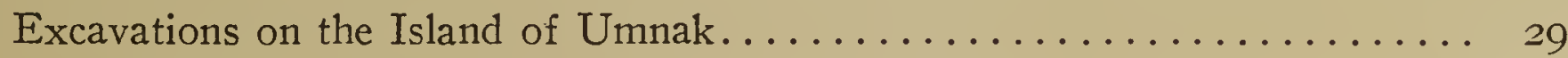

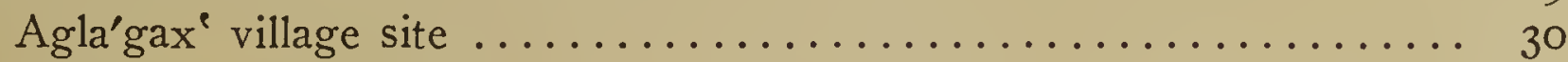

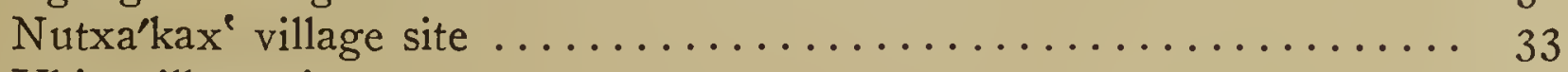

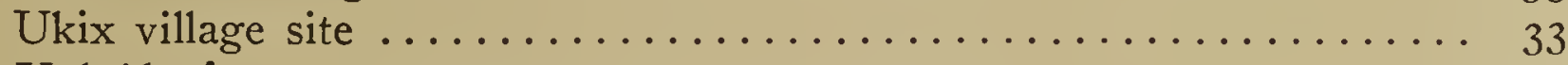

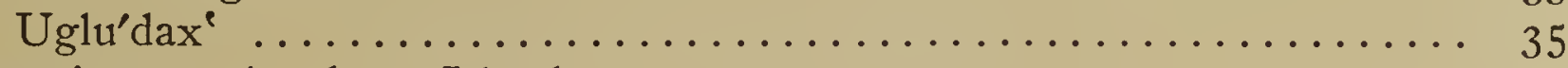

Excavations on Amaknax Island . . . . . . . . . . . . . . . . . 37

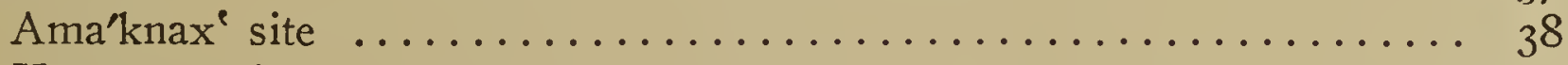

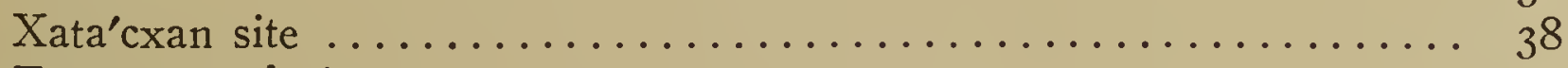

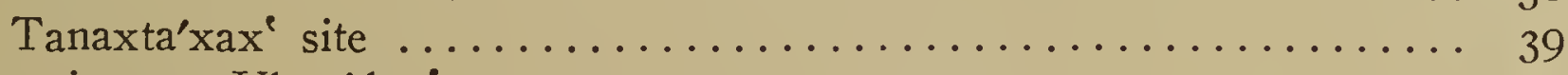

Excavations on Ukna'dax $\ldots \ldots \ldots \ldots \ldots \ldots \ldots \ldots \ldots \ldots \ldots \ldots . \ldots \ldots$

Chapter IV.

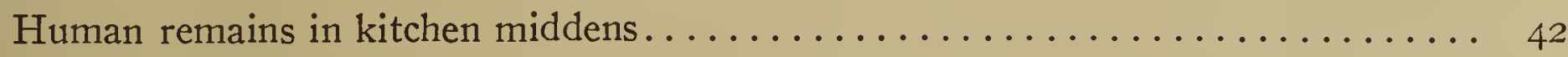
Chapter V.

Archæological remains from kitchen middens................... 53

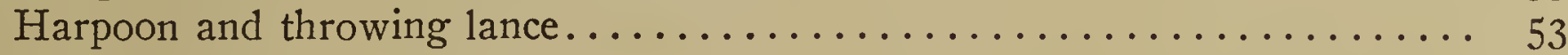

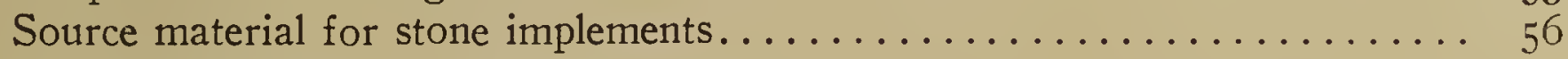

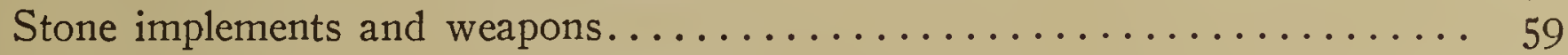

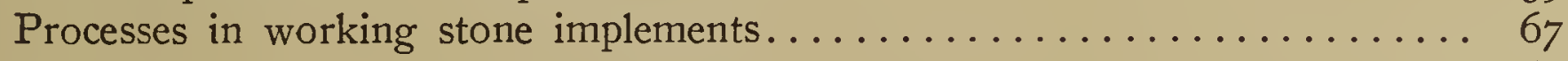

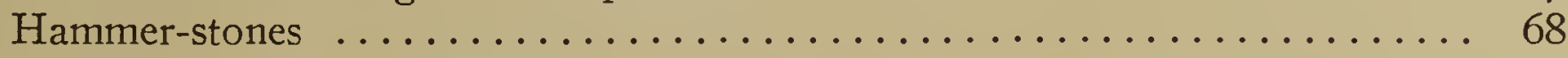

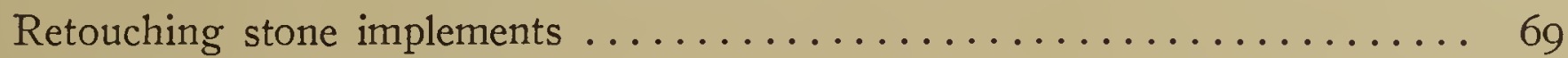

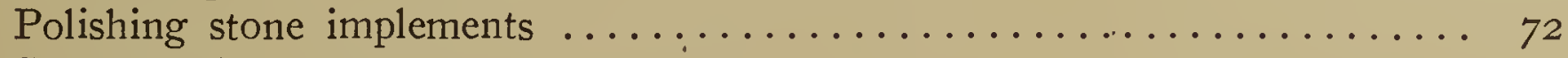

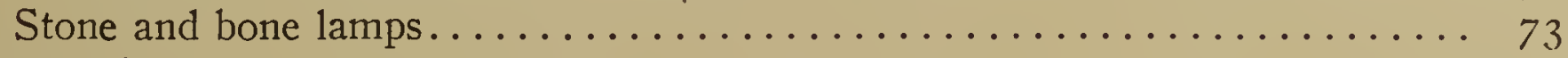

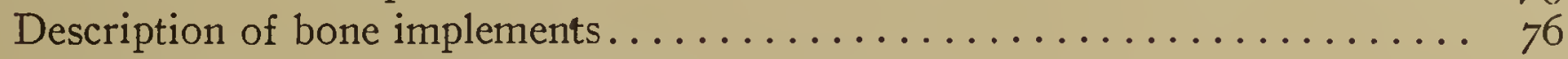

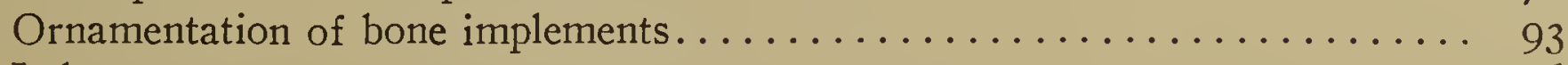

Chapter VI.

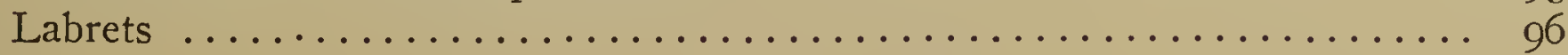

Critical survey of previous work in Aleutian archæology $\ldots \ldots \ldots \ldots \ldots \ldots \ldots$ IO I Chapter VII.

Archæological and ethnological inferences..................... I I

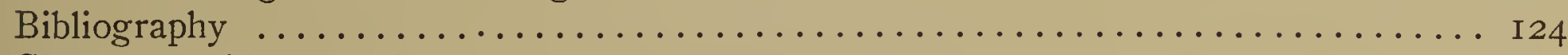

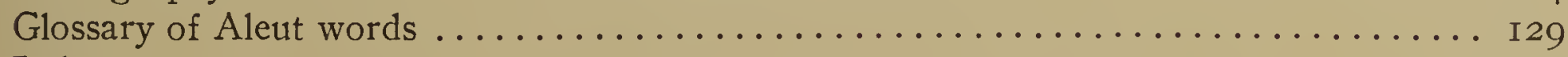

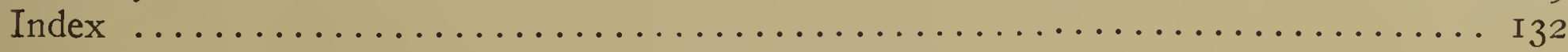





\section{PREFACE.}

During the year 1909-10, the author led the anthropological division of the Aleut-Kamchatka Expedition, sent out under the auspices of the Imperial Russian Geographical Society. Part of the time spent in the Aleutian Islands was given to archæological research, and the results of these investigations are presented in the accompanying paper. The original manuscript was prepared in Russian, was ready for the printer in 1916, and was presented to the Academy of Sciences of Russia, where it received the Akhmatoff prize. Its publication was, however, delayed because of the war. Later, in the autumn of 1917 when the Russian revolution broke out, the office of Riaboushinsky Brothers in Moscow, where the manuscript was to be printed, was destroyed by the mob, and it was with difficulty that the author succeeded in saving the Russian manuscript, drawings, and maps from destruction. Of the plates, however, but one copy of each was saved, from which the reproduction used here was made. After reaching the United States the author rewrote the manuscript in English and added new material, so as to include a comparative study of the EskimoAleut collections in America. To this end, collections in the following institutions were studied: the United States National Museum, Washington; the American Museum of Natural History, New York; the Peabody Museum of Harvard University, Cambridge; the University Museum, Philadelphia; the Museum of the American Indian, Heye Foundation, New York.

The specimens herein described are on exhibition in the Ethnographical Division of the Rumiantzeff Museum in Moscow. The archæological and ethnographical objects obtained on the Aleutian Islands and the Kamchatka Peninsula occupy a large hall called the Riaboushinsky Hall. The anatomical specimens, however, were deposited in the Museum of the Anthropological Institute of the Moscow University. The plates for the original manuscript were made in the photoartistic institute of P. P. Pavloff in Moscow, from photographs taken by the author. The drawings were made in Moscow by the artists W. I. Kondratyeff, A. I. Warshavsky, and P. S. Listchuk. Mr. C. A. Weckerly, of the U. S. Geological Survey, has also contributed some redrawings and other artistic work.

Acknowledgment should be made here to Professor W. L. Komarov for the determination of the botanical specimens obtained on the islands; to Professor W. A. Obruchov for a like determination of the minerals of which the ancient Aleut made their stone implements and weapons; to Professor N. M. Knipovich for the definition of shells of mollusks found in the Aleut excavations. The author is under special obligations to Professor Obruchov for the numerous visits he paid to the Rumiantzeff Museum to study the stone objects in the Aleut collection, and to Professor C. I. 
- Bogdanovich, who kindly revised the manuscript of the first and last chapters of this work in so far as they deal with geological problems.

In the excavations on the Aleutian Islands the author was assisted by Mrs. Jochelson, who was also the anthropologist of the expedition, by A. M. Yachmeneff, the Aleut chief of Unalaska Island, and by L. I. Sivtzeff, the assistant priest of the Greek Catholic Church in Unalaska.

Finally, in respect to the publication in its present form, the author is under obligations to the American Museum of Natural History, New York, for assistance in the clerical work and the revision of the English translation.

WALDEMAR JocheLson. 


\section{ILLUSTRATIONS.}

\section{PLATES.}

I. Nazan Bay and the village on Atka Island; 2, Excavation of the ancient village site, Atxa'lax', on Atka Island; 3, 4, Excavations of the ancient village site, Nani'kax', Attu Island; 5, Excavation of Uglu'dax' village site, Umnak Island.

2. Mollusks: I, Venus petiti Desh (Aleut, satma'yux') ; 2, Saxidomus nuttali Conr, Saxidomus squalidus Desh (Aleut, imu'lux') ; 3, Pecten sp.; 4, Cardium sp.; 5, Litorina sitchana Mid. (Aleut, cimka'yux'); 6, Acmæa patina Esch. (Aleut, ci'knax'); 7, Katharina tunicata Wood (Aleut, kasi'gux', Attu dialect, qasu'gix') ; 8, Mytilus edulis L. (Aleut, hwa'yigix ) ; 9, Triton cancellatus $\operatorname{Lan} . . . \ldots \ldots \ldots \ldots \ldots \ldots \ldots$

3. Excavations on Umnak Island. I, section of Pit 3 at the Ukix village site, depth 2.5 meters; 2 , section of Pit 2 at the Agla'gax' village site, depth 6.5 meters; 3 , bones of whales amid the kitchen refuse on the ancient village site, Agla'gax'; 4, excavation of Pit 2 at the Uglu'dax' village site at the beginning of operations; 5 , Aleut laborers lunching in the depression formed by a former underground dwelling at the Uglu'dax' site; 6 , neck of land between the bay and a lake on which was located the

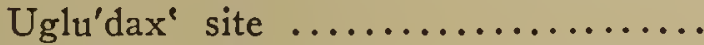

4. I, Drying skulls and other human bones uncovered by the excavations on Umnak Island. In the sacks is the party's coal supply in preparation for wintering on the island. 2, section of Pit 4 of the Nani'kax site, Attu Island, depth, 5 meters; 3, section of Pit 2, Umnak site, Umnak Island, depth, 2.5 meters.....

5. Excavations on Umnak Island. I, section of Pit 3, Uglu'dax' Site, depth, 2.I meters; 2, section of Pit I, Ukix site, depth, 2.3 meters; 3 , section of Pit I, Uglu'dax site, depth, 3.3 meters..............

6. Section of pit at the ancient village site Xata'cxan, Ama'knax' Island, depth, 5.I meters; 2 to 5 , parts of section of Pit I of the Uglu'dax' site, Umnak Island, showing echini and mollusk shells....

7. I, Members of the expedition and Aleut laborers crossing a mountain ridge on Attu Island; 2, camp at a village site, Attu Island; 3 , beginning excavation of a pit at the Sin village site, Attu Island; the frame of the roof is of whale-bone;
8. I. Burial cave $B$, near the Atxa'lax site, Atka Island, before excavation ; 2 , burial cave $C$, near Atxa'lax', Atka Island, before removing the skeletal remains; 3 , burial cave $C$, after removal of skeletal remains ; 4, location of the ancient village, Atxa'lax' $(A)$ and two burial caves ( $B$ and $C$ ), Atka Island; 5, waterfall near Atxa'lax', an ancient village site.....

9. I, Excavations at the ancient village site, Ama'knax', situated on a neck of land on Ama'knax' Island; 2, bird's-eye view of the neck of land on Ama'knax' Island; 3, burial cave on Ama'knax Island investigated by Doctor Dall....

Io. Model of section of Pit 3 on ancient village site, Agla'gax', Umnak Island, with skeleton discovered at depth of I.9 meters. The model is on exhibition in the Rumiantzeff Museum in Moscow...... II. I, skeleton found in the excavation of the Nani'kax' site, Attu Island, at depth of I.5 meters; 2, skeleton from the Agla'gax' site, Umnak Island, found at depth of 1.9 meters; 3, skeleton from the Ukix site, Umnak Island, found at depth of I.8 meters; 4, skeleton from the Uglu'dax' Site, Umnak Island, found at depth of I.I meters...............

I2. I, skeleton from Ukix, Umnak Island, found at depth of I.2 meters; 2, skeleton from Uglu'dax', Umnak Island, found at depth of I.I meters.....................

I3. I, skeleton from Ukix, Umnak Island, found at depth of I.2 meters; 2 , skeleton from Uglu'dax', Umnak Island, found at depth of I.2 meters; 3 , skeleton of a child from Ukix, Umnak Island, found at depth of I.5 meters; 4, skeleton from Natxu'kax', Umnak Island, found at depth of I.7 meters .........................

I4. I, four skeletons found in excavation of Nani'kax', Attu Island, at depth of I.5 meters; 2 , five skeletons found in the excavation of Agla'gax', Umnak Island, at depth of I.8 meters; 3, skeleton from Agla'gax', Umnak Island, found at depth of $\mathrm{I} .5$ meters; 4, skeleton from Tanaxta'xax', Ama'knax Island, found at depth of I.3 meters ....................... 52
PAGE 


\section{PLATES-Continued.}

I5. Stone knives, adzes, and other stone implements. About two-fifths natural size...

16. Knives and other implements of stone. About two-fifths natural size...............

17. Hammers, sinkers, paint-grinders, and other implements of stone. About two-fifths

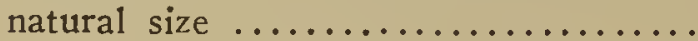

18. Stone lamps. About two-sevenths natural size.

19. I, 2, stone lamps; 3 , bowl made from a whale's vertebra; 4 , stone on which paints were ground, a grinder, and pieces of ocher. About one-fourth natural size........

20. I, 2, 5, and 7 , bone lamps; $3,4,8$, and 9 , stone lamps; I0, bone mortar for grinding tobacco. About two-sevenths natural size ........................ 76

2I. I, stone lamp in process of manufacturing; 2 , stone frying-pan ............... 76

22. Bone harpoon-heads, knife-hafts, adze-handles, scrapers, flakers, and other bone implements. About two-fifths natural size...

23. Bone heads of war and hunting darts and
PAGE
58

64

66

72

74

76

78

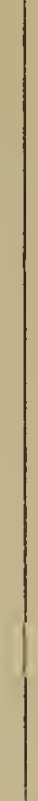

24. Bone points for throwing-implements, bird points for throwing-implements, bird
darts, small harpoons, and sections of other bone implements. About twofifths natural size................

5. Bone points for throwing-implements, foreshafts of bow-arrows, sections of fishhooks, and other bone implements. About two-fifths natural size......... 26. Bone spoons, wedges, root-diggers, and other bone implements. About two-sevenths natural size ....................

27. I, Bone wedges, drill-heads, and a bone adze, about one-third natural size; 2 , bone awls and a knife, about three-fifths natural size; 3 , bone harpoon heads. About one-half natural size........ 90

28. $A$, bone awls and chisels, about one-half natural size; $B$, bone awls and needles, about three-fifths natural size; $C$, bone awls. About one-half natural size..........

\section{TEXT-FIGURES.}

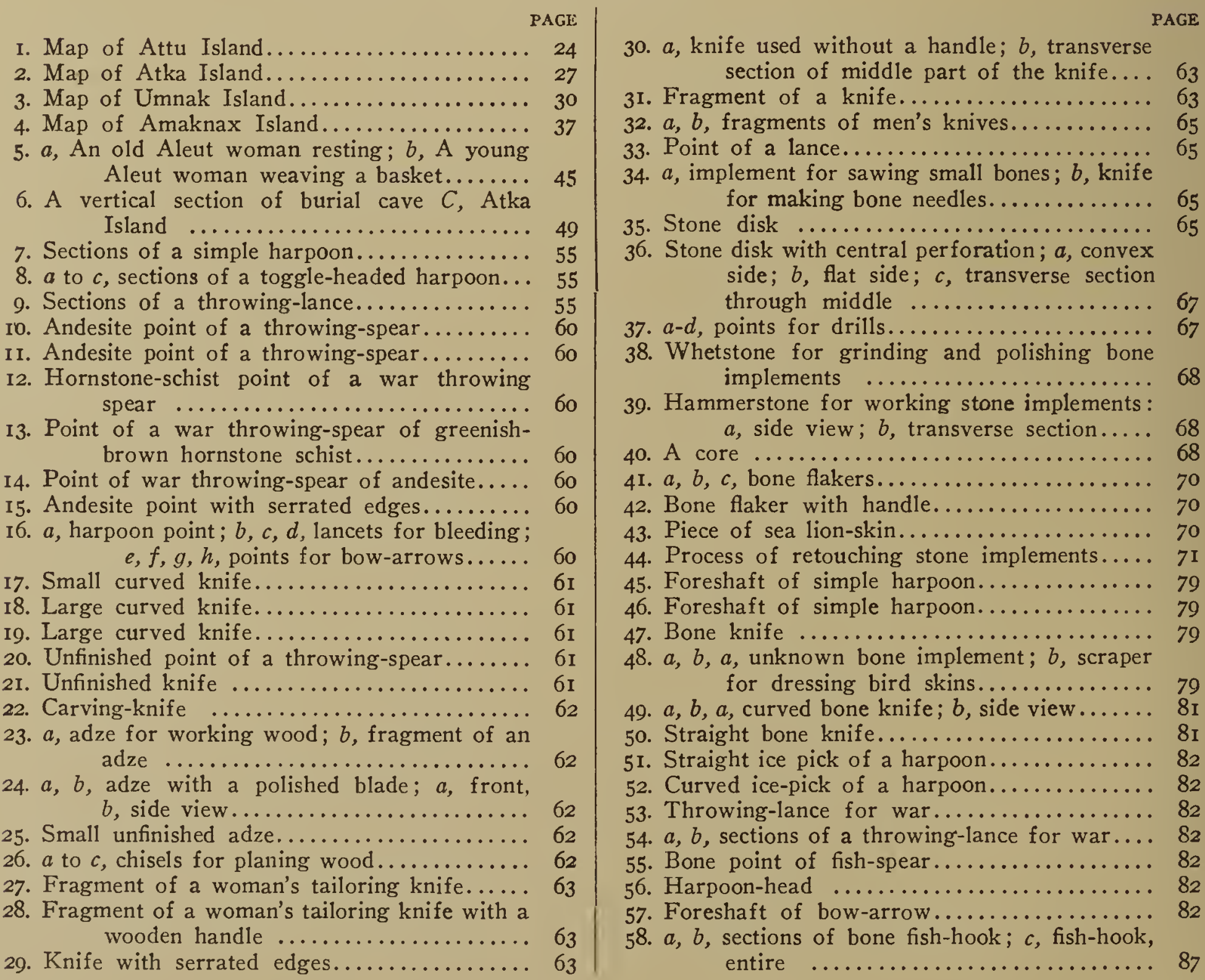




\section{TEXT FIGURES-Continued.}

\section{PAGE}

59. $a$, simple bone fish-hook; $b$, a simple bone fishhook in process of manufacture.......

60. $a, b$, both sides of bone skin-dressing scraper.

61. Fragment of back-scratcher.

62. Fragment of bone comb.

63. Fragment of bone comb.............. 9I

64. Fragment of back-scratcher ........... 9 I

65. Bone mouthpiece for bladder............ 9 I

66. Albatross humerus for making needles and awls ..................... gI

67. $a$ to $h, a, b$, needles; $c$, fragment of point for fish-spear; $d$ and $f$, awls; $e$, toothpick; $g$ and $h$, unfinished points for fish-hooks

68. Fragment of bone head for a throwing-lance.

69. Fragments of bone haft for stone knife, both sides $\ldots \ldots \ldots \ldots \ldots \ldots \ldots \ldots \ldots$

70. Two blunt-shaped heads of casting-lances

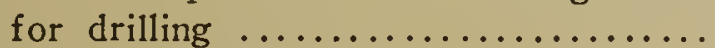

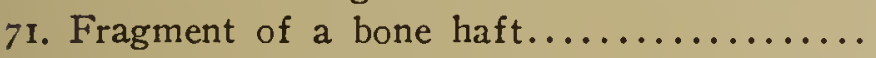

72. $a$ to $c$, fragments of heads of throwinglances

73. Fragment of bone haft for stone knife.

74. $a, b$, fragments of bone implements......

$75 . a, b$, mouthpieces for bladdered harpoons.... 94

76. A drum-bone handle................ 94

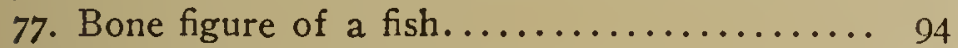

78. Bone figure of some sea animal......... 94

79. $a, b$, stone figures of a man........... 95

80. Stone figure of a whale............. 95
8I. $a, b$, fragment of bone head of a war-lance; $a$, side view; $b$, front view.......... 95

82. $a, b$, fragments of bone heads........... 95

83. $a, b, c$, bone harpoon head: $a$, flat side; $b$, side view ; $c$, a barb................. 96

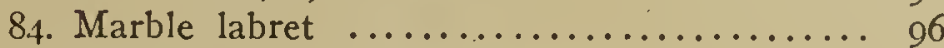

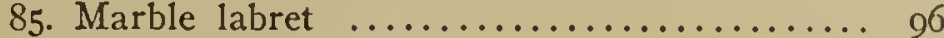

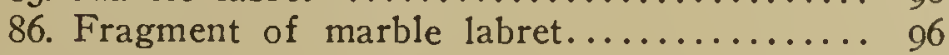

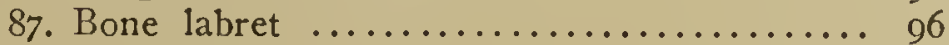

88. Marble labret .................... 96

89. $a, b, c$, bone labrets................ 97

90. $a, b, c$, bone labrets................. 97

9I. Stone shaft-straightener ............. 97

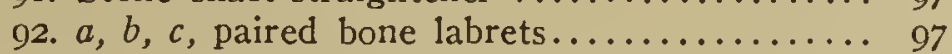

93. $a, b$, bone sections of skin boat-frame..... 97

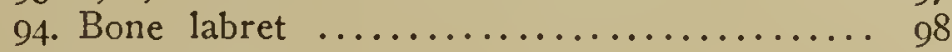

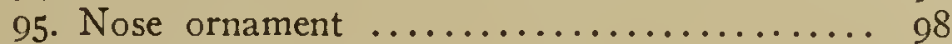

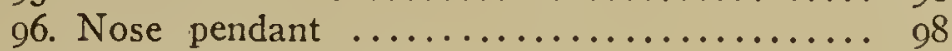

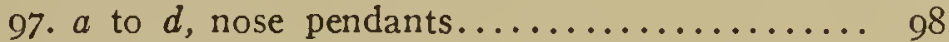

98. Bone ear-ring ..................... 100

99. Nose or ear pendant................ IDo

I00. Plug for enlarging labret perforation........ I00

I0I. Sea lion tooth.................... I00

I02. Bone buckle .................... I00

I03. $a$, bone ring; $b$, stone ring............. I00

104. $a, b$, rings of halibut vertebra........... I00

I05. Marble stopper ................... I00

106. Shell of Telina calcarea............... I00

107. Sea-urchin ....................... I04

108. Sea-urchin without needles ............. I04

I09. Fragment of sea-urchin shell without needles. I04

I IO. Split pieces of sea-urchin shell.......... I04 

Inิ |1 + 15 
JOCHELSON
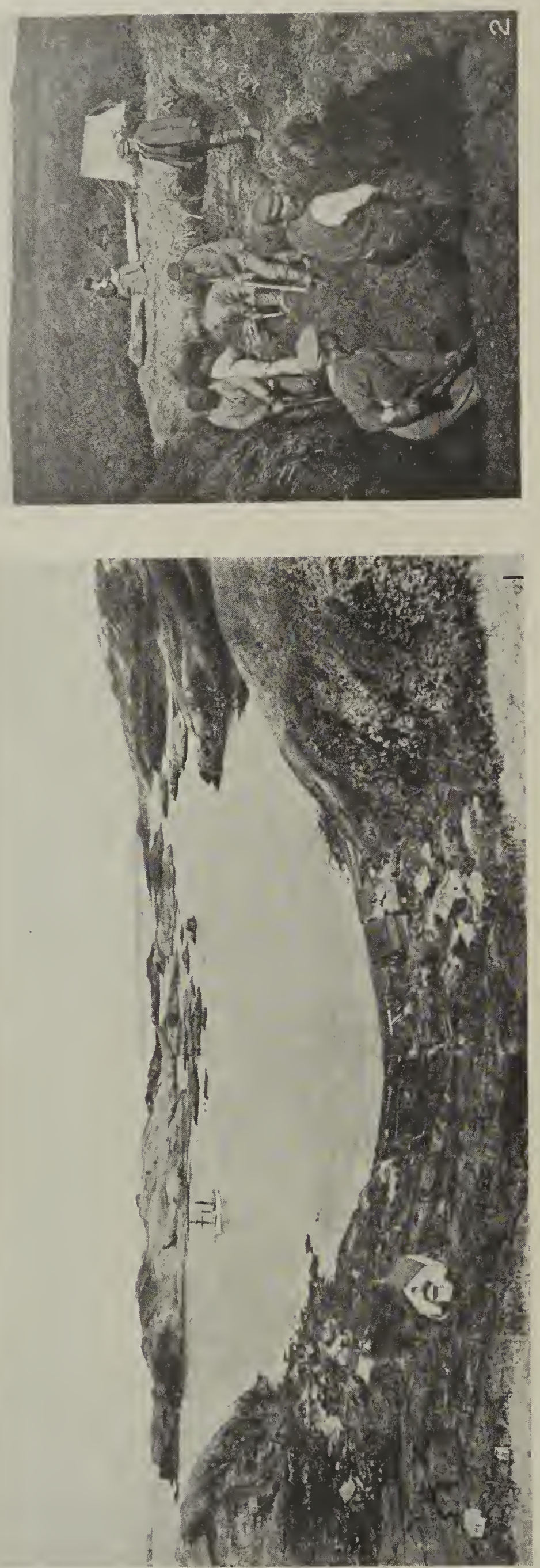

PLATE 1
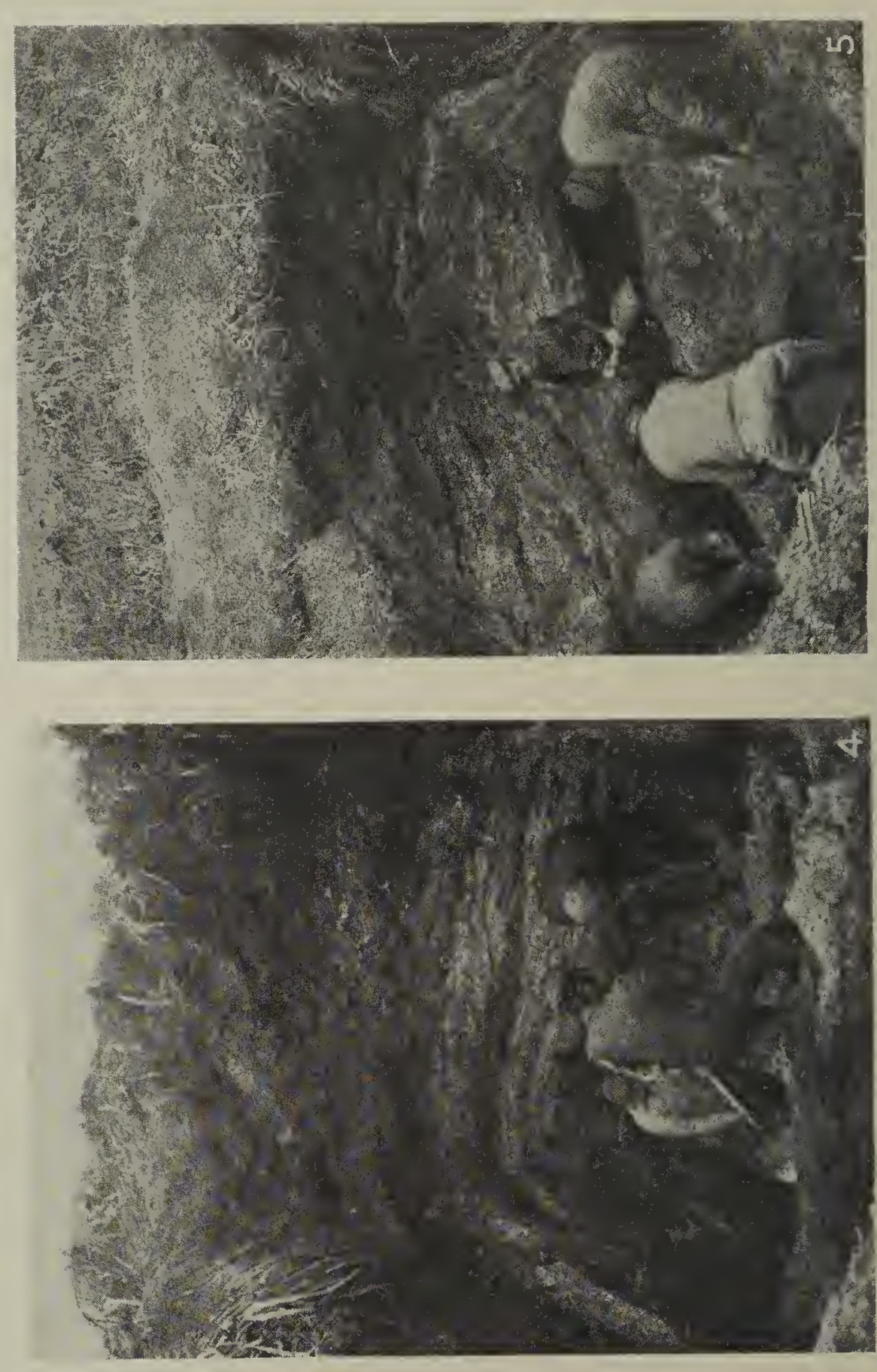

造

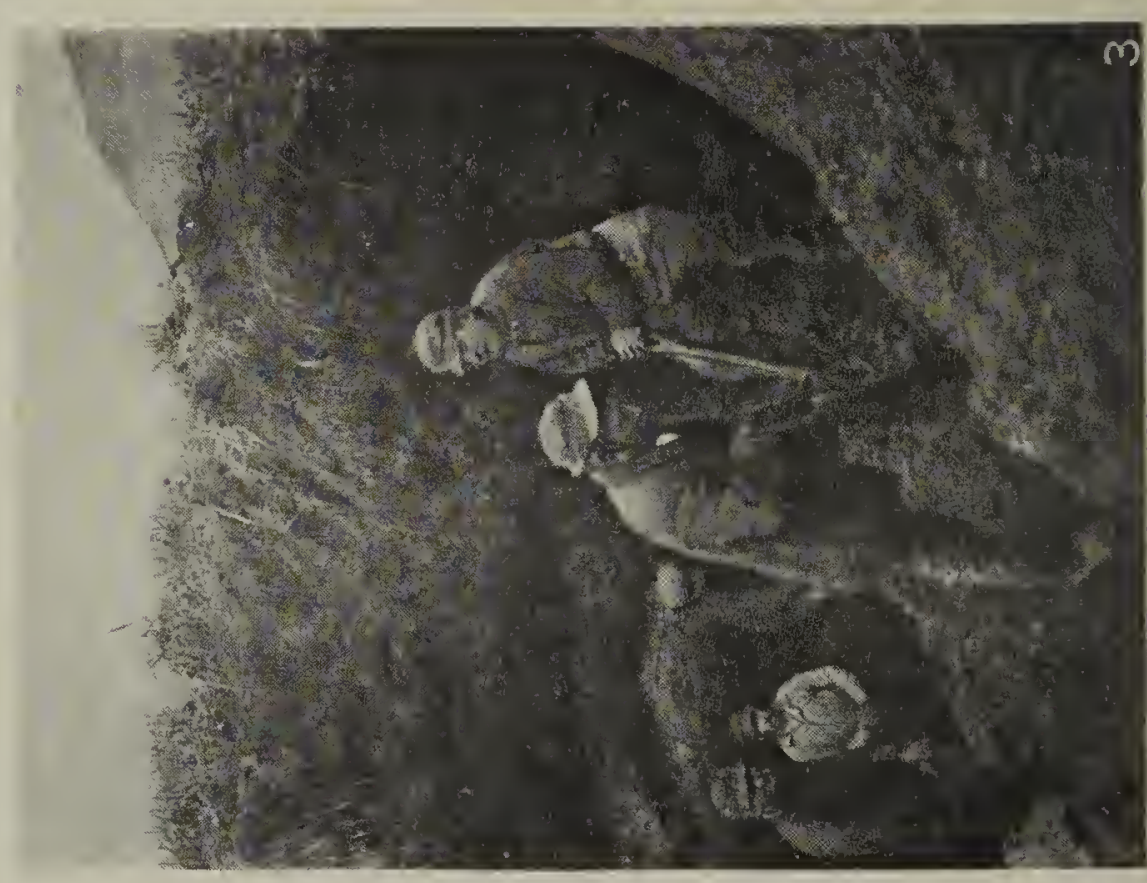




\section{CHAPTER I.}

\section{ORGANIZATION AND PERSONNEL OF THE EXPEDITION.}

In the fall of 1907 the author was invited by the Moscow banker, F. P. Riaboushinsky, to conduct the anthropological work of the so-called Kamchatka Expedition, which was organized by $\mathrm{Mr}$. Riaboushinsky at the suggestion of his former teacher, Professor A. A. Ivanovsky, of the University of Moscow.

The following were the leaders of the other divisions of the expedition: Professor Wladimir L. Komarov, Botanical Division; Professor Peter J. Schmidt, Zoological Division; Doctor W. A. Vlassov, Meteorological Division; the mining engineers S. A. Konrady and E. W. Krug headed two subdivisions in geology-Historical Geology and the Kamchatka Volcanoes. Each division had several assistants and the expedition as a whole had 20 scientific members.

Toward the end of 1907, Mr. Riaboushinsky requested the Imperial Russian Geographical Society to take the expedition under its patronage. The late president of the society, P. P. Semenov-Tyan-Shansky, warmly accepted this proposal and appointed a committee consisting of the heads of departments of the society and the division leaders of the expedition, with himself as chairman. In the work of organization, the present president of the society, Lieutenant General J. M. Shokalsky, took an important part.

Aside from the brief accounts by the leaders of the several divisions of the Kamchatka Expedition published in the Bulletins of the Imperial Russian Geographical Society and other scientific periodicals, only one volume of the expedition reports, that of the Botanical Division, by Professor Komarov, has been published. Preliminary accounts of the excavations on the Aleutian Islands and Kamchatka were published by the author in the Bulletins of the Imperial Russian Geographical Society (Vol. XLV, Part IX, I909, and Vol. XLVII, Parts I to V, I9I I) under the title "Letters of the leader of the Ethnological Division of the Kamchatka Expedition to the Secretary of the Imperial Russian Geographical Society." The author also read two papers at the Eighteenth International Congress of Americanists in London (I9I2): (I) The Aleut Language and its Relation to the Eskimo Dialects, and (2) Scientific Results of the Ethnological Section of the Riaboushinsky Expedition of the Imperial Russian Geographical Society to the Aleutian Islands and Kamchatka (Proceedings, i8th International Congress of Americanists, pp. 96-194 and 334-343). In the Bulletins of the Russian Academy of Sciences (I9I3, pp. I33I53 and 287-3I5) the author published a critical article: "The Aleut Language in the Light of Weniaminoff's Grammar." 


\section{REASONS FOR AN INVESTIGATION OF THE ALEUT.}

Thirty-nine years ago ( 1886 ) the author began his ethnological studies, spending I9 years among primitive tribes. For Io years (I 886 to I895) he studied the tribes of northeastern Asia while living among them as a political exile; 3 years (I895 to I897) were spent in the northern districts of the Province of Yakutsk as a member of the Yakut Expedition of the Imperial Russian Geographical Society, which was financed by Innocent Sibiriakoff; for 3 three years (1900 to I902) he was engaged in the investigations of the Jesup North Pacific Expedition of the American Museum of Natural History as a leader of the Siberian division of that expedition. Finally, for 3 years (Ig09 to I9II) he was leader of the Ethnological Division of the Kamchatka Expedition referred to previously.

In the first years of his stay with the Siberian natives, the author became interested in the culture of the so-called Palæ-asiatic tribes. During the Yakut Expedidition he became convinced that there were cultural and somatological connections between the Palæ-asiatics and the Indians of North America, and later, while occupied with the Jesup Expedition, a closer comparative study of the subject brought to light certain affinities between the cultures of the Palæ-asiatics and the tribes of the North Pacific Coast of North America; but we should point out that the culture of the Palæ-asiatic tribes is a complex of Asiatic, Indian, and Eskimo elements.

The Asiatic elements are: reindeer breeding as practiced by the nomadic divisions of the Palæ-asiatic tribes, Siberian methods of dog driving, ancient pottery of the Koryak and Kamchadal, and the specific traits of Siberian shamanism. Indian elements may be distinguished in the identity of folk-lore, similarity in the methods of fishing, in the pictographic writings of the Yukaghir, in the germs of clan organization of the Yukaghir, in the dug-out boats of the Yukaghir and Kamchadal, and in bone armor. In addition to these correspondences in culture, we find close somatological parallels between the Palæ-asiatic tribes and the tribes of Alaska and Canada.

Eskimo elements, in their main features, whether they originated in America or Siberia, may be called circumpolar, as they are adaptations to natural conditions of life in that region. The specific Eskimo features of culture are sea-hunting, certain ritual associated with sea-hunting, skin boats, tailored fur clothing, the composite bow, snowshoes, dog-breeding, harpoons, and the earth hut. The Eskimo type of pictographic art and realistic carvings reach their highest perfection among the Koryak. The loose social organization of the Eskimo tribes and of the Palæ-asiatics should also be mentioned; also the present primitive pottery of the Chukchee.

The identity of the mythologies of the Siberian Koryak and Kamshadal and of the Indians of the northwest coast of America may be evidence of former direct cultural connection between these two groups. All of these tribes look upon the mythical Raven as a tribal ancestor, as a culture hero, and as a reformer of the world; at the same time, he is described as a trickster and as a humorous, lustful, and obscene mythological personage. The Kamchadal methods of fishing, in which skin boats are not employed, are the same as those of the northwestern Indians. Thus, the common spiritual culture, certain phases of the material culture, as well as similar physical traits, may indicate that intercourse between the northern 
Palæ-asiatics and the Indians of the northwest coast of America is of a very old date. Later, the Eskimo formed a wedge, as it were, between these two, and interrupted the contact. The tip of this wedge was held by the Aleut. However, little attention has been given to the Aleut problem, though comparative studies of the Eskimo in Alaska were carried on by Nelson, Murdoch, and others. Further, the Aleut were not studied by members of the Jesup Expedition. In consequence, the author proposed that the area investigated by the Kamchatka Expedition be extended to include the Aleutian Islands.

The term Palce-asiatics ${ }^{1}$ was first proposed by Professor Schrenk ${ }^{2}$ as the groupname for the Siberian and American tribes occupying the circumpolar area, but this grouping was not based upon specific data, for there had been no satisfactory field studies. The fusion of these tribes into a single ethnic group was based on assumed linguistic characters and on negative evidence; the scanty notes on the language of these peoples which were available at that time showed that, according to structure, they could not be classified with the Ural-Altaic group of languages $;^{3}$ but how far the so-called Palæ-asiatic languages were interrelated, and whether the tribes speaking them were anthropologically kindred peoples remained an open question. Consequently, it was not without reason that the well-known German ethnologist, Peschel, called one group of the Palæ-asiatics "Nordasieten von umbestimmter systematischer Stellung," thus confessing his inability to classify them. "Even now we can not make a definite statement as to the relations of the Yenissei-Ostyak to the Chukchee, Koryak, and other northern Palæ-asiatics; also, the puzzling question of the Ainos, the pre-Japanese inhabitants of Japan, is still far from solution, although such an authority as the late Professor Baeltz ascribed a Caucasian origin to them. ${ }^{5}$

Some other attempts to classify the northeastern tribes of Siberia should be mentioned. Friedrich Müller calls them, on geographical grounds, together with the Aleut and Eskimo, "Arctic or hyperborean races," "but it is a question whether the Ainos can be called an Arctic tribe. Moreover, from an anthropological point of view, this classification is as meaningless as Schrenk's Palæ-asiatics. Miss Czaplicka" proposed another classification, grouping them into "NeoSiberians" and "Paleo-Siberians" instead of the terms "Ural-Altaians" and

1 The group comprises: the Chukchee, Koryak, Kamchadal, Yukaghir, Chuvantzi, Ainos, Gilyak, and the Yenissei Ostyak. The Aleut and the Eskimo were also included in this group.

2 Leopold Schrenk, Die Völker des Amurlandes, pp. 254-262. Petersburg, I87i.

${ }^{3} \mathrm{We}$ may mention here some articles on the languages of the Yukaghir, Chukchee, and Gilyak published by the Russian Academy of Sciences, the results of careful work of learned linguists, based, however, on materials, quantitatively scanty and qualitatively of little value, brought together by casual and unqualified collectors (officials, missionaries, and naturalists).

A. Schiefner, Ueber die Sprache der Jukagiren (Bull. Hist. Phil., XVI, I859, pp. 24I-253, and Mél. asiat., III, pp. 595-6r2) : Beitrage zur Kenntniss der jukagirischen Sprache (Bull. XVI, I871, pp. 273-399, and Mél. asiat., VI, pp. 409-446) ; Ueber Baron v. Maydell's jukagirische Sprachproben (Bull. XVII, I87I, pp. 86-I03, and Mél. asiat., VI, pp. 600-626).

L. Radloff, Ueber die Sprache der Tschuktschen und ihr Verhältniss zum Koriakischen, St. Petersburg (Mémoirs de l'Acad. III, No. I0, I86I).

Dr. W. Grube, Giljakisches Wörterverzeichniss nebst grammatischen Bemerkungen (Anhang zum III B. der Reisen u. Forschungen im Amurlande v. Dr. Leopold v. Schrenk, Lief. I).

4. Peschel, Völkerkunde, p. 413. Leipzig, i876.

5 E. Baeltz, Die Menschenrassen Ostasiens (Verhandlungen der Berliner anthropologischer Gesellschaft, I90I, March, p. 202) ; ibid., Zur Vor- und Urgeschichte Japans (Zeitschrift für Ethnologie, pp. 287-3Io. Berlin, I907).

6 F. R. Müller, Allgemeine Ethnographie, p. I88. Wien, I873.

7 M. A. Czaplicka, Aboriginal Siberia, a Study in Social Anthropology, Oxford University Press, I5. I9I4. 
"Palæ-asiatics." Such a grouping was very convenient for the special aims of this author, which were to give a sociological survey of the Siberian population only. Hence, her "Neo-Siberian" group does not include the related tribes outside of Siberia; neither does her "Paleo-Siberian" group include other indigenous Asiatic peoples, now becoming extinct. So in many respects, this classification is less satisfactory than that of Schrenk. While it is true that on the basis of linguistic, or rather linguo-psychological, characters ${ }^{8}$ the Ural-Altaians form a single ethnic group, this does not fully meet the requirements of an anthropological classification. Again, "Neo-Siberian" is not a somatological term, and the Finnish tribes included in this designation can hardly be called "Neo-Siberians."

The designation "Palæ-asiatics," as proposed by the late Professor Schrenk, was based chiefly on historico-geographical considerations, no account being taken of somatological data. This is also true of the term "Paleo-Siberians." On the other hand, according to Schrenk, the so-called Palæ-asiatics were driven to northeastern Siberia from the south. In this sense the name "Paleo-Siberians" does not correspond to the term "Palæ-asiatics," for the latter, according to the understanding of Professor Schrenk, were not ancient dwellers of Siberia. To avoid the inexactness of both terms (Paleo-Siberians and Palæ-asiatics), ${ }^{\circ}$ the present author prefers another historico-geographical term, that used by Ratzel, "die Rand-Völker" (marginal peoples) which includes the American Eskimo.

The Yakut Expedition of I895 considerably extended our knowledge of two tribes, the Chukchee and the Yukaghir, in whose cultural development and language structure some Indian elements were found. ${ }^{10}$

Later, the investigation of the Palæ-asiatics by the Jesup Expedition was carried out on a much broader comparative basis. The problems of the investigators were not only to study the Palæ-asiatic tribes, but to clear up the ethnological connections between the natives of northeastern Asia and northwestern America and to further the solution of the question of the origin of the American race. A brief survey of the phases through which this question has passed follows:

It is well known that America, when discovered, was taken for India, and the inhabitants for natives of India. Later, as its geographical position was determined, the question of the origin of its inhabitants arose. From the beginning they have been identified as immigrants from Asia, Polynesia, or Europe, or regarded as descendants of two (Mongolian-Malayan) or three (Malay-Mongolian-Caucasian) races. Originally, these associations were quite speculative, but during the course

${ }^{8}$ In explanation of this term it should be stated that in the Semitic or Aryan languages, for example, we understand them to be languages having a common origin. This, however, is not the case with the Ural-Altaian group of languages, to which we ascribe only common or similar phonetic and structural principles.

${ }^{9}$ The term "Palæ-asiatics" may, besides, incorrectly suggest that all the rest of Asiatic peoples were not the ancient inhabitants of Asia.

10 See W. Bogoras, "Brief Account of the Investigation of the Chukchee of the Kolyma District (Bulletin of the East Siberian Division of the Imperial Russian Geographical Society, Vol. XXX, part I, Irkutsk, I897); idem, Materials for the Study of the Chukchee Language and Folklore collected in the Kolyma District, part I, edited by the Imperial Russian Academy of Sciences, Petrograd, Igoo; W. Jochelson, Preliminary account of the Investigation of the Natives of the Kolyma and Verkhoyansk Districts (Bulletin of the East Siberian Division of the Imperial Russian Geographical Society, Vol. XXIX, part I, I898); idem, Materials for the Study of the Yukaghir Language and Folklore, part I. edited by the Imperial Russian Academy of Sciences, Petrograd, Igoo. 
of the nineteenth century more rational theories on this subject appeared. ${ }^{11}$ In opposition to these theories was a new hypothesis presented by Professor Ameghino, the South American palæontologist. In brief, he holds that not merely the American race, but all mankind, originated in South America. ${ }^{12}$ From the beginning European anthropologists took a skeptical position as to this theory and eventually proved that the fragments of the skull upon which Ameghino had based his hypothesis were those of a human skull of the present period. ${ }^{13}$ Lehmann-Nitsche also took a critical attitude toward Ameghino's theory; however, he regarded some of the fossil bones of man from South America as belonging to the Pleistocene period. ${ }^{14}$ Doctor Hrdlička, after a careful study of the pseudo-ancient remains of man in South America, came to the conclusion that in these cases we are dealing with recent bones. ${ }^{15}$ The same is maintained by Doctor Hrdlička with regard to the skeletal remains of supposed ancient man in North America. ${ }^{16}$

It should be noted that Doctor Hrdlička had previously admitted that some of the skeletal remains of man in North America might belong to the Pleistocene period, ${ }^{17}$ but, after a further study of the subject, he changed his opinion. In his work on early man in South America he states:

"Subsequent researches, however, cleared up most of the uncertain points and the entire inquiry appeared to establish the fact that no specimen had come to light in the Northern continent, which, from the standpoint of physical anthropology, represented other than a relatively modern man." 18

Thus, it may be said that up to the present time, neither in North America nor in South America have remains of Tertiary or of Diluvial man been discovered. From what has been said before, we may conclude that man appeared in America later than in the Old World and that America can be considered neither the cradle of mankind nor the place of origin of the American race. The absence of anthropoid apes in America lends support to the second supposition, even if the polygenetic theory be admitted.

If the question of the independent origin of the American race is solved negatively, then the question arises: Whence and in what geological period did man appear on American soil? The absence of Diluvial remains of man in America may

11 See A. Hrdlička, Origin of the American Aborigines, Historical Notes (Amer. Anthropologist, vol. I4, Jan.Mar., Ig12, p. 5; idem, The Peopling of America (Journal of Heredity, vol. 6, No. 2, February 1915, p. 5I).

12 F. Ameghino, Le Diprothomo platensis, un précurseur de l'homme du pliocène inférieur de Buenos Aires (Anales Museo Nacional, Buenos Aires, XIX, Ig0g).

13 See G. Steinmann, Das Alter des Menschen in Argentinien (Ber. Prähist. Vers. Cöln, 1908) ; L. Wilson, Spuren des Vormenschen aus Süd-America (Korr.-Blatt der Deutschen Gesellschaft für Anthropologie, Ethnologie und Urgeschichte, XXXIX Jahrgang, 1908, Braunschweig); G. Schwalbe, Studien zur Morphologie der Südamerikanischen Primatenformen (Zeitschrift für Morphol. und Anthr., Band XIII, Heft 2, Stuttgart, Igro, pp. 209-258) ; M. Friedmann, Vorlage eines des Schädeldachs von Diprothomo platensis Ameghino (Zeitschrift für Ethnol. Berlin, Heft 6, IgIo) and Professor von Luschan's note to Friedmann's article. See also Professor von Luschan's latest publication: Völker, Rassen, Sprachen, Berlin, I922, p. 9.

14 R. Lehmann-Nitsche, El hombre fossil pampeano (Bol. Ofic. Nac. Estad. La Paz, Bolivia, VI, IgIo, pp. 363-366) ; Nouvelles Recherches sur la formation pampéenne et l'homme fossile de la République Argentine (Rev. Mus. La Plata, T. I4, I907); Homo sapiens und Homo neogceus aus der argentinischen Pampas formation (Verh. I6 Internat. Amerik. Kongr. S. 63, I909).

15 A. Hrdlička, Early Man in South America (Bureau of American Ethnology Bull. 52, Washington, 1912). ${ }^{16}$ Ibid., Skeletal Remains Suggesting or Attributed to Early Man in North America (Bureau of American Ethnology Bulletin 33, Washington, I907).

17 Ibid., The Crania of Trenton, New Jersey, and their bearing upon the Antiquity of Man in that Region (Bulletin American Museum of Natural History, XVI, pp. 23-62, New York, 1902).

${ }^{18}$ Ibid., Early Man in South America, Preface, p. v. 
answer the second part of the question. The question whence man came to America may be answered in favor of Asia. For a mass migration convenient physicogeographical conditions were necessary. Such conditions did not exist between Europe and America in the Pleistocene period. The so-called Icelandic bridge which, as geologists suppose, connected northwestern Europe with northeastern America existed as far back as the Miocene and not later than the Pliocene period of the Tertiary Age, ${ }^{19}$ when the existence of man, even in Europe, is doubtful, or positively rejected by leading anthropologists. Besides, the earliest traces of man found on the remnants of the former Icelandic bridge still standing above water or on the neighboring shores may be referred to the Azilian stage, as in Scotland, ${ }^{20}$ or to the early neolithic period, as in Scandinavia. ${ }^{21}$

Immigration of Polynesians in southern America may have been only accidental and then only in recent times, when their culture rose to the point where skill in navigation was sufficiently developed. Besides, some data point to the fact that the Polynesians may be recent arrivals in the Pacific. ${ }^{22}$

Geological and palæontological data show that Alaska and Siberia were connected in the middle of the Pleistocene period, when the mammoth passed over from Asia to America, or, even toward the end of the Pleistocene, when the reindeer, elk, musk-ox, bison, mountain sheep, and bears appeared in America. ${ }^{23}$ According to Dawson, ${ }^{24}$ man probably passed from Asia to America, in pursuit of migrating animals, over the Asian-American bridge or over that vast continental plateau which occupied what is now Bering Sea, Bering Strait, and a part of the Arctic Sea. Professor K. I. Bogdanovich also supposes that Bering Strait was formed during the Quaternary period at the end of the era of the mammoth, as a result of a postPliocene sinking of the sea, and that the final separation of the Asiatic and American continents took place at the beginning of Recent time. ${ }^{25}$ Proof of the former land connection between the Seward and Chukchee peninsulas may be found in the similarity of rock structure on both sides of Bering Strait. ${ }^{26}$

It is natural, then, to anticipate similarities between the northern Asiatics and the American races. In spite of great variety in types, the American natives show definite similarities to Asiatics. New data on this point were sought by the Jesup North Pacific Expedition, which, taking for granted the migration of man from the Old World to the New, had as its objective a detailed comparative investigation of the American-Asiatic tribes nearest Bering Sea. The careful investigation of these tribes gave very significant indications as to the character of the ethnological

${ }^{19}$ See R. F. Scharf, On the Evidence of a Former Land-Bridge between Northern Europe and North America (Proc. Roy. Irish Acad., I909, vol. XVIII, Sect. B., pp. 3-28).

${ }^{20}$ See J. Anderson, Proc. Soc. Antiq. of Scotland, Vol. XXIX, I895, p. 2 Ir.

21. See W. J. Sollas, Ancient Hunters and their Modern Representatives, London, I9r I, p. 379.

22 See A. C. Haddon, The Wanderings of Peoples, Cambridge, I9II ; Clark Wissler, The American Indian, 390.

${ }^{23} \mathrm{~J}$. W. Gidley, Palcentological Evidence bearing on the Problem of the Origin of the American Aborigines (American Anthropologist, vol. I4, No. I, p. I9. I9I2).

${ }^{24}$ G. M. Dawson, Geological Notes on some of the Coasts and Islands of the Bering Sea and Vicinity (Bull. Amer. Geol. Society, I894, V., pp. II7-I46).

${ }^{25}$ C. I. Bogdanovich, Sketches on the Chukchce Peninsula (in Russian), pp. I52-I54. Petrograd, I90I. 1902).

${ }^{28}$ See Fr. Immanuel, Nordwest-Amerika und Nordost-Asien (Petermanns Mitteilungen, Band 48, pp. 49-58. 
connections between the northern Palæ-asiatics, the Indians, and Eskimo. The mythologies of the Indians of the northwest coast of America and the northern Palæ-asiatics, in outline and in detail, in form and in content, are so similar that there can be no question as to their interdependence. Many similarities were also found in their spiritual life as well as in their material culture. ${ }^{27}$ The languages of the northern Palæ-asiatics, according to their grammatical structure, must be ranged with American languages. ${ }^{28}$ In physical type, also, the northern Palæ-asiatics are nearer to the northwestern Indians than to their Asiatic neighbors. Thus, we may call the northern Palæ-asiatics the Americanoid tribes of Siberia.

Based on above data, Professor Boas made the following inferences:

"A consideration of the distribution, and the characteristics of languages and human types in America and Siberia, have led me to formulate the theory that the so-called Palæasiatic tribes of Siberia must be considered as an offshoot of the American race, which may have migrated back after the retreat of the Arctic glaciers." ${ }_{29}$

The basic idea of this hypothesis is that the American race migrated from Asia to America in one of the interglacial periods, then was pushed southward by the advance of the ice, and after the retreat of the glaciers some of the people moved northward again and some returned to Asia. In this manner may be explained the cultural and physical affinities of the Northern Palæ-asiatics (Chukchee, Koryak, Kamchadal, and Yukaghir) and the Indians of the northwest coast of America.

The theory of the Asiatic origin of the American aborigines and of the reemigration from America into Asia of the Siberian tribes which we call Americanoids, may find a corroborative parallel in the history of the distribution of certain Asiatic zoological species. Professor Peter P. Sushkin, of the Russian Academy of Sciences, in his paper "Outlines of the History of the Fauna of Palearctic Asia," read April 25, 1925, before the National Academy of Sciences in Washington, ${ }^{20 a}$ stated:

"M. Severtzoff and Professor Nassonov, after studying the distribution and structure of the wild sheep, have both come to the conclusion that this genus migrated from High Asia to America before the last glaciation; that in America they were driven south by the glaciation; that afterwards the American stock spread again to the north and gave origin to another group; and finally that this new group spread back into the Asian continent and occupied

27 Franz Boas, Die Jesup Expedition (Verhandlungen des XVI Internationalen Americanisten-Kongresses, Wien, Ig09) ; Waldemar Bogoras, The Folklore of Northeastern Asia (American Anthropologist, Vol. IV, No. 2, 1902, p. 62I) ; ibid., The Chukchee (Jesup North Pacific Expedition, Vol. VIII, 1905-I910). Waldemar Jochelson, Ueber Asiatische und Amerikanische Elemente in den Mythen der Koryaken (Verhandl. des XIV Internationalen Amerikanisten Kongresses, Stuttgart, I904); The Koryak, Jesup North Pacific Expedition, Vol. VI.

${ }^{28}$ Waldemar Jochelson, Essay on the Grammar of the Yukaghir Language (Annals of the New York Academy of Sciences, Vol. XVI, part 2, March, 1905). Reprinted as a supplement to the American Anthropologist, vol. 7. No. 2, 1905. Sternberg, Bemerkungen über Beziehungen zwischen der Morphologie der Giljakischen und Amerikanischen Sprachen (Verhandl. des XIV Internat. Amerikanisten Kongresses, Stuttgart, 1904), pp. I37-I40. Waldemar Bogoras, Chukchee Language (Handbook of American Indian Languages, Bureau of American Ethnology, Bull. 40, part 2).

${ }^{29}$ Franz Boas, Ethnological Problems in Canada (Journal of the Royal Anthropological Institute, London, Igro, Vol. XL, p. 534) ; see also, Franz Boas, The History of the American Race (Annals, New York Academy of Sciences, Vol. XXI, I911, pp. 177-183, New York, 1912).

29a See Science, May I5, 1925.

2 
Eastern Siberia, so that the present Siberian sheep stand, geographically and structurally, in no close relation with the sheep of High Asia."

The Eskimo, to which stock the Aleut belong, should be given special consideration here; despite some specific characters which differentiate them from the Indians, they are considered as a division of the American race. At present, the Alaskan and Siberian Eskimo separate the Northwestern Indians from the Palæasiatics. We believe that the Eskimo recently came from the east and interrupted the relations of, the Palæ-asiatics and Indians. In a certain sense this supposition may be contradictory to the generally recognized views on the Eskimo, but we must distinguish two periods in the Eskimo migrations-a recent and an ancient one.

At a time when the data for an Asiatic origin of the American race were not so well worked out as they are now, Rudolf Virchow, basing his opinion on measurements made on a small number of Greenland and Labrador Eskimo, expressed his belief as to their Mongoloid origin, despite their dolichocephalic head indices. ${ }^{30}$ Schrenk, based chiefly on historico-geographical considerations, ranks the Eskimo among the Palæ-asiatic tribes. ${ }^{31}$

Wrangel says:

"There are traditions which relate that two centuries ago the Onkilon occupied the whole of the Arctic coast from Cape Shelagskoi to Bering Strait, and it is true that there are everywhere along this tract the remains of huts constructed of earth and whalebones and quite different from the present dwellings of the Chukchee." 32

Bogoras also recognizes the fact that on the Arctic coast there was previously more of the Eskimo element, which, little by little, became assimilated with the Chukchee. Some of the names of the present Chukchee villages on the Arctic shore can be explained only on the basis of the Eskimo language. ${ }^{33}$ The Danish investigator of Greenland, Doctor Thalbitzer, ${ }^{34}$ expressed his belief that the Eskimo came to America from Siberia.

To the number of adherents of the hypothesis that the Eskimo migrated to America from Siberia, many names, both old and new, may be added, such as Chamisso, Litke, Weniaminoff, Patkanoff, and many others. If we regard the Eskimo as a division of the American race, this hypothesis is quite in accord with the theory of the Asiatic origin of the aboriginal American population in general.

On the other hand, we meet with the opposite opinion. Thus Billings, Klaprot, Rink, Dall, and Boas believe the Eskimo went to Siberia from America. One of the latest investigators of the Eskimo, V. Stefansson, states that " the Eskimo appeared in Alaska from the east and have reached Bering Strait comparatively not far back, probably less than a thousand years ago. ${ }^{\mathbf{3 5}}$

${ }^{30} \mathrm{R}$. Virchow, Zeitschrift fïr Ethnologie, Band XII, I880.

31 Schrenk, Die Völker des Amur-Landes, Band III, p. 249.

32 Wrangel, Voyage, etc., p. 357, Under "Onkilon" Wrangel understands “Eskimo," but actually it means

"Coast dweller." (See Jochelson, The Koryak, p. 463.)

${ }^{33}$ Bogoras, The Chukchee, p. 22.

34 William Thalbitzer, The Amassalik Eskimo, p. 717, Copenhagen, I9I4.

35 V. Stefansson, On Eskimo Work, I908-1912. (Summary Rept. Geological Survey Canada, I9I2, p. 488.) 
These controversies concerning Eskimo migrations may be reconciled, for undoubtedly migrations of some Eskimo divisions from America to Siberia, and vice versa, could and actually did occur under present geological conditions. The migrations mentioned above took place in the not far distant past. Another hypothesis concerning Eskimo migrations from the Old World to the New, in remote prehistoric times, is that of Professor Boyd Dawkins, who connects them with man of the Magdalenian period in Europe, basing his opinion on the similarity of their realistic art in carving and engraving human and animal figures. ${ }^{36}$

Some ethnologists are returning to this hypothesis. Of special interest in this connection is Sollas's marshaling of cultural parallels and anatomical data to prove his case. According to his theory, two races of long-headed men of the Magdalenian period emigrated from the Old World through Asia to America. From one race of high stature, the Cro-Magnon, the Algonkin division of Indians originated; from the other, that of Dordogne, people of low stature, the Eskimo originated. ${ }^{37}$

From what has been said before, the points on which the Aleut, a tribe of the Eskimo stock, need investigation may be surmised. As we shall see in Chapter VII, the same differences of opinion existed concerning the Aleut as of the entire Eskimo stock. The aims of the Jesup North Pacific Expedition were to study a certain chain of Asiatic and American tribes, in order to clear up their former history, their connections among themselves, and their relations to neighboring tribes. The Aleut formed one of the missing links of that chain. The investigation of the Aleut, and particularly, the investigation of their prehistory, so far as this can be carried forward through excavations of ancient village sites, will throw some light on questions referring to remote times and to ancient ethnical relations. Thus, the investigation of the connections between the Americanoid tribes of Asia, the Northwestern Indians, and the Eskimo may help to clear up the migration question.

Leading anthropologists regard the whole of mankind as belonging to one species: Homo sapiens. Although, up to the present time, fossil remains of ancient man have been discovered only in Europe, Asia has been looked upon as the place of man's origin. Asia was the place of origin of higher civilizations, the domestication of animals, and the cultivation of plants. ${ }^{38}$

Before the appearance of man Asia is believed to have been the cradle of evolution and the center of animal dispersion both westward and eastward. ${ }^{30}$

Professor von Luschan, though acknowledging the hypothesis that the American continent was peopled by immigration from northeastern Asia, believes, however, that the physical type of some American tribes may have been influenced to a certain degree by Scandinavian navigators, who probably reached the northeastern

${ }^{36}$ Boyd Dawkins, Die Höllen und die Urbewohner Europas (translated from English), i876, p. 224. See also W. J. Hoffman, The Graphic Art of the Eskimo (Report, U. S. National Museum, Washington, I897), p. 764.

37 W. J. Sollas, Ancient Hunters and their Modern Representatives, London, I9I I, pp. 370-383.

${ }^{38}$ See, e. g., K. Keller, Die Haustiere, in Hans Kremer's, "Der Mensch und die Erde," Vol. I, p. I8I. I905.

${ }^{39} \mathrm{H}$. F. Osborn, Proving Asia the Mother of Continents (Asia, The American Magazine on the Orient, Vol. XXII, No. 9, pp. 72I-724. I922). 
coast of America in very remote times. ${ }^{40}$ But in our opinion accidental visits of North European adventurers could hardly affect the somatology of Indian tribes.

The high cultures of Mexico and Central America do not interfere with the theory of the Asiatic origin of the American population. It is now generally admitted that America was originally populated from Asia on a culture-level no higher than the Neolithic and that there is abundant evidence that ceramics, weaving, and cultivation of plants were independently invented long after the original settlement.

Not long ago, Doctor Hrdlicka took up the task of investigating the direct relations between the American population and the Mongol tribes of Asia, thus enlarging the scope of the investigations by the Jesup North Pacific Expedition. Such an enterprise is very welcome, but up to the present time Doctor Hrdlička's published statements give only general impressions of the types of local populations received in the course of his travels in I9I2 over Transbaikalia and Northern Mongolia. Based on these observations, Doctor Hrdlička advanced the following opinion:

"There exist to-day over large parts of Eastern Siberia, and in Mongolia, Tibet, and other regions in that part of the world, numerous remains, which now form constituent parts of more modern tribes or nations, of a more ancient population (related in origin perhaps with the latest Palæolithic European), which was physically identical with and in all probability gave rise to the American Indian." 41

Judging by the citation from Doctor Hrdlička, he connects the American race not with the Mongoloid or other East Asiatic tribes, but with those Palæ-asiatic tribes which entered into the formation of the former. In that way, while the Jesup Expedition built a bridge between the Indians and the Palæ-asiatic tribes of northeastern Siberia, Doctor Hrdlička strives to establish a close relation between the American race and the Palæ-asiatic elements now diffused among the present East Asiatic nations. To that end it is necessary to establish scientifically the proposed Palæ-asiatic elements. Such an intricate problem can not be solved by a local anthropological investigation, and certainly not by an exclusively anthropological investigation, but in a detailed and many-sided study of the tribes of Eastern Asia with reference to their prehistory, somatology, and ethnology. The conclusion to Doctor Hrdlička's paper may be cited here:

"The task of learning the exact truth remains for the future. In relation to opportunities for further investigation, the author has satisfied himself that the field for anthropological and archæological research in eastern Asia is vast, rich, to a large extent still virginal, and probably not excessively complicated. It is surely a field which calls for close attention not only on the part of European students of the Far East, but especially on the part of the American investigator who deals with the problems of the origin and immigration of the American Indian."

40 Felix von Luschan, Völker, Rassen, Sprachen, Berlin, p. 21. I922.

41 A. Hrdlička, Remains in Eastern Asia of the Race that peopled America (Smithsonian Miscellaneous Collections, vol. 60, No. 16, Washington, 1912). See also by the same author, "Restes dans l'Asie orientale de la Race qui a peuplé l'Amérique (Congrès International d'Anthropologie et d'archéologie préhistorique, Compte Rendu de la XIV Session, Genève, 1912). 


\section{CHAPTER II. \\ THE JOURNEY TO THE ALEUTIANS.}

For reasons to be detailed below, the Ethnological Division of the Kamchatka Expedition began its work on the Aleutian Islands and not in Kamchatka with the rest of the party. To work in Kamchatka simultaneously with the other divisions of the expedition would have added to the difficulties of travel and transportation by dog-team and horses, neither of which was easily obtainable. Then, too, the Aleutian Islands are not readily accessible from Kamchatka, there being no boat service between Kamchatka and the Aleutians. So our only means of reaching them was by way of the United States. It was necessary, too, to obtain assistance from American scientific institutions and permission to work on the islands from the United States Government. Consequently, the members of the Ethnological Division set out from Petrograd for the United States, visiting England en route.

\section{PREPARATIONS FOR THE JOURNEY.}

We arrived in New York, October I, I908, and left for San Francisco on November 2I. With the exception of a Io days' visit to Washington, the entire period was spent in New York in preparing for the expedition, in purchasing stores, instruments, books, and all the impedimenta of a long voyage. This preliminary work was carried on in the American Museum of Natural History, where the author was able to make liberal use of its library. The museum also placed an office at our disposal and rendered assistance in the packing and transportation of our equipment. For this kind hospitality acknowledgment is made to the president of the American Museum, Professor Henry Fairfield Osborn; its former director, Doctor H. C. Bumpus, and the curator of the Department of Anthropology, Doctor Clark Wissler.

As before stated, it was necessary to obtain permission to excavate on the Aleutian Islands; to apply to the United States Treasury Department for leave to use the vessels of the Revenue Service in transportation from one island to another; and to ask permission of the Department of Commerce and Labor to land on the seal islands of the Pribilof group, to make ethnological and anthropological observations.

The negotiations to obtain the necessary permits were carried on by the Imperial Russian Geographical Society through the Russian secretary of state, and, due to the kind offices of the Russian ambassador in Washington, these permits were granted.

Doctor Charles D. Walcott, the Secretary of the. Smithsonian Institution, who must approve all permits before they are issued, not only added his sanction, but the 
Bureau of American Ethnology, having planned an expedition to the Aleutians, withdrew in our favor. Professor W. H. Holmes, then chief of the Bureau, kindly gave the writer access to all correspondence on the subject, from which it became clear that in the opinion of the bureau the author was competent to conduct the work on the Aleutians and that two expeditions were unnecessary. It may be added that the American authorities raised no objections to exporting the specimens found during the excavations.

En route, we visited San Francisco to study the Aleutian collections in the Anthropological Museum of the University of California; also to secure the assistance of the Alaska Commercial Company, which had agents both in Alaska and the Aleutians. Thanks to the kindness of Professor A. L. Kroeber, of the University of California, the author had opportunity to examine the Aleutian Island collections. The Director of the Alaska Commercial Company, Mr. Schloss, kindly furnished us with letters of introduction to the agents of the company, and from him also we obtained a letter of credit.

We left San Francisco by rail on November 30 and reached Seattle on December I, whence, on December 8, I908, we sailed on the Santa Clara of the Alaska Steamship Company. Our destination was Seward, a village on the Kenai Peninsula, whence it was possible to reach Unalaska by the small mail-steamer which covered this route monthly. We arrived in Seward on December I5, on which date the mail steamer, Dora, was expected to sail for Unalaska. Though we had been advised against a winter trip on Bering Sea, we preferred to winter in Unalaska, so that we could become acquainted with local conditions and, in addition, arrange for transportation to the other islands during the summer. It had been impossible to obtain exact information as to the means of communication between the islands, labor conditions, and other practical questions concerning our proposed work, even from some former Alaskan Government officials we had met in Washington. Some information had been obtained from Professor T. A. Jaggar, then of the Massachusetts Institute of Technology, who, the previous year, had studied the volcanoes of the Aleutians.

The Santa Clara followed the route through the so-called Inside Passage of the straits between the islands off the coast of British Columbia and Alaska and the mainland. We had a very quiet passage to Juneau. To our regret, we did not touch at Baranof Island and thus had no opportunity to visit Sitka, the former capital of Russian-American territory. Russian influence appears to have been stronger at Sitka than at any other point in Alaska. During the summer months numerous tourists take the trip through the Inside Passage, where are combined the beauties of Scandinavian fjords, Alpine mountains, imposing waterfalls, and snow-crowned peaks with ice-clad slopes.

From Juneau we passed out into the open sea and were at once agreed that "Pacific" was a misnomer for the northern portion of the ocean, particularly in winter. We stopped at several points and after a very stormy passage reached Seward December I7, I908. 
The Santa Clara was a small freight steamer with good cabins. In spite of the season, the cabins were all occupied-engineers, traders, officials, laborers, and gold hunters made up the passenger list. Some passengers left the steamer in Juneau to start to the Yukon River with mail-horses; others went from Valdez to the mines of Fairbanks, Klondike, and other mining districts. During the winter, Nome, on the Seward Peninsula, may be reached from Valdez by dog-team. We had our first view of an Alaskan dog-team in Valdez. The Alaskan method of harnessing dogs is very efficient. Everywhere we saw fisheries and canneries closed down for the winter.

The mail steamer Dora, which, according to the schedule, was to await us at Seward, did not appear, having been sent for inspection to San Francisco. Instead, a freighter, Faralon, was substituted. This steamer left Seattle simultaneously with the Santa Clara, loaded with benzine and explosives and carrying no passengers, and arrived at Seward 7 days later. We left Seward December 24, I908, and arrived in Unalaska on January 3, I909. In summer this is a trip of only 3 days. We had a very stormy passage. The Faralon was a river boat, not at all suitable for ocean waters, and yet, with the exception of the passage through Shelikhof Strait, between Kodiak Island and the Alaska Peninsula, it sailed the open sea. A storm delayed us 3 days at Kodiak Island and gave us an opportunity to visit Kodiak village, where we found an old orthodox church and a school maintained by the Holy Russian Synod.

During the last 2 days of our voyage the poop and mast were broken and we proceeded through Akutan Pass under extreme difficulty. Just before entering Unalaska Bay the weather calmed. The snowy summits of the bay, the precipitous rocky shores, and the smoking volcano Makushin presented a sublime and majestic spectacle. We went first to Dutch Harbor, on Amaknak Island, lying in the middle of Unalaska Bay. Here were the headquarters of the North American Commercial Company, the lessees of the Pribilof Islands.

After leaving Seward we had few fellow-travelers. Two left for Kodiak, three for Unga, the largest island of the Shumagin group, and we were the only passengers for Unalaska. At that season of the year only absolute necessity leads one to make the trip and it is only to carry out a mail contract that the steamship company maintains communication between Unalaska and the mainland. A month later the Faralon was completely wrecked on the rocky shores of Kodiak Island.

\section{UNALASKA.}

In Unalaska we were very kindly received by Mr. N. Gray, the Alaska Commercial Company agent, who put one of the company storehouses at our disposal gratis and recommended that we hire the house of the late Russian priest, Shayeshnikov.

A more complete description of life in Unalaska will appear elsewhere, but the following will present the general setting for our future activities. Unalaska, the village, known also by its Aleut name, Iliuliuk, is the principal settlement on the island of that name. It was founded by Solovyov between I660 and I670. In I909 
it had a population of 28I. Of that number 242 were Aleut and 39 whites or "strangers," chiefly Americans. The village is situated on a narrow sandbar between a rivulet and the bay. In the village were a Greek Catholic church, a Russian home for Aleut boys, a Methodist mission home for Aleut and Eskimo boys and girls, and a Government elementary school which the children living in both homes were obliged to attend. Of American officials, there were the United States marshal, Mr. Harman; the superintendent of the Government school and commissioner, Mr. Brown; the custom-house officer, a Russian-Tlingit, born in Sitka, Mr. Bolshanin, and the mail clerk, Miss Wagner. The Rev. Nicholas Rissov was the priest of the Russian church; he was born in Sitka, in the family of a Russian official. Of Russians who became American citizens after the purchase of Alaska by the United States, there were two sons of the late Russian priest, Shayeshnikov, and the son-inlaw of the Reverend Rissov. In the Russian home for children was a teacher recently arrived from Russia. The representatives from other European countries in the village were two Germans, one Norwegian, one Dane, and one Swede. With the exception of the Swede, Nyuman, who was married to the daughter of the late Russian priest, all the other Europeans had Aleut wives. The superintendent of the Methodist mission home was Doctor Spence, missionary and surgeon; four American women, including Mrs. Spence, taught in the home. In the Government school, besides the superintendent, were two women teachers. Others in the village were Captain Applegate and his family. Captain Applegate was at one time United States Signal Service recorder, but at the time of our visit was engaged in sea-otter hunting. In Dutch Harbor lived Mr. Schroter, the manager of the North American Commercial Company, and two American clerks.

We established ourselves for work in Unalaska until the spring. The question of means of transportation between the islands during the summer, however, caused us much worry, there being no regular communication. Once a year the Alaska Commercial Company sent a schooner carrying merchandise to Atka and Attu. In former years, Mr. Dirks, a German from Hamburg, who in his youth was a sailor and later engaged in trade with the Aleut, used to take a small schooner to Atka. But since his retirement he had sold his schooner. Mr. Lee, the Dane, also had a small sailing schooner which he used for trading in the islands nearest to Unalaska. He was willing to take us to Atka, but aside from the danger, this would have entailed great loss of time, since sailing to the west in summer would have been checked by contrary winds.

When in New York another plan for transportation had been formulated. In cooperation with Dr. T. A. Jaggar, jr., ${ }^{1}$ of the Massachusetts Institute of Technology, on behalf of the Geological Survey, and Dr. A. H. Brooks, of the Alaska division of the survey, it had been agreed that we jointly hire a sailing vessel with auxiliary motor to carry us to the western islands. But all inquiries led to the conclusion that such a craft was unfitted for a voyage in Bering Sea, while the cost of a steamer was prohibitive. After various other unsuccessful attempts to obtain

1 Doctor Jaggar is at present the volcanologist of the U. S. Weather Bureau and director of the Hawaiian Volcano Observatory at Kilauea. 
transportation, we learned that the Geological Survey had been obliged to postpone its expedition to the islands. Thus we were left to depend on our own resources, so far as transportation was concerned.

Finally, the following arrangements were made: In March a new sailing vessel of the Alaska Commercial Company was expected to arrive from Kodiak. We planned to sail on her to Attu Island and in July a revenue cutter could carry our party from Attu to Atka. Captain Applegate, in September, would take us from Atka to Umnak, where we intended to spend the winter of r909-ro, and at the end of April of that year Captain Applegate would take us back to Unalaska. As he usually spent the winter in Unalaska, starting in the spring for Umnak to take on his schooner the Umnak people and their skin boats in order to carry them to places where sea otters can be hunted; this would necessitate one special trip for our expedition. He was an educated man and was sympathetic toward our scientific work. Our proposed route included all the inhabited western Aleutian Islands, since we wished to combine excavations of old village sites with an investigation of the ethnology of the Aleut. To our regret, it was necessary to abandon our original plan to excavate on the islands uninhabited at the time of our visit.

The schooner expected in March by the Alaska Commercial Company did not arrive until June. We employed this period of waiting in a study of the Aleut language and in recording myths and tales. We could not leave Unalaska, even for a short trip, for fear of missing the schooner, thus losing the opportunity to visit the Aleut of the Alaska Peninsula or the Shumagin Islands.

About the end of May the northern portions of Bering Sea became free of ice, and passenger vessels and freighters entered Unalaska Harbor on their way north. Many whalers also appeared, also a Department of Commerce and Labor steamer with freight for the Pribilof Islands. We were told then that the Alaska Commercial Company schooner was under construction at Kodiak, but no one knew when it would put to sea. Simultaneously, the revenue cutters, upon which we had counted to a certain extent for transportation, began to come into the harbor. As before stated, we had received permission from the Treasury Department to request transportation by the revenue cutters.

The Bering Sea patrol fleet, a distinct part of the American Revenue Cutter Service, cruises in Bering Sea and in polar waters from June to the end of September. During our stay in the Aleutians it consisted of five or six vessels of the gunboat type. Three vessels were on duty to prevent pelagic sealing and other illicit activities of Japanese and other schooners. Two of them constantly cruised around the Pribilof Islands, while a third remained in Unalaska Harbor, each being on duty for 12 days with 6 days in port. A fourth cutter spent the summer in the polar ocean to protect and assist American whalers and trading vessels, while a fifth served to carry the members of the district court from place to place, to hear civil and criminal cases outside the jurisdiction of the local commissioners, to hear appeals, and to defend the interests of the native population. ${ }^{2}$ A sixth cruiser usually came to

2 The commanders of the revenue cutters have magisterial functions where there are no resident commissioners. 
Unalaska in the middle of the summer. Also, at the end of the summer, one cutter went westward as far as Attu, stopping at other inhabited islands en route. ${ }^{3}$

The chief of the patrol fleet, Senior Captain William Jacobs, had his summer headquarters in Unalaska, whence he directed the fleet. Captain Jacobs informed us of his instructions to assist us. Everywhere we were rendered assistance by officials and others, but the most important service rendered the expedition came from Captain Jacobs. To make it possible for us to reach Attu he hastened the western cruise and on June 9, I909, we left Unalaska on the revenue cutter Perry. Before our departure, Captain Jacobs informed us that at the end of July he expected the arrival of a new vessel, Tahoma, which, on its way to Unalaska from the west, would stop at Attu, and could then carry us to any other island on our schedule. He also promised that in the event of the failure of this cutter or the Alaska Commercial Company schooner, he would not abandon our party, but would send a cutter for us in the fall.

The Perry was the smallest vessel in the Bering patrol fleet, with a tonnage of 456 , and was under the command of Captain F. J. Haake. On the way to Attu we stopped at the village of Chernofski, on Unalaska, at Bogoslof Island, and at Atka, where we unloaded food, scientific instruments, and other equipment for work there after our return from Attu. We arrived at Attu, June 15, and landed in Chichagof Bay, at the winter village of the Attu Aleut. On the following day, Captain Haake, after obtaining information as to the Japanese schooners sailing past Attu to the east, started on the return cruise. After a few days we moved with the Aleut to their summer village on Sarana Bay. Our freight was transported in skin boats while we walked over the mountain ridge separating Chichagof from Sarana Bay. A description of our work at Sarana Bay will be given later.

June and July passed and neither the expected schooner nor the Tahoma appeared; we concluded that they would not come until the following year. The supplies in the local store had come to an end long ago, so at first we shared ours with the Aleut, but early in August these, too, began to run low. We hoped, of course, that we would be taken off the island in the fall, but were troubled by the thought that we might have to remain until the next year, and, though the threatened privations gave us some concern, we were more concerned with the possibility of being unable to complete our work on the Aleutians. If the revenue cutter came for us in the fall it would be possible to winter on Umnak Island, a most significant place for our work, but we would have to omit Atka, a no less important station.

When our anxiety had reached its climax and not only we, but the Aleut were aware of the serious state of affairs, an Aleut boy, early in the morning of August 8, ran down the mountain slope crying repeatedly, "Steamer at Chichagof Bay!" At first we were a little suspicious, since we had had our hopes aroused by similar cries before. However, we immediately ran over the ridge to Chichagof Bay and from the top of the mountain saw the smoke of a vessel in the harbor.

\footnotetext{
${ }^{3}$ It is the duty of the commander of this cruiser to visit the volcanic island Bogoslof, to report on whatever changes may have occurred during the year.
} 
It was the longed-for Tahoma, arriving from the Atlantic by way of the Suez Canal. Captain Quinan, its commander, had received a cable in Yokohama directing him to take our party off from Attu. Hearing that we were at Sarana Bay, Captain Quinan ordered the vessel there. In order to detain the steamer as little as possible, we spent the night packing, and early in the morning, accompanied by a choral song of the Aleut, praising our goodness, liberality, and other virtues, embarked on the revenue-cutter. What remained of our supplies we left to the Aleut and some of the Tahoma's supplies were sold to them.

The Tahoma reached Atka the evening of August io and lay at anchor outside the entrance of Nazan Bay, fearing to enter it on account of its shallow waters and reefs. After taking our mail and putting us ashore, Captain Quinan hurried away in order to reach Unalaska in the prescribed time.

In the village we learned that the Alaska Commercial Company's schooner Leti had left Unalaska for a western trip July Io, reached Atka July I5, and left Atka for Attu July I8; 23 days had elapsed since that date and nothing had been heard of the schooner. During our passage from Attu to Atka we also had met with no vessel. We feared some accident. On August I9 the Leti returned to Atka, with its crew completely exhausted, not having reached Attu. Incessant contrary winds and gales had carried the schooner into the open sea and despairing of approaching Attu and fearing to be wrecked by the storm, after $3^{2}$ days' struggle with the elements they resolved to return to Atka. So, were it not for the courteous assistance of the Revenue Cutter Service our party would have shared the unlucky experience of the Leti's crew.

The Leti had brought from Unalaska our mail and other papers, also food and clothing forwarded by Mr. Brown, the school-teacher at Unalaska, for distribution among the Attu Aleut. ${ }^{*}$ A letter came from Captain Applegate expressing his regret that he could not bring his schooner to Atka to carry us to Umnak. These events forced us to ask Captain Jacobs to transfer us from Atka to Umnak before the cutters left for the south. To our great delight the Bear appeared in Nazan Bay on September 14, back from a cruise in the polar ocean. The same day we were taken aboard and carried to Nikolskoye village on Umnak Island, where we remained until May I9Io.

The commander of the Bear, the late Captain Bertholf, ${ }^{5}$ had visited Russia in I9OI, when he obtained permission from the Russian Government to travel through Siberia to the district of Okhotsk to purchase reindeer for breeding in Alaska. This was, so far as we knew, the second exportation of domesticated Siberian reindeer to Alaska. In accordance with our request he stopped at $\mathrm{Ka}^{\prime}$ gam-I'lan Island, where a cave containing a mummified body had been reported. Unfortunately, we did not find the cave, but later learned from the Umnak Aleut that we had actually been in its near vicinity.

4 Every summer American charitable institutions were in the habit of sending clothing and food for distribution among the Attu, the poorest and least provided for of all the Aleut.

5 Captain Bertholf plotted out a detailed chart of the routes of the vessels of the second Bering Expedition for F. A. Golder's "Bering's Voyages," published by the American Geographical Society, New York, Ig22. 
We arrived at Umnak after Captain Applegate's departure for Unalaska. All the hunters had returned home and the Umnak people, Ioo in all, were present. Among them there waited the chief of the Unalaska village, Yachmenev, whom we had engaged as interpreter and who had been brought there by Captain Applegate.

To complete this sketch of our trips among the Aleutian Islands, it may be added that we left Umnak on Applegate's schooner May 3, I9Io, and after a stormy passage, reached Unalaska May 5. About the end of May the vessels of the Bering Patrol Fleet again appeared, this time with a new commander, Senior Captain Foley, who permitted us to board the Perry to go to the Pribilof Islands; permission to land there had previously been secured from the Department of Commerce and Labor. After we had landed the Perry, while cruising around St. Paul Island in a fog, struck a reef and sank; fortunately, the crew reached the island safely.

From the Pribilof Islands we returned to Unalaska on the Russian military transport Kolyma, under the command of Captain B. Kuzmin-Karavayef, which had been ordered from Vladivostok to carry our party and collections to Petropovlovsk, Kamchatka. After various festivities arranged for each other by the American and Russian naval officers and sailors, the Kolyma sailed for Kamchatka on July 26 , I9Io.

We have intentionally dwelt in detail on the description of the difficulties encountered in traveling in the Aleutian Islands to make clear, that without the assistance of the revenue-cutters it would have been impossible to carry out our plans. Without this assistance we should have had to content ourselves with work on Unalaska and Umnak only.

For any future investigations, archæological, geological, or any others, ${ }^{6}$ on the Aleutian Islands, it should be borne in mind that the explorer should have at his disposal a vessel more trustworthy than a sail or motor boat. The feeble motors of a boat are as impotent in the struggle with gales and storms as are sails.

We take this opportunity to express our gratitude for assistance in transportation between the islands, for the kind attention and hospitality to the chiefs of the Bering Sea patrol fleet, the senior captains, William V. E. Jacobs and Daniel P. Foley; also to Ellsworth P. Bertholf, Frederick J. Haake, and Johnston H. Quinan, the commanders of the Perry, Bear, and Tahoma, and the other officers of the vessels named. During our stay on the vessels we were placed in the commander's cabin, our Aleut interpreter with the non-commissioned officers, and the Aleut laborers with the sailors. We are especially indebted to Senior Captain Jacobs and Captain Quinan for their efforts in our behalf.

6 Much remains to be learned both of the (prehistoric) archæology and the geology of the Aleutian Islands. In its studies in Alaska, the U. S. Geological Survey has had in view mainly practical ends. The observation of a volcanic chain may produce not only purely scientific data, but also some indications as to the volcanic activities of adjacent countries, and thus save life and property.

7 The geological expedition of Professor Jaggar left Seattle for the Aleutians on its own schooner, carrying a small motor-boat for the investigations of inner bays, on May 20, 1907, and returned to Seattle, September II. The expedition lasted 3 months and 2I days, of which time 2 months were spent at sea and was time lost for scientific work. The passage from Seattle to Unalaska took 40 days, while it may be accomplished on a steamer in 5 days. (See T. A. Jaggar, jr., Journal of the Technology Expedition to the Aleutian Islands, 1907, Technology Review, vol. Io, No. I, Boston, I908.) 


\section{NATURAL FEATURES OF THE ALEUTIAN ISLANDS.}

A detailed description of the Aleutian Islands had been planned for the ethnographic section of this report, but a brief summary of the natural features of the islands seems necessary here. For more than 800 miles the Aleutian Islands stretch out from the Alaskan peninsula in a long, bow-shaped chain of 70 treeless islands, excluding islets. All the islands are of volcanic origin, and are covered with high mountains, among which are extinct and still active volcanoes. According to the geologist Suess, they appear to be a continuation of the Alaskan range, though of a later formation. The shore-line is irregular, the rocky mountains sloping abruptly to the sea. The bays are shallow, full of reefs, and are dangerous for navigation. Though the vegetation is luxurious, it is limited to grasses, berry-bearing shrubs, creeping bushes, and varieties of low willows. On the mountain slopes we find an alpine vegetation and various species of mosses and lichens. In the narrow valleys between the mountain ridges or on isthmuses having insufficient drainage are freshwater lakes with hummocky shores, such as characterize Siberian tundras. The only means of inland communication was by walking, but this was decidedly uncomfortable on account of the tundra-like hummocks covered with sedge-grass. The absence of arboreal vegetation may be ascribed not to the climate, which is comparatively mild, but to the constant gales, fogs, and mists which are encountered in Aleutian waters, thus depriving the plants of much sunlight.

\section{CLIMATIC CONDITIONS.}

Meteorological observations, using a centigrade thermometer, were made three times daily. The following table gives the mean monthly temperature and shows the Aleutian climate as far from harsh:

\begin{tabular}{|c|c|c|c|c|c|c|c|c|c|}
\hline Ig09 & Place & $\begin{array}{l}\text { Mean } \\
\text { temp. }\end{array}$ & $\begin{array}{l}\text { Max. } \\
\text { temp. }\end{array}$ & $\begin{array}{l}\text { Min. } \\
\text { temp. }\end{array}$ & 1909 & Place & $\begin{array}{l}\text { Mean } \\
\text { temp. }\end{array}$ & $\begin{array}{l}\text { Max. } \\
\text { temp. }\end{array}$ & $\begin{array}{l}\text { Min. } \\
\text { temp. }\end{array}$ \\
\hline March ........... & Unalaska . & -3.0 & 3.0 & -10.5 & October $\ldots . . .$. & Do $\ldots .$. & 5.I & 8.0 & -2.0 \\
\hline April ........... & Do $\ldots$. & I.7 & 6.5 & -11.5 & November ....... & Do $\ldots .$. & $2 . I$ & 6.5 & -5.5 \\
\hline May ............ & Do $\ldots$. & 3.0 & 8.5 & -5.0 & December $\quad . . .$. . & Do ..... & O.I & 4.5 & -9.5 \\
\hline June I to $8 \ldots \ldots$ & Do ... & 5.1 & 8.5 & 2.0 & I9IO & & & & \\
\hline June 23 to $30 \ldots$. & Attu $\ldots .$. & 8.4 & 12.5 & 4.5 & January & Do. & -0.5 & 5.0 & -9.5 \\
\hline July ........... & Do $\ldots$. & 8.5 & 16.0 & 4.0 & February & Do . & -2.7 & 3.0 & -13.0 \\
\hline August I to $7 \ldots$ & Do & 8.1 & I I.O & 6.0 & March & Do. & $-\mathrm{I} .8$ & 4.0 & -13.5 \\
\hline August II to $31 \ldots$ & Atka & 9.I & 16.5 & 2.0 & April ........... & Do $\ldots$. & $\longrightarrow 0.3$ & 5.5 & -8.0 \\
\hline September I to 4 .. & Do .. & 7.8 & 12.0 & 2.0 & May 6 to $17 \ldots .$. & Unalaska . & 2.3 & 7.0 & -5.5 \\
\hline September 19 to 30 & Umnak ... & 6.1 & 10.0 & I.O & & & & & \\
\hline
\end{tabular}

As may be noted, in some months observations were made on more than one island. This, of course, was because we did not remain long enough to complete our observations. But even where observations were recorded on different islands the mean temperature does not deviate to any great extent from the actual average. If we calculate the annual mean (taking the period from March I, I909, to March I, I9ro) we find it to be $3.9^{\circ}$, with a maximum of $16.5^{\circ}$ (on the island of Atka, 
August I2, I909) and a minimum of $-\mathrm{I} 3.0^{\circ}$ (on the island of Umnak, February I, I9IO). The lowest temperature noted during the 15 months of our observations, - $13.5^{\circ}$, was on the island of Umnak, March 7, I9Io. Thus, in the course of a year (from March I, I909, to February 28, I910), for only 3 months (March, 1909, and January and February, I9I0) was the mean temperature below zero and not one minus in the maxima.

With regard to the temperature of the air, it may be said that there are only two seasons: a long autumn and a short, mild winter. But the incessant winds and gales cause the slightest cold to be felt, and in summer, particularly, the constant fogs hide the sun. Throughout our meteorological observations the sky appeared quite clear on only 9 days. 


\section{CHAPTER III. \\ EXCAVATIONS OF ANCIENT ALEUT VILLAGE SITES.}

\section{KITCHEN-MIDDENS.}

Cultural processes are admittedly slow. Though, for a period of I 20 years the Aleut were under the cultural influence of the Russians, who first visited the islands in I74I, they had not, at the time of the purchase of Alaska by the United States, become entirely Russianized. The adaptation and adoption of new manners and customs involved in the process went on gradually, but the "civilizing" process had not yet been completed. Be this as it may, the fact remains that 200 years ago the Aleut lived in the Stone Age.

Everywhere in the Aleutian Islands are numerous depressions and deep cavities, the outward evidences of ancient underground dwellings. The depth of these sunken places is an index to their age; the less deep the depression the more remote is the time the sites were inhabited. In and about these the decay of the accumulated organic refuse of centuries has in the past and will in the future so fertilize the soil as to foster a luxuriant growth of native grasses, which in their turn add to the filling of the pits. Very often long-stemmed wild barley (Elymus), wild pea (Lathyrus maritimus), lupins, some grasses as tall as a man, and flower-like anemones, orchids, marguerites, and other flowers completely concealed the pits where the old dwellings once stood. Depressions concealed by these luxuriant growths were very often not discovered until we tumbled into them when walking. In the lower levels of these pits, in their turn, were to be found the remains of Aleut life before the arrival of the Russians, and the deeper the layers of kitchen refuse penetrate into the earth the older they are.

Up to the time of our work, no systematic excavations, except those of Doctor Dall, ${ }^{1}$ had been made on the Aleutians. Doctor Dall, however, carried on his archæological work only casually, in the hours of enforced leisure from his duties as director of the hydrographical and geographical investigation of the islands carried on under the auspices of the United States Coast Survey in I870 to 1874; when work at sea was impossible because of stormy weather, he excavated wherever he happened to be. So owing to the casual character of Doctor Dall's investigations, his conclusions as to the nature and development of the former Aleut culture were in need of verification by further excavations. It should be stated, however, that it was impossible for us to reach a full solution of the Aleutian archæological problem, as our excavations were necessarily confined to sites on the inhabited islands, while according to data gathered in the course of our work, perhaps still more interesting excavations could be conducted on islands no longer inhabited. Then, too,

1 Mention should be made here of the French ethnologist, A. Pinart, of whom we shall speak later, and of many curio hunters who ransacked the caves and other accessible ancient burial-places of the Aleut. 
in view of the manifold aims of the expedition, only a small part of our time was devoted to archæological work. ${ }^{2}$ At the same time it was important to examine as many village sites as possible, so that we had to limit ourselves to the excavation of only some of the pits on a site instead of examining all. These circumstances influenced the method of procedure. The ideal method would have been to dig a trench along one edge of the site until bed-rock or undisturbed soil was reached, thus uncovering a vertical wall of refuse for the whole site. This wall should then be photographed and measured. Then, by taking off horizontal layers, one after another, the outlines of individual habitations, fireplaces, and the stratigraphic order of the refuse would be revealed. But for such trenching and working out a whole village site many months would be needed. So, since time was an important factor, our excavations were limited to separate dwellings, and the following method adopted: first, to determine the depth, outlines, size, and direction of the pit, the grass was cut off and the site cleared. Then the pit was dug out at one side in terraces, the laborers on the lower steps passing the dirt to those on the upper ones, etc. In this way we uncovered a vertical wall opposite the terraces, showing all the strata of the pit. Digging proceeded until undisturbed soil, showing no trace of refuse, was reached. If this lowest layer consisted of soft sedimentary soil, digging was carried to a further depth of approximately 0.5 meter to ascertain that there was no deeper stratum of an older culture. After the vertical wall was examined, measured, and photographed, the terraces were dug out and the débris carefully sifted for implements, etc. When an archæological specimen of any kind was disclosed, note was taken of the depth at which it was found. If there was any doubt as to whether the specimen had been displaced in digging, a note was taken only of the number of the pit. The same procedure was followed with specimens found when sifting the soil. Ordinarily, two adjoining pits were dug simultaneously under the surveillance of the writer, Mrs. Jochelson, and the interpreter.

In all, we excavated at $I 3$ ancient village sites, investigated 57 pits of various sizes, 3 burial caves, and 3 other caves. If we estimate the average length of a pit as 56 feet, the average breadth as 35 feet, and the average depth as 14 feet, the débris moved from one pit would amount to 27,440 cubic feet and for 57 pits to I,564,o80 cubic feet.

The excavations were made within a period of 47 days. Ancient village sites were pointed out to us by the Aleut, but for excavation we had to choose those most easily accessible; there being no riding or driving animals, we were confronted with the problem of transportation. It was necessary to walk to the places we chose to excavate; passage by skin boats was too slow ${ }^{2 a}$ and too difficult, owing to the frequent

2 It may be added here that, according to the estimate in our original plans, only one year was to be devoted to the Aleut problem. Actually, the field-work on the Aleutians stretched over a period of I9 months, while the journey from Petrograd to. Unalaska and the preparatory work occupied 3 months more.

2a We preferred to cross narrow and long islands like Umnak by walking rather than to go in skin boats all around them. We speak here of small skin boats of the kayak type. The large type of skin boat, called by the Eskimo $u^{\prime}$ miak and by the Aleut nixa'laxi, is no more used by the Aleut on account of lack of skins of larger sea mammals. 
storms. Besides, the skin boats were incapable of transporting much freight. Thus, our Aleut assistants had to carry on their backs boxes containing food, cooking vessels, digging implements, instruments, tents, cameras, guns, clothing, and other supplies. On the return trip from an excavated site they carried stone and bone implements, skeletal remains, and other archæological specimens. It was exceedingly difficult to transport heavy stone specimens like stone lamps; for that reason we abandoned all animal and bird bones excavated, taking note of them, however, since the Aleut laborers were able to identify them.

With huge bundles and boxes on their backs, the laborers had to climb high mountains separating opposite coasts or one bay from another (plate 7, fig. I). In some places, as for instance on Attu, while passing from Sarana to Lastova Bay (see map, fig. I) we had to walk over a pass covered with snow-fields and glaciers. Here the Aleut walked barefooted to save their boots.

Of the 47 days devoted to excavation, only 8 were dry and calm; the remainder of the time we worked in rainy and stormy weather, and the wind scattered the small particles of kitchen refuse. Diggings on the ancient village sites, Nanikax (Attu Island) and Ukix (Umnak Island), were left unfinished because of the inclement weather and resumed later.

All the ancient Aleut villages were situated on the sea-shore, not on the high land above the sea, and usually on land between two bays, so that their skin boats could easily be carried from one body of water to another at the approach of foes. Thus the usual location of villages was on narrow isthmuses, on necks of land between two ridges, on promontories, or narrow sandbanks. An indispensable adjunct to a village was a supply of easily accessible fresh water-a brook, fall, or lake. River-mouths were never used as permanent dwelling-places, because the topographical conditions were conducive to unexpected attacks. The underground dwellings of the old Aleut were much like traps; if an attack were made when the inhabitants were within, they could leave it alive only through the single opening in the roof. For this reason villages were built on open places, whence observations could be made far out to sea. Near every village was an observatory (agi'saxi) on a hill where constant watch was kept. The sentry was called amgi'gnax'. Here, too, hunters watched for the appearance of sea-mammals, and in turn the people of the village watched for the return of the hunters, greeting them with songs and dances.

At the time of our investigations the Aleut villages were situated mainly in valleys at the river-mouths, where they were settled by the Russian invaders. This change had some advantage, since, with the advent of the Russians, internal wars ceased; moreover, the Aleut were in a position to take advantage of the annual spawning migration of salmon, which they caught and dried in the summer for winter use. In ancient times the Aleut visited such rivers to catch salmon, but never had permanent villages on their banks; moreover, they caught sea-fish, chiefly halibut, cod, and sculpin, from skin boats out on the open sea. 


\section{EXCAVATIONS ON ATTU.}

On Attu three village sites were excavated: first, the ancient village, Sin, situated within a half-mile of the present winter village on Chichagof Bay; second, near the present summer village on Sarana Bay; third, the site of the ancient village, Nanikax, on Lastova Bay (Aleut, Igu'lux'). (See map of Attu.) The most significant results were obtained from the excavations at Nanikax. The village site, Sin, and the pits on both banks of the river flowing into Sarana Bay seem to have been inhabited at a later period than Nanikax, which was on a small cape projecting into Lastova Bay.

On the site of Nanikax were traces of 15 pits, of different sizes and not in any regular order. None of the pits observed here appeared to be of a size suitable for a so-called kashim, ${ }^{3}$ a remark which may be applied to the two other village sites also.

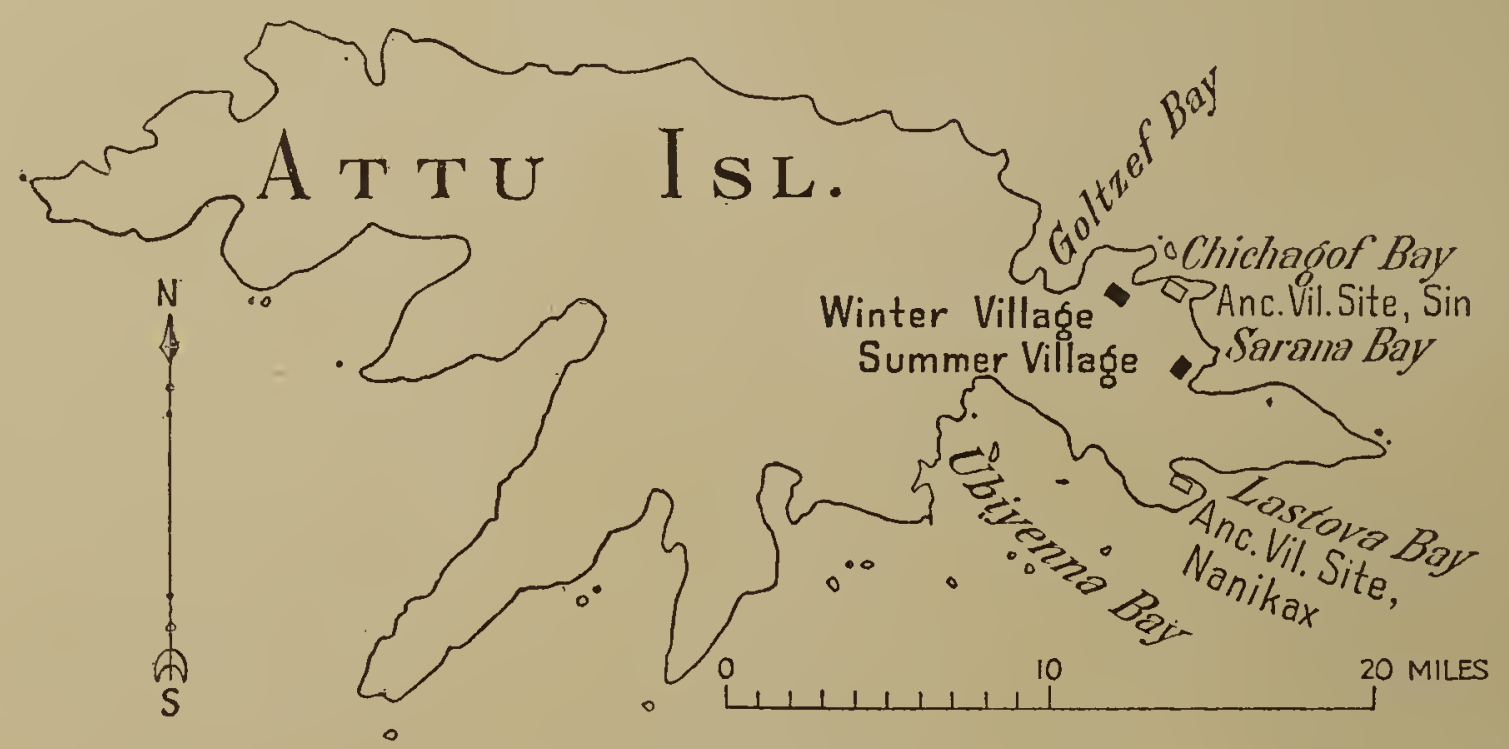

FIG. I.-Map of Attu Island.

Lastova Bay is separated from Sarana Bay by a rocky promontory, with a pass at a height of goo meters. The pits were oblong rectangles, some with rounded corners. Prior to digging, all the pits were about a meter in depth. At Nanikax 6 pits were excavated.

Pit I, with its longitudinal axis from east to west, was 8.7 meters long and 6 meters wide. Strata 3.5 meters deep contained shell and other refuse, and rested on a gravel-bed. The depth of the excavations was reckoned from the upper edge of the pit. Pit 2, with longitudinal axis extending northeast-southwest, was 8 meters long and 4.8 meters wide. Refuse strata extended to a depth of 3.8 meters on the northeastern side and 3.4 meters on the southwestern side. Pit 3 was located somewhat nearer the sea on the slope of the hill. Its longitudinal axis also extended from northeast to southwest. It was 9.6 meters long and 6.8 wide. Refuse was found to a depth of 2.7 meters. Pit 4 was situated at the apex of the hill on which the village had stood and contained deeper layers of refuse. Its longitudinal axis was from northeast to southwest; its length 8.7 meters and its width 5.5 meters. The shell-heaps extended to a depth of 5 meters. A section of the northeastern wall

${ }^{3}$ A special earth-hut of the Eskimo for gatherings, festivals, and dances. 

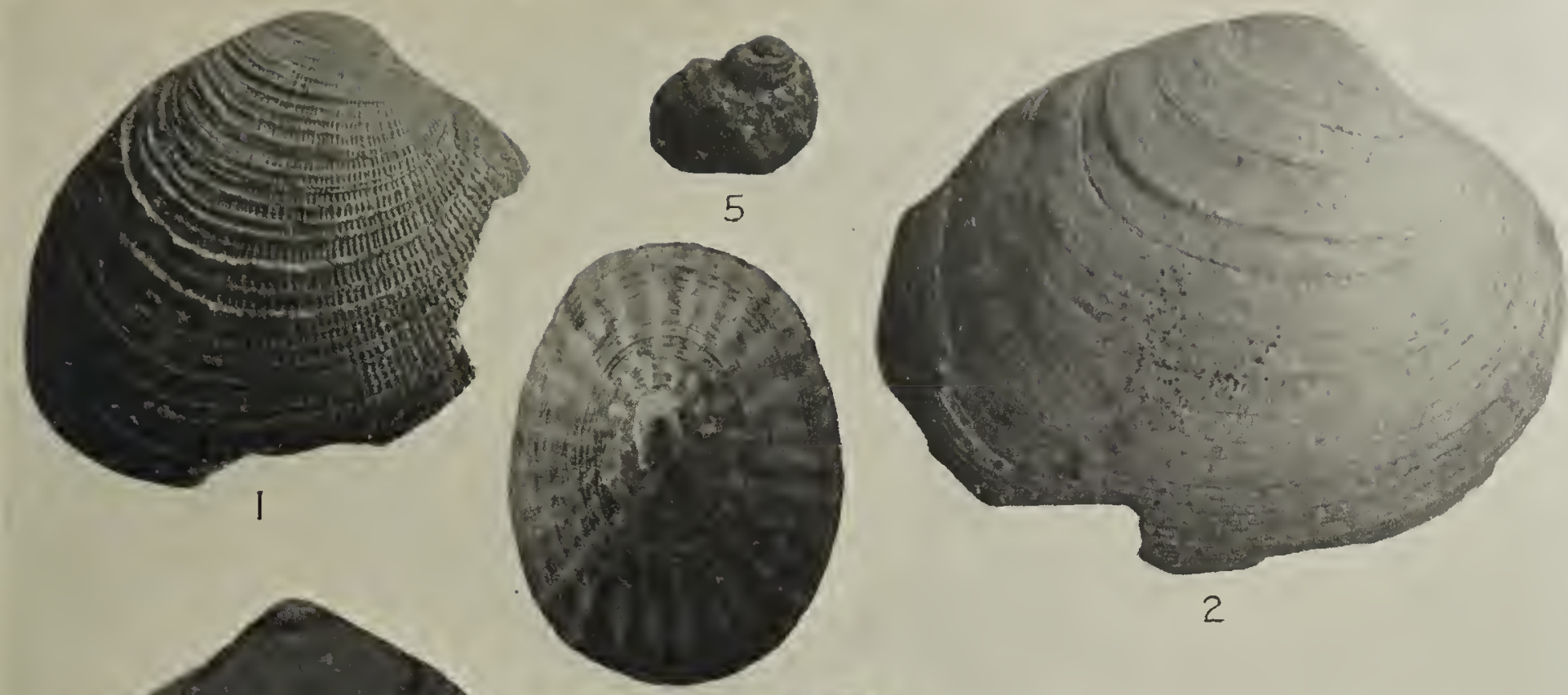

2
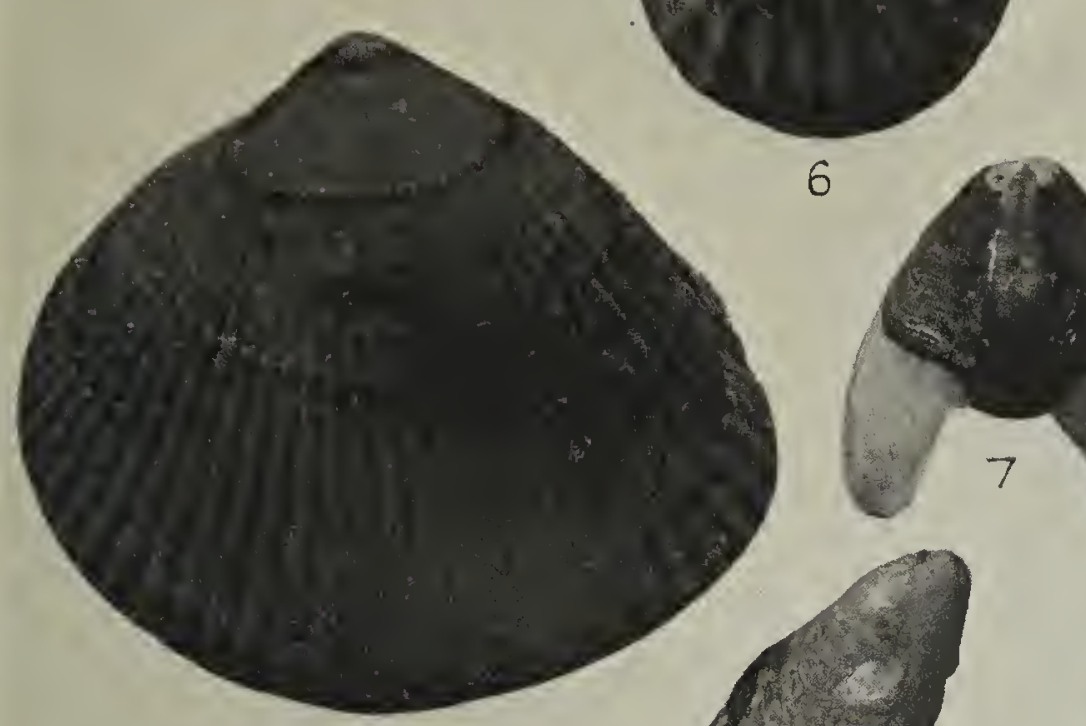

4
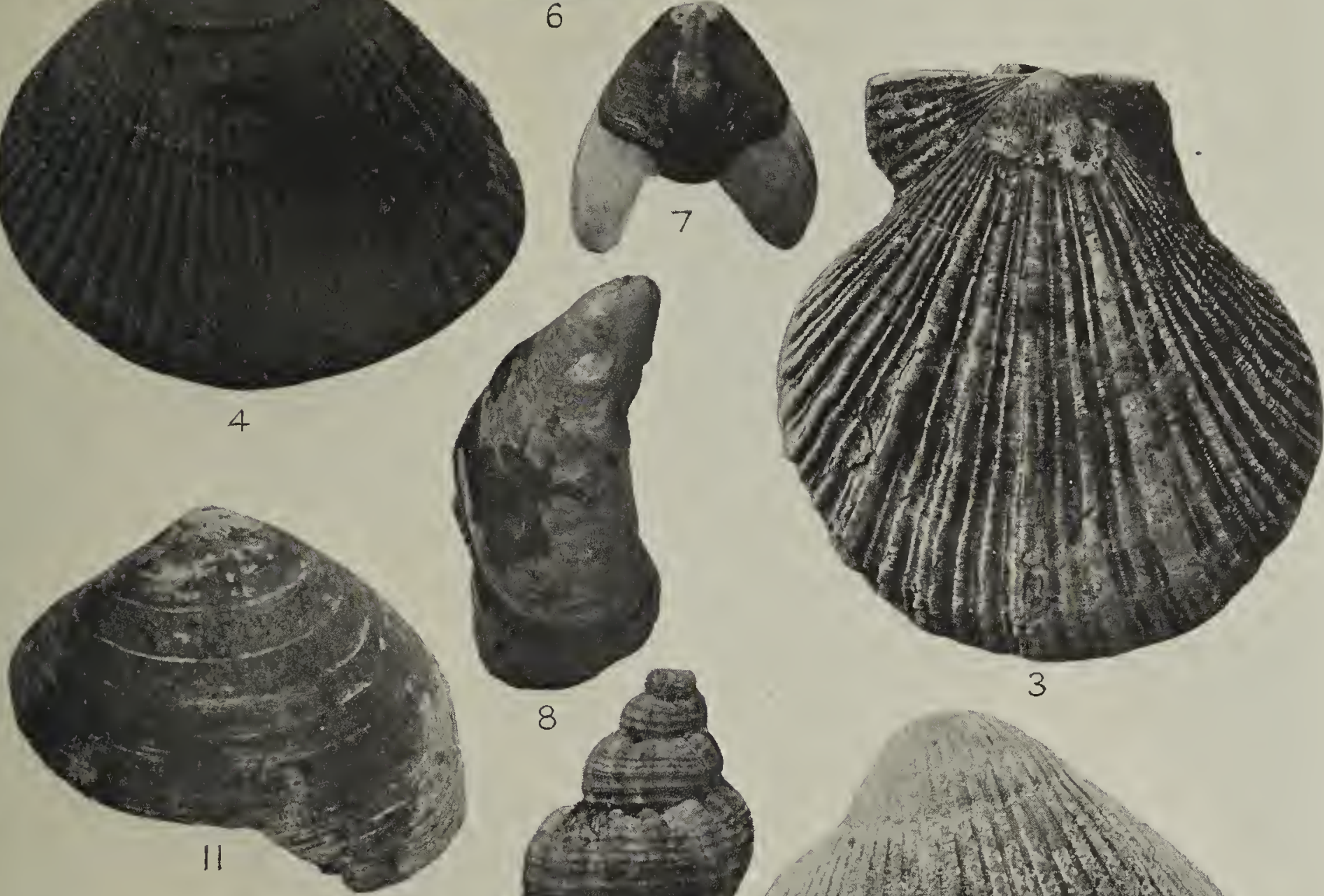

3
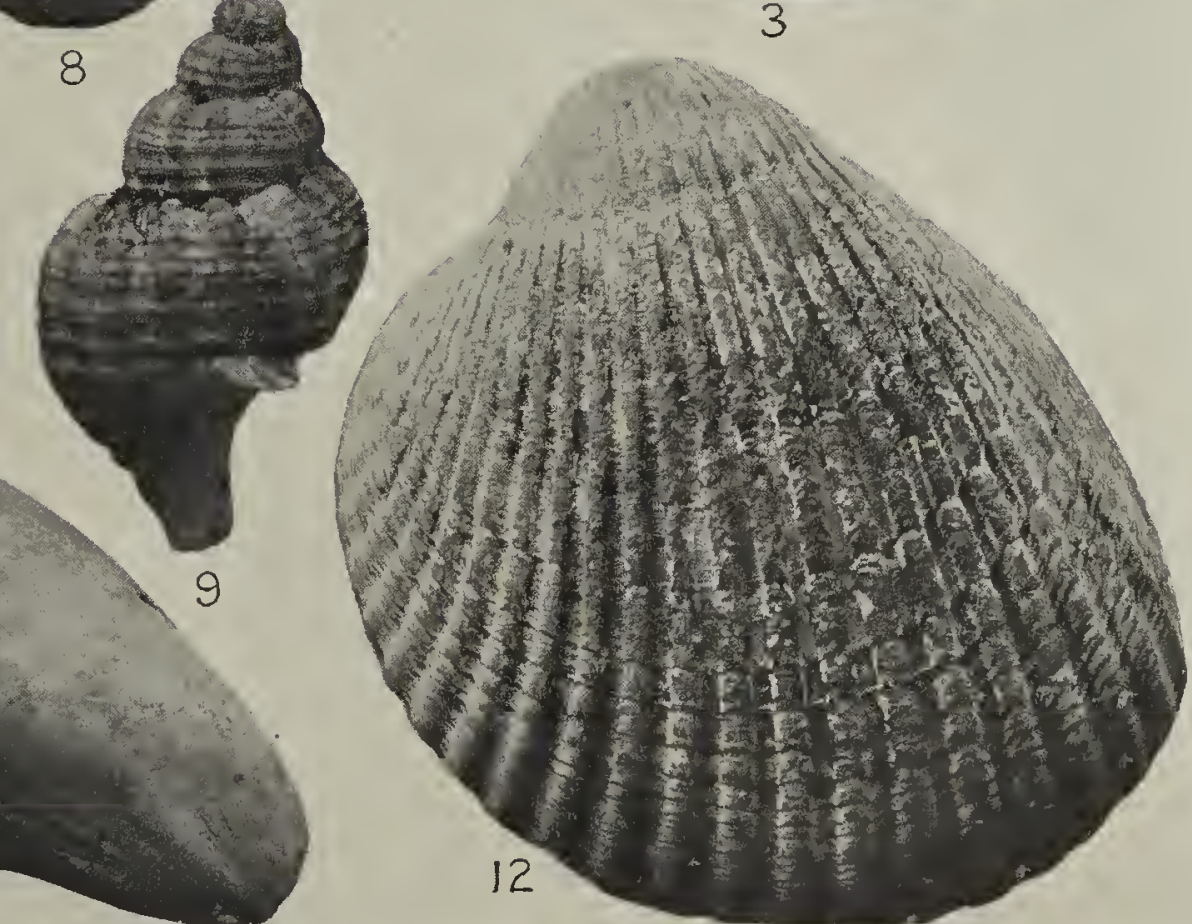

I. Venus petiti Desh. (Aleut, satma'yux').

2. Saxidomus nuttali Conr. $=$ Saxidomus squalidus Desh. (Aleut, imu'lux').

3. Pecten sp.

4. Cardium sp.

5. Litorina sitchana Mid. (Aleut), cimka' $y u x^{e}$ ).

6. Acmrea patina Esch. (Aleut, ci'knax').
7. Katharina tunicata IVood (Aleut, kasigux', Attu dialect, qasu'gix ${ }^{e}$ ).

8. Mytilus edulis L. (Aleut, hwa'yigix).

9. Triton cancellatus Lan.

Io. Modiola modiolus L. (Aleut, cu'sux').

II. Cardium nuttalli Conr. (Aleut, qama'kux').

12. Mactra ponderosa Phil. s. ovalis Say (Aleut, ca'lax"). 

of the pit is shown on plate 4, fig. 2. The contents of the layers, with refuse from top to the bottom of the pit, were as follows:

(I) I.28 meters.-Mold, with plant-roots and mixed refuse. Bones of sea mammals prevailed, but bones of birds and fish, mollusk shells, and echini were also found.

(2) 0.21 meter.-A layer of kitchen remains exclusively-bird and fish bones, and shells of echini. Echini predominated.

(3) 0.21 meter.-Fat mold containing whale-bones.

(4) 0.32 meter.-Pure kitchen remains-fish-bones, mollusk and echini shell. Echini predominated.

(5) 0.12 meter.-Mold only.

(6) 0.37 meter.-Layer of mollusk shells with a small admixture of echini and fish-bones.

(7) 0.I9 meter.-A layer of fish-bones and the lower jaw of a large whale.

(8) 0.52 meter.-Fish-bones and shells of shellfish and echini. Shellfish and echini prevailed.

(9) 0.92 meter.-A layer of fish-bones with a small admixture of shellfish and echini.

(Io) 0.62 meter.-A layer of fish-bones, shellfish, echini, and whale-bone.

(II) 0.19 meter.-Shingle, like that of the seashore, and quite a little echini.

Bones of the following sea mammals were found in this section: sea-otters (Enhydris marina; Aleut ca'xtux ${ }^{\prime}$ ); a large species of seal (Erignatus barbatus; Aleut, $i^{\prime}$ sux $x^{\prime}$ ); sea-lions (Eumetopias stelleri; Aleut, $q a^{\prime} h w a x^{i}$ ); and three species of whale. Unfortunately, two of these could not be identified. The Aleut call them agya'x, one of the largest whales, probably Balcena mysticetus; agama'xcix', a small whale, probably Balcnoptera velifera; hi'xtax'; the whale Ziphinus, the oil of which is used for burning only and not for food, as it is a purgative. Guests whom the Aleut wished to deride were treated with fat of the Ziphius whale.

The bird-bones found were: uriles or black cormorants (Phalacrocorax urile; Aleut, agayu'x') ; Pacific eider (Somateria v. nigrum Gray; Aleut, Attu dialect, cayu'sux', Unalaska dialect, $s a^{\prime} k u x^{\prime}$ ) ; Pacific gull (Larus glaucescens Neum., Aleut, slu'kax'); guillemot (Pseuduria columba Pallas; Aleut, si'mlux and si'blux $x^{\prime}$ ); tufted puffin (Lunda cirrhata; Aleut, ux'cux'); petrel (Synthliborramphus antiquus Gmelin; Aleut, sa'tax and qida'nax'); albatross (Diomedea albatross Pallas; Aleut, agli'gax') ; rosy finch (Leucosticte tephrocotis; Aleut, qu'lgax' and uluga'six $\left.{ }^{\circ}\right)$. The Aleut used the reddish down of the rosy finch to ornament their birdskin parkas (shirt-like overcoats).

The fish-bones were: Russian terpug, a species of Cottoidæ (Hexagrammus; Aleut, sax), cod (Gadus macrocephalus Til.; Aleut, atki'yax'), and halibut (Hippoglossus vulgaris; Aleut, ca'qixi').

The mollusks were (see plate 2): Acmaea patina Esch. (Aleut, ciki'cax' and ci'knax $^{\prime}$ ), Katharina tunicata Wood (Aleut, qasu'gix and kasi'gux' ${ }^{\prime}$ ), Litorina sitchana Mid. (Aleut, cimi'gix' and cimka'yux'), Modiola modiolus L. (Aleut, kyux ${ }^{\circ}$ and $c u^{\prime}$ sux $^{\circ}$ ), Mytilus edulis L. (Aleut, ma'yigix and hwa'vigix'), Mactra ponderosa Phil. s. ovalis Say (Alett, ca'lax'), sea-urchin (Strongylocentratus drobachiensis Müll.; Aleut, agu'nax').

According to my field-notes, the depths at which the specimens were found in Pit 4 are as follows: Layer I, a bone needle (text-fig. 63b), a comb (text-fig. 58), a small bone plate with holes (plate 26 , fig. 2I), a bone lamp (plate 20, fig. 7), a bone arrow-point (plate 25, fig. 9), a bone arrow-point (plate 24, fig. 43), a bone arrow-

4. Where two Aleut names are given, the first is in the Attu or western dialect and the second is in the Unalaska or eastern dialect. 
point (plate 27, fig. 24), a marble stopper (text-fig. I05), a stone lamp (362). ${ }^{5}$ Layer 3: a bone harpoon-head (plate 22, fig. I). Layer 4: a bone carving of a whale (text-fig. 77). Layer 8: a bone arrow-point (plate 23, fig. I8). Layer Io: a stone spear-point (text-fig. 33). The last layer, I I : a bone lamp (plate 20, fig. 5).

The contents of the various layers in Pits I to 3 were approximately the same as in Pit 4, although the order of the layers was not quite identical. Echini and mollusks predominated in the lower strata.

Close to Pits I and 4, to their west and southwest respectively, were excavated two smaller pits in which kitchen refuse and skeletal remains were found. These small pits, separated from the large pits by walls I.5 meters wide, were evidently for burial. Pit 6 , the small pit near Pit 4 , was 2.5 meters long and 1.9 meters wide. Here, at a depth of I.5 meters, close to the wall, a skeleton (plate II, fig. I) was found. In other sections of this pit and at the same depth 8 more skeletons were uncovered. Four were crushed under the weight of a heavy whale-bone. In this pit, strata-bearing culture remains reached a depth of 3.4 meters. At a depth of 3.3 meters, a stone spear-point (4I6) was found.

Two pits were excavated in the Sin village site: No. I was I I meters long and 8.2 meters wide; No. 2 was 4.5 by 3.8 meters. In the latter were preserved all the whale-bones which had served as the ceiling frame (plate 7 , fig. 3 ). In both pits specimens bearing layers containing bones of sea mammals, fish, mollusks, echini, and bone and stone implements reached a depth of a little over 2 meters. Though no objects showing Russian influence were found here, the writer is inclined to the opinion that the Aleut lived in Sin after the Russian advent. Kitchen remains were very meager, and these were mixed with earth. The village was situated on a mountain slope right over the sea, a location which would not have been chosen by the ancient Aleut. The site was occupied by a kitchen-garden where the Aleut had planted potatoes and turnips.

Excavation of pits in the banks of the small river flowing into Sarana Bay, above the present summer village, bore similar results. On the right bank of the river, a pit was dug $\mathrm{I} 3.4$ meters long and 5.3 meters wide. Two smaller pits were excavated on the left bank; Pit A was 4.8 by 3.7 meters and Pit B was 6.8 by 5.4 meters and revealed few traces of kitchen refuse. Thin streaks of sea-urchins were disclosed, but no deeper than at about I.5 meters. Doubtless the Aleut lived in these underground dwellings after the arrival of the Russians. The larger pit on the right bank of the river was evidently the remains of an earthen barrack-hut, in which Aleut men had lived when hunting under Russian direction. It has already been pointed out that the ancient Aleut did not settle in an inclosed bay or in river valleys.

\section{EXCAVATIONS ON ATKA.}

Two ancient village sites, Atxa'lax and Hala'ca, were excavated on Atka; also, two burial caves, which will be described later, were examined.

5 The number in parenthesis gives the number of the specimen in the Ethnographical Division of the Rumiantzev Museum in Moscow. All unillustrated specimens are marked by such museum numbers. 

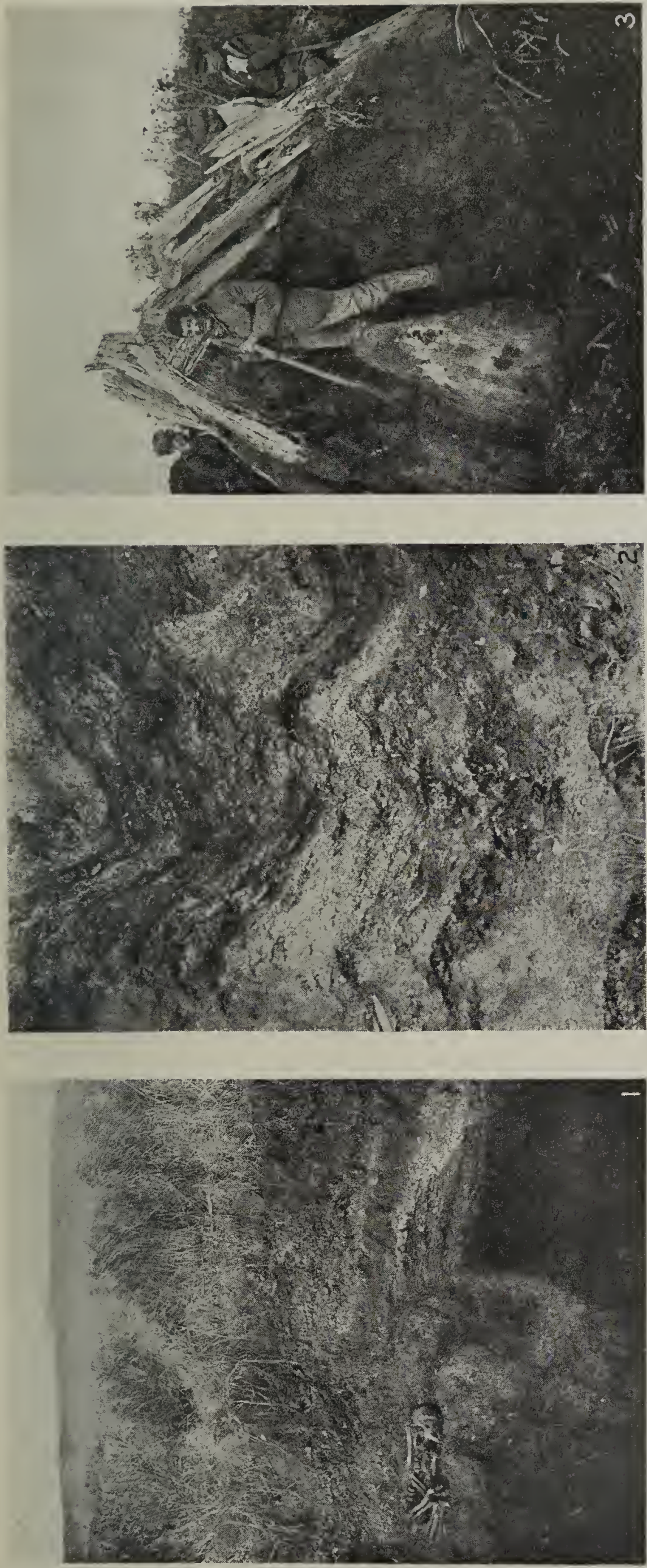
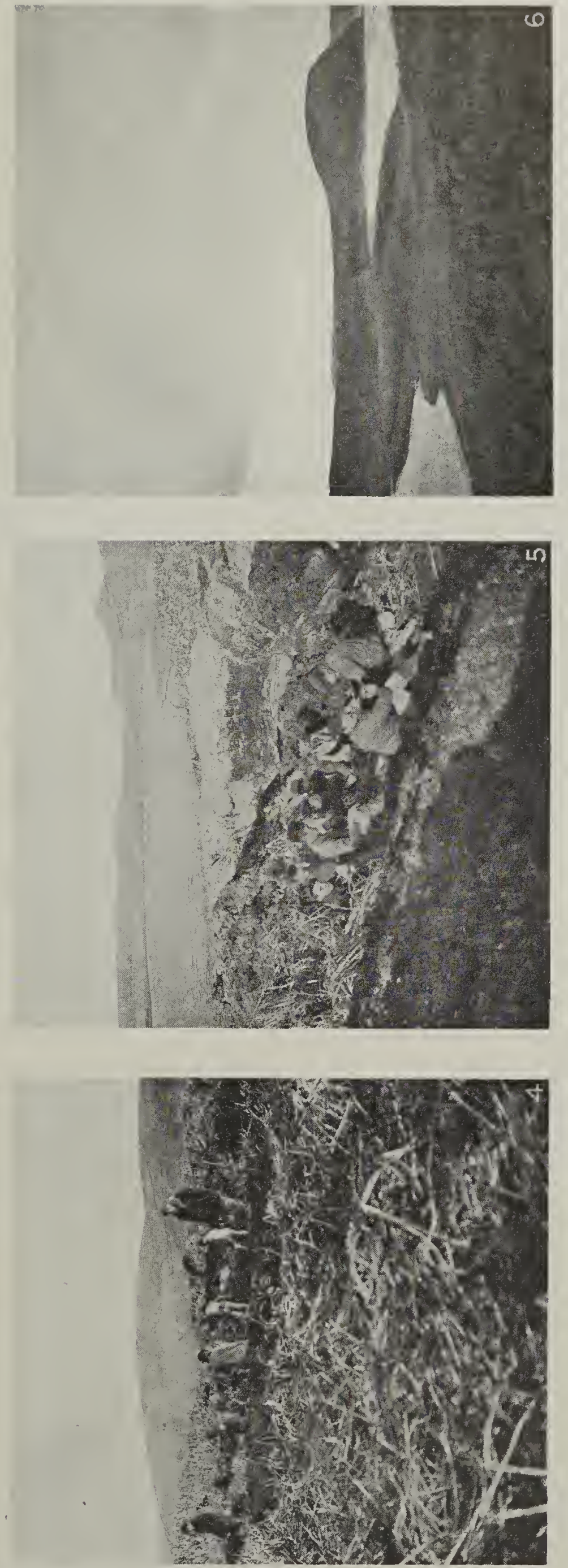

$=$

or

$\stackrel{\Xi}{\Xi} \overline{0}$

政

คे

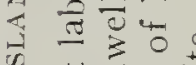

क

要

否的

西

z

n

$\frac{\pi}{60}$.

ए

.

.

$\stackrel{5}{=} \stackrel{\square}{=}$.

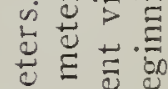

$\Xi$ in:

in

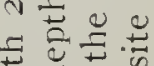

可

数

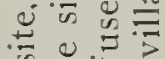

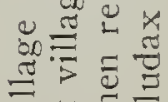

$\exists x \bar{y}$

$\times$ 要

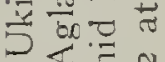

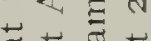

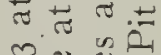

$\rightarrow+\frac{\pi}{2}$

的是

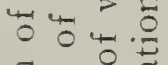

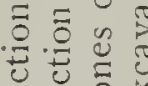

通品

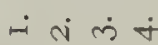



Atxa'lax. - This village site, according to the Aleut, was very ancient and was inhabited long before the arrival of the Russians. Before that time few Aleut lived on Atka, but Russian hunters transferred to Atka Aleut from the islands of Tanaga, Kanaga, and Adax. The site of the present village was selected by Russian hunters because of its protected position on Nazan Bay, which was cut off from Bering Sea by a semicircle of small islands and rocks. Atxa'lax was situated on a promontory covering the entrance to the bay from the north and, with the nearest island, forming a narrow strait for the entrance into the bay. This passage, because of the reefs, is not navigable by ships (plate I, fig. I). Atxa'lax was situated, not on the elevated rocky end of the promontory, but on the low, narrow middle portion about 25 feet above sea-level. On either side of this narrow section of the promontory are two small bays, one facing Nazan Bay, the other the open sea (plate 8, fig. 4); 25 depressions were noted on this site, all of moderate size, and some rather small.

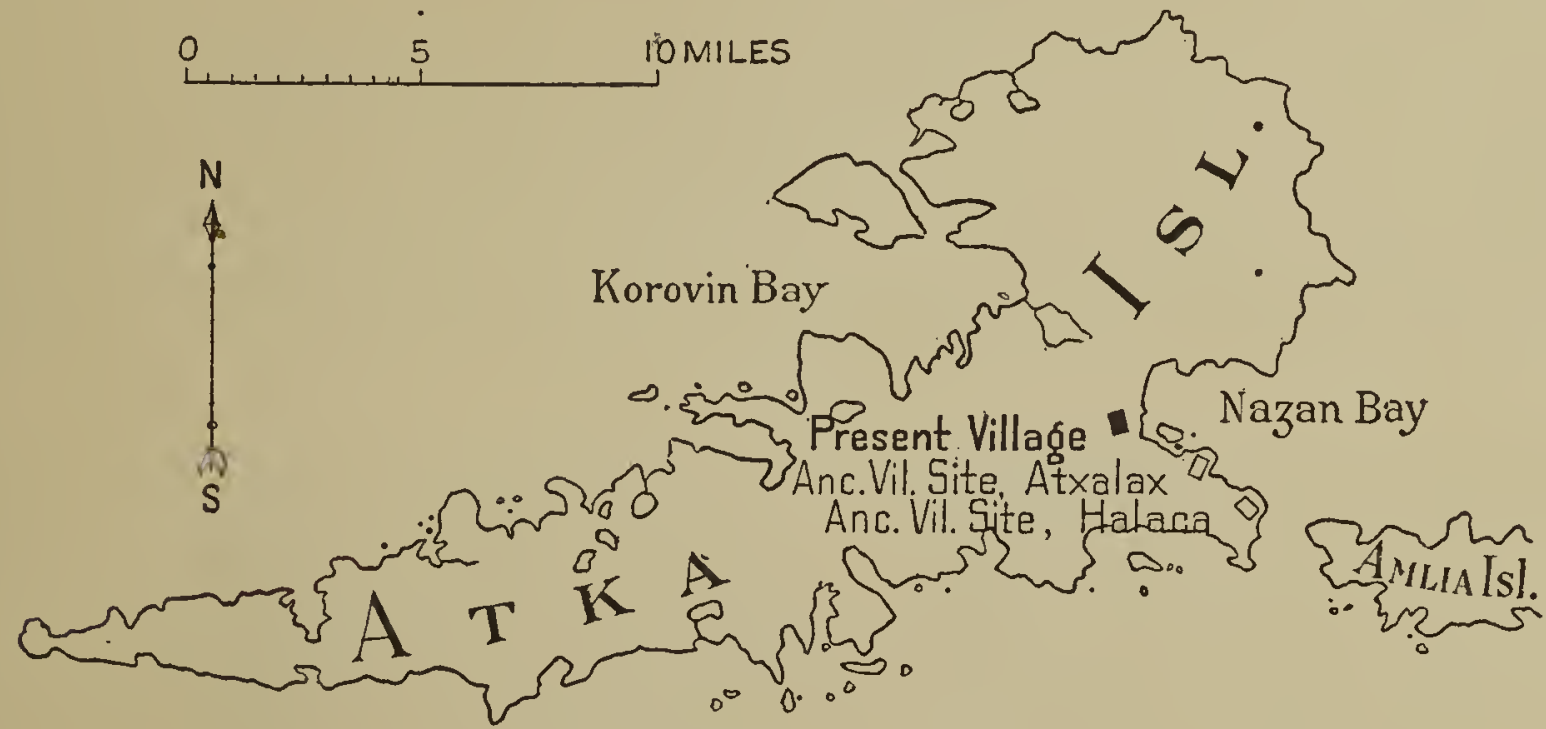

FIG. 2.-Map of Atka Island.

We succeeded in excavating only 2 pits on the Atxa'lax' site-a large one $(A)$ and a much smaller one $(B)$, side by side. We dug both pits simultaneously, with the expectation of digging out the wall separating them. The large pit was 8 by 5.5 meters and about a meter in depth before digging. The small pit to its south was 4 by 3 meters. The depth of the section of the large pit was 4.2 meters; the strata from the top down contained the following layers:

(I) 0.85 meter.-Mold with roots and a mixture of kitchen refuse. The contents of the upper layers differed considerably from those at Attu, where bones of sea mammals predominated. Here there were fish-bones, mollusk-shells, and sea-urchin cuirasses. Of sea mammals there were the bones of small seals (Phoca vitulina), sea-lions, sea-otters, and whales; of birds, bones of uriles, guillemot (Uria lomvia arra; Aleut, sakitaxi), and eiders; of fish, cod and halibut bones; of mollusks, shells of Mytilus edulis.

(2) 0.2 meter.-Kitchen refuse without any admixture of earth: echini and shells of Mytilus edulis.

(3) 1.55 meters.-Kitchen refuse mixed with earth. In this layer were found bones of seal, sea-otters, whales, puffins, uriles, guillemots, eidcrs, and bones of codfish and halibut. Shells of the following mollusks were found: Mactra ponderosa Phil. and Saxidomus muttali Conr. Thin streaks of echini and Mytilus edulis aiso occurred.

(4) 0.55 meter.-The layer consisted almost exclusively of kitchen refuse, mainly echini and shells of Mytilus edulis, among which were also found sea-otter and seal bones.

(5) 0.9 meter.-A layer of mold which in former times was evidently the top soil. This contained a small admixture of miscellaneous kitchen refuse, containing echini, mollusks (in the same varieties as in the other layers) bones of fish and sea-mammals, especially seal.

(6) 0.15 meter.-Pure yellow sand. 
The following objects were found at the depths indicated: at 2.4 meters, at the bottom of layer 3 , half of the lower jaw of a large whale. It was 3.3 meters long and at its widest part was 0.6 meter. Both ends were rounded and polished smooth, and in the heavier end were two perforations made with a stone drill. These were evidently for tying the bone to a post, rafter, or another bone in the ceiling frame. On both sides and for its entire length the bone was grooved and nicely polished. Because of its weight it was impossible to remove the bone and the photograph taken of it turned out very poor. However, it is illustrated in plate I, figure 2 , where it can be seen near the tent in the general view of our excavations. Under the jaw were found some bone arrow-points and a bone club for stunning small seamammals $(767,768,769)$.

At a depth of 3.4 meters, in the upper part of layer 5 , were found a bone awl (plate 27, fig. 22), a flat stone frying-pan, a large stone lamp (plate I9, fig. 2), and the bone of a seal and a small whale.

In the lower part of layer 5 , at a depth of 4 meters, among the bones of cod-fish and sculpin, were found a stone for grinding colors (plate I9, fig. 4), a stone pestle (plate I7, fig. I9), pieces of ocher for paint, a stone frying-pan ( I697, Aleut, $c u^{\prime} \tilde{n} l u x^{\circ}$ ), a bone arrow-point, and a stone sinker (plate I8, fig. I).

The layers in the smaller pit followed approximately the same order as in the larger pit. In the upper mold layer, fish-bones and echini and mollusk shells predominated. At a depth of 1.8 meters we found a broken human skull with its lower jaw and some decayed bones of the skeleton. Under these was a thin layer of clayey sand; below, at a depth of 2.I meters, were the bones of a large whale. Under these, at a depth of 2.4 meters, was another human skull with the lower jaw. The upper jaw was entirely decayed. No other skeletal remains were found. It is possible that when the ceiling fell it tore the skull from the body and the rest of the skeleton lay somewhere outside the limits of our diggings; or the skull may have been a trophy of an enemy killed, since the ancient Aleut warriors used to bring home the head of a slain enemy, which they set up on a pole on the roof of their dwelling. Without doubt the bones of the large whale at one time formed the framework of the roof of the underground dwelling and the first skull belonged to a man of a generation later than that of the lower skull.

In the same layer with the lower skull were found the bones of a sea-lion, a lamp made of diabase porphyrite (788), the outer side smoothly polished, and half of an unbaked clay lamp (78r), which fell to pieces when touched. This was the only trace of Aleut pottery. At a depth of 2.5 meters were bones of sea-lions, seaotters, seals, and a small whale (Aleut, $c i^{\prime} d a x^{\circ}$ ). Among these were fragments of ornamental bone-arrows, a narrow bone foreshaft of a drill, and stone frying-pans burned by fire.

Halaca Village.-This site was situated on a rocky promontory composed of conglomerate. The promontory lies on the southeastern side of the island, overlooking the strait separating Atka from Amlia. The village was situated 20 meters above sea-level. Jutting out from the rocky end of the promontory, the island formed an isthmus 8 to Io meters high, with small bays on either side, north and 


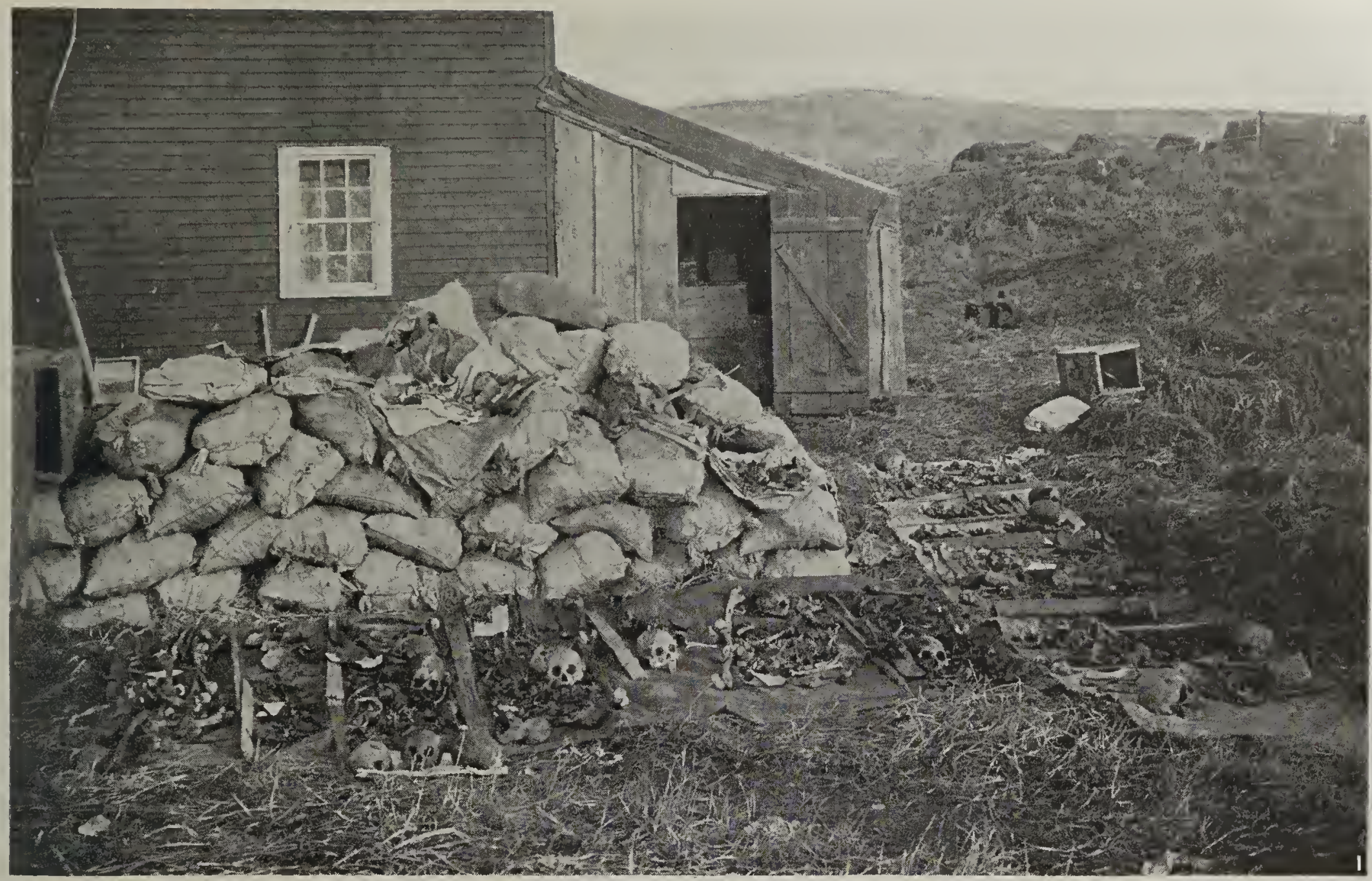

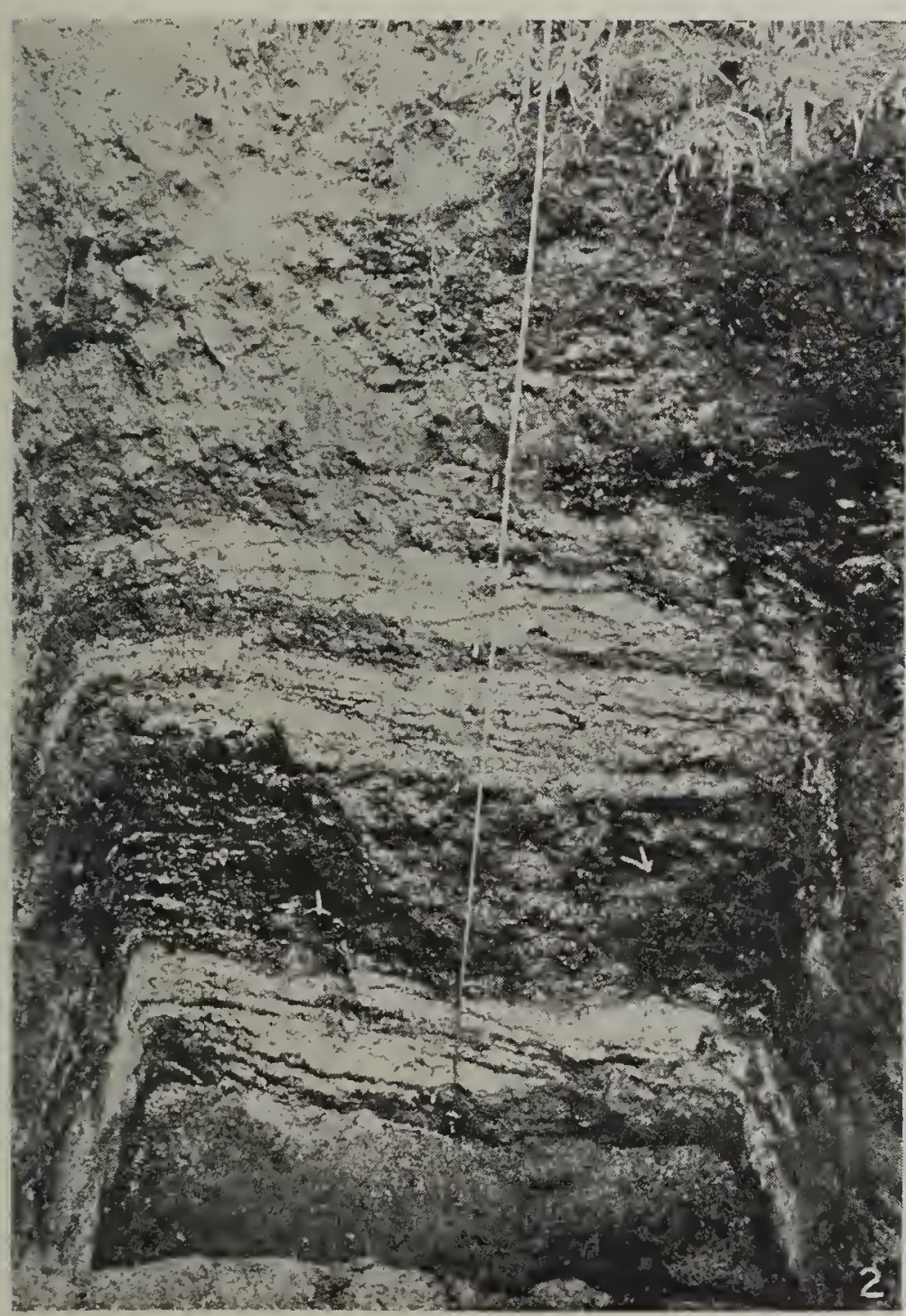

1. Drying skulls and other human bones uncovered by excavations on Umnak Island. In the sacks is the party's coal supply in preparation for wintering on the Island.

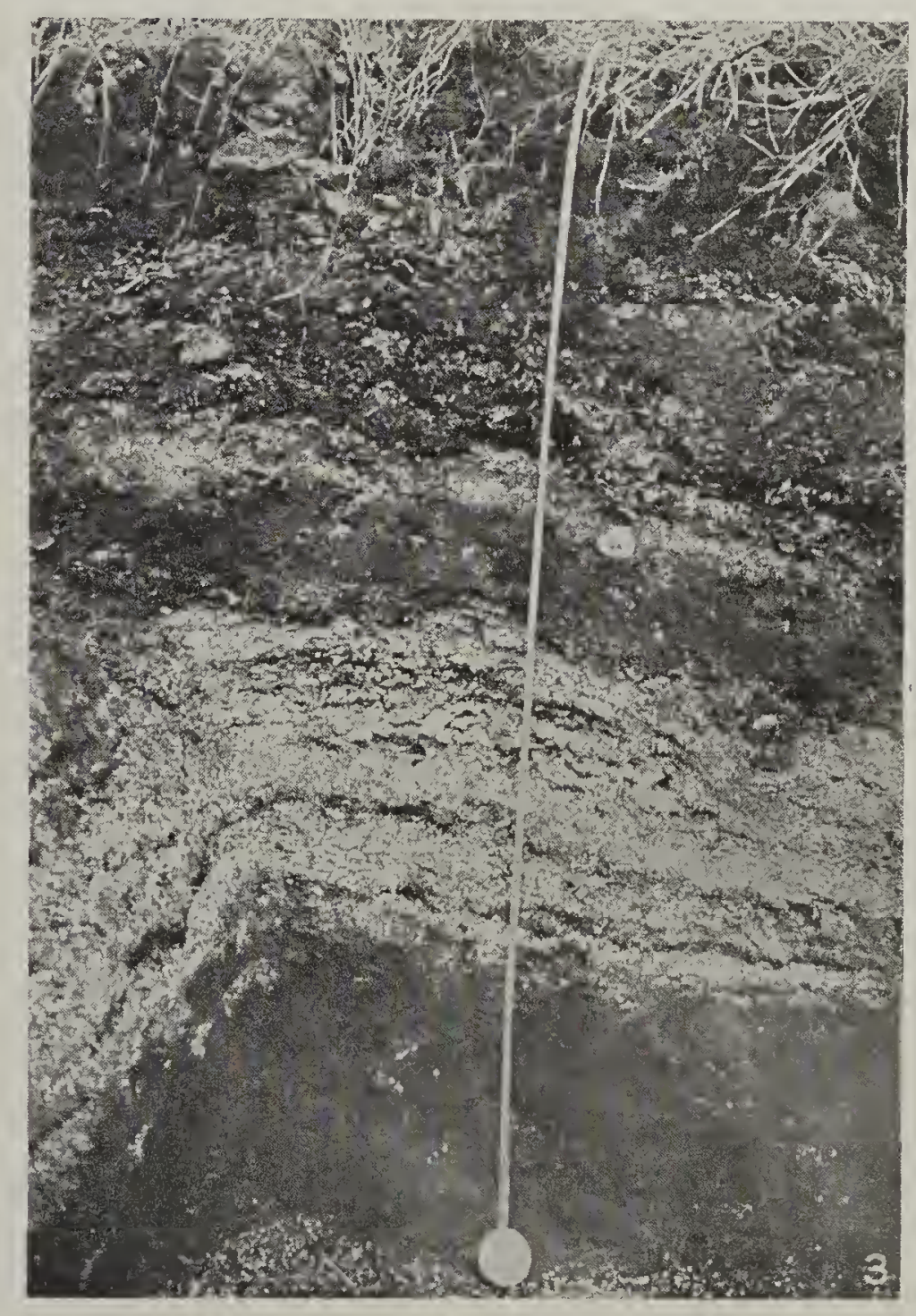

2. Section of Pit 4 of Nanikax site, Attu Island. Depth Section of Pit 2, Ukix Site, Umnak Island. Depth $3.3 \mathrm{~m}$. 

south. In short, this promontory represents a typical site for an old Aleut village. From its rocky extremity one could look far out to sea and in case of danger the skin boats could be readily carried from one bay to the other. Generally, however, villages were not situated on the high, rocky extremity of a promontory, but on the low isthmus, as was the case with Atxa'lax' on the island of Atka and Nani'kax' on Attu.

All the evidence pointed to the fact that Halaca was an old site, but judging from the small quantity of kitchen refuse found and the absence of human bones, with the exception of the lower jaw of a child, it may be inferred that Halaca was a summer village and probably a summer resort for the inhabitants of Atxalax, an hour's journey in a skin boat. This fact may also explain why the excavations in Atxalax and the examination of nearby caves yielded so large a quantity of skeletal remains. This supposition that Halaca was only a summer resort may also be corroborated by its situation on the high rocky extremity of the promontory, fully exposed to the stormy winds, which, however, were less violent during the summer.

In Halaca there were only 8 large pits. The largest was excavated; its length was Io meters and its width 6.8 meters. Its longitudinal axis was northeast. The depth of the pit before digging was I meter; depth of section 3.5 meters. Layers bearing remains were as follows:

(I) 1.2 meters.-Fat clayey mold containing plant roots. Scant remains of kitchen refuse. In the upper part of the layer were bones of sea-lions, sea-otters, seals, and albatross, pieces of burned wood, flat stone frying-pans, a stone knife, and stone arrow-heads (830, 83I, 832, and 834). In the lower part of the layer were shells of Mytilus edulis, echini, bones of cod-fish, some bones of sea-otters, seals, and bones of a large whale, much decayed.

(2) 0.4 meter.-Very little earth and much kitchen refuse: shells of echini, Mytilus edulis and Acmea patina, and fish and bird bones. Among these were found an awl made of an albatross wing-bone, a bone harpoon-foreshaft, and many bird bones for making needles.

(3) I meter.-Fat clayey earth. The kitchen refuse consisted chiefly of cod-bones, echini and Mytilus edulis shells, the partially burnt jaw of a whale, a bone needle-case, and a stone knife.

(4) o.I meter.-A layer of mold containing bones of seals, sea-lions, and cod-fish, and shells of Mytilus edulis, and echini.

(5) 0.2 meter.-A layer of pure kitchen refuse, without earth, consisting chiefly of echini shells, Mytilus edulis, and fish-bones.

(6) 0.4 meter.-A layer of mold containing a small quantity of bones of cod, albatross, and seals.

(7) 0.2 meter.-A layer of yellow clay without any trace of cultural remains.

No lamps or fish-hook sinkers were found in this pit and other objects also were scarce.

Besides the 8 large pits, there were Io small round ones. They were not situated in a certain order, but were found chiefly on the upper part of the hill-slope. Three of these small pits were excavated; they were 1.5 meters in diameter. Excavation of 2 of the pits yielded nothing, while in the third, at a depth of 2 feet, we found a small layer of echini. These small pits very likely served for storing food supplies.

\section{EXCAVATIONS ON THE ISLAND OF UMNAK.}

On Umnak four ancient village sites were excavated: Agla'gax', Nutxa'kax', $\mathrm{U}^{\prime} \mathrm{kix}^{\prime}$, and Uglu'dax' (see map).

Agla'gax'.-Agla'gax' was situated about 20 miles to the south of the present village of Nikolskoye. To reach this site from Nikolskoye, it was necessary to pass 
over a promontory, near the old village site of Nutxa'kax', where a summer hut of the Aleut Shepetin was located, and then from there to proceed south along the coast, to cross a lofty hill on a high promontory to the southwest, and thus approach the coast within sight of the Four Crater Islands. From here we walked for 2 hours along the coast on a sandy beach to a small bay, where, on a high promontory, the village of Agla'gax' was situated. We found traces of two villages, the lower one situated I 5 meters above sea-level, the upper 5 meters higher, at the top of the hill. Agla'gax village was situated on the narrowest part of Umnak Island and only 4 miles from its southern extremity, which is separated from Samalga Island by a strait. From the high hill on which the village site is situated can be seen the waters of Bering Sea and the Pacific Ocean. Below the lower village, the entire low and

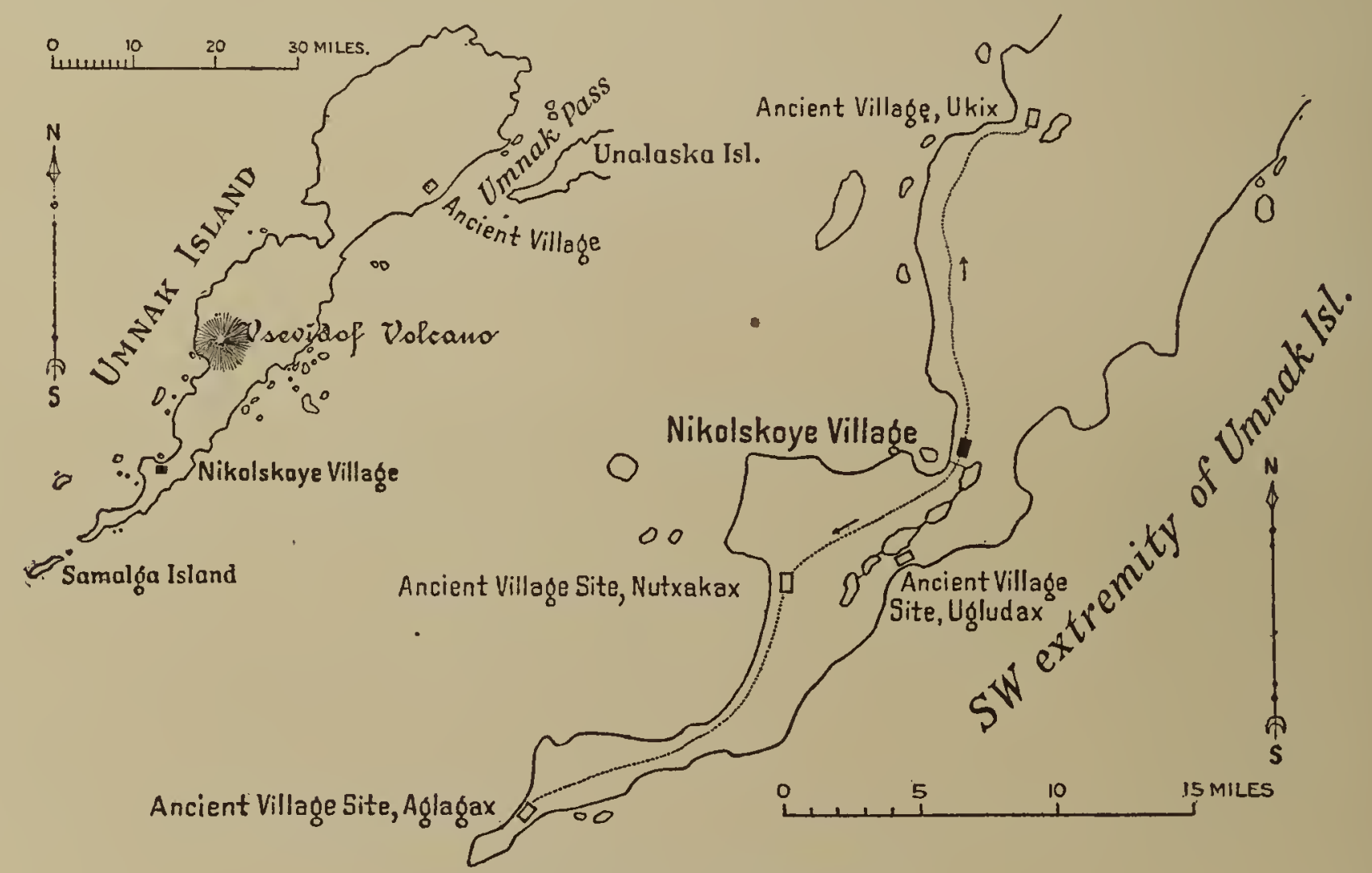

FIG. 3.-Map of Umnak Island.

narrow part of the promontory is marshy tundra whose waters form a lake, separated from the sea only by a small rampart, 20 to 25 fathoms wide. This lake was the only source of fresh water for the inhabitants of the village.

It is difficult to determine the relative ages of these two villages. Very likely, at one period, the villages were occupied simultaneously, but apparently the lower village was still inhabited after the coming of the Russians, since in the upper layers excavated were found objects of Russian origin. In both villages we excavated 4 large and 8 small pits called $u l a^{\prime} k a x^{i}, i$. e., burial huts. On the upper village site were 8 large and Io small pits. The large pit (No. 2) yielded the deepest section containing cultural remains; it was I 2 meters long and 9.5 meters wide, and before digging was I. 3 meters deep. Its longitudinal axis was from northeast to southwest, while the height of the shaft was 6.5 meters (plate 3, fig. 2). The cultural layers from the upper edge of the pit to the undisturbed soil were as follows: 

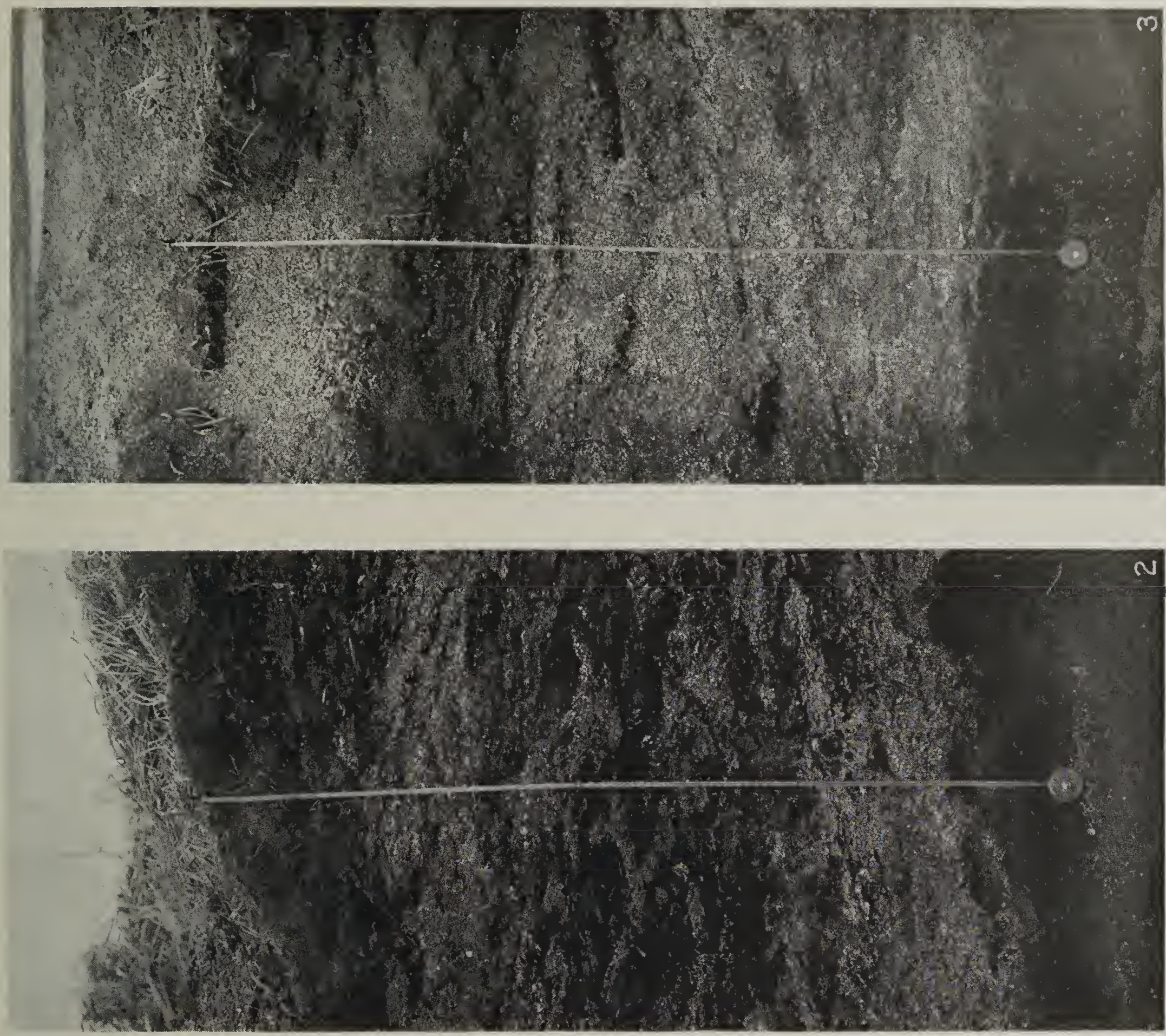

(I) 0.3 meter.-A layer of mold containing scant kitchen refuse or other remains.

(2) 0.85 meter.-A layer of pure kitchen refuse in which echini predominated. There was also a small quantity of mollusk shells (Acmcea patina and Mytilus edulis) and bird-bones.

(3) I.2 meters.-A layer of kitchen refuse intermingled with earth, in which a skeleton was found (see Chapter IV). Under the skeleton, in the lower part of the layer, were found the bones of a large whale which had served as the ceiling frame; from this we may conclude that the skeleton belonged to a later generation than the inhabitants of the dwelling of which parts of the bone ceiling were found

(4) 0.75 meter.-A layer of fat mold evidently due to the decay of organic substances. This contained many rotted whale-bones which crumbled to pieces when handled. In some places the putrified whalebones looked like yellow sand. Much better preserved were the bones of sea-otters found in the same layer.

(5) 0.06 meter.-A thin layer of sea-urchin shells.

(6) 0.25 meter.-A layer of mold containing some trace of kitchen refuse, with the bones of sea-otters and of the large whale (Balcena sieboldii, the Pacific right whale, Aleut. kula'max), predominated.

(7) 0.75 meter.-A layer of kitchen refuse with very little earth. Fish bones and mollusk shells predominated, but there were also echini shells, bird-bones, and other animal bones. The bottom of this layer was composed of the vertebræ of the Pacific right-whale and sea-lion bones.

(8) 0.9 meter.-An earth layer containing kitchen refuse. There were very few echini, the bones of seamammals predominating, chiefly those of sea-otters (Callorhinus ursinus; Aleut, laku'dax $x^{\circ}$ ).

(9) 0.6 meter.-A layer of the same character as Pit. 8. In the right corner was a heap of mollusk shells (Acmaa patina Esch. and Litorina sitchana Desh.) 0.4 meter thick. Bones of a small whale were found in the lower part of the layer.

(10) 0.6 meter.-A layer containing bones of the bowhead whale (Balcena mysticetus; Aleut, ugama'xcax ${ }^{\circ}$ ) and a few echini shells. In the right angle of this layer, kitchen refuse was more evident than at the front of the shaft. Here were found mollusk and echini shells and bones of fish and birds in equal quantity. Of bird-bones, those of uriles were most prominent. Some parts of this layer consisted of pure kitchen refuse, while others were kitchen refuse intermixed with earth.

(II) 0.25 meter.-A layer of pure sand with no trace of human refuse.

In this pit, aside from the skeleton which will be referred to later, there were found 80 objects. For the following, the depth at which they were found could be ascertained. Near the skeleton, in layer 3, a marble labret (fig. 84), a bone labret (fig. 87), an arrow-head of andesitic obsidian (plate I5, fig. 2I), two bone prongs of a bird-dart (plate 24, figs. 4I, 42), a stone carving of a whale (fig. 80), a whetstone ( $\mathrm{IOO}_{3}$ ), bone dart-prongs ( $\mathrm{IOO}_{2}$, IOO4), a bone tool for chipping stone (fig. 4I $a$ ). In layer 4 were found a stone lamp (I639), a bone lamp (plate 20, fig. 2), a bone needle (plate 28 , fig. $2 \mathrm{I}$ ), and a bone dart-prong barbed on one side only ( 1362 ). A bone scraper ( 1680 ) was found in layer 6 , while in layer 7 were found a bone wedge and a bone head of a fish-spear ( I028). A stone dart-head (plate I5, fig. 22) and a bone section of a throwing-lance (plate 26 , fig. 42) were found in layer 8 . In the ninth layer a bone root-digger was found (plate 26 , fig. I). In the last or tenth layer were found a bone head for a fishing-spear (plate 24, fig. $5 \mathrm{I}$ ), two bone awls (I031, I032), a bone scraper (IO70), a bone prong of a bird-dart (plate 24, fig. 40), the curved head and base of a bone fish-hook (plate 25, fig. 48 and No. 1073), and a whetstone for sharpening bone awls and needles (fig. $3^{8}$ ).

On the slope of the hill leading to the lower village we dug a pit (No. 3), Io by 7.9 meters. The depth of the shaft was 4.5 meters. A model of a part of this pitits northeastern side from the upper edge to a depth of 1.9 meters, where the skeleton was found-is now on exhibition in the Ethnographical Division of the Rumianzev Museum in Moscow. Materials for the model, dry kitchen-refuse together with the specimens excavated, were obtained on the spot. The model was constructed in natural size by the sculptor P. P. Kamensky; a photograph is shown in plate IO. As will be seen, the layers have been lettered. They contain the following remains: 
(I) Mold, containing plant-roots and other organic remains.

(2) A mixed layer of fish-bones and echini and mollusk shells.

(3) Fish-bones.

(4) Echini and mollusks.

(5) Fish-bones (in the right corner of the section).
(6) Echini.

(7) A thin layer of mold containing no refuse.

(8) Echini.

(9) Fish-bones and echini shells.

(Io) Echini and mollusk shells and fish-bones; the skeleton in a squatting position.

Beneath the skeleton were found many bones of cod and halibut and a few echini shells. Bones of birds and sea-mammals were scattered throughout all the layers down to the undisturbed soil. Among the implements found were many bone wedges, and at a depth of 4.3 meters, where the yellow sand began to appear, a small stone lamp was uncovered.

In the upper village, besides Pits 2 and 3, three ula'kax' were excavated in which were found skeletons to be described later. Six pits were excavated in the lower village-a small pit in which whale-bones were set up in cone-shape stood, a large pit, and 4 small ones.

Pit I, which contained the cone of whale-bones, was the first excavated. However, we abandoned this place and turned to the excavation of the upper village, and after completing our work there returned to Pit I. The whale-bone cone stood on the edge of the pit, with earth covering the lower ends of the bones to about I.55 meters of their length. The best-preserved piece was found to be 2.7 meters long. The conical framework of whale-bone was strongly reminiscent of a Yukaghir tentframe; however, these had not served as the framework for a ceiling, but had been stacked for future use in building. Since they had not been used for a long time, their lower ends were covered with earth and refuse (plate 3, fig. 3). The bones were the lower jaws of large whales and had been prepared, as usual for rafters and beams, by perforating the ends for tying together, polishing, and decorating the sides with grooved channels.

After the removal of the whale-jaws, we proceeded with the excavation of Pit I. Strata bearing cultural remains were uncovered to a depth of 3.6 meters, at which depth we found undisturbed soil, a pure clayey sand. As was the case with Pit 2 , in the various layers of Pit I we found bones of sea-mammals intermingled with other refuse, which in this pit consisted mainly of bird and fish bones and echini and mollusks.

Eight pits, the largest seen at any of the ancient village sites examined, were found at the lower Aglagax village. Of these, 3 large pits were of the same size. One excavated, Pit 4, was 29.9 by I0.7 meters, with its longitudinal axis from northeast to southwest. It is possible that these depressions were the remains of large dwellings constructed after the advent of the Russians, who very often segregated parties of Aleut hunters in one of these dwellings called caserns. Yet, on the other hand, excavation of this pit revealed culture-layers to a depth of 4.3 meters, which might be regarded as evidence of the great age of the site. But it should be added that the section did not reveal any considerable layers of kitchen-refuse or other remains. There were very few echini, and these were in thin strata; neither were there many bones of birds or sea mammals and these were mingled in fat earth. 

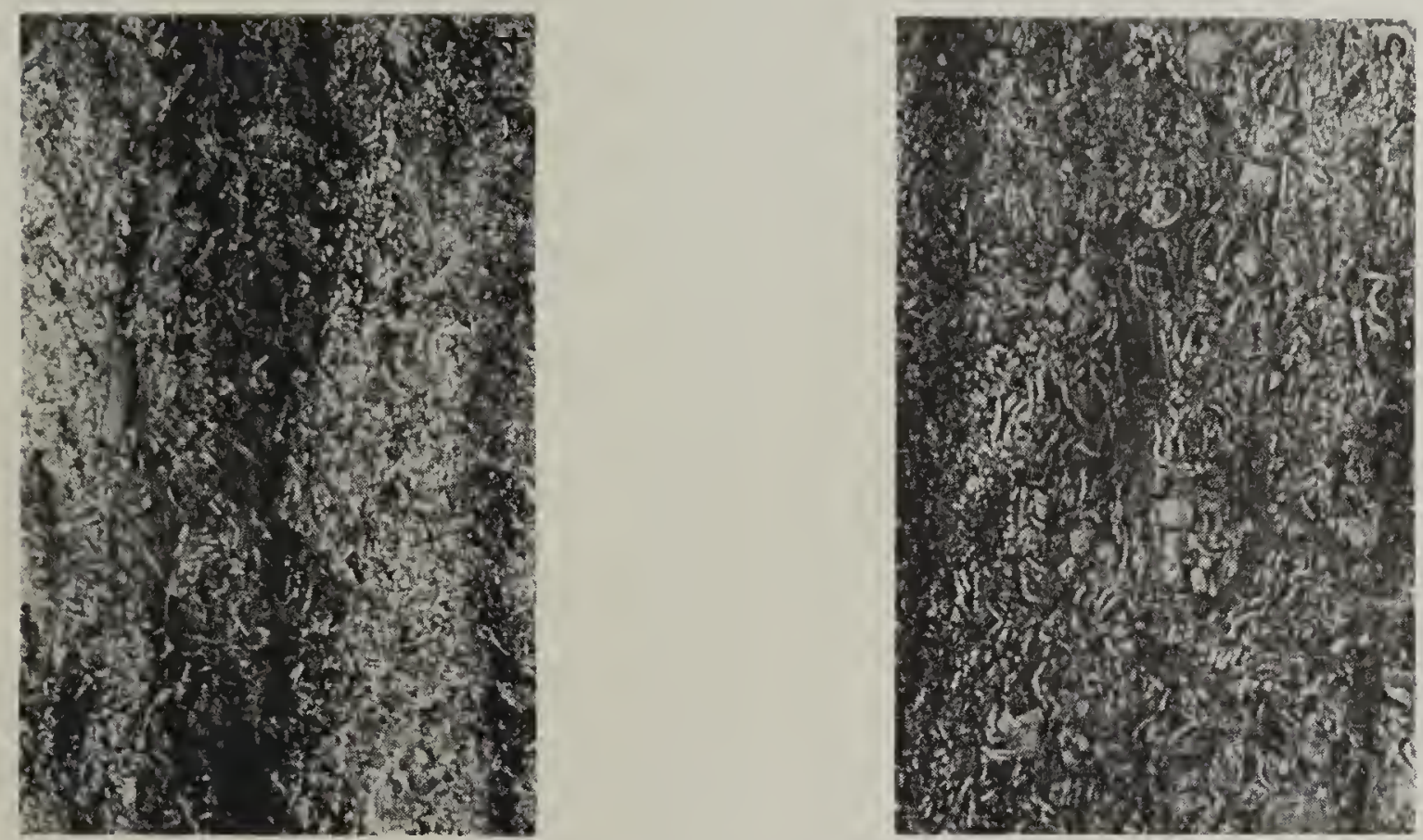

苞

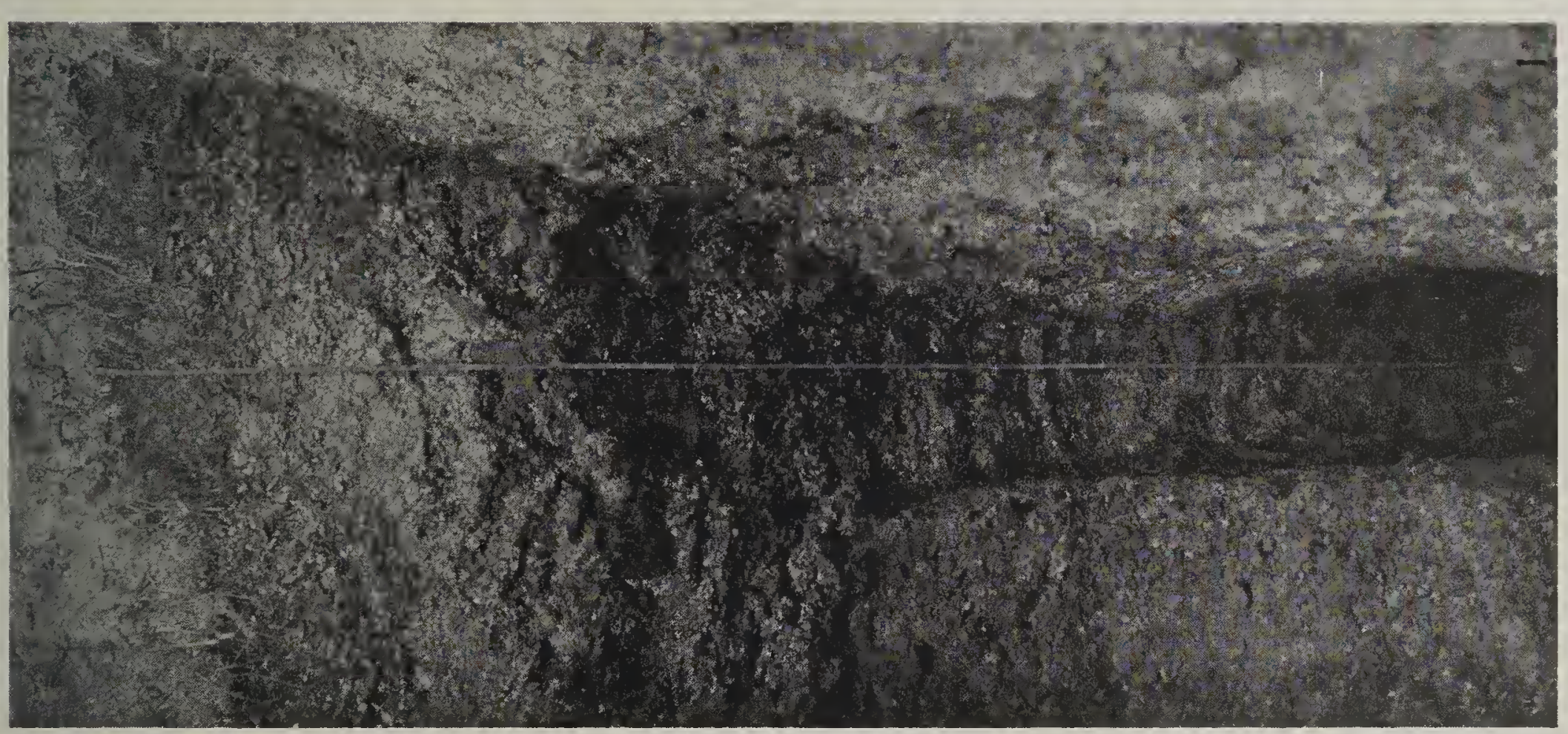

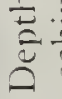

莺

总

吾

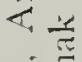

旅

苞

मे

藏管

0
$\infty$
0
$=$

ज故

苛

ฮ.
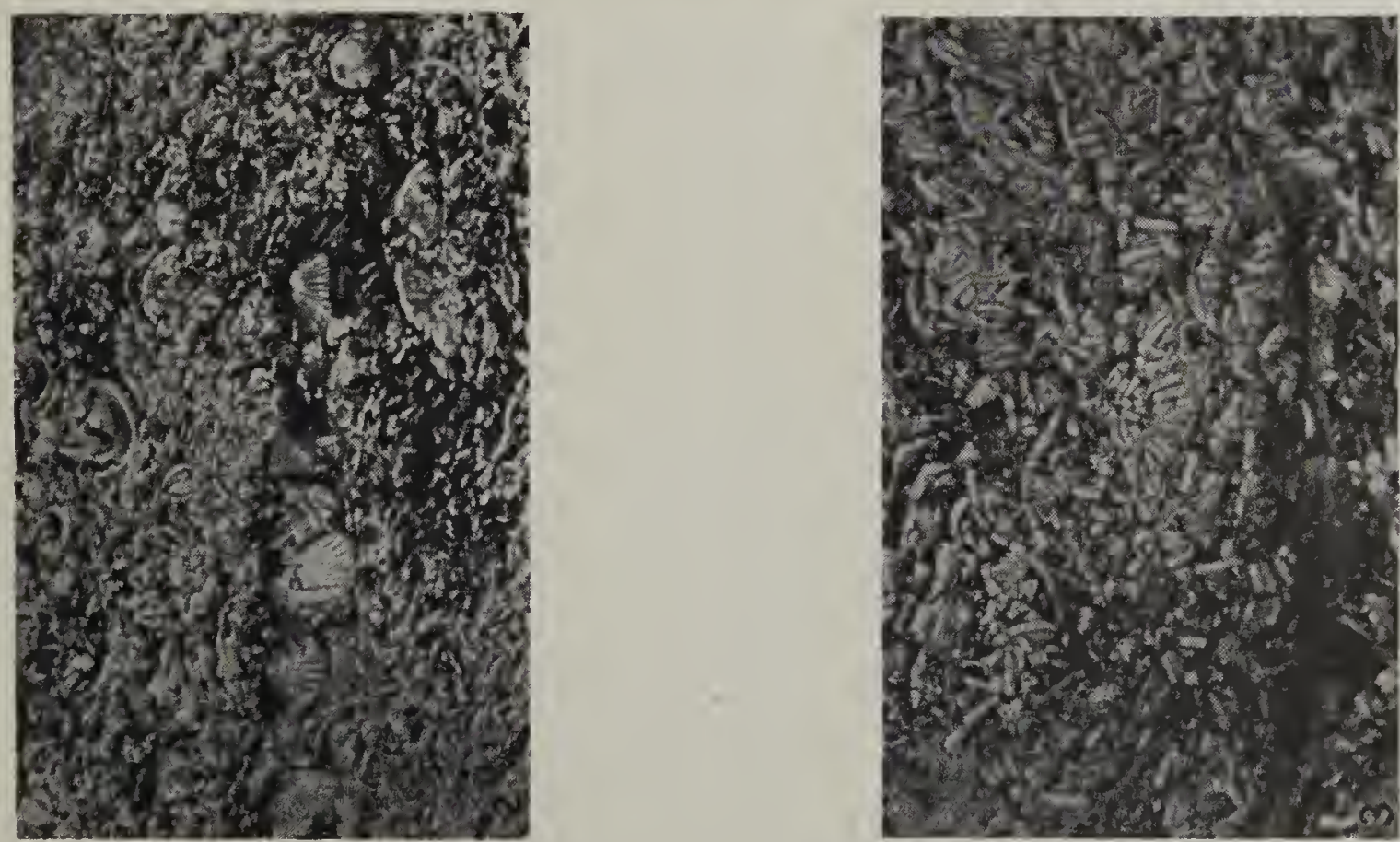

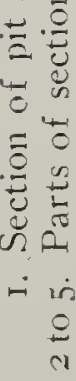



More numerous were the bones of cod and halibut. Only 20 objects of stone or bone were found, and in the uppermost layer a fragment of a porcelain cup, evidently Russian, was uncovered.

The small pits, almost circular in form, which were supposed to be ula'kax', $i$. e., burial-lodges, contained no skeletal remains. Kitchen refuse, too, was very meager. In one were found glass beads and pieces of brass, while in another a bone post driven into the earth had been notched with an iron ax. Obviously, these small pits were the remains of dwellings of a later period.

Nutxa'kax Village.-On our return to Nikolskoye village, where we had our headquarters on Umnak, we stopped at the ancient site at Nutxa'kax' (see map of Umnak Island). On the sea-coast there was then an earth lodge in which the Aleut, Mark Shepetin, lived. Not far from this lodge was a small river which provided fresh water for the village. The ancient village was situated above Shepetin's lodge, on a hill 20 meters above sea-level. There were no large depressions, and we were told that the pits were of ula'kax', or burial lodges. In old times, one or two families had evidently lived here, and the pits were often changed, or else the village was inhabited only during part of the year. There were 15 pits in all, for the most part burial lodges, to judge from their size. Refuse in these depressions reached no great depth. Two larger pits, evidently the remains of dwellings, and 4 of smaller size, supposedly the remains of burial lodges, were excavated.

Strata bearing remains reached only to a depth of $\mathrm{I} .5$ meters in Pit I. The upper layer of mold contained only a small amount of mixed kitchen refuse. The second layer consisted of fish-bones; the third, of mixed refuse; the fourth of fishbones; the fifth of mixed refuse. The prevalence of fish-bones may serve to prove that the settlement was for summer only, since fish formed the most important item in the summer diet.

Pit 2 was excavated to a depth of 2 meters, but remains were found only to a depth of I.8 meters. The layers followed almost the same order as those in Pit I. Along the southern wall of the pit, at a depth of I.2 meters, were found 6 skeletons. (See Chapter IV.)

Four of the so-called ula'kax' were excavated. In one, nothing was found; evidently, it had not been a burial place and may possibly have been a food-storage pit. In the remaining 3 ula'kax', fragments of skeletons were found.

Ukix Village.-Like the present village of Nikolskoye, the site of Ukix was situated on the southwestern part of Umnak, a 4 hours' walk from Nikolskoye to the northeast. Two trails lead from Nikolskoye to Ukix; the shorter one passes over high hills, the longer is more winding and is nearer the coast. The village was situated I 5 meters above sea-level, on a hill overlooking a small bay, and departs from the usual ancient Aleut custom of locating a village between two bays. Fresh water was obtainable from a lake lying at the foot of the hill on which the village stood. At the time of our examination, the Aleut Ivan Cherkashin had a winter earth-lodge at this place, where he spent the months of November to January hunting foxes. When the weather is favorable he fishes in the sea from his boat. 
At this site we found traces of 14 dwellings. In the course of time some of the pits had been so filled and leveled that the depressions in the middle and elevations along the edges were scarcely perceptible. As noted at other ancient sites, neither the size nor the form of the depressions were similar. Some of the pits were oblong, while others were almost circular. As has been stated before, the present Aleut assert that the ancient Aleut had no separate kashims, ${ }^{\circ}$ as do the Eskimo. Among the larger pits were three oblong depressions of almost the same size. The largest of these three (Pit 3 ) was excavated. In all, 3 large and 5 small pits, which could be regarded as ula'kax', were excavated at Ukix.

The excavations here disclosed only shallow culture-layers; at a depth of 7 or 8 feet, undisturbed soil, bearing no evidences of human activities, was reached. Nevertheless, it can not be said that Ukix belonged to a later period than did the sites where deeper relic-bearing layers were found. The slight depression of the pits before excavation, bears witness of their old age. All the layers contained bones of birds and sea-mammals scattered amongst echini and mollusks and fish-bones. Some of the larger pits had supplementary circular depressions at the side which may have served as kitchens, caches, sleeping-rooms, or hiding-places for women and children in case of attack.

On the western part of the site, Pit I was excavated to a depth of 2.3 meters. The middle of the section of the southeastern wall is shown in plate 5, fig. 2. On this side culture remains reached a depth of only 2 meters. The contents of the layers were as follows:

(I) 0.5 meter.-Mold intermingled with plant-roots and a small quantity of kitchen refuse.

(2) o.I meter.-Kitchen refuse and a thin layer of mold. The refuse consisted chiefly of cod and halibut bones and shells of mollusks (Acmaea patina and Mytilus edulis) and echini.

(3) 0.36 meter.-Mixed kitchen refuse with fish-bones

(4) 0.2 meter.-Earth containing a small quantity of kitchen refuse.

(5) 0.3 I meter.-Echini, mollusca, and fish-bones, with a slight admixture of earth.

(6) 0.25 meter.-Yellow sand, containing no specimens.

(7) 0.08 meter.-The beginning of a layer of gravel.

Separated by a narrow wall from Pit $I$ was Pit 2. A section of the northwestern wall is shown in plate 3 , figure $I$ and plate 4 , figure 3 . The skeletal finds in these pits will be discussed later (Chapter IV). Specimen-bearing strata in Pit 2 were as follows:

(I) 0.85 meter.-Mold containing a small quantity of

(2) 0.2 meter.-Fish-bones.

(3) 0.06 meter.-Echini.

(4) 0.25 meter.-Mold, intermingled with bones of birds and sea-mammals.

(5) 0.65 meter.-Echini, mollusks, fish, and bird bones.

(6) 0.9 meter. A narrow strip of mold.

(7) 0.3 meter.-Pure yellow sand.

(8) 0.1 meter.-Small waterworn pebbles, which evidently had been covered by the sea at some earlier period.

From the above it appears that this refuse heap had a depth of only 2.I meters.

Of the 5 small depressions, 2 (Nos. I and 4), revealed no traces of refuse. It is difficult to explain the use of these pits; they may possibly have served for storing food. The small pits, Nos. 2 and 5, appear to have been burial lodges. Pit 3 contained no skeletal remains, but in one of its walls were found bones of whales, echini, mollusks, and fish-bones, as in the large pits.

${ }^{6}$ Special large houses for gatherings, festivals, and dancing. 

A large oblong pit (No. 3) was I2.9 meters long and 6.7 meters wide, with its longitudinal axis from west to east. It was excavated to a depth of 7 feet, until yellow sand was reached. Kitchen refuse turned up sporadically. Below the yellow sand layer, near the western wall, were several pits I foot in diameter and about 3 feet deep. These depressions were covered with flat stones and had evidently served as storage places for edible roots, since in one were found the half-decayed roots of Polygonum viviparum and Fritillaria kamtschatica (Aleut, qugcu'dax' and alu'ga $\left.x^{\circ}\right)$. In the middle of the longitudinal axis we found a quantity of charcoal, possibly the remains of a fireplace under the entrance-hole in the roof, although the ancient Aleut did not heat their living rooms and food was cooked in separate earth lodges. It is worthy of note that among the objects found in Pit 3 were 14 stone lamps which may have served to light the separate family compartments or for the general illumination of the dwelling during social festivities or contests.

Uglu'dax'.-Uglu'dax is situated to the south-southwest of the village of Nikolskoye. The territory between Nikolskoye and Uglu'dax' is occupied by three lakes, separated from one another by narrow necks of land, about 125 paces each, and connected by small streams. Beyond these lakes, to the south, is a whole series of lakes, rising one above the other in terraces, each successively draining into the other, until the Nikolskoye village lake is reached. This lake empties directly into the sea by a small rivulet. Uglu'dax' is on the isthmus between the third and fourth lakes, counting from the sea, and turning to the northwest (see map). The inhabitants of this village procured fresh water from the lake, which was I6 meters above sea-level. The Aleut informed us that Uglu'dax" was an "odinochka," "i. e., a dwelling for one or two families. Possibly a few families lived here for a part of the year. At the time of our visit the site was not occupied; according to the Aleut, this was not the case when the Russians arrived. Still there are traces of kitchen-gardens made under the tutelage of the Russians. The present-day Aleut plant potatoes and turnips far away from the present dwellings on ancient village sites.

However, in the excavation of this village site no traces of iron implements or other objects of Russian origin were found; all our finds belonged to the Stone Age. Though it is true that no deep refuse sections were found at Uglu'dax', it does not necessarily follow that the site was later than others with sections of greater depth. It is quite possible the village was abandoned in olden times. Some sections contained deeper layers of echini and mollusk shells than ever before noted by the writer. This may point to the fact that the village was inhabited only during the seasons when the chief food consisted of mollusks and sea-urchins.

Four pits were excavated in Uglu'dax'. Pit I was I6.8 meters by 6.7 meters, with its longitudinal axis from northwest to southeast. In the section at the northwestern wall were found 2 skeletons. The trench was dug to a depth of 3.3 meters (plate 5, fig. 3).

${ }^{7}$ A Russian word meaning single, sole, person living in solitude. 
The strata from the top down contained the following:

(I) I.I meters.-Mold with a small quantity of mixed refuse.

(2) 0.3 meter.-Fish-bones and mollusk and echini shells without any admixture of earth.

(3) 0.15 meter.-Fish-bones only.

(4) 0.1 meter.-Fish-bones and mollusk and echini shells.

(5) 0.07 meter.-Fish-bones.

(6) I.4 meters.-A compact layer of kitchen refuse, chiefly shells of mollusks and echini. The mollusks were intermingled with the echini, while in some spots mollusks and fish-bones formed distinct narrow layers. Scattered throughout the whole were bones of sea mammals and birds. In two spots narrow layers of mold were found containing decayed organic matter, but sea-urchins predominated in the entire layer. In plate 6 , figures 2 to 5 , are shown different parts of layer 6 . Figure 2 shows a strip of shells of the mollusk Acmea patina Esch., in the middle of a layer of echini and fish-bones. Figure 3 shows a pure stratum of echini, while in figure 4 may be seen a dark strip of cod and halibut bones in the midst of a heap of echini. There were also some bones of seals and sea-otters. Figure 5 shows a layer of mixed refuse, in which echini and mollusks predominated.

(7) 0.18 meter.-An undisturbed layer of brownish clay.

Stone and bone implements were found at various depths, as follows:

0.7 meter.-Bone nose-pendant (text-fig. 99); stone arrow-point (1547); vertebra of a shark (text-fig. I04b); 2 bone fish-hooks (plate 25, figs. 46 and 47); bone harpoon-head (plate 24, fig. 29).

0.9 meter.-Bone head of a throwing dart (plate 24, fig. 26); bone buckle (text-fig. I02); head of bone lance for catching sculpin (1526).

I.53 meters.-Two stone knives (plate 15, figs. 32 and 38 ); stone adze (plate I5, fig. 25).

2.50 meters. -Large stone knife (plate I5, fig. 6) ; bone wedge (I556); 2 spoons, one of reindeer antler, the other of the chest-bone of an urile (plate 26 , figs. 10 and 20 ); 2 stone sinkers (plate 17 , figs. 8 and 20).

2.75 meters.-Bones of a sea-lion and charcoal.

At a depth of 3.I meters, 2 labrets (figs. 85 and $92 c$ ) were found in the lower part of layer 6 in a heap of sea-urchin shells.

Pit 2, on the slope of the hill, also yielded culture remains, but to a lesser depth. At $\mathrm{I} .52$ meters the undisturbed soil, a brown clay, without any trace of kitchen refuse, appeared. The refuse consisted of intermingled shells of echini, fish-bones, bird-bones, and a small quantity of bones of sea mammals. In the middle of the section was a narrow layer consisting of shells of echini and mollusks only.

Pit 3 was at the side of No. I and was of the same size. Only the northwestern wall was excavated, and the following layers were uncovered:

(I) 0.54 meter.-A layer of mold, including a small quantity of kitchen refuse.

(2) 0.35 meter. $-A$ layer of fish-bones.

(3) 0.58 meter.-Kitchen refuse, without earth, and chiefly echini, mollusks, and fish-bones.

Among the shells of echini in layers 3 and 5 were found the decayed bones of sea-mammals which disintegrated when touched.

Pit 4 was dug to a depth of 2.7 meters; strata containing remains reached a depth of 2.55 meters. The strata were as follows:

(I) 0.5 meter.-Mold with a small quantity of echini, mollusks, and fish-bones.

(2) 0.13 meter.-A layer of compact refuse consisting of fish-bones and shells of echini. Also a small quantity of mollusk shells.

(3) 0.38 meter.-Mold and a large quantity of echini, mollusks, and fish-bones.

(4) 0.6 meter.-Refuse as in preceding layer, but less earth and more shells of Litorina sitchana and lamellæ of the chiton Katherina tunicata.

In all the above layers were found a small quantity of bones of birds, seals, and whales. A decayed skeleton, whose skull fell to pieces, was found at a depth of I.3 meters. Before digging, the edges of the pit were barely visible, from which we may conclude the site to be an old one.
(4) 0.16 meter.-A layer of mold.

(5) 0.05 meter.-A layer of echini.

(6) 0.42 meter.-Primeval soil, clayey earth.

(5) 0.1 meter.-A compact layer of kitchen refuse, consisting of echini and shells of mollusks, Acmeea patina, Mytilus edulis and Venus petiti, and of a small quantity of fish-bones.

(6) 0.87 meter.-Mollusks, echini, and fish-bones and narrow layers of mold.

(7) 0.12 meter.-A layer of brownish clay without any refuse. 

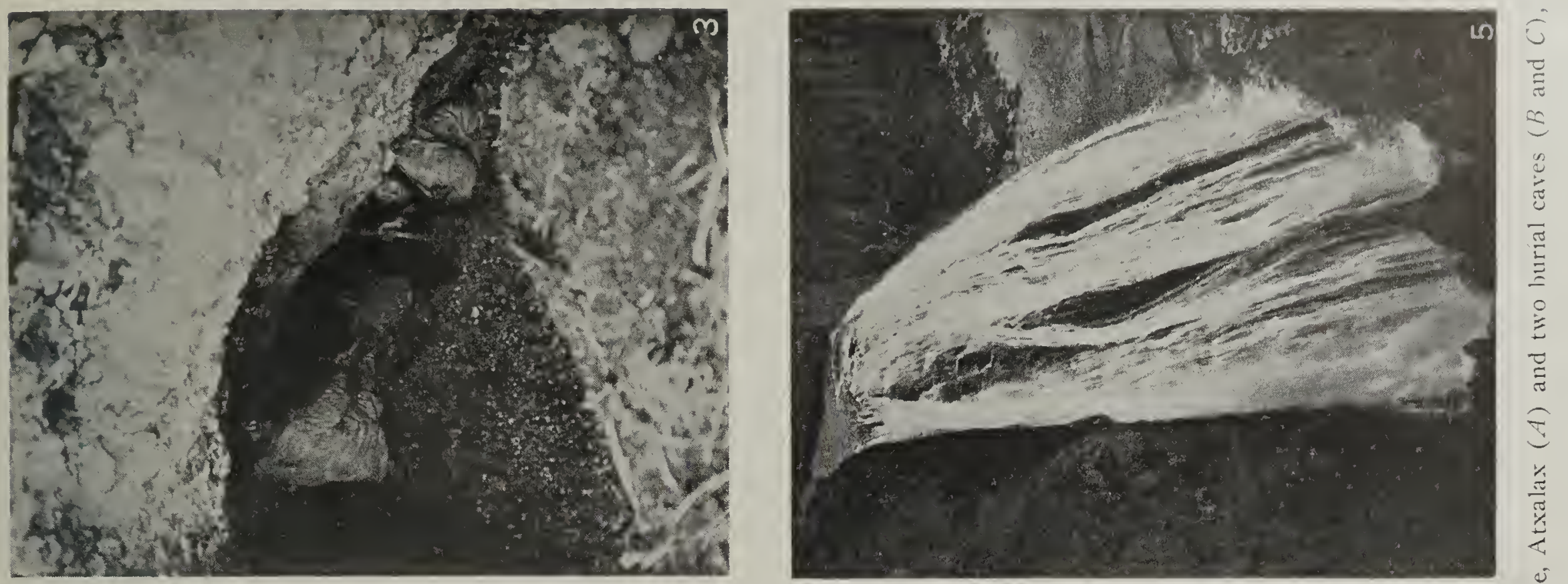

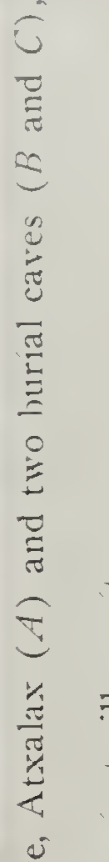
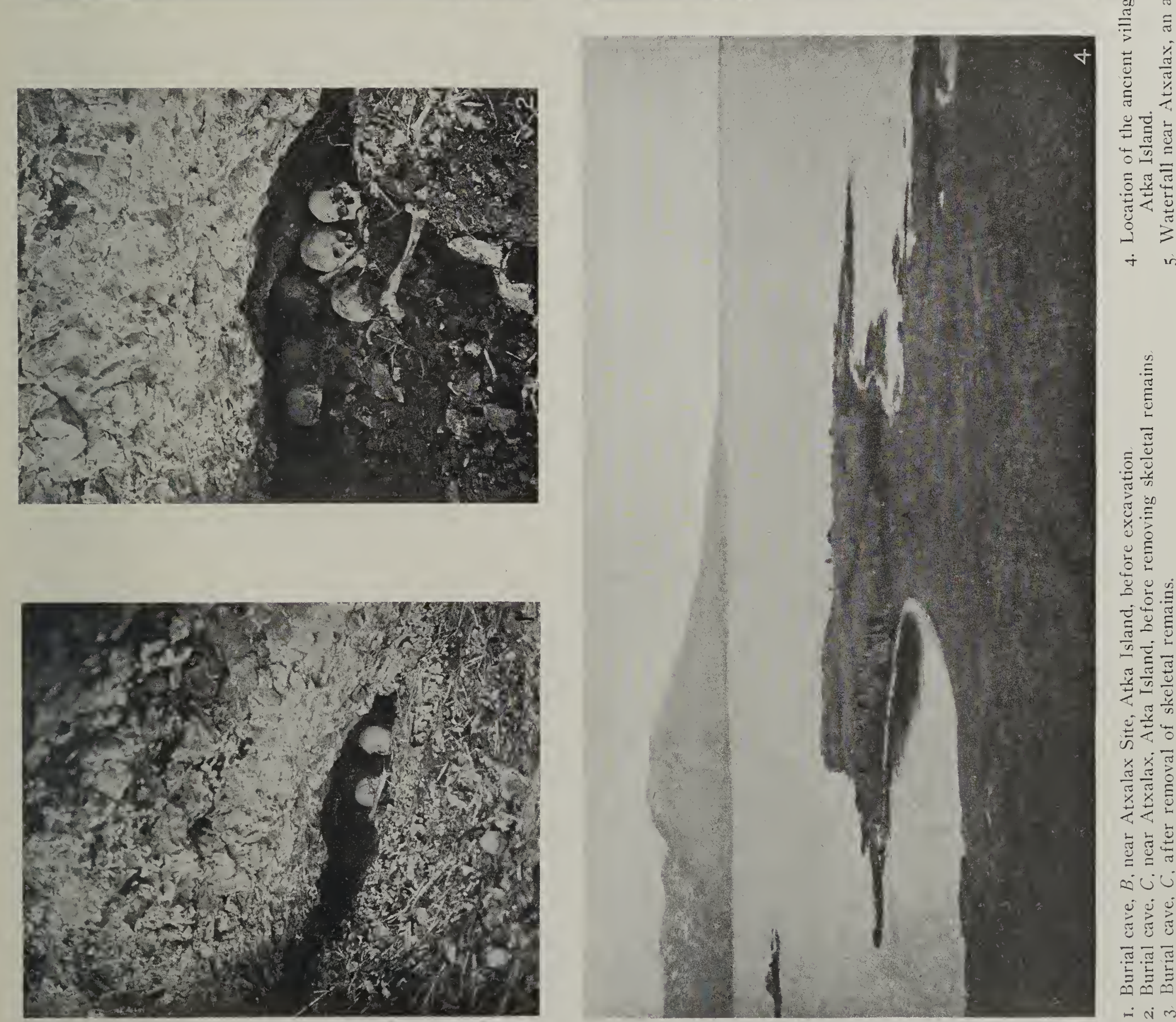



\section{EXCAVATIONS ON AMAKNAX ISLAND.}

Amaknax Island is situated in Unalaska Bay, with its southern extremity approaching Captain Cove. It consists of 4 rocky mountains, separated by 3 low and narrow valleys; the latter evidently rose from the sea at a later date, connecting the 4 volcanic rocks and forming an island. The northernmost is a conical mountain r,640 feet high, sloping abruptly to the sea. The low land between the rocky heights of the island afforded very suitable places for settlements. At the time of our visit, Amaknax Island was uninhabited, except for the storehouses and houses for the employes of the North American Commercial Company at Dutch Harbor. Early

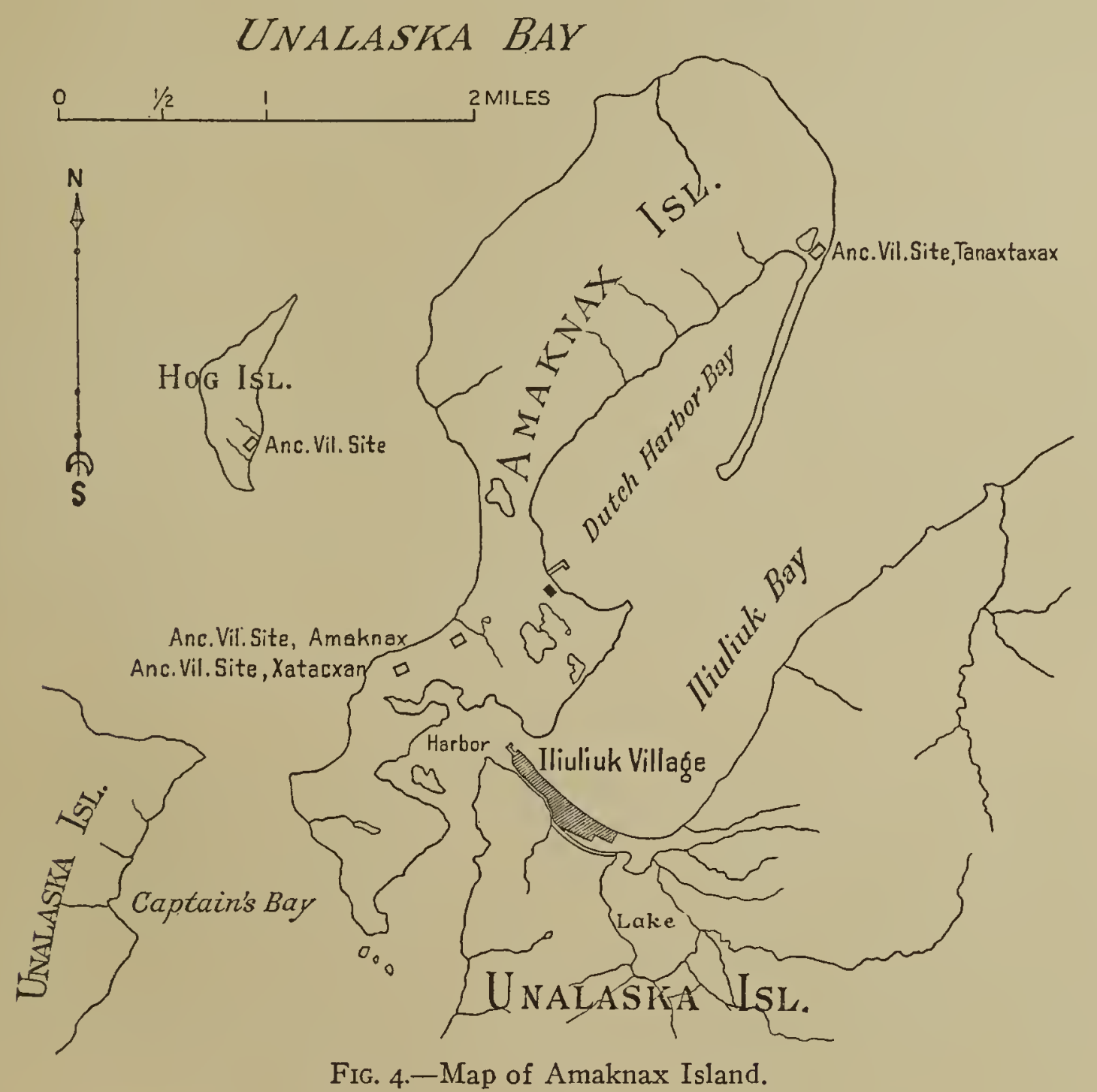

in the nineteenth century, in the time of Weniaminoff, the Aleut settlements had already been abandoned. Three ancient village sites were excavated; two of them, Xatacxan and Amaknax, were located on the middle isthmus of the island, and the third, Tanaxtaxax, was in the northeastern part of the island, at the bottom of a long, narrow, sandy neck of land, separating Dutch Harbor from Unalaska or Iliuliuk Bay (see text-fig. 4).

According to Weniaminoff, there were three Aleut villages on Amaknax Island before the arrival of the Russians, ${ }^{8}$ but he neither names nor locates them, so we do not know whether the villages excavated are those mentioned by Weniaminoff

8 Rev. J. Weniaminoff, Notes on the Islands of the Unalaska District, St. Petersburg, I840, part I, p. I88 (in Russian). 
or whether more than 3 villages were ever in existence on Amaknax. The Unalaska Aleut informed us that the sites excavated by us were very ancient.

When excavating on Amaknax we had our headquarters on Unalaska and traveled back and forth in a motor-boat.

Amaknax Village Site.-Amaknax was evidently a small village. It was approximately a mile from another old village, Xatacxan. The site, bearing the name of the island, Amaknax, was situated on a hill about I2 feet above sea-level. One large and three small pits were excavated. The large depression was I9.5 meters long, 7 meters wide, and about I meter deep before excavation. Its longitudinal axis lay from northeast to southwest. The specimen-bearing layer was not thick. The pit was dug out to a depth of 3 meters, though the refuse reached a depth of only 2.4 meters, beneath which was a stratum of compact gray clay. Sectioning of this pit revealed some peculiarities, but our finding in no way correspond to Doctor Dall's description of succeeding layers, as noted by him in his diggings on the island. (See Chapter VI.) The clayey earth was so hard that before digging with spades it had to be broken up with picks. Kitchen refuse in irregular layers appeared. There were few echini and many mollusks, chiefly Mytilus edulis. Of fish, there were the bones of halibut and cod. We also found bones of sea-otters and of large and small whales. Generally speaking, the kitchen refuse was mixed up, but in the deepest part of the trench we found bones of sea mammals and whales only and in the upper layers shells of echini and mollusks. At I.4 meters we found a decayed skeleton, lying, as will be seen later, in the usual squatting position. The bones of a large whale which had at one time served as the framework of the roof of an underground dwelling were found at a depth of I.9 meters. From this we may conclude that the dwelling under the whale-bones belonged to a generation older than that to which the skeleton belonged. The three small pits excavated on the Amaknax site yielded no remains.

Xatacxan Site.-This site was located on the same isthmus as the Amaknax village and quite close to a burial-cave examined by Doctor Dall (plate 9, figs. I and 3 ). At this site we excavated only one pit to a depth of 5. I meters (plate 6, fig. I), in which the culture strata reached a depth of 5.05 meters. The contents of the successive layers were as follows:

(I) 0.4 meter.-Mold.

(2) I.3 meters.-Mixed kitchen refuse, with scarcely any admixture of earth, consisting of fish-bones and mollusks (mainly Mytilus edulis); very few echini.

(3) 0.35 meter.-Fat dark clayey earth containing bones of sea mammals (whales, sea-lions, sea-otters, and seals) and birds (mainly uriles); very few mollusks.

(4) 0.65 meter.-Shells of mollusks (Mytilus edulis, Acmea patina, and Venus petiti, bones of fishes, birds, and of a small quantity of sea-mammals.

(5) 0.15 meter.-A layer of fish-bones and a small quantity of echini.

(6) I.I meters.-A layer of mixed kitchen refuse, very few echini, with shells of mollusks and bird-bones predominating.

(7) 0.3 meter.-A layer of cod-bones.

(8) 0.5 meter.-A layer of mollusks, bones of birds, sea-lions, and seals.

(9) 0.3 meter.-Bones of whales and birds and shells of mollusks.

(I0) 0.05 meter.-A layer of yellow sand containing no refuse.

Particular attention should be directed to the whale-bones, which provided material for the roofs of underground dwellings, and which were found at different 

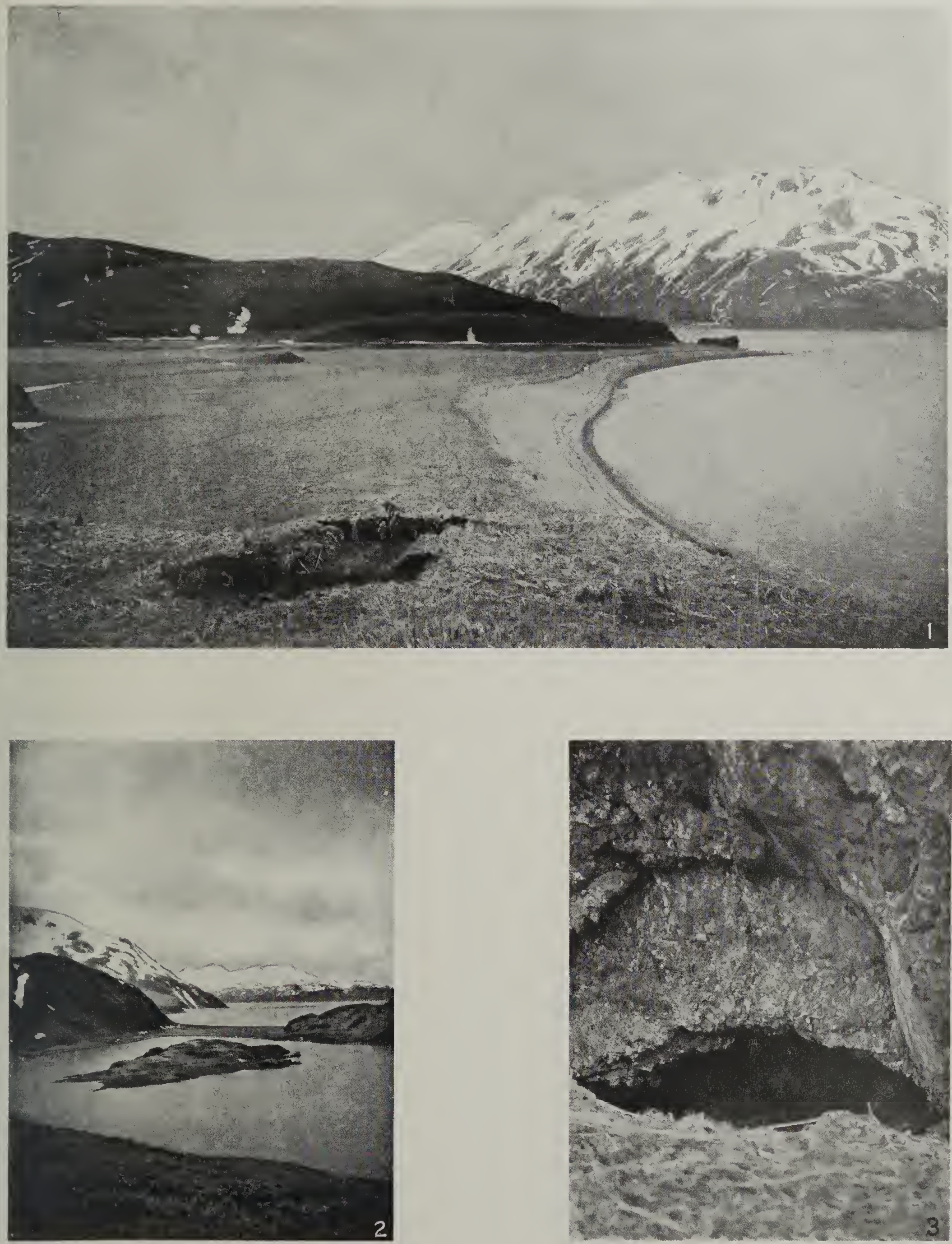

I. Excavations at the ancient village site, Amaknax, situated on a neck of land on Amaknas Island. 2. Birdls-eye view of neck of land on Amaknax Island

3. Burial cave on Amaknax Island investigated by Doctor Dall. 

depths in this pit. Thus, in layer 4 , at a depth of 2.5 meters, we found bones of the Pacific right whale with perforated ends and longitudinal grooves; other bones of this species were found in layer 6 at a depth of 3.4 meters. Finally, at the very bottom of layer 9, were found the vertebræ of a large whale. These bones were evidently the remains of underground dwellings of different periods.

The following specimens were found at the depths indicated: Two stone knives, 2.2 meters (plate I6, figs. 4 and 7); a stone sinker, 2.6 meters (plate I7, fig. 4); a bone wedge, 3 meters (plate 26, fig. 2).

This pit, like those on the Amaknax site, were very difficult to excavate. The fat clayey earth held the specimens firmly, so that we were compelled to break the earth with picks at the risk of injuring the bone and stone objects found.

Tanaxtaxax Site.-Tanaxtaxax was located at the head of a long neck of land on a hill approximately 20 feet above sea-level. There were traces of about 12 pits, none of them very large. The depressions had been almost entirely filled with windcarried earth and made it difficult to define their borders and in addition bears testimony to the great age of the pits. The Aleut also believed these pits to be very old, as did Doctor Dall, who had excavated at this site. Some of the depressions were overgrown by the gardens of the people of Unalaska. To the west of this site was a salt-water lake which had evidently been part of the sea before the isthmus rose and cut it off. The only available fresh water is from a small brook with its source in the northernmost mountain of the island.

One pit in the northern part of this site was excavated. A trench was dug 4.9 meters deep and strata bearing remains reached a depth of 4.8 meters. The layers, from the surface down, were as follows:

(I) 0.95 meter.-Mold containing a small quantity of halibut and cod bones and shells of Mytilus edulis. There were very few echini-shells and of sea mammals only the bones of a fur-seal were found.

(2) 0.6 meter.-A small quantity of earth and much kitchen refuse, chiefly cod-bones. This was accompanied by shells of mollusks (Mytilus edulis and $V$ enus petiti), and bones of fur-seals, sea-lions, seals, and whales, and a small quantity of bones of uriles and murres (Uria arra).

(3) 0.6 meter.-A layer of mold containing a small quantity of shells of Venus petiti and echini. Some sea-lion bones were also found.

(4) I.25 meters.-Little earth and much kitchen refuse, among which were bones of whales, sea-lions, and fish, and shells of mollusks Mytilus edulis and Venus petiti, and a small quantity of echini.

(5) 0.3 meter.-A layer containing only bones of sea-lions and cod and shells of Mytilus edulis and Venus petitu, with no admixture of earth.

(6) 0.5 meter.-A layer of bones of cod and shells of Venus petiti.

(7) 0.1 meter.-A layer of echini.

(8) 0.5 meter.-A small quantity of earth, bones of sea-lions and cod, and shells of $M$. edulis and Venus petiti.

(9) 0.I meter.-A layer of shingle similar to the character of the sea-bottom.

In all layers, the soil was clayey and dark, the result of organic decomposition. The earth, as elsewhere on Amaknax Island, was so hard that it had to be broken up with picks, and, in addition the excavations were hampered by the presence of large stones, evidently brought to line the walls, some bearing traces of red paint. Specimens were found at the following depths:

A prong for a bird-dart (plate 24 , fig. 5), 0.6 meter.

Two stone adzes of greenish quartzite (plate 15 , fig. 26, and text-fig. 25), I meter.

A woman's knife, 2 meters.

A bone handle (2122) and stone knife (text-fig. 22), 2.4 meters.

A stone lamp (plate I8, fig. 2), 2.6 meters.

A stone sinker (plate 17 , fig. I5), 3 meters. 


\section{EXCAVATIONS ON UKNADAX ISLAND.}

The small island, Uknadax, is now called Hog Island, because the Russian American Company kept hogs there. It lies in Unalaska Bay between Amaknax Island and Natykin Bay (see map of Unalaska Bay, text-fig. 4). The ancient village was located on the southeastern side of the island. During our visit, the Unalaska Aleut Nikifor Dyakonov lived on the island. Some years before an American trader had established a blue-fox farm on the island, bringing the foxes from St. Paul Island. However, the undertaking failed, since there was insufficient food for the foxes. It is possible also that the foxes were secretly hunted by the Unalaskans. So the American abandoned the island, presenting the house to Dyakonov. Traces of old dwellings were found on the shore, as well as higher up on the hill. On the shore were indications of large oblong dwellings, but on the hill the pits were round and small. According to Dyakonov, the Aleut had lived on the hill when under Russian domination. We excavated the two largest pits on the shore; one was 28.3 by 5.5 meters, the other 20.4 by 5.2 meters. The longitudinal axis of both large pits lay from east to west. Before digging, the depth of both pits was about a meter. At the sides of the large pits was a row of smaller depressions which may have served as sleeping-places for children, with passages to the main pit, or storageplaces for food. In the large depression the refuse was only 2 feet deep, but the smaller pits seemed to have served especially for the reception of refuse.

The digging of the two large oblong pits revealed similar situations; on either side were 8 small pits, 3 to 8 feet in diameter. In the smaller pits on the southern side was kitchen refuse and whale-bones, which presumably had served as material for the ceiling. Three of the small pits, evidently for burial, contained quite decayed skeletons. The remaining 5 pits contained no skeletal remains. It is difficult to assign a use for them. They may possibly have been sleeping-places for children, which communicated with the main pit by an underground passage. According to tradition, such compartments were skilfully hidden and covered by mats, so that attacking enemies could not discover them. The pits to the north of the large oblong one contained no skeletal remains, but were full of kitchen refuse and may have been especially dug for this purpose. At the western and eastern walls of the large pit was a pit somewhat larger than those to the south and north. These contained some kitchen refuse, but not in such quantities as in the small pits. These last two pits had evidently been storage-places or possibly special cooking-lodges.

The village site was 5 meters above sea-level. All the pits contained a considerable number of large stones, which evidently supported the posts of whalejaws. All the bones found, including those of sea mammals and whales, were in a much decayed state. Many of the whale-bones, which are usually distinguished by their hardness and solidity, fell to pieces when handled. This bears witness to the comparatively old age of the site, despite the fact the refuse layer was not deep. 


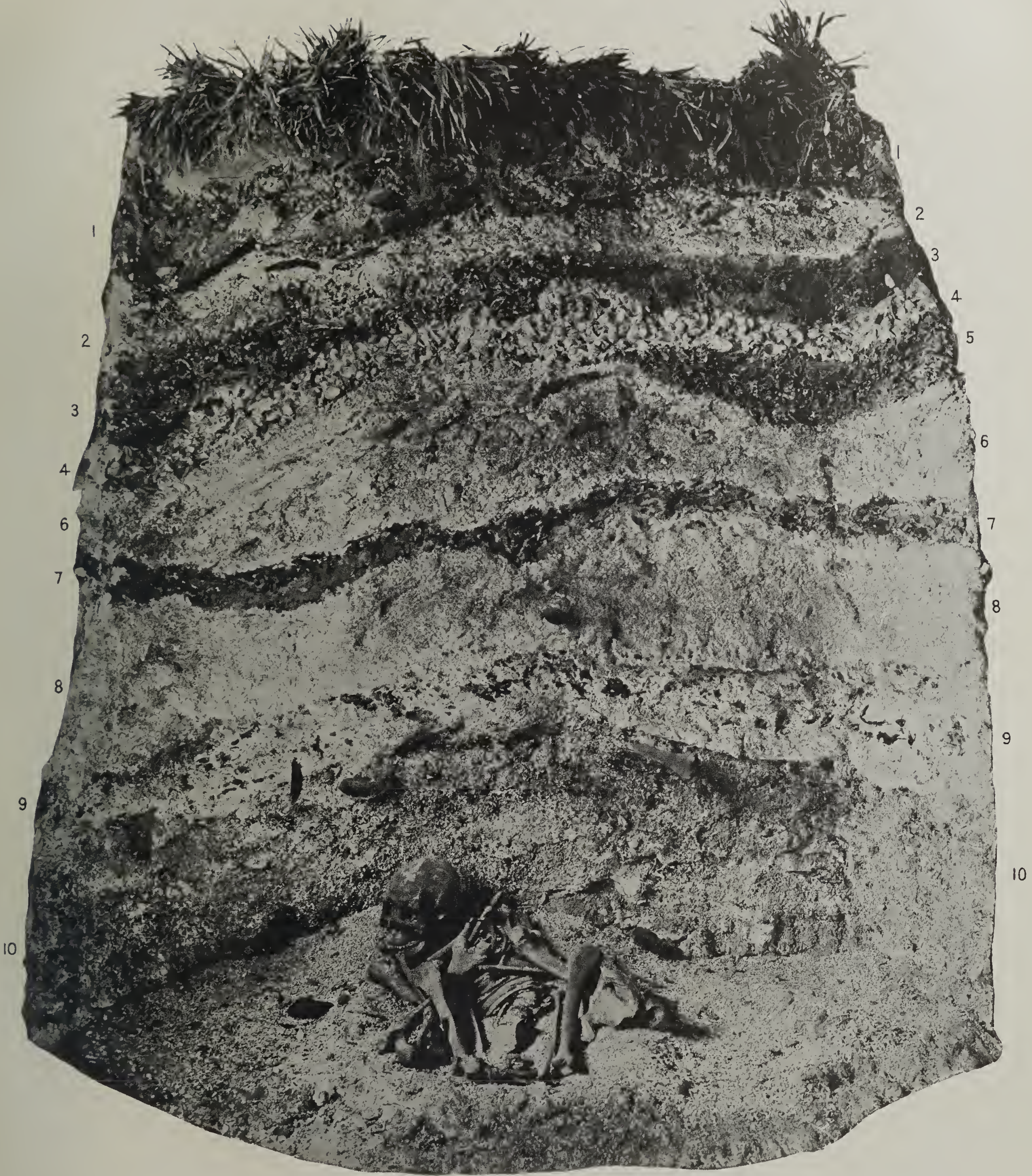

Model of section of Pit 3 on the ancient village site, Aglagax, Umnak Island, with a skeleton found at a depth of 1.0 meters. (For a description of layers, see p. 3I.) The model is on exhibition in the Rumiantzev Museum in Noscow. 



\section{CHAPTER IV. \\ HUMAN REMAINS IN KITCHEN MIDDENS.}

At present the Aleut, as devout Christians, inter their dead in coffins in cemeteries, according to the Russian custom. They show no evidence of respect either for their former mode of burial or for the graves of their non-baptized ancestors. Influenced by the Russian missionaries, the Aleut called their "impious" dead ancestors "propastchi," meaning "perished," and referring to dead animals only. These circumstances greatly facilitated the work of excavating ancient Aleut graves; the Aleut laborers dug the graves without fear and even in a spirit of flippancy. Thus, Unalaska Aleut would say to their tribesmen of other islands: "Well, we will now dig out your great-grandfathers," and the great-grandsons were not displeased. The Aleut indifferently washed the bones of their pagan ancestors before drying them out, and it was only on Umnak that the old people asked us not to wash the bones in the sea, rivers, or lakes because the fish might disappear from the waters.

Of the two principal methods of disposal of the dead, aiming either at the preservation or the destruction of corpses, the Aleut practiced the first method. They did not employ the methods prevailing among the tribes of northeastern Siberia $^{1}$ (with the exception of the Yukaghir ${ }^{2}$ ) and among some of the North American Indians, ${ }^{3}$ cremation or discarding the corpse to be devoured by beasts and birds. The ancient Aleut preserved bodies of their dead with great care, a custom founded first on their beliefs and secondly on the psychical peculiarities of the tribe.

According to the religious concepts of the Aleut, the soul $\left(\mathrm{an}^{\prime} \operatorname{gix}^{ }\right)$continues to have some connection with the dead body; therefore the burial place must be a reminder of the dwelling of the living, $i$. e., an earth lodge, or a place where hunters spent their time when hunting sea mammals far from their village, $i$. e., caves.

On the other hand, relatives, parents and children, and husbands and wives were greatly attached to each other. Parting with the dead was deferred as long as possible; the corpses were kept in the dwellings, relatives sitting nearby and watching and sleeping near them. Fear of the dead, at least of related dead, was unknown to the Aleut, since their conception of those departed was not that of hostile spirits

1 See W. Bogoras, The Chukchee, p. 526; W. Jochelson, The Koryak, p. I04; S. Krasheninnikov, Description of the Kamchatka Country, St. Petersburg, I818, Vol. II, p. I84 (in Russian); G. W. Steller, Beschreibung von dem Lande Kamtschatka, Frankfurt und Leipzig, I774, p. 273.

2 See W. Jochelson, The Yukaghir, Part II, Religion and Myths, p. 222.

$3 \mathrm{H}$. C. Yarrow, Introduction to the Study of Mortuary Customs among the North American Indians, Washington, I880; T. Preuss, Begräbnissarten der Amerikaner und Nordost Asiaten, Königsberg, I894. 
but as the same loving beings as when they were alive. Among most primitive peoples, as the Siberian natives and the Eskimo, kindred to the Aleut tribes, the departed inspires fear to such an extent that the dwelling in which a death occurred is very often abandoned. Among the Siberian natives we found an analogy only among the Yukaghir; they, too, have no fear of departed relatives. ${ }^{4}$ As will be seen in the section dealing with religion, the Aleut dead may do harm to enemies or to alien hunters after helping them in the chase, but they always preserve a benevolent attitude toward relatives.

Judging, however, from the excavation of burial-places, no uniform method of disposing of the dead prevailed. The present Aleut tell how their ancestors kept the dead, attired in their best clothing, in their living-rooms, before the final disposal. Mothers kept dead infants for months, and very often for a whole year, carrying them around as when alive or rocking them in cradles. In Aleut folk-lore are many pathetic tales of women who did not part with their dead husbands or lovers for a long time. One tale is that of a young woman who killed her husband, stealing upon him at the side of her rival, but afterwards she insisted on her right to remain with the corpse, preferring it to her rival. Her rival did not yield, and both women remained with the dead, spending several days without food or drink at the side of the corpse.

Another tradition relates the tale of an Aleut who killed his nephew, the son of his sister, ${ }^{5}$ being suspicious of the conduct of his wife and nephew. The aunt carried the body of her nephew-lover to the top of a rock, where she spent several days with it, speaking to it and caressing it as if it were alive. Finally, heart-broken and weeping, she threw herself into the sea with the corpse.

Under such circumstances it is scarcely to be wondered at that the Aleut achieved the art of mummifying the bodies of their dead, which made possible their preservation and postponed the time for final disposal. It may be contended that mummification could not succeed in the cold and wet climate of the Aleutian Islands, but such is not the case. The Aleut used no drugs for embalming, but proceeded as follows: An incision was made in the perinæum and the intestines removed through the pelvis, or an incision was made over the stomach for that purpose. The intestines were carefully cleaned, all fatty substances removed, and then stuffed with dry scented grasses. Then the corpse was arrayed in its best clothing, over which a kamleika (water-proof shirt made of the guts of sea mammals) was drawn. Then it was arranged in a squatting position with knees drawn up to the chin. Wrapped in closely plaited grass-mats and seal or sea-lion skins taken from the cover of the dead man's boat, the corpse was lashed into a compact bundle with thongs or seaweed ropes. Then the whole package was again wrapped in a net made of sea-lion sinews.

The arrangement of a corpse in a squatting position has a wide distribution throughout the world, not excluding Europe. It was prevalent in the palæolithic

${ }^{4} \mathrm{~W}$. Jochelson, The Yukaghir, Part II, Religion and Myths, pp. 163-165.

${ }^{5}$ According to the old Aleut custom, a woman's son was reared by her brother. 

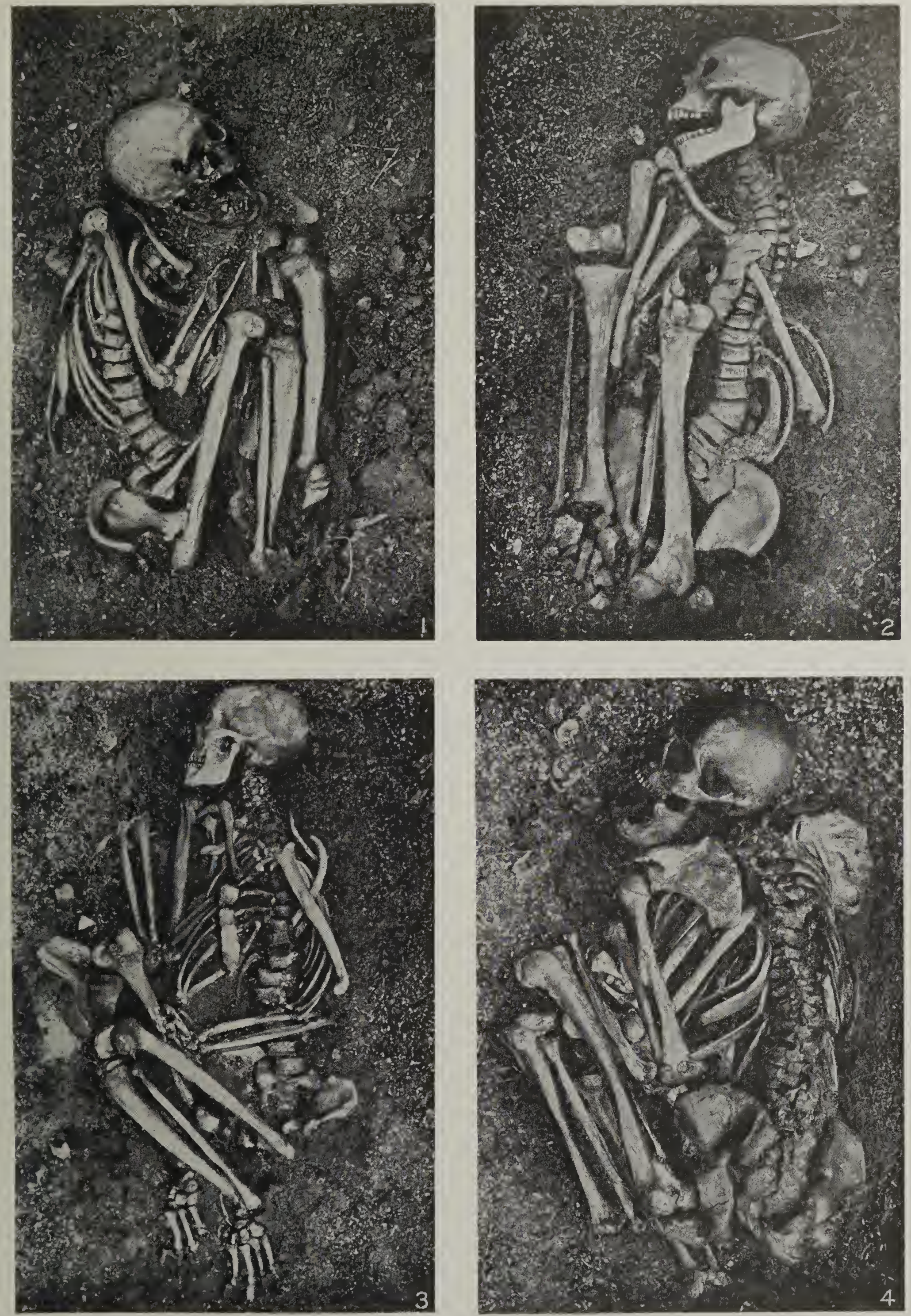

I. Skeleton found in the excavation of the Nankax site, Attu Island, at depth of I 5 meters

2. Skeleton from the Aglagax site, Umnak Island, found at depth of I 9 meters.

3. Skeleton from the Ukix site, Umnak Island, found at depth of I 8 meters.

4. Skeleton from the Ugludax Site, Umnak Island, found at depth of I I meters. 

period and the custom is still followed in some parts of Africa (among the Hottentot and Bantu tribes), Asia (Indo-China and Japan), America (among some of the Eskimo and some Indian tribes like the Comanche), and in Australia. Only in Europe has this custom completely disappeared.

Various interpretations of this method of disposal of the dead have been offered. For example, it has been suggested that the squatting position of the dead was to imitate the position of a child when in the mother's womb, i. e., (I) that the posture of man when leaving this world may correspond to that before his birth; (2) that the doubling up of the body was for economy of space; and (3) to give the dead a crooked position to prevent their returning and harming the living.

None of these interpretations can be applied to the Aleut method of disposal of the dead. The first explanation came from missionary-travelers who applied to this custom the Christian conception of death. It is quite doubtful whether any tribe following this practice attached this or a similar explanation to the custom. The second explanation might be applicable where urn burial was practised, as in India, Hindustan, and South Carolina. The third explanation, fear of the dead, undoubtedly presents a real cause, which might, however, refer not to the doubling up of the corpse, but to binding it or putting it into an urn. Both these methods may have been to hamper its movement. The Aleut lashed the body with thongs only to keep the bent bones together, while the squatting position corresponds to the posture of which the living Aleut are so fond.

Even now, when the Aleut are familiar with the use of chairs and stools, many of them, particularly the women, perform their household tasks squatting on the floor. This is also the usual posture when at leisure or when playing chess, a game they adopted from the Russians and of which they are very fond. The usual position is to sit on the heels, clasp the hands around the knees, or rest the chin on them. In this position the Aleut rests his whole foot on the ground. The author was unable to attain such a position and always fell on his back when attempting to do so. To sit on the heels as do the Aleut one must have well developed leg-muscles capable of keeping the trunk in equilibrium; besides the Aleut curve their backs and drop their heads forward to assist in balancing themselves. Apparently the use of this posture by many generations of Aleut has made them adept at assuming it. Not only are they not fatigued thereby, but they seem to find it restful after their work. So the dead are arranged likewise. Text-figure $5 \mathrm{~A}$ shows an old Aleut woman sitting on her heels, resting after her work; in figure $5^{\mathrm{B}}$ is a young Aleut woman weaving a suspended grass basket.

According to one tradition recorded in a text, the ancient Aleut, when prevented from hunting at sea by continuous gales, used to squat in their huts, cover themselves with grass, and wait until the storm subsided or they died of starvation.

Doctor Dall states that during the historic period, at the time of the advent of the Russians, burials were found with bodies stretched out on their backs at full length $;{ }^{6}$ however, we found no bodies lying thus. Only one unflexed skeleton was

${ }^{6}$ W. H. Dall, On the Remains of Later Prehistoric Man, etc. (Smithsonian Contributions to Knowledge, Washington, 1878), 5 . 
found, but this lay, not on its back, but on its side, and judging from its length and the measurements of the skull, the skeleton may be that of a Russian left where he had been killed (plate I4, fig. 4).

An old Aleut informed us that not all Aleut were embalmed, this being the privilege of noted hunters, especially whale-hunters. The Atka Aleut regarded them as bewitched after death and called them asxi"nan, which properly means "the departed ones." The asxi'nan were hung up in caves in troughs resembling large cradles which were attached to a cross-beam resting on two posts. Colored posts were placed in front of the entrance, which was also painted in different colors. The asxi'nan, according to Aleut belief, were busy throughout the night; they rose, hunted, prepared food for themselves, held feasts and festivals, and in the morning resumed their squatting position.
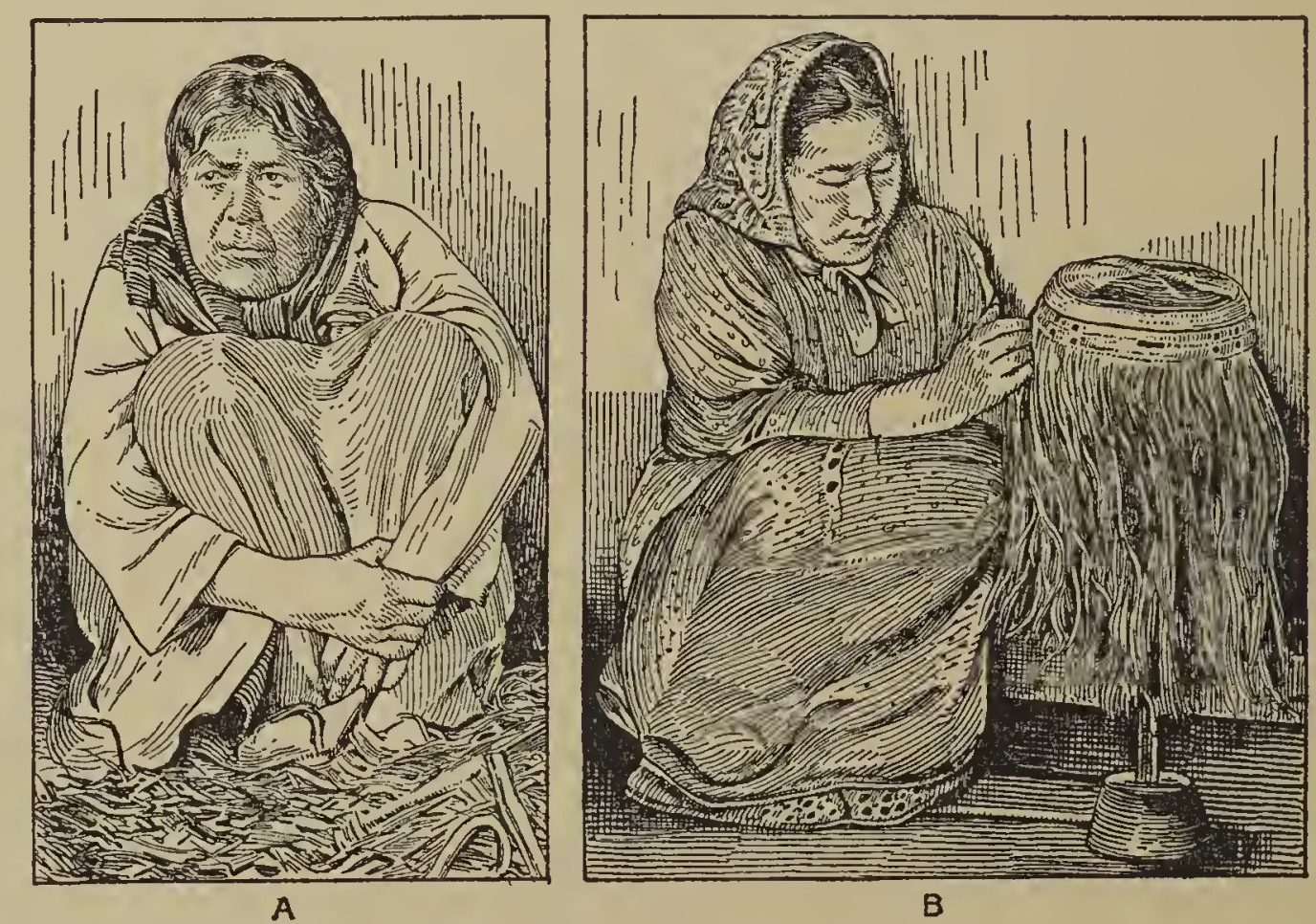

FIG. 5. $-A$, Old Aleut woman resting; $B$, young Aleut woman weaving a basket. Drawn from author's photographs.

Corpses of honored people and of the families of chiefs were also mummified. Doctor Dall has also described the Aleut mummies found in caves, and we were told of other caves containing mummies, but were unable to examine them. He has also described the outer appearance of the mummies obtained by Captain Henning, of the Alaska Commercial Company, on the islands of the Four Craters in 1874. Two of these were presented to the California Academy of Sciences and the remainder were forwarded as a gift to the U. S. National Museum. Unfortunately, Captain Henning did not give a detailed account of the position of the mummies, nor of the circumstances under which they were obtained. According to information obtained from some intelligent natives, Doctor Dall placed the age of the mummies as shortly before the period of the advent of the Russians. Doctor Dall relates a tradition concerning these remains, a variant of which was recorded by the author as follows: 
On the island of $\mathrm{Ka}^{\prime}$ gam-I'lan ${ }^{7}$ there lived an old chief. He was the best warrior and hunter among all the Aleut and took constant care of his people. Therefore he was respected and honored far outside his island. He was a widower and had two children, a son and a daughter, whom he loved very much. At the request of his son, the old man made a small skin boat $\left(i^{\prime} q y a x^{\prime}\right)$ for him. When it was ready the boy was allowed to go out in it on condition that he did not go beyond the limits of the bay. However, the boy saw some ducks, chased them, and, carried away by his interest in the hunt, left the bay, and his father lost sight of him. Just at this time, the son-in-law of the old man, a young Aleut from Umnak Island, appeared from the sea. He was on his way to visit his pregnant wife; who, according to Aleut custom, must remain with her father until after the birth of the child. The boy did not see his brother-in-law, as his back was toward him. The young Aleut saw with delight how skilfully and bravely the boy followed the chase. He resolved to frighten him and threw a dart, aiming above the boy's head, but unfortunately he hit him in the back. The boat capsized and the boy drowned. The brother-in-law, frightened by the incident, carried the skin boat and the boy's body to the shore, left it among the weeds and returned to Umnak, giving up the visit to his wife. The chief ( $t u^{\prime} k u x^{\circ}$ ) hunted for his boy all night and the next morning found him dead among the algæ close to the shore. He embalmed the body and arranged an elaborate funeral. While the corpse was being carried to the family cave, the chief's daughter stumbled and fell down the rock to her death, giving premature birth to a dead child. The boy's funeral was halted and the chief prepared the bodies of his daughter and the child and carried them to the cave. Grieving over his loss, the chief did not survive his children long, and soon the people added his body to those in the cave.

Such, in brief, is the tale of the origin of the mummified corpses found in a cave on the island of Ka'gam-I'lan. But Doctor Dall, who examined the mummies found by Captain Henning, states that, judging from their age, they do not correspond to those referred to in the tradition. On the other hand, we were told by the Umnak Aleut that the mummified corpses of the members of the family of the late chief of $\mathrm{Ka}^{\prime}$ gam-I'lan Island are still untouched in one of the caves on the island.

Two types of caves were used as burial-places: one with deep grotto-like passages with a large opening, the other in the form of small hollows in the rock. Neither type of cave is due to solution and erosion processes; but rather they are a part of the original structure of the solid volcanic rock or lava tunnels similar to those known in Hawaii and Oregon. The caves are dry and no surface water penetrates them.

Mummified corpses of distinguished people were hung up chiefly in the bottom of the grotto-like caves, while in the small caves, which evidently were regarded as village cemeteries, all the less distinguished dead were placed. According to Weniaminoff, common people and slaves were buried in such small caves, while chiefs and other eminent people were hung up in high, square, wooden boxes with slanting

${ }^{7}$ Doctor Dall erroneously spells this name Kagamil. 
roofs, or were buried in separate earth lodges. However, it should be stated that we nowhere found traces of burials above the ground in boxes, as related by Weniaminoff, and no other Aleut knew of such graves. Such burials were called $q u^{\prime}$ mnax $x^{\prime}$ by Weniaminofi, but the Aleut use this designation for any place for the disposal of a body, whether it be a cave, a special burial hut, or a compartment for the dead in an occupied underground dwelling.

It should be added that in the caves examined on Attu, as, for instance, the large cave on Goltzef Bay (plate 7, fig. 6), within 15 miles of the present winter settlement, or the two caves on the little island Kixsin, opposite the settlement on Chichagof Bay, no traces of burials were found. The Kixsin caves were used by the Attu Aleut for storing grasses for weaving. It is possible that the Attu people did not use caves as burial-places. The large cave on Goltzef Bay is grotto-shaped and is divided into two passages. A narrow gorge, into which the sun does not penetrate, leads to the wide cave-entrance near which stalagmite-like pillars of ice still stood in spite of the lateness of the season (June 20). These ice-pillars were formed from the melting of the snow on the rock over the cave. It was cold, and in some places inside the cave water dripped throngh crevices in the basaltic rock. Few vestiges of human activities were found. Among the splinters of rock fallen from the vault of the cave and in the earth carried into the cave by the winds, were found some bones of fishes, sea mammals, and foxes. At the time of our examination, Aleut hunters often stayed there for the night when hunting foxes and seals when they did not wish to return home in the dark. During stormy weather the hunters often spent many days in the cave.

There are two caves on the small island in Chichagof Bay, within a mile of the present winter village, and opposite the ancient village site, Sin. One of the caves is a large grotto (plate 7, fig. 4), similar to the cave on Goltzef Bay, but not so deep. Besides a quantity of shells of mollusks and seal-bones, no other refuse or traces of burials were found. Dry, tumbled grass, a hunter's sleeping-place, was found in the bottom of the cave. The second cave was smaller in size, not deep, but dry. In the summer the Aleut women preserve their supply of grasses which, during the winter, they make into mats and baskets.

Small cave cemeteries of the second type, sack-shaped hollows in the rock, were found on Atka and Amaknax. Two such caves were discovered on Atka, near the Atxalax village site (plate 8). Evidently both caves had served as burial-places for the inhabitants of the village. They were located in the southeastern part of the porphyritic rock of a promontory separated from the abrupt shore of Atka by a narrow neck of land, on which a village site $(A)$ was located. The cave $(B)$ was evidently a one-family burial-place. From this cave we secured four uninjured skulls, two broken, and some well-preserved bones (plate 8, fig. I). Of much greater importance was the second cave $(C)$, located about 30 paces from the former and a little higher up on the rock. Three days were occupied in excavating the cave, August I5 and I7 and September 4, I909. The interruptions were due to the heavy rains and stormy weather, making it unsafe to go from the village to the promontory at Atxalax in skin boats. 

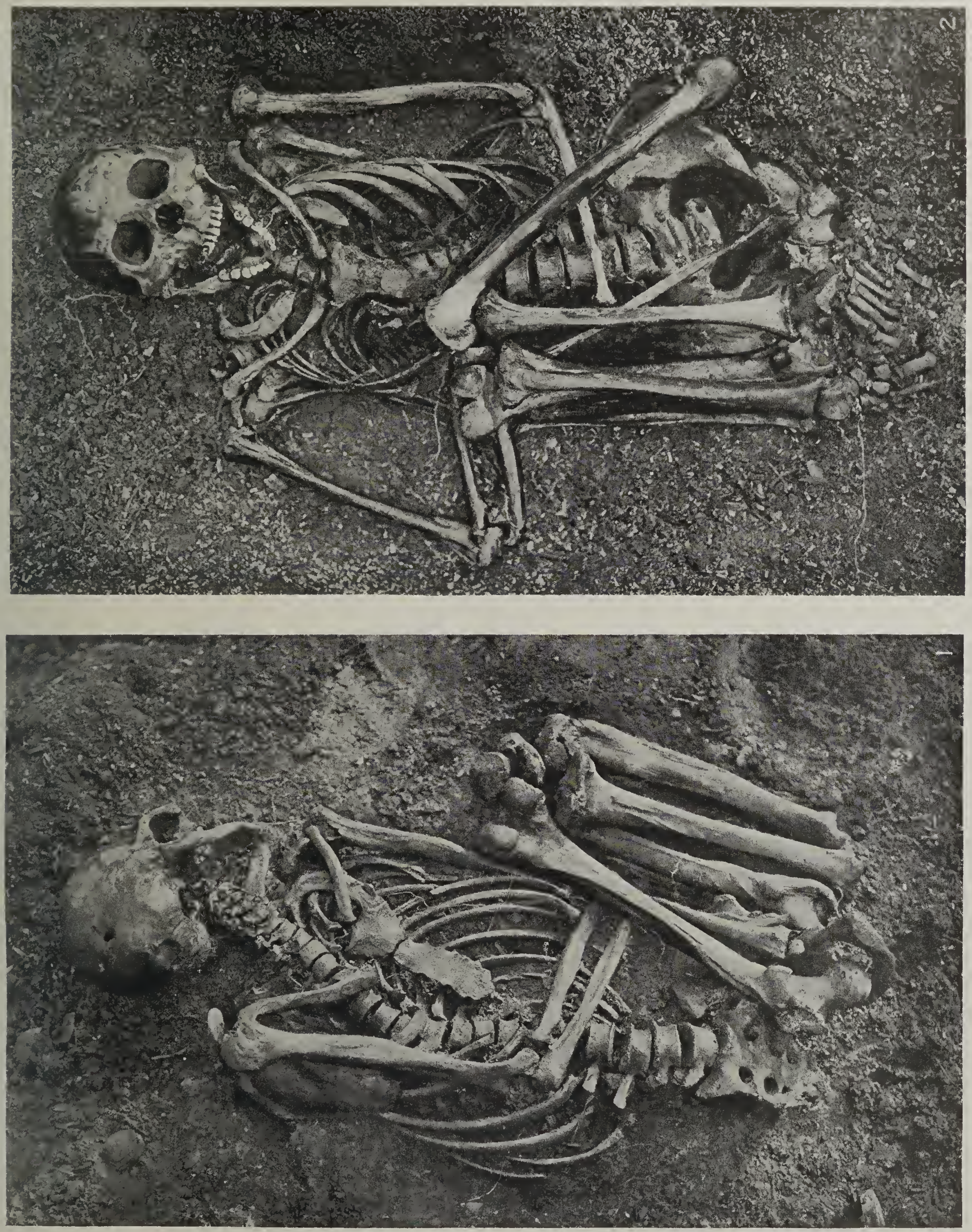

On first examination, the cave $(C)$ presented the appearance of a small rocky vault, under which three skulls, whitened by weathering, were observed. The vault over the skulls was only a foot high. With the removal of stones which had fallen from the vault and wind-borne earth, additional skulls were disclosed. The cave as it appeared early in the excavations is shown in plate 8 , figure 2. With the removal of stones and other débris a threshold of whale-bones came to light. This had evidently been intended to wall up the cave. Intermingled with the stones and earth was much decayed skeletal material, and about 2 feet below the first skulls found more skulls were uncovered. Judging from the number of skulls, 22 bodies had been buried in the cave. There may possibly have been more bodies, since some of the skulls may have been totally destroyed; of those found only ro were intact. All the others were broken to some degree by stones dropping from the vault or had decayed as a result of weathering, so they were abandoned.

Evidently, the cave had been the burial-place for the Atxalax village over a long period of time, though it is difficult to make a specific statement in years or to refer the skulls to a particular period. From the position of the skeletal remains, no conclusion could be drawn as to the original position of the bodies. The bottom of the cave was 2 meters square. All the bodies could scarcely have been placed in the usual squatting position in one layer. It must, therefore, be assumed that the squatting bodies were in 2 layers at least or were laid out on their sides like those on Umnak Island (plate I4, fig. 2).

That this cave was an ancient one may be deduced from the fact that all the perishable body-wrappings, such as water-proof coats, fur clothing, grass mats, skins of sea mammals, masks and other wooden objects, and implements had completely decayed, and most of the human bones had disintegrated. Of objects usually deposited with the dead, only stone implements and a few of bone were found uninjured. Thus, among the skeletal remains were found stone labrets, arrow and harpoon points, and those parts of throwing implements that were of bone. The total depth of the débris was 1.5 meters.

Beneath the skulls and other bones was a layer containing kitchen refuse mixed with earth and fragments of rock. The cave was excavated to the original rock bottom; the total depth of the excavations was 2.9 meters.

A vertical section of the cave is shown in figure $6 . A$, is the skeletal layer; the dotted line passes through the rock fragments and the bone threshold which closed the entrance to the cave. In $B$ are shown the fallen rocks covered with grassgrowing earth; $C$ is the kitchen-refuse layer beneath the bone layer; $D$ is a layer of shingle or water-worn stones.

The stratum of kitchen refuse was of the same character throughout. The remains generally predominating were shells of mollusks (Mytilus edulis, Acmcea patina, Litorina sitchana, and Mactra ponderosa). Shells of echini were much less in evidence than those of mollusks. Of fish, there were the bones of cod and halibut and of sea mammals those of sea-lions, seals, and sea-otters. The bird-bones were those of uriles, albatross, and puffins. In the layer containing the skeletal remains were found several raven beaks which had evidently served as amulets. In the 
kitchen refuse beneath the skeletal remains were found the same kind of stone and bone weapons and implements as in the skeletal layer, which is evidence that Aleut culture did not change, at least in the course of the accumulation of these 2 layers of débris. In the opinion of Doctor Dall the occurrence of kitchen refuse beneath skeletal remains indicated that at certain periods caves had not served as burialplaces, but as dwellings. This conclusion does not appeal to the author, since all the remains found during excavation tend to support the supposition that the Aleut came to the islands with a definitely developed culture and with a knowledge of building of houses suitable for protection from the inclemencies of the Aleutian climate. It is true that remains of food have been found in the caves, but these may show that it had been used as a temporary shelter and not as a permanent dwelling. The presence of stone lamps in the cave does not necessarily prove that it had been used as a dwelling, since lamps were used not only for light, but for warmth as well. Hunters always carried stone lamps in their skin boats and when ashore used them to warm themselves. Possibly they kept special lamps in caves for this purpose.

A third burial cave was discovered on Amaknax, near the ancient village site Tanaxtaxax. On the other side of the lagoon and opposite the village site on the slope of Amaknax ridge, Io feet above the level of the lake, was a small cave so filled with stones and earth overgrown with grass that from a distance it was scarcely visible. After close examination we found a narrow slit between the rocky vault of the cave and the floor, where could be seen a broken skull and fragments of other bones. We cleared the cave until its original surface was reached. At the Fig. 6.-Vertical section of burial cave, C, Atka Island. front of the cave a layer, I.2 meters thick, was removed and this gradually thinned down to a depth of 0.7 meter at the cave wall. Whale-bones which had served as a threshold to the cave were discovered outside the vault about 0.5 meter away. The bones were supported by large stones. The location of the threshold makes it probable that the cave vault had formerly protruded farther and that the front of the cave had collapsed. Among the fragments of rock and earth taken from under the vault were the remains of I6 skeletons, judging from the number of skulls. More than half of the bones were so decayed that they crumbled to dust when handled. Only 9 skulls sufficiently complete for measuring were obtained. When all the débris had been removed it appeared that the vault protruded 0.5 meter; thus, the former width of the cave was I meter. Its height was I meter and its length I.5 meters. This small cave had contained at least 16 bodies. It is difficult to say whether they had been in a sitting position or laid on their sides one over the other. Evidently this cave cemetery was very ancient; not only were there no vestiges of wooden objects and masks, but no remnants of bone objects were found. Of objects of stone 

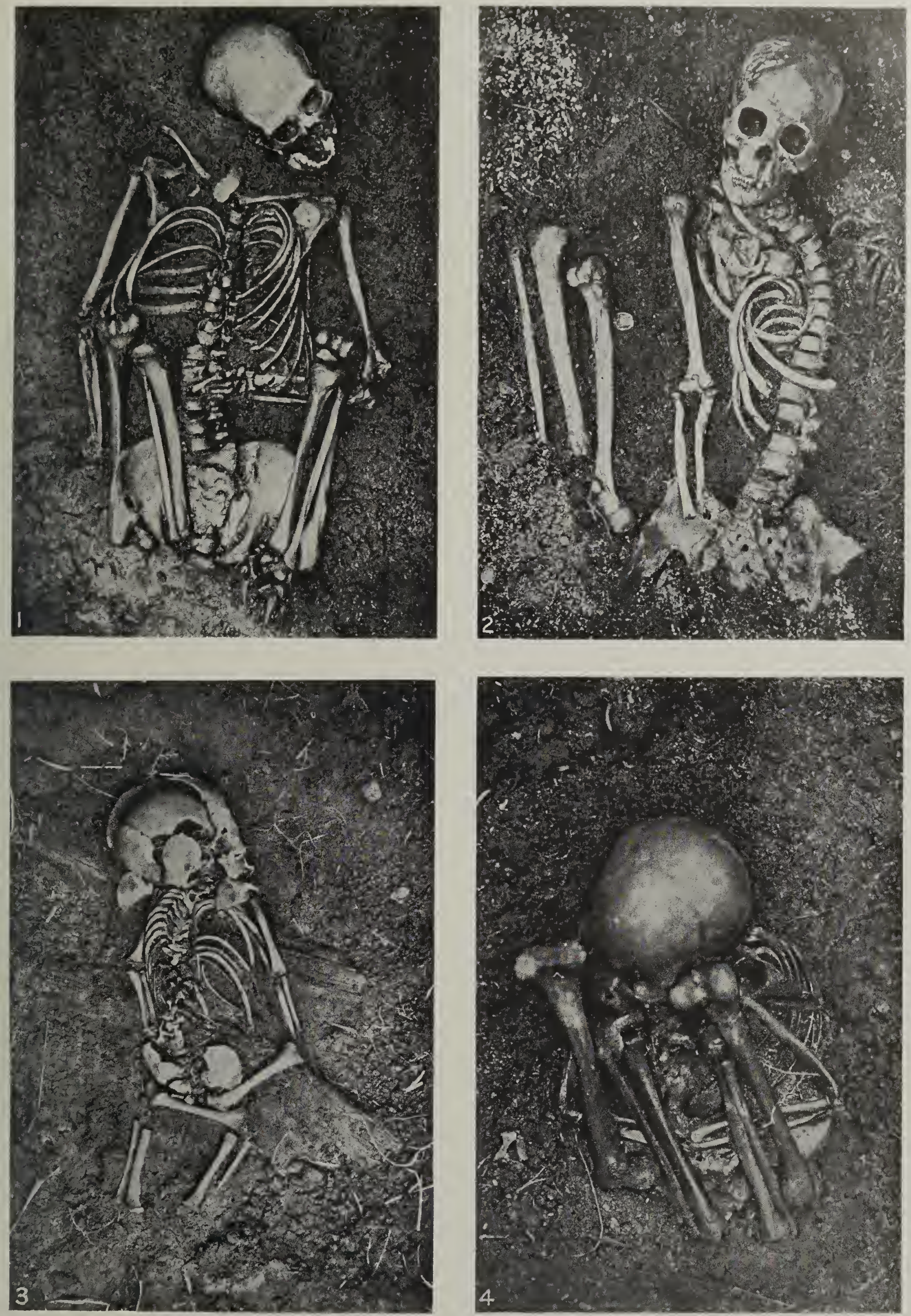

I. Skeleton from Ukix, Umnak Island, found at depth of I.2 meters.

2. Skeleton from Ugludax, Umnak Island, found at depth of I.2 meters.

3. Skeleton of a child from Ukix, Umnak Island, found at depth of I.5 meters

4. Skeleton from Natxakax, Umnak Island, found at depth of I.7 meters. 

we found two woman's knives, a man's crooked knife, a fragment of a stone lancehead, and two whetstones. The only kitchen refuse found was a small quantity of mollusk shells.

It is interesting to note that Doctor Dall, who made excavations on the Tanaxtaxax site, had evidently not noticed this cave from the other side of the lagoon; otherwise it is scarcely possible that he would have left it untouched. We reproduce here the photograph of the cave examined by Doctor Dall (plate 9, fig. 3 ) more than 45 years prior to our expedition. Plate 9, figure $\mathrm{I}$, shows the isolated rock at the end of the promontory where the cave is located, and the middle neck of land on which were situated the two sites, Amaknax and Xatacxan, which were excavated. The burial cave was situated near the latter site. In the bird's-eye view in plate' 9 , figure 2, may be seen the third or southern neck of land on Amaknax Island, which we were unable to examine. In the strait between the last neck of land and Unalaska is a small island called Expedition Island, on which Weniaminoff has planted some fir trees brought from Sitka.

In addition to the large grotto-like caves in which the Aleut suspended their mummified dead and the smaller caves which served as village cemeteries, the Aleut used compartments in their underground dwellings or special lodges for the disposal of their dead. For the latter 2 methods the bodies were prepared as for cave burial. As will appear later, skeletons were found during the excavation of the usual type of underground dwelling as well as in special burial pits. In some underground dwellings were uncovered lateral burial compartments which had been walled up by stones and earth and covered with grass mats while the underground house continued to be occupied. In a large dwelling one side often contained compartments for the dead, while the other was for the accommodation of children or for storage. These latter partitioned spaces could also be used for burials of the members of the family and were then walled up.

The greater number of skeletons was discovered through the excavation of the large pits, remnants of underground dwellings, where they were usually located at one side only.

Special burial pits were called $u l a^{\prime} k a x^{i}$ from $u^{\prime} l a x^{i}$, house or dwelling, and $k a$, element of the potential mood, i. e., a possible house. Such burial huts, when they collapsed, left indications of their former presence in the form of almost circular pits I to 2 meters in diameter. There were burial pits for one, two, or three individuals, according to the number that had died at the same time. A burial pit for one person was designated as a "solitary burial hut" by the Aleut. In these pits the skeletons were found either in a sitting posture or on their sides. In some places, as on Hog Island, small burial pits were located in rows along one side of the large oblong underground dwelling.

As has been stated before, some of the skeletons were found in a sitting position, with knees drawn up to the chin, while others were found lying on their sides. In plate 3 may be seen the position of a skeleton as found upon excavation. Figure I is a skeleton found in Pit 3 of the Ukix village site on Umnak Island. The 
skeleton lay on its left side on the northwestern side of the pit, at a depth of 3.5 feet. At a distance of 3.5 feet from the first, another skeleton lay on its right side, with the cranium missing, though the lower jaw was found. This may be some indication of the former position of the skeletons; apparently, the bodies had been placed as if sitting, and later they had fallen over. One evidence of this may be seen in the curvature of the vertebral columns, something which could not have occurred had the bent bodies originally been laid on their sides. The skeleton with the skull had the right arm drawn up to form a right angle, while the left arm was stretched out at full length, both arms having evidently fallen into this position when the skeleton fell over. The skull appeared turned by its neck to front.

In the model of an excavated section of the ruin of an underground dwelling now in the Rumiantzev Museum in Moscow (plate Io) the skeleton was arranged to appear as if having fallen from a sitting position.

Plate I I, figure I, shows the best-preserved skeleton of 9 found on the Nanikax village site on Attu, in a small lateral pit separated from Pit 4 by a small elevation. It is possible that this was a burial pit for the inhabitants of Pit 4. The skeleton was found on its left side at a depth of $\mathrm{I} .5$ meters, intermingled with kitchen refuse. At the same depth were found skeletons in much better condition: in the middle of the pit were 4 with skulls shattered from the weight of the fallen whale-bones which had served as ceiling rafters.

A skeleton was found on the Aglagax village site (plate II, fig. 2) on Umnak Island, at a depth of 1.9 meters while excavating Pit 2. It lay bent over on its right side. It is difficult to determine whether this was its original position or whether it had fallen thus. The curved position of the vertebral column may support the second supposition. The pit was one of the largest on the site and the body had evidently been buried in one of the compartments of the dwelling. About 2 feet below the skeleton were found large whale-bones which had evidently served as the framework for an underground dwelling antedating the one in which the skeleton was found.

Not far from Pit 2 we excavated an $u l a^{\prime} k a x^{*}$ (burial pit). At a depth of I.3 meters were found the much decayed skeleton of a woman and a child. No refuse was found with the bones, merely earth black with decayed organic matter.

In plate I I, figure 3 (also plate 5, fig. 2), may be seen the skeleton found in Pit I on the Ukix site on Umnak Island at a depth of r.8 meters. Lying on the skeleton were war throwing-lances (plate 23, figs. 2 to 6 and 8), indicating the burial of a warrior. The skeleton lay on its right side, with the left arm bent at right angles and the right at a sharp angle. The position of the arm may testify as to the original sitting position of the body; but judging by the normal curve of the spine, by the position of the skull on its right side, and by the undisturbed position of the neck vertebræ, it seems more probable that the bent corpse was laid out on its side. The skeleton lay with head to the southeast and feet to the northwest; it was surrounded by kitchen refuse consisting of shells of echini and mollusca, and fish-bones. The body had evidently been laid, as was true in most cases, on the kitchen remains left by 
former generations, and covered by grass mats, which have since decayed. The presence of kitchen remains above the skeleton may be explained by their falling when the ceiling of the lodge collapsed.

The skeleton in plate II, figure 4, was found together with another in Pit I of the Ugludax site on Umnak Island, at a depth of I.I meters, in the midst of kitchen remains (plate 5, fig. 3 ). Both skeletons lay at the northwestern side of the pit, the first on its right side and the second on its back; but judging from the position of the bones, the bodies had originally been in a sitting position.

Of the two skeletons shown on plate I2, figure I, has already been shown in plate 3, figure I, and has been described above. The skeleton in figure 2 has been described along with the skeleton shown in plate I I, figure 4 .

In plate 13 the following skeletons are illustrated: Figure $I$ was found in the burial Pit 5, on the Ukix village site on Umnak Island, at a depth of I.2 meters, intermingled with refuse. The bones had partly decayed; the skeleton lay on its back, with the skull turned to the right. The left arm was bent at right angles and the right stretched out at full length. The original position of the body had evidently been a sitting posture. In the photograph may be seen the bones of the foot and the left hand. Only the skull and the lower jaw were worth preserving for our collection, since the rest of the bones were much decayed.

The skeleton shown in plate 13 , figure 2 , was found at a depth of 1.2 meters in Pit 3 (plate 5, fig. I) of the Ugludax site on Umnak Island. The skeleton lay on its right side, but from the distorted position of the spine and the skull, we decided that it had been in a sitting position. The bones of one foot and one hand were missing.

The skeleton of a child may be seen in plate $\mathrm{r}$, figure 3 . It was found in Pit 2 of the Ukix village site on Umnak Island, at a depth of I.5 meters. Beneath the upper layer of dark earth was found a layer of clay containing pieces of rotted wood. Evidently these were the remains of wooden rods which had formed the frame for the ceiling of the burial lodge. The skeleton lay on its left side on some rotted wooden planks which had evidently served as the floor of the earth lodge. Both arms were outstretched; the tibia and fibula of the left leg lay apart.

In burial-hut 2 on the Nutxakax village site on Umnak Island was found the skeleton shown in plate 13 , figure 4. It was uncovered at a depth of 1.7 meters, and had preserved its sitting position. The skeleton was surrounded by kitchen remains: echini, mollusks, and fish-bones.

In plate $\mathrm{I} 4$ the following skeletons are shown: Figure I represents 4 skeletons mentioned in the description of the skeleton shown in plate I I, figure I.

The 5 skeletons shown in figure 2 were found in burial Pit 3 on the Aglagax village site on Umnak Island. The bones of the first skeleton were encountered at a depth of I meter. It soon became obvious that beneath these were the bones of other skeletons. When the entire heap of bones had been cleared of earth and kitchen refuse, it appeared that there were 5 skeletons in the pit, with knees drawn up to the chin, and lying one over the other. Doubtless this was their original posi- 
tion, since if they had fallen afterwards, their disposition would not have been so regular. Three of the skeletons lay with skulls to the east, and 2 with skulls to the west. Evidently 2 bodies had been placed on the floor of the pit with heads to the east; the second pair was placed above these with heads to the west, and then the fifth was laid with head to the east. The pairs of bodies lay back to back with knees drawn up to the chin. It may be supposed that all 5 bodies were disposed of at one time and were probably warriors killed in battle. As has been explained, the Aleut disposed of their dead and set them up in the favorite squatting posture of the living. There is, in my opinion, no contradiction in the fact that some of the skeletons were found on their sides, since while sleeping the Aleut also like to draw up their knees.

Figure 3 represents I of 2 skeletons found in burial Pit 2 of the Aglagax site. The framework of the roof of the pit had evidently been made of wooden planks. On the floor were the remains of 4 decayed posts, 2.5 meters apart. Under the skeleton were vestiges of decayed logs which had evidently served as a floor. It should be noted that driftwood is more common on Umnak Island than on any other of the Aleutian chain. Therefore the Umnak people often used logs as material for the framework of their dwellings or burial pits and not the more usual whale-bones. The remnants of rotted wood give an approximate indication of the recent age of the burial place. Evidently the skeleton had originally been in a sitting posture and had fallen when the ceiling crumbled. In falling on its back, the arms had stretched out, and the bent legs fallen to the sides. The clayey earth of the pit was intermingled with decayed organic matter. There was no kitchen refuse, but near the skeletons were found many bone wedges which had been used for splitting the logs for the burial pit. After the removal of the skeletons, the pit was dug down another meter, but no further remains were found.

In figure 4 may be seen a skeleton found during excavation of the large pit on the Tanaxtaxax site on Amaknax Island, at a depth of I.3 meters. Somewhat above the skeleton, about a meter deep, were found the disjointed fragments of 2 quite decayed skeletons, whose original position it was impossible to determine. The skeleton illustrated was stretched out on its right side and was the only one found in this position. The arms as well as the legs were stretched to their full length. Somewhat deeper than the skeleton, near the walls of the pit, were found the bones of large whales, which evidently had been the framework of the roof of an underground dwelling older than the one in which the skeleton was found. The skeleton had evidently been left in the position in which the individual had been killed. Judging from the length of the skeleton and the dolichocephalic index of the skull, it was the body of a Russian. 

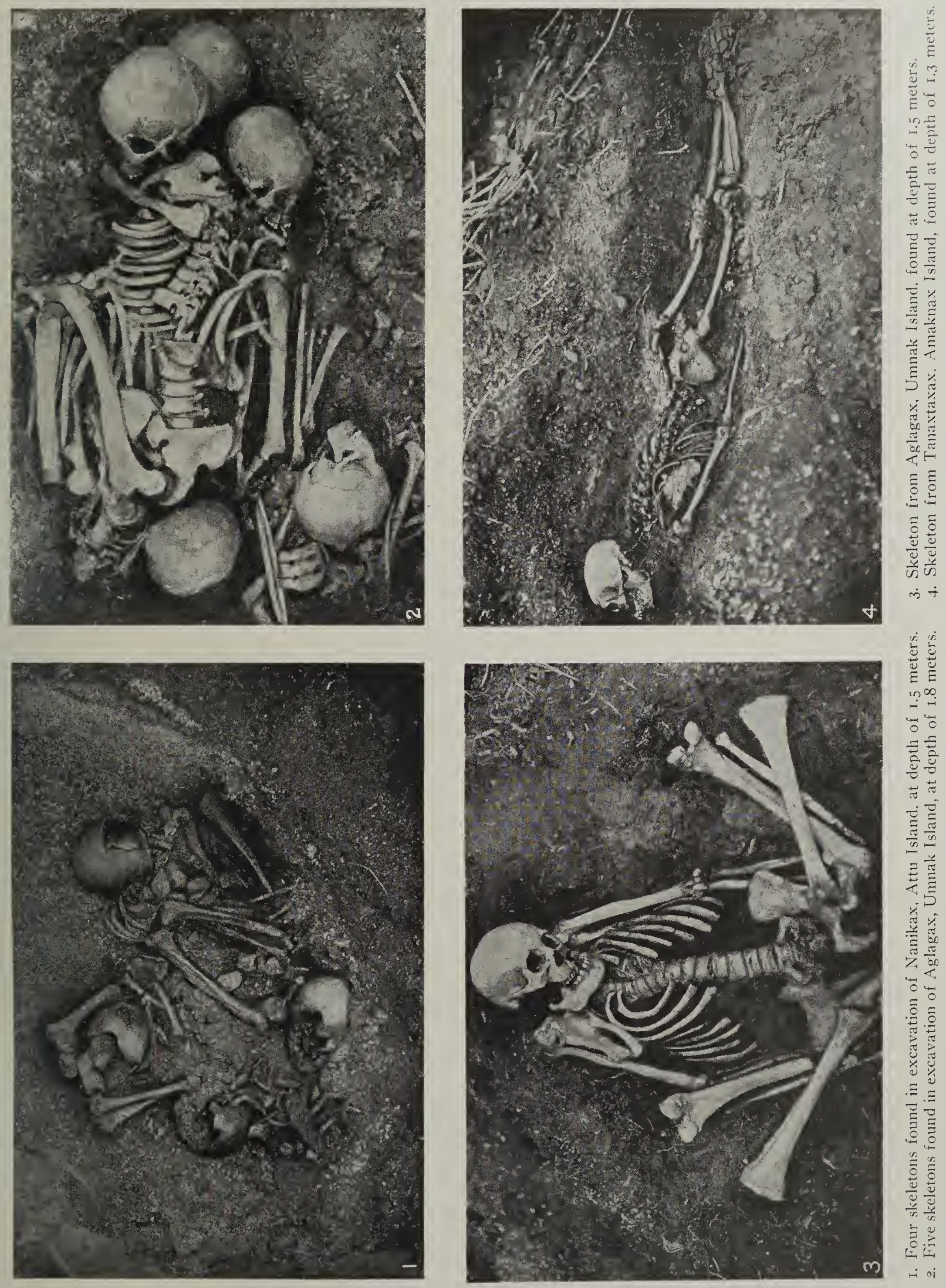



\section{CHAPTER V.}

\section{ARCHAEOLOGICAL REMAINS FROM KITCHEN MIDDENS.}

During the excavation of ancient Aleut villages many sections of stone and bone weapons and implements used in war, hunting, fishing, and manufacture were brought to light. However, parts of wooden implements and weapons and binding materials like thread, sinew, or leather thongs had decayed, not leaving any traces.

To make clear the significance of stone and bone sections of weapons and implements illustrated in this work, it seems necessary, as a preliminary, to present a general characterization of these both for the old and the present-day Aleut. A detailed description of implements, their form, size, methods of attaching distinct parts, etc., will be given in the section on material culture. ${ }^{1}$ At this point we will give only a schematic representation and general description of the 2 main types of Aleut weapons-the harpoon and throwing-lance.

\section{HARPOON AND THROWING-LANCE.}

Harpoons are called throwing-arrows or spears when the pointed head fits loosely into the socket of the foreshaft of the weapon and is detached from it when it strikes the animal, remaining in the wound. There are 2 main types of harpoons: (I) a simple harpoon, with a head that retains its original position after striking an animal; (2) a compound or toggle-headed harpoon in which the head assumes a transverse position when an obstruction is encountered.

The simple Aleut harpoon (ayu'kdax', a small harpoon; aga'lgix', a large harpoon) usually consists of 4 parts, exclusive of the binding materials-threads, glue, and paints. These are (fig. $7 a$ to $d$ ): $a$, shaft (Alett, $i^{\prime}$ glax ${ }^{\circ}$ ); $b$, bone foreshaft (Aleut, tumga'kix ${ }^{2}$ ); $c$, bone head (Aleut, saxsi'dax', a small harpoon; cuni'lgix", large harpoon) with pointed barbs projecting backward. The barbed head is loosely fitted into a socket at the end of the foreshaft and when the animal is struck, it pulls out from the foreshaft. The sharp-pointed barbs (Aleut, $t a^{\prime} l i n$; plur. from $t a^{\prime} l i x x^{5}$, branch) penetrate easily, but can not be pulled out of the wound; $d$ is a line of braided sinew or a thong (Aleut, $a \tilde{n}$ ). One end of the line is attached to the neck of the head between the point and the barbs or fastened into a line-hole of the barbed head (see $c^{\prime}$ ). The other end is attached to the shaft or is held in the hand of the hunter. In the first case we are dealing with a small and light harpoon thrown from a throwing-board with the right arm at sea animals in the water only, while the hunter sits in his skin boat. In the second case, on land, a heavy harpoon is thrown at sea mammals at short range while they lie in their rookeries. After throwing the

I It had been the intention of the late patron of the Aleut-Kamchatka Expedition, Mr. F. P. Riaboushinsky, to publish the Aleut work in several parts.

2 Tumga'kix means "its (i. e., of the implement) two bones." The dual is evidently used to show that the foreshaft is bifurcated from the side where it is attached to the wooden shaft. 
heavy harpoon the hunter tightens the line with his hand to prevent the escape of the wounded animal, while another hunter kills it with a spear or club.

Figure 8 represents parts of a compound or toggle-head harpoon (Aleut, akagu'six ${ }^{*}$ ) in the most prevalent Aleut form. $a$ is the shaft (Aleut, $i^{\prime}$ glax $x^{\prime}$ ); $b$, a bone ring (Aleut, $t u^{\prime} m u x^{\prime}$ ); and $c$, a bone foreshaft (Aleut, tu'mgax'). The tang of the bone foreshaft is driven into a socket at the thicker end of the wooden shaft, which tapers backward, and a bone ring $(b)$ is placed over the joint to prevent the wooden shaft from splitting when the animal is struck. On the upper tip of the bone foreshaft the bone toggle-head $(d)$ (Aleut, akagu'six $\left.{ }^{\prime}\right)^{3}$ with an inserted stone point (e) (Aleut, $k a^{\prime} d a x^{\circ}$ ) is attached.

Text-figure $8 b$ shows how the parts of the Aleut toggle-head harpoon are held together, while in figure $8 c$ may be seen the position of the head in the body of the wounded animal. It closes the wound inside like the toggle of a cuff-button and performs the same function as the barbed bone head of the simple harpoon, but much more efficiently.

The schematic representation of an Aleut toggle-headed harpoon given in figure 8 is drawn after a specimen secured on Umnak Island (Cat. No. I888). In this case, the head is loosely attached to the foreshaft and the implement sticks closely to the body of the wounded animal, preventing it from plunging into the water. The ancient Aleut also had other types of toggle-headed harpoons. In one type the head was attached to a long line, the other end of which was fastened to the shaft. When an animal is struck, the head becomes detached, the heavy bone foreshaft dips into the water, and the lower thin end of the wooden shaft floats on the surface of the water, indicating to the hunter where the wounded animal has dived. ${ }^{4}$

The throwing-lance may be distinguished from a harpoon by the fact that all its parts are fixed and immovable. This lance was formerly the chief weapon in war, and also used to kill aquatic animals after they had been struck by a harpoon. The throwing-lance usually consists of three parts (fig. 9): $a$, a wooden shaft (Aleut, $i^{\prime}$ glax $x^{\prime}$ ); $b$, bone ring or belt (Aleut, tu'mux $x^{\prime}$ ); and $c$, $d$, the compound head, consisting of the barbed Bone head (Aleut, igi'qax') and stone point. (Aleut, $\left.k a^{\prime} d a x^{*}\right)$. The bone ring consisted usually of two halves (plate 26 , figs. 3I, 33 , and 40 ), and was an essential portion for keeping the deadly weapon. The length of the bone section of the head was equal to the distance between the planes of the chest and the spine of a man. The lance striking the chest passed out through the back. The barbs which project behind hold the lance in the wound. Any attempt to pull the lance from the wound would cause great pain and might injure tissues and organs not touched before. Aleut warriors used the beak of an albatross as

3 The same name as that of the whole harpoon.

4 It is not our intention to enter here into a comparative study of harpoons as described by Boas, Kroeber, Mason, Murdoch, Turner, Nelson, and others. At this point it is necessary only to mention harpoons with two foreshafts, of which the upper one is called a loose foreshaft. The toggle-head is placed on the upper end of the loose foreshaft. The lower end of the loose foreshaft forms a joint with the upper end of the foreshaft. Some writers state that by bending the loose foreshaft one prevents the accidental breaking of the shaft. It appears to the writer, however, that when the loose foreshaft is bent the toggle-head is assisted to take a transverse position in the wound. It may be added that a toggle-headed harpoon similar to the Aleut specimen described, where the loose toggle-head is not detached from the foreshaft, has not been reported from other regions where the harpoon has been used. 
pincers to extract the lance from the wound. Above the tang is a hole $(c)$ or sometimes 2 (e) or a projection, by means of which the head is permanently tied to the shaft and bone belt (figs. 53 and 54). Such perforation or projections are sometimes seen above the tang of the head of a simple harpoon. But the tangs of both these weapons differ; that on a harpoon is always broad and flat, while on the head of a throwinglance it is usually conical in form. Writers on pre-historic archæology usually
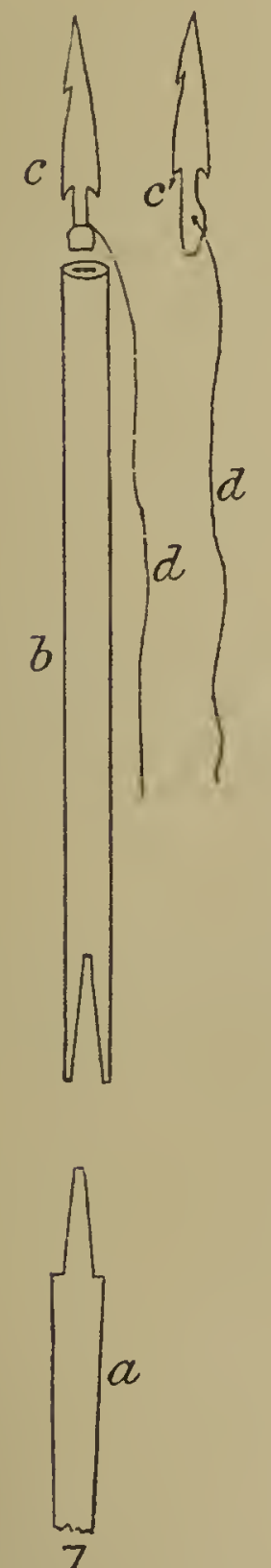

FIG. 7.-Sections of a simple harpoon.

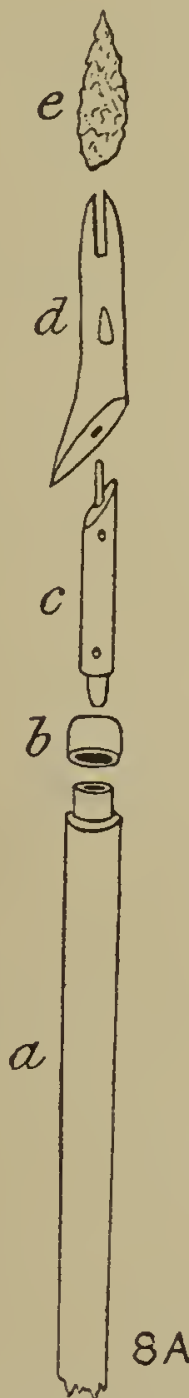

FIG. 8.-Sections of a toggle-headed harpoon.

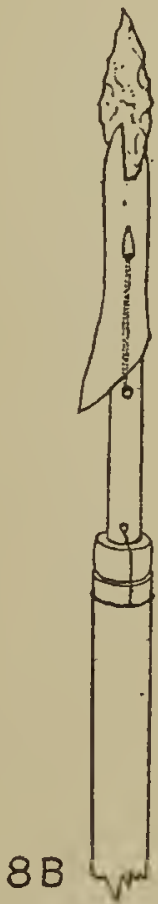

a)
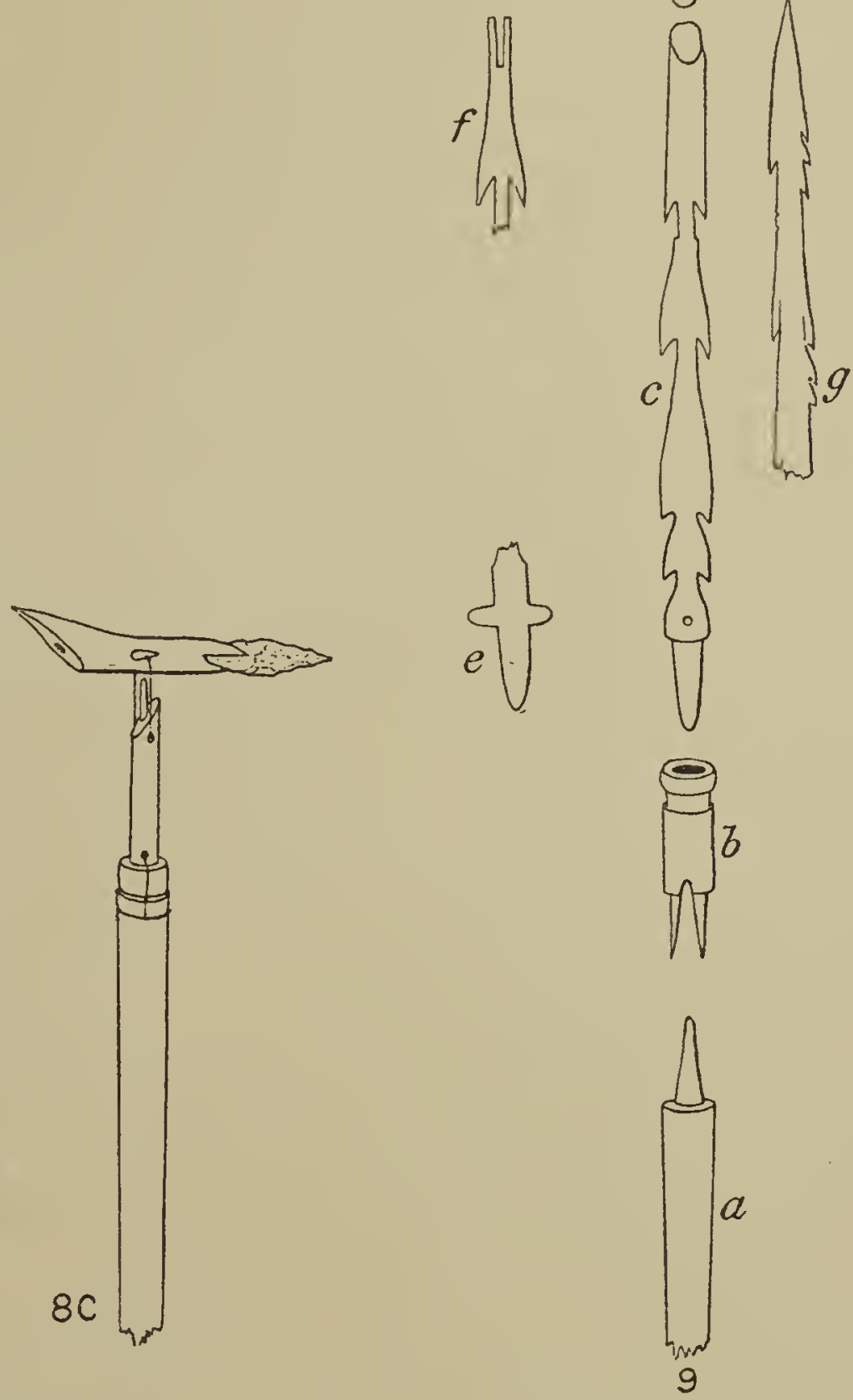

FIG. 9.-Sections of throwing-lance.

regard the bone heads of implements of the latest Palæolithic period of Western Europe as harpoon-heads. The present writer believes that most of these were not harpoon-heads, but heads of throwing-lances or arrows, i. e., that they were permanently tied to the shaft. We refer particularly to the heads ascribed to the Magdalenian and Azilian epochs, which were attached to the shaft by means of projections above the tang, or the tang had a conical and not a flat form. ${ }^{5}$

${ }^{5}$ See J. Déchelette, Manuel d'Archéologie, Vol. I, Archéologie Préhistorique, Paris, I908, fig. 57, p. I53; M. Hoernes, Natur und Urgeschichte des Menschen, B. II, figs. 77, 78, pp. I59, I60, Wien, I909; H. Obermaier, Prehistoric Man (Russian translation from German), Petrograd, I9I3, figs. I22, I32, I35, pp. 227, 242, 24I. 
The bone head of a throwing-lance usually terminates in a stone blade or point $(d)$. In this case, the tang of the stone blade may be inserted in a slit of the barbed bone head $(f)$ or fastened to it by means of a spoon-like socket. In both cases the stone blade is parallel to the plane of the barbs. The second method of attaching the stone blade to the bone head predominates (figs. 53, 54) and may be regarded as an Aleut invention, since it has not been reported from any other people. The tang of the stone blade is fastened by fish-glue before binding. Sometimes the bone head of a throwing-lance is pointed at the top $(g)$ and has no stone blade.

\section{SOURCE MATERIAL FOR STONE IMPLEMENTS.}

As has been stated in the introduction, we are under obligations to Professor W. A. Obruchov for the determination of the minerals from which Aleut stone implements were manufactured, and in addition for an indication of the comparative hardness of the minerals. Professor Obruchov prepared a list of the minerals in the order of their diminishing hardness, as shown by knife tests. His list follows:

(I) Very hard, corresponding to No. 7 of the mineral- 1 - (4) Soft, corresponding to No. 3 of the mineralogical ogical scale.

(2) Hard, corresponding to No. 6 of the mineralogical scale.

(3) Medium-hard, corresponding to No. 4 of the

(5) Very soft, corresponding to No. 2 of the mineralogical scale.

Nos. I and 2 can not be scratched by the blade of a steel knife, which leaves a gray metallic streak, as on flint. No. 3 may, with difficulty, be very slightly scratched with a steel blade. A deeper impression can be made on No. 4 without difficulty with a steel knife; No. 5 is easily scratched with a steel knife.

\section{MINERALS LISTED ACCORDING TO THE DETERMINATION OF THEIR HARDNESS. ${ }^{6}$}

No. I.-(I) Hornstone schist; *(2) hornstone schist with thin veins of quartz; (3) quartz schist; (4) quartzite; (5) opal; (6) semi-opal; (7) chalcedony (agate) with quartz and carnelian; *(8) hematite with quartz, epidote, and chlorite.

No. 2.-**(9) Andesite, very glassy, with very small porphyritic crystals; *(Io) obsidian, andesitic; *(II) lava (andesitic), very glassy and vesicular; *(I2) quartz diorite, microgranular, with a hornblende altered in a green brown stuff;*(I3) augite andesite; *(I4) enstatite augite andesite; *(I5) felsite spherulitic, banded, brick red; $*$ (I6) tuff of porphyrite, silicified.

No. 3.-(I7) Andesitic lava, altered; *(I8) diabase porphyrite, altered; (I9) quartz limestone (hard marble). Nos. 3 or $4 .^{7}-*(20)$ Tuff of andesite; (2I) hornstone marl.

No. 4.-*(22) Quartz slate, very fine granular; *(23) tuff of tachylite (basaltic, glassy); (24) marble; *(25) porphylite, a form of andesite altered by volcanic action; *(26) serpentine of an antigorite type.

No. 4 or $5 .^{7} \ldots(27)$ Slate containing a volcanic stuff.

No. 5.-(28) Slate; (29) red ocher; (30) white volcanic tuff similar to the sinerite of Auvergne, France.

In describing stone objects, the number of the mineral as given in the list above will be appended, as well as its degree of hardness. The hardness of the mineral is an important factor in the determination of its ultimate ise. For instance, stone hammers for chipping arrow or lance heads, stone knives or adzes, or stone adzes for use in the manufacture of bone objects, are of the hardest minerals, of hornstone or quartz-schists. Andesite (No. 9) was most frequently used by the Aleut for stone implements. This took the place of flint, a much harder material. Of all

- Those minerals of which slides were made for microscopic study by Professor Obruchov are marked by asterisks (*). The slides were made by Mr. O. W. Knyrko, preparator of the Mineralogical Museum of the Academy of Sciences in Petrograd.

7 Independency of alteration as a result of weathering. 
the stone implements excavated on the Aleutian Islands, numbering over $\mathrm{I}, \mathrm{OOO}$, not a single one of flint was found. It may be concluded, therefore, that chalky deposits in which concretions of veins of flint occur are lacking on the Aleutians. ${ }^{8}$ Andesite, although not as hard as flint, has a conchoidal cleavage and gives a sharp cuttingedge, and is, therefore, an available material for manufacturing stone implements.

Soapstone, of which the Eskimo usually make lamps and kettles, was not used among the Aleut. However, Chamisso found kaoline porphyry which may be altered into steatite, ${ }^{\circ}$ between Unalaska and Makushin villages on Unalaska Island.

The Eskimo prefer soapstone as lamp material. It is readily carved, has no cracks, lends itself to a high degree of surface finish, and retains heat. Fat is easily melted in a soapstone lamp. Where steatite only is available, the Eskimo use it for manufacturing lamps. The Central Eskimo, according to Professor Boas (The Central Eskimo, p. 469), undertake long journeys in search of soapstone, which is found only in a few places and seldom in quantities sufficient for manufacturing lamps and cooking vessels (see Holmes, Handbook of Aboriginal American Antiquities, Part I, Introductory, The Lithic Industries, Washington, I9I7, p. 228). This is also true of Alaska. Soapstone has been one of the most valuable and important objects for barter (see Hough, The Lamp of the Eskimo, Report of the U. S. National Museum for I89I, p. I03I). The Eskimo of Baffin Land and Hudson Bay also manufacture their lamps and kettles of steatite (Boas, The Eskimo of Baffin Land and Hudson Bay, Bulletin American Museum of Natural History, New York, vol. I 5, part I, I9or, p. 4I). The Aleut, as will be seen, manufactured lamps of harder minerals (see plates I8, I9, and 20). The Kodiak also use harder minerals for lamps (see Hough, 1. c., p. IO32). Sandstone lamps are also used as objects of barter among the Asiatic Eskimo and Chukchee (see Bogoras, The Chukchee, Jesup North Pacific Expedition, Vol. VII, I904, p. I87).

The ancient Aleut recognized and discriminated between the qualities of different minerals and their usefulness for different types of implements. Some of the Aleut terms for minerals were recorded. The general name for stone is nux? Andesite is called $u m g i^{\prime} d a x^{i}$; slate is called $i^{\prime}$ gax ${ }^{i} ;{ }^{10}$ the hard schists (hornstone and quartz schists) are called $a^{\prime} n$.kix; green hornstone schist is called $n u^{\prime}$ gim-cidgay $\bar{u}^{\prime}$, i. e., the green stone; tuff of andesite, uya' $\tilde{n} x^{\prime}$; vesicular andesitic lava, amdi'xtixi; microgranular andesitic lava, cigu'nixi.

According to information received from the Aleut, all the minerals enumerated in the preceding list were obtained by their ancestors on the Aleutian Islands. Thus, boulders of green hornstone-schist, for axes and celts, were brought from Agatu Island by the Attu people; pebbles of the same material were collected on Umnak Island on the shore near the former village of Natxu'kax:. The Atka people went to Siguan Island for andesite and andesitic lava. Only the marble of which the labrets were manufactured was obtained from the Alaskan Peninsula through barter.

(Text continued on p. 59.)

${ }^{8}$ It may be noted that Weniaminoff mentions one chalky deposit on Samalga Island (see Weniaminoff, part I, p. I57).

See O. Kotzebue, Voyage, I815-1818, Vol. III, p. 340, Russian edition.

10 As will be seen later, the woman's flat knife is called iga'dax', the diminutive of $i^{\prime} g a x^{\prime}$, of which material it is usually made. 


\section{Description of Plate I5.}

FIG. I (I3I2). A leaf-shaped knife of andesite, without a handle (hardness 2, No. 9): length, I40 mm., width $48 \mathrm{~mm}$. It had served as a hand weapon in war and in hunting was used to cut up sea mammals. It was called cunu'sixt. As will be seen later, such knives could have no handles. From the village site, Natxu'kax', Umnalk Island.

FIG. 2 (565). Andesite point or blade $\left(k a^{\prime} d a x^{*}\right)$ of a throwing-lance (akagu'six') for sea-lions and seals (hardness 2, No. 9). The lance, akagu'six', was thrown at a sea mammal after the animal had been wounded by a harpoon. From Nani'kax', Attu Island.

FIG. 3 (640). An andesite point of a throwing-lance called in the Atka dialect uga'lux (Hardness 2, No. 9), used for hunting sea-lions and seals. Found in cave 2, Atxa'lax', Atka Island.

Fig. 4 (357). A spear-point like No. 2 (565). From Nani'kax', Attu Island.

FIG. 5 (424). A spear-point of quartz-slate similar to preceding (hardness 4, No. 22). From Nani'kax', Attu Id.

FIG. 6 (I555). A fragment of an andesite knife called cunu'six' (see No. I, I3I2). Found at a depth of 2.5 meters at Pit I, Uglu'dax', Umnak Island.

Fig. 7 (1314). A semicircular knife of andesite (hardness 2, No. 9), length 9I mm., width $55 \mathrm{~mm}$., which had served also as a scraper and saw. From Natxu'kax', Umnak Island.

FIG. 8 (472). A point of an unfinished andesite throwing-lance (see No. 2, 565). From Nani'kax', Attu Island.

FIG. 9 (I293). A fragment of a knife, cunu'six (see No. I, I3I2). From Agla'gax', Umnak .Island.

FIG. Io (872). A point of a throwing-lance of andesite. It differs from No. 2 (565) in that the base is not rounded, but straight. Evidently it had not been inserted in a spoon-like cavity of a bone head, but in its bifurcated upper end. From Hala'ca, Atka Island.

FIG. II (1234). An unfinished andesite point for a throwing-lance used in hunting seals. Length $97 \mathrm{~mm}$., width $30 \mathrm{~mm}$. From Ukix, Umnak Island.

FIG. I2 (I233d). A knife (cumu'six'), fragment (see No. I, I3I2) of andesitic obsidian (hardness 2, No. I0). From Ukix, Umnak Island.

FIG. I3 (I3II). A fragment of a curved carving-knife (umqisi'six') of andesite. From Natxu'kax', Umnak Island.

FIG. I4 (1233). A saw of andesite (hardness 2, No. 9) for cutting bones. Evidently it had had no handle. From Ukix, Umnak Island.

FIG. I5 (I389). A skin-scraper of slate containing volcanic tuff (hardness 4, No. 27). From Ukix, Umnak Island.

FIG. I6 (398). Andesite point of a throwing-lance (see No. 2, 565). From Nani'kax', Attu Island.

FIG. I7 (402). Andesite adze for wood working, called sña'sim iga $\bar{a}^{\prime} .^{12}$ The blade is finely chipped but not polished. From Nani'kax', Attu Island.

FIG. I8. An adze, similar to the preceding. of quartz schist (hardness I, No. 3), for working in bone. From Ukix, Umnak Island.

FIG. I9 (1283). An adze, like the preceding, of green quartz schist, polished. Length $60 \mathrm{~mm}$., width $57 \mathrm{~mm}$. From Ukix, Umnak Island.

FIG. 20 (I472). An adze of green quartz schist with the blade only polished. From Uglu'dax', Umnak Island.

FIG. 2I (996). Point of a war throwing-dart (igi qax $x^{i}$ ) of andesitic obsidian (hardness 2, No. Io). The end of the point is broken off. From Pit 2, Agla'gax', Umnak Island.

FIg. 22 (1029). An andesite point like preceding. From a depth of 5.I meters in Pit 2, Agla'gax', Umnak Id.

FIG. 23 (1973). A curved andesite knife (umqisi'sixi). Such a knife had a bone handle. From Amaknax, on the island of the same name.

FIG. 24. A knife like the preceding, of andesite. Length $76 \mathrm{~mm}$. From Natxu'kax', Umnak Island.

FIG. 25 (I546). An adze (sñ $a^{\prime}$ sim-ig $\bar{a}^{\prime}$ ) of green quartz schist. The blade is polished. Found at a depth of I.5 meter in Pit I at Uglu'dax', Umnak Island.

Fig. 26 (2097). A small unfinished ax of green quartz schist. Length II5 mm. Found at a depth of 3 meters, at Tanaxta'xax', Amaknak Island.

FIG. 27 (I998). An andesite knife which had originally had a wooden or bone handle. From Natxu'kax', Umnak Island.

FIG. 28 (I I25). A curved knife of andesite (see No. 23). Length, $74 \mathrm{~mm}$. From Natxu'kax', Umnak Island.

FIG. 29 (1296). A fragment of an adze of green quartz schist with a polished blade. From Agla'gax', Umnak Id.

FIG. 30 (I2I4). A chisel of green quartz schist with polished blade. Length $45 \mathrm{~mm}$., width $22 \mathrm{~mm}$. From Pit 3 , Ukix site, Umnak Island.

FIG. 3I (I976). Andesite point of a toggle-head harpoon. From Amaknak village site, Amaknak Island.

FIG. 32 ( I477). A curved knife of andesite with a broken point. From Uglu'dax', Umnak Island.

FIG. 33 (1222). A knife similar to No. 32, of volcanic andesitic tuff (hardness 3. No. 20). Ukix, Umnak Island.

FIG. 34 (925). A fragment of an andesitic adze used for wood working. Though the adze is not polished, it is finely chipped (see No. I7). From Cave 2, Atxa'lax', Atka Island.

FIG. 35 (1286). A small polished adze of green quartz schist. Length $44 \mathrm{~mm}$., width $37 \mathrm{~mm}$. From Ukix, Umnak Id

FIG. 36 (1285). A curved carving-knife (umqisi'sixi) of andesite. Length II2 mm., width $30 \mathrm{~mm}$. From Agla'gax', Umnak Island.

FIG. 37 (1475). An andesite knife similar to the preceding, but without a projection for securing it to a handle. However, we were informed by the Aleut that the back of the knife was inserted in a wooden handle. Length $95 \mathrm{~mm}$., width $40 \mathrm{~mm}$. From Uglu'dax', Umnak Jsland.

Fig. 38 (1476). A curved knife of andesite. Length $65 \mathrm{~mm}$., width $36 \mathrm{~mm}$. From Uglu'dax', Umnak Island.

FIG. 39 (994). Unfinished point of andesitic obsidian for a small toggle-head harpoon (hardness 2, No. I0). From Pit I, Agla'gax', Umnak Island.

FiG. 40 (I982). A fragment of an andesite knife. From Amaknak, Amaknak Island.

FIG. 4I (406). An adze of green quartz schist (hardness I, No. 3), with polished blade. From Nani'kax', Umnak Id.

$12 S \tilde{n} a^{\prime} \operatorname{sim} i g \bar{a}^{\prime}$ means "stone of the ax," from sña'six', ax or adze, with a wooden handle, and $i^{\prime} g a x^{*}$, stone of slate. Axes and adzes were made chiefly of quartz and hornstone schists. 


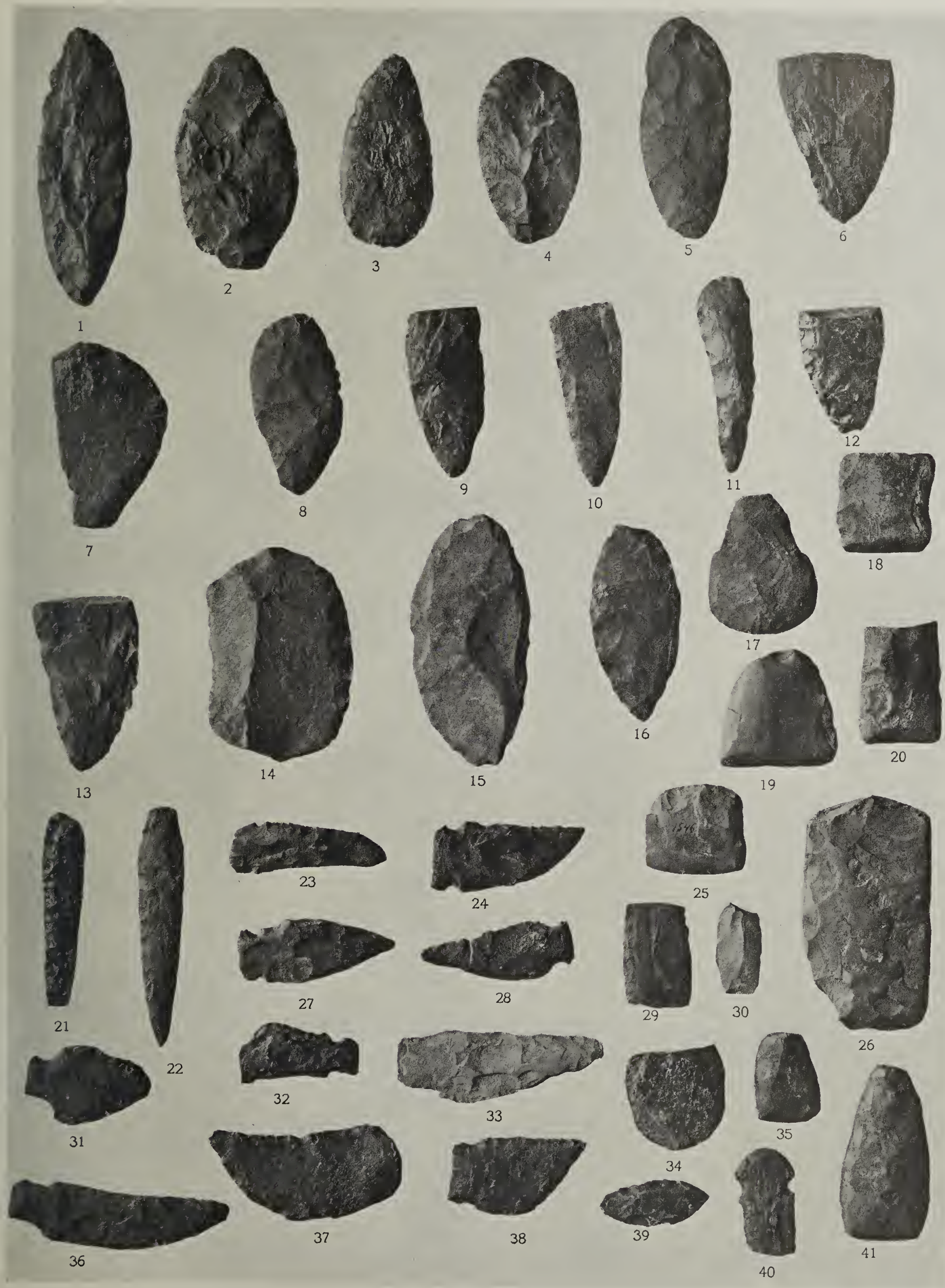



Doctor Dall states that "there is hardly any stone on the islands, such as serpentine, fit for making celts or adzes," and that "in only one case, that of a comparatively modern, though prehistoric, burial place, has one adze or celt been found in the Aleutian Islands." "We have shown that on the islands may be found harder minerals than serpentine for making implements, which is fourth with reference to hardness in our list. That many stone adzes, chisels, and some axes were found will be seen in the descriptions of the plates and drawings. Dall says, further, that no grooved axes or hammers were found. This is true only with reference to axes (plate I7). The fact that grooved axes were not found, may be explained, not by lack of skill to manufacture them, but by lack of need for this type of implement. There are no standing trees on the islands, and bone wedges and stone hammers suffice for splitting driftwood.

For polishing stone and bone implements, the Aleut used andesitic lava, evidently because of the absence on the islands of pumice or rhyolitic lava, which is a better polishing-material than andesitic lava.

It is of interest to note that the Aleut prefer andesitic minerals for their implements to the more ancient volcanic rocks of the basaltic series, although basalt is found on many of the islands.

Red ocher and white volcanic tuff (Nos. 29 and 30 in the list of minerals) were often found in the excavation of ancient dwellings, and served as paint materials. In some sections, pieces of red felsite (No. I5) occurred, but nowhere were implements of this material found. We were told that felsite, when powdered and mixed with oil, furnished an excellent lasting paint. More frequently than felsite were found pieces of hematite (No. 8) which evidently had some religious significance. It was called a'xsix', a term applied to all objects supposed to have miraculous power. The present-day Aleut call hematite, ca'gax'. Pieces of hematite were worn by every hunter, for they were said to have the power of attracting sea mammals, and particularly whales.

\section{STONE IMPLEMENTS AND WEAPONS.}

Descriptions of the objects excavated will be given in the order of their appearance on the plates. The material has been arranged according to types of specimens rather than by locality in order to obtain a clearer view of Aleut culture. For the same reason the drawings in the text follow the same order as the plates. In the following description of plates the specimens will be given their designation as in the plates, followed by the field number or that under which they are at present to be found in the Rumiantzeff Museum in Moscow.

Text-figures Io to 26 should be considered in connection with the specimens illustrated in plate 15 .

(Text continued on p. 67.)

11 See Dall, On Succession of Shell-Heaps on the Aleutian Islands, p. 83. 

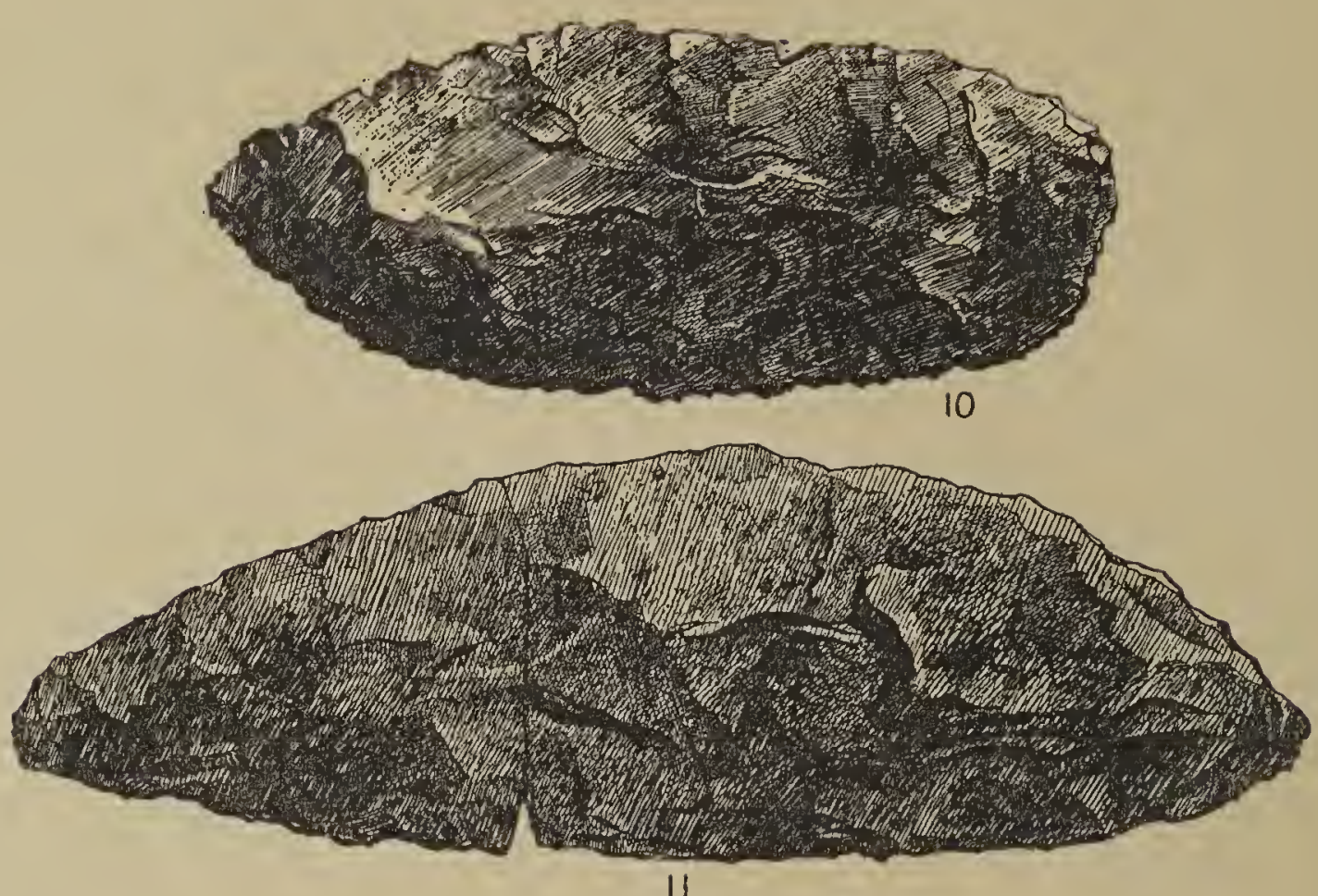

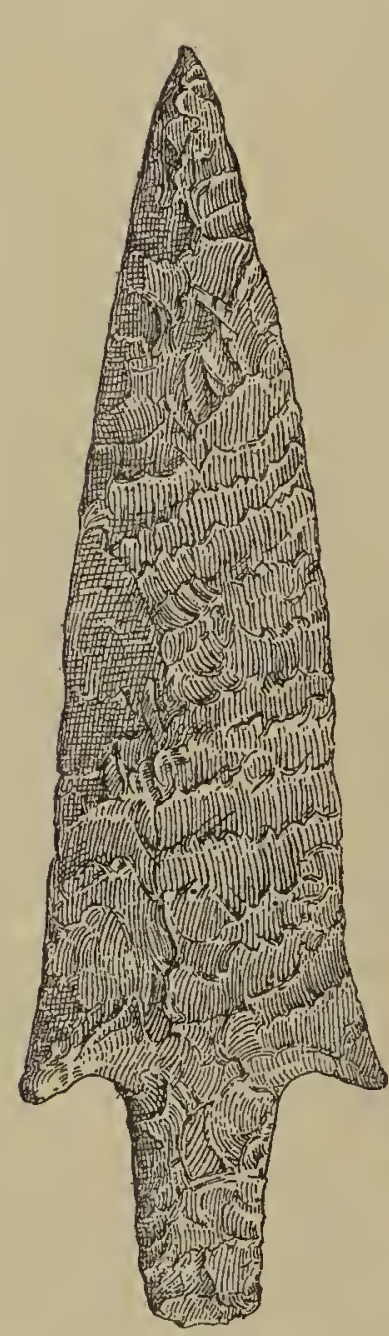

13

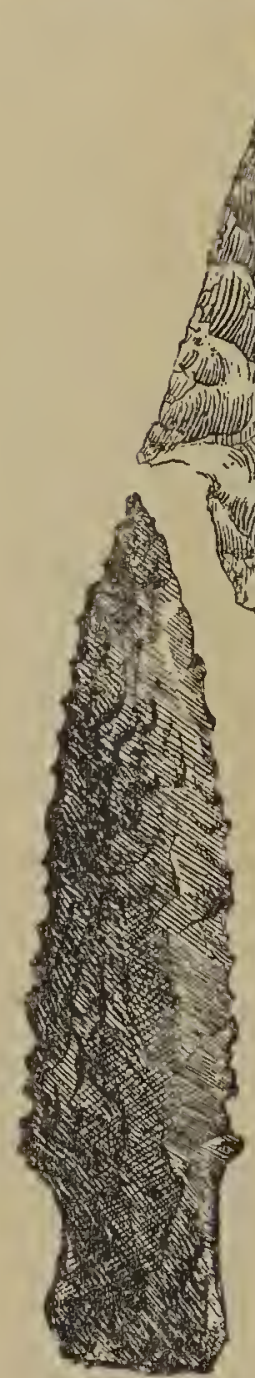

14

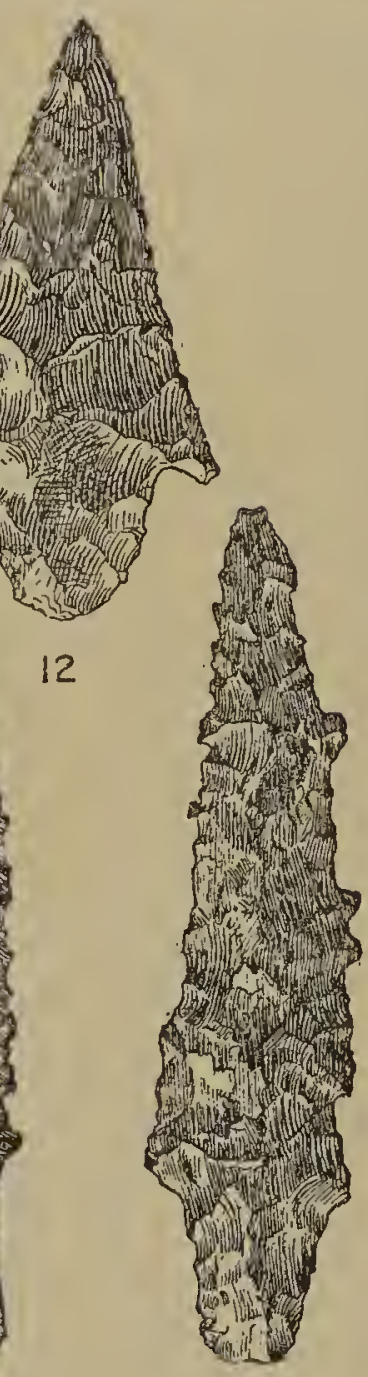

15

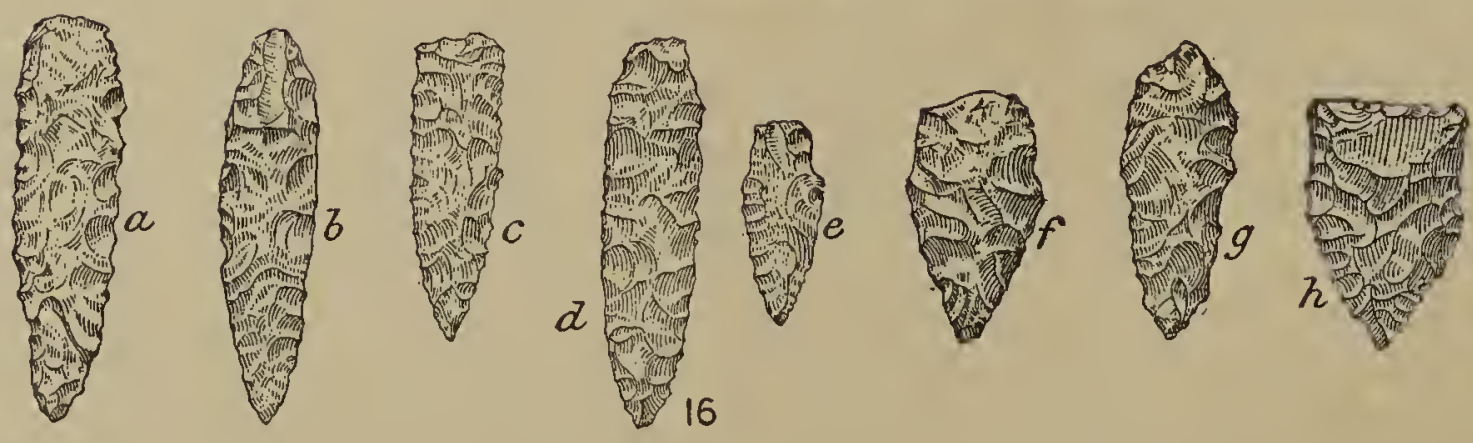


Text-Fig. Io (540). Andesite (hardness 2, No. 9) point of a throwing-spear (igi'qax') used in hunting large sea mammals. It is roughly chipped and carelessly trimmed to produce the saw-like edges, which cause a lacerated wound. Its form is reminiscent of the Acheulean weapons of western Europe. From Sin, Attu Island.

TEXT-FIG. II (860). Andesite point of a throwing-spear used for hunting sea-lions and whales. Its form is like that of a knife (cunn'sixi) but the old Aleut informed us that it is the blade of a throwing-spear made by an unskilled worker. It is roughly worked up with unequal sides. Found broken at Hala'ca, Atka Island.

Text-FIG. I2 (447). Point of a war throwing-spear made of hornstone schist with a thin vein of quartz (hardness I, No. 2). It is carefully chipped, the edges are well trimmed, and it has barbs projecting backward and a rounded stem. From Nani'kax', Attu Island.

TEXT-FIG. I3 (220). A point similar to figure 12, but larger. It is of greenish-brown hornstone schist (hardness I, No. I). Found in the cave of Goltzef Bay, Attu Island.

TEXT-FIG. I4 (I53I). An andesite point similar to the preceding, more roughly made, not carefully trimmed, and with serrated edges. Found in Pit 4 at Uglu'dax', Umnak Island, beneath the kitchen remains on the clayey undisturbed soil.
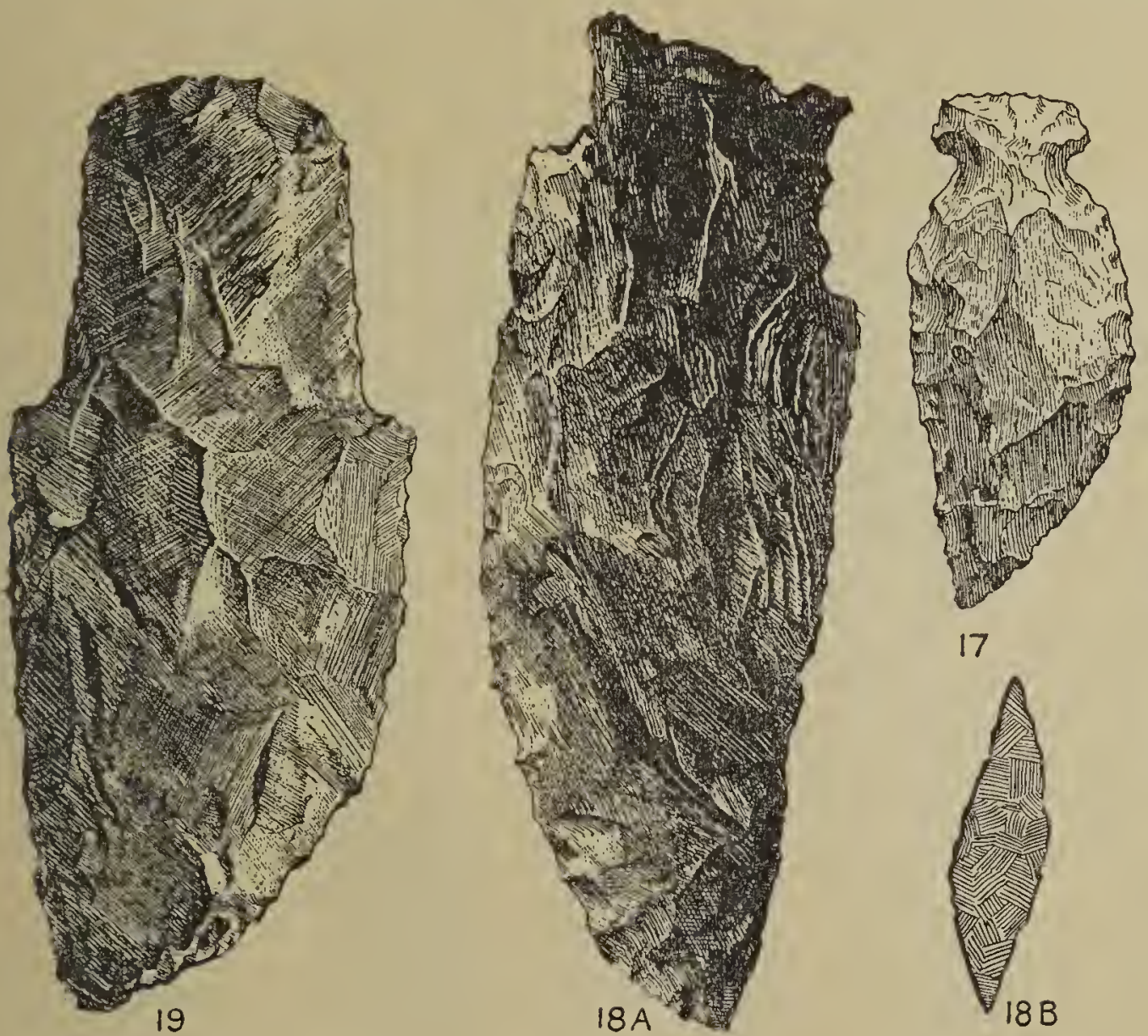

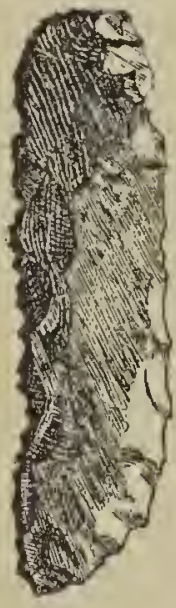

20

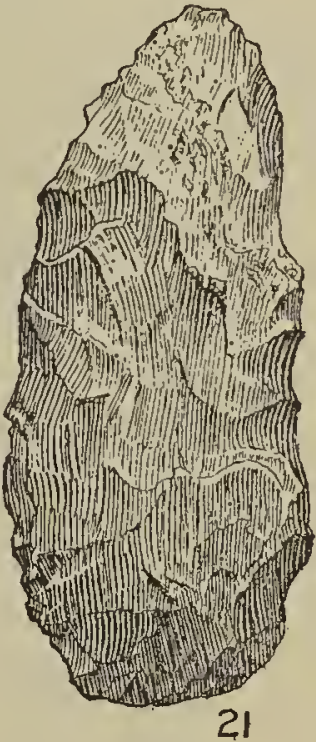

21

TEXT-FIG. I5 (I9I2). An andesite point with serrated edges made for causing a lacerated wound. Found at a depth of 4 feet at Amaknax, on Amaknax Island.

Text-FIG. I6 $(a$ to $h) .(a, 830)$ a point of andesite for a harpoon called akagu'six'. From Hala'ca, Atka Island. $(b, \mathrm{I} 290 ; c, \mathrm{I} 54 \mathrm{I}$, and $d, \mathrm{I} 29 \mathrm{I})$ are lancets for bleeding (uxtu'sin, plural of $u x t u^{\prime}$ six $^{\prime}$ ) of andesitic obsidian with sharp edges. ${ }^{13}$ They were used by ancient Aleut surgeons or curers without a handle. Found on Umnak Island, $b$ and $d$ at Ukix and $c$ in Pit $4, U_{\text {glu'dax }} \cdot e, 1294 ; f, 1535 ; g$, 995, and $h$, 2103 ) are points of arrow heads for a bow (sa'yigim agada'gan kada'nin). $e$ is opal; $f, g$, and $h$ are made of andesitic obsidian. $e$ was found at Amaknax, Amaknax Island; $f$ at Uglu'dax', Umnak

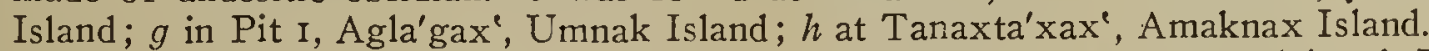

TExT-FIG. I7 (1066). A small curved knife (umqisi'six) of andesite. From Pit 2, Agla'gax', Umnak Island.

Text-Fig. I8 (765), $A, B$. $A$ is a large curved knife (umqisi'six') of andesite, with a short bone handle attached to the stem of the knife. It had served as a tool for working in wood or bone and for cutting up sea mammals. In fighting it was used like a dagger. The straight back of the dagger was sharpened like the curved side and, like all other curved knives, it is two-edged. $B$ is the transverse section through the middle. Found in Cave 2, Atxa'lax', Atka Island.

Text-FIG. I9 (64I). An andesite knife similar to the preceding, but somewhat shorter and with a rounded stem like that of the stone point of a war throwing-spear (see fig. 12). Found in Cave 2, Atxa'lax', Atka Island.

\footnotetext{
13 For comparison, see H. Newell Wardle, Stone Implements of Surgery from San Miguel Island, Cali-
} formia (American Anthropologist, vol. 15, No. 4, 1913, pp. 656-660). 
TeXt-FIg. 20 (644). Unfinished point of a throwing-spear. Found in the same place as figure I8.

TEXT-FIG. 2I (I98I). Unfinished knife of white chalcedony with specks of red carnelian and quartz crystals (hardness I, No. 7). Amaknax Site, Amaknak Island.

TEXT-FIG. 22 (2I06). A small knife of dark-green hornstone schist almost as hard as flint. It was used for cutting and carving bone. The back is thicker than the nicely trimmed blade and well polished. Found at a depth of 2.4 meters at Tanaxta'xax', Amaknax Island.

Text-FIg. 23, $A, B . A$ (I473), an andesite adze used for working in wood. From Uglu'dax', Umnak Island. $B(576)$, the upper part of an andesite adze. It has two notches on the top for fastening to the handle in transverse positions. From Sin, Attu Island.
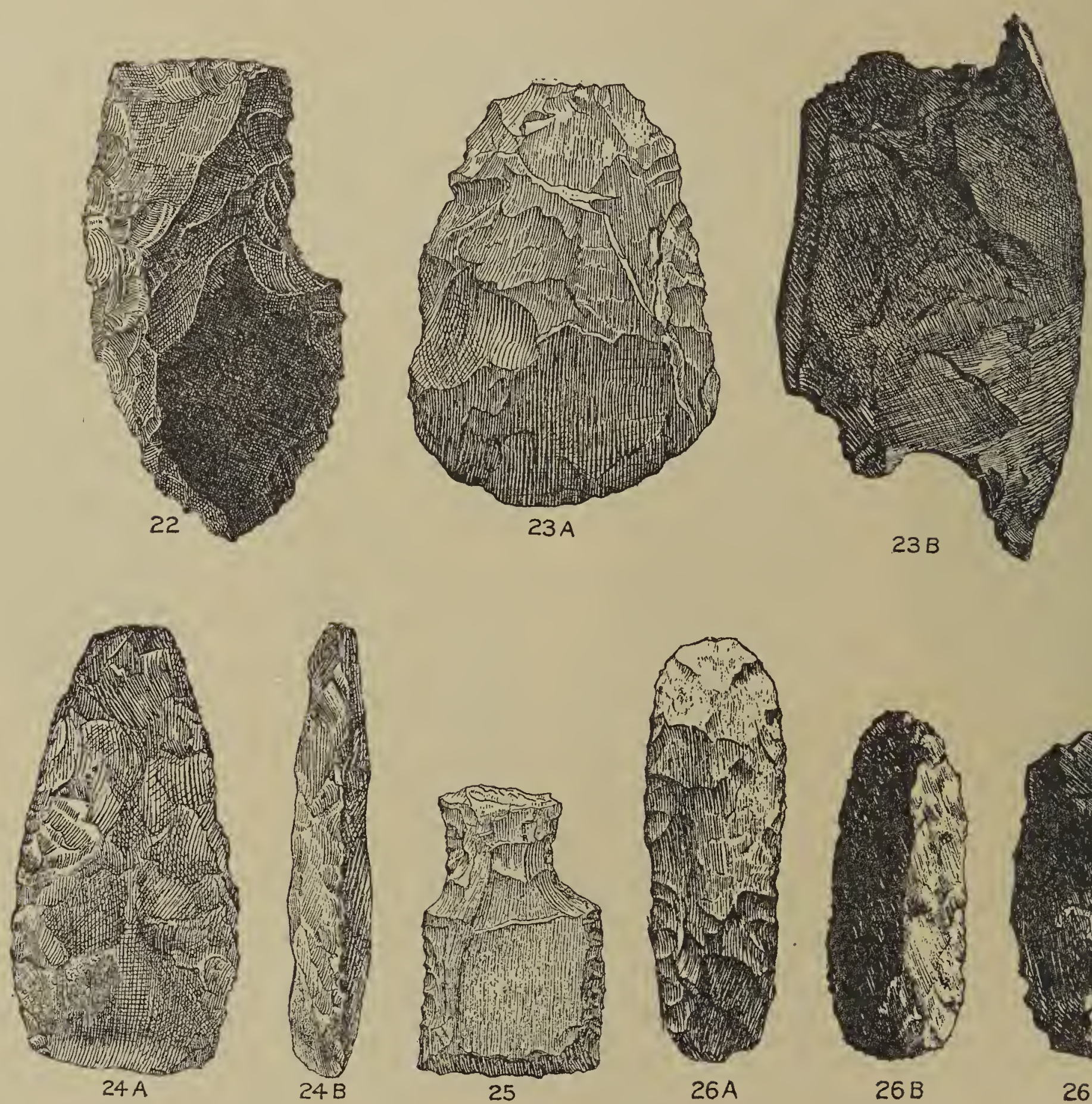

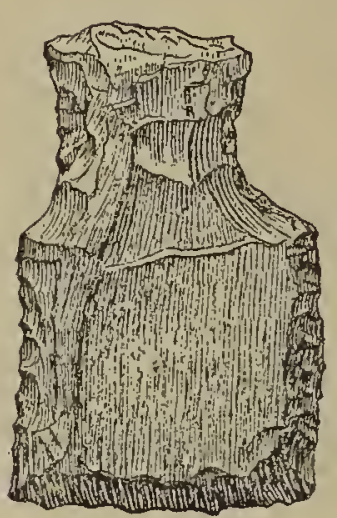

25

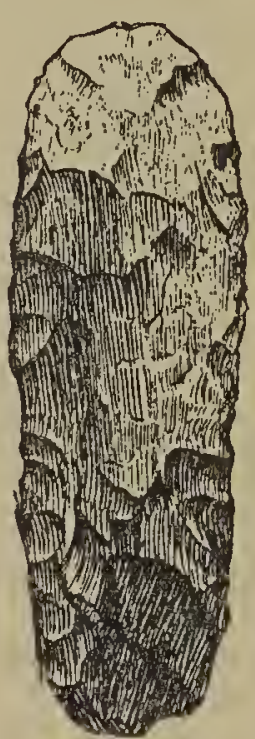

$26 \mathrm{~A}$

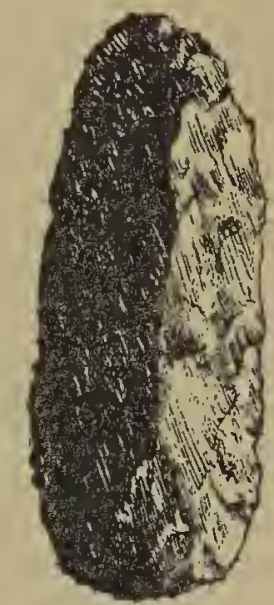

$26 B$

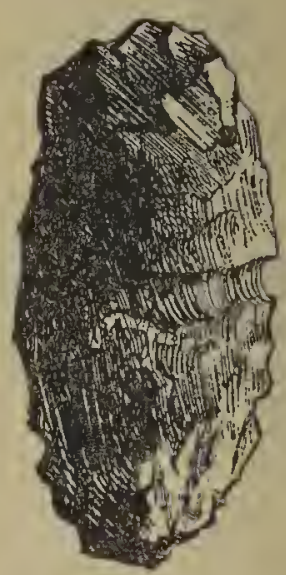

$26 \mathrm{C}$

Text-Fug. 24 (406). An adze of hornstone schist (hardness I, No. I), with a polished blade. A, front; B, side view. From Nani'kax', Attu Island.

TExT-FIG. 25 (2995). A small unfinished adze of silicified porphyritic green tuff. The edges are finely chipped and the sides polished. Found at a depth of I meter at Tanaxta'xax', Amaknax Island.

TEXT-FIG. 26 ( $A$ to $C$ ). Three andesite chisels used for planing wood, called Ya'gam-ñan agu'six', $i$. e., "tool for working in wood." With this tool were made shafts for weapons and instruments and frames for skin boats. These tools had no handles and are finely chipped on all edges. $A$ (I534) was found at Uglu'dax', Umnak Island; $B$ (I22I) was found at Ukix, Umnak Island; $C$ (I984) was found at Amaknax, Amaknax Island. 
The following text-figures all refer to the objects shown in plate i6:

Text-fig. 27 (I377). Fragment of a woman's tailoring knife (iga'dax') of hornstone schist, with a drilled hole, for fastening to a wooden handle. Ukix. Umnak Island.

TEXT-Fig. 28 (439). Fragment of a woman's slate tailoring knife (hardness 5, No. 28). The dotted line shows the size of the entire knife with a wooden handle fastened to it. This type of knife was used by women for cutting hides and leather for clothing and footwear. From Nani'kax', Attu Island.

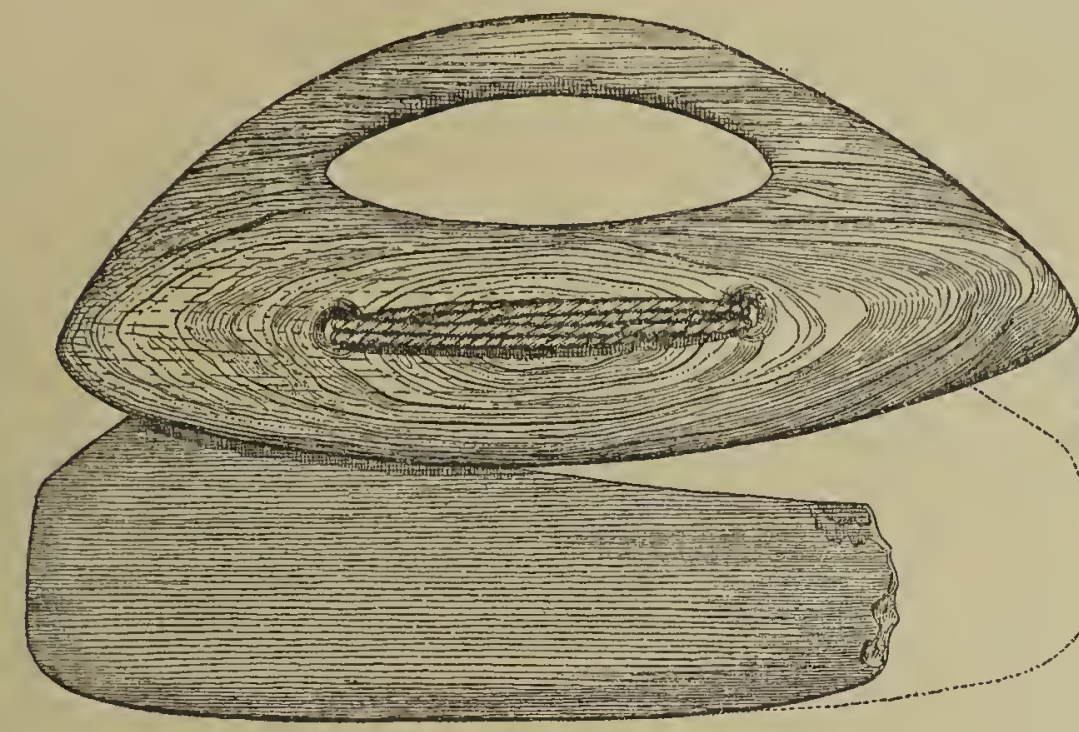

28
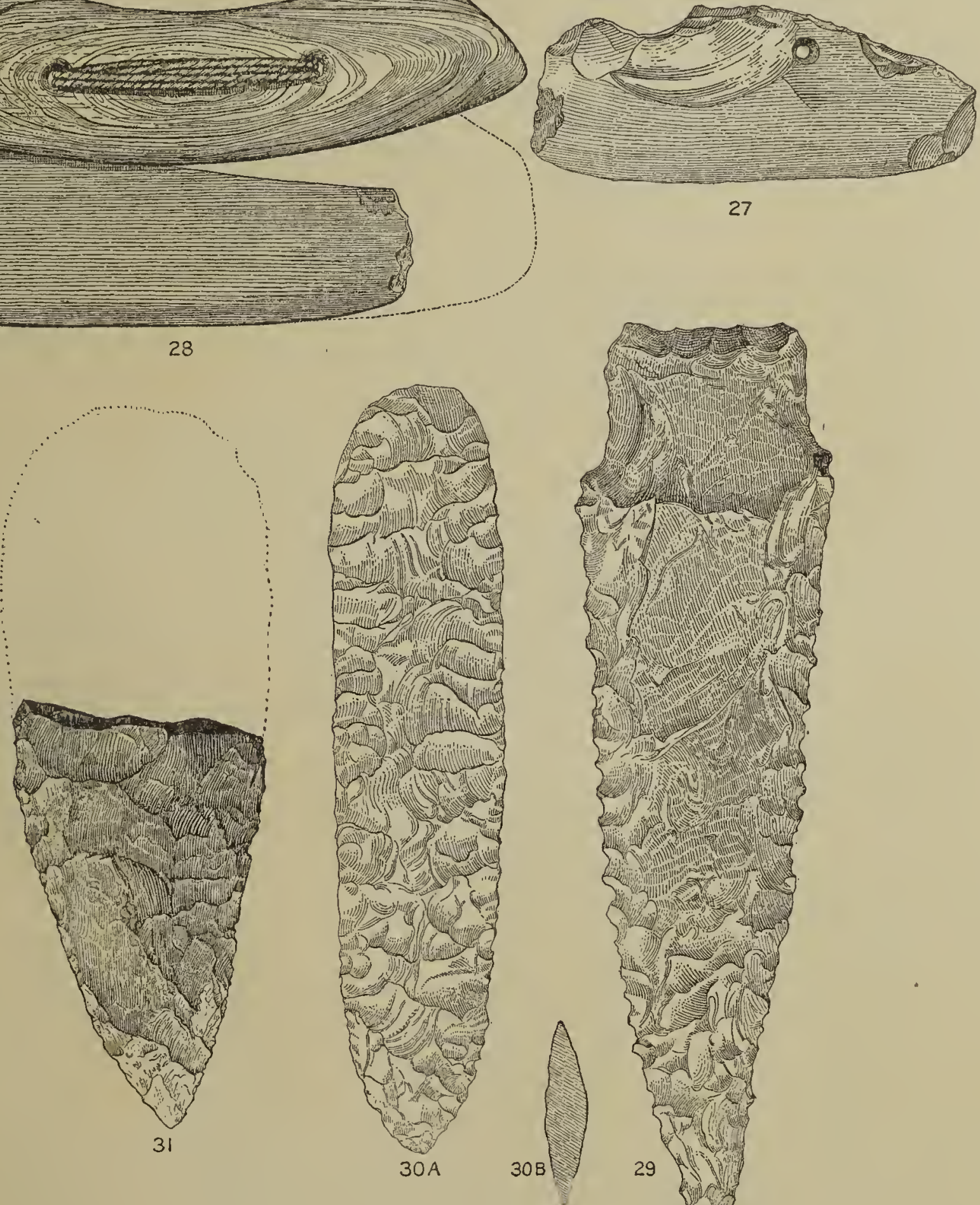

27

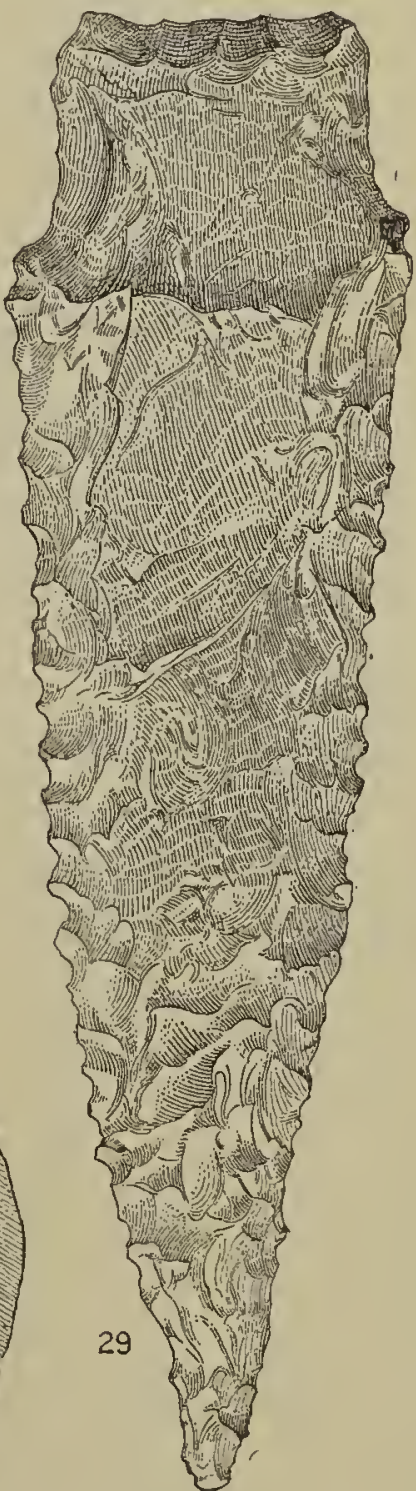

TEXT-FIG. 29 (1854). Andesite knife (cun $u^{\prime}$ six $\left.^{2}\right)^{14}$ with serrated edges. This type of knife had a short handle. From Uglu'dax', Umnak Island.

TEXT-FIG. 30 (218) $A, B$. $A$, knife (cunu'sixi) used without a handle and made of dark-brownish hornstone schist, with thin veins of quartz (hardness I, No. 2); $B$, transverse section of middle of this knife. Found in the cave at Holtzef Bay (see plate 7, fig. 6), Attu Island.

TEXT-FIG. 3 I (876). Fragment of a knife (cunu'six $\left.{ }^{*}\right)$ used without a handle. The dotted line, showing the probable missing portion of the knife, has been drawn in accordance with directions by the Aleut. From Hala'ca, Atka Island.

14 See above, p. 60. 


\section{Description of Plate i6.}

FIG. I (848). Fragment of a man's large knife of andesite, called $u t u^{\prime} q n u x^{*}$. This type of knife was used for any work in wood. The Aleut who assisted in the excavations were of the opinion that the knife was inserted into a wooden handle. Its unusual width was explained by the desire to use it for a long time, since it would be continually ground off when being sharpened. The knife is polished, particularly at the blade. It was found in two pieces which were later glued together. From Hala'ca, Atka Island.

Fig. 2 (1965). A fragment of a ground knife $\left(u t u q^{\prime} n u x^{*}\right)$ of andesite. From Amaknax, Amaknax Island.

FIG. 3 (222). Fragment of a knife similar to the preceding. In the Attu dialect a large knife is called qama'xtix', and a small one, $m a^{\prime} g y i x^{2}$. This type of knife was used chiefly for cutting food-fish, seals, octopi, etc. Found in the cave at Holtzef Bay (see plate 7, fig. 6), Attu Island.

FIG. 4 (2011). Fragment of an andesite knife $\left(u t u^{\prime} q m u x^{\circ}\right)$. Found at a depth of 7 feet 9 inches at Xata'cxan, Amaknax Island.

FIg. 5 (735). Man's knife, utu'qnux', like figure I, but of quartz slate (hardness 4, No. 22). It is polished all over. Slate is more easily polished than andesite. Found in Cave 2, Atxa'lax', Atka Island.

Fig. 6 (920). Fragment of an andesite knife reminding one of a woman's knife ( $\left.i g a^{\prime} d a x^{\prime}\right)$. At the top are traces of perforations by which it may have been attached to a wooden handle. Found in digging a kitchen garden at Captain Bay, Unalaska.

FIG. 7 (2014). Fragment of an andesite knife, evidently a woman's knife, judging by the trace of a perforation in the middle. Found at a depth of 2.4 meters at Xata'cxan, Amaknax Island.

Fig. 8 (849). Fragment of a knife similar to figure I and made of green quartz slate (hardness 4, No. 22). From Hala'ca, Atka Island.

FIG. 9 (2086). Fragment of an andesite knife similar to No. I, which has been ground off from sharpening. Found on Hog Island.

FIG. Io (1966). Two-bladed knife of slate containing volcanic tuff, polished. The stem, which had been attached to a bone handle, is broken off. From Amaknax, Amaknax Island.

FIg. II (1982). Knife, similar to the preceding, of slate containing volcanic tuff. Length $\mathrm{I}_{3} 6 \mathrm{~mm}$. From Pit $\mathrm{I}$, Agla'gax', Umnak Island.

FIG. I2 (734). Knife of quartz slate with a rounded blade, reminding one of a woman's knife. From Cave 2, Atxa'lax', Atka Island.

FIG. I3 (735a). Slate (hardness 5, No. 28) knife similar to figure I. From Cave 2, Atxa'lax', Atka Island.

FIG. I4 (1383). Fragment of a woman's knife of slate, with a perforation made by drilling for attaching to a handle. Ukix, Umnak Island.

FIG. I5 (358). Fragment of an andesite knife, similar to figure 2. From Nani'kax', Attu Island.

FIG. I6 (I224). Woman's slate knife $\left(i g a^{\prime} d a x^{\circ}\right)$. Length $137 \mathrm{~mm}$. From Ukix, Umnak Island.

FIG. I7 (I292). Man's andesite knife. The straight stem was inserted in a wooden handle; the point is unfinished. The Aleut give it the same name as the two-pointed knife in plate I5, figure I, cunu'six'. Length I22 $\mathrm{mm}$., greatest width $47 \mathrm{~mm}$. From Agla'gaxi, Umnak Island.

FIG. I8 (II63). Knife similar to the preceding, finished. Length $134 \mathrm{~mm}$., width $49 \mathrm{~mm}$. Ukix, Umnak Island.

FIG. I9 (763). Andesite blade of the head of a throwing-lance. Found at a depth of 2.8 meters in Cave 2, Atxa'laxe, Atka Island.

FIG. 20 (I456). Whetstone of andesitic tuff, for grinding and polishing bone foreshafts and heads. The Aleut call it cumli'six'. From Ukix, Umnak Island.

FIG. 2I (I342). Unfinished andesitic point of a throwing-lance. From Agla'gax', Umnak Island.

FIG. 22 (67I). Tool for softening skins (Aleut, cigu'nix ${ }^{\prime}$ ) of micro-vesicular andesitic lava. From Cave 2, Atxalax, Atka Island.

FIG. 23 (2024). Whetstone of micro-vesicular andesitic lava for polishing stone implements. From Xata'cxan, Amaknax Island.

FIG. 24 (1225). Fragment of a woman's knife of andesitic tuff. From Ukix, Umnak Island.

FIG. 25 (506). Piece of andesitic lava, glassy and coarse vesicular, used for a rude preliminary polishing of stone and bone implements (hardness 2, No. II). From Nani'kax', Attu Island.

FIG. 26 (I3I5). Implement of andesite with a rounded fine chipped blade which had evidently served as a scraper. Length $92 \mathrm{~mm}$., width $60 \mathrm{~mm}$. From Natxu'kaxi, Umnak Island.

FIG. 27 (I287). Curved andesite knife. Length I $23 \mathrm{~mm}$., width $34 \mathrm{~mm}$. From Ukix, Umnak Island.

FIG. 28 (355). Point of a throwing-lance made of quartz schist (hardness 7, No. 3). From Nani'kax', Attu Island. 


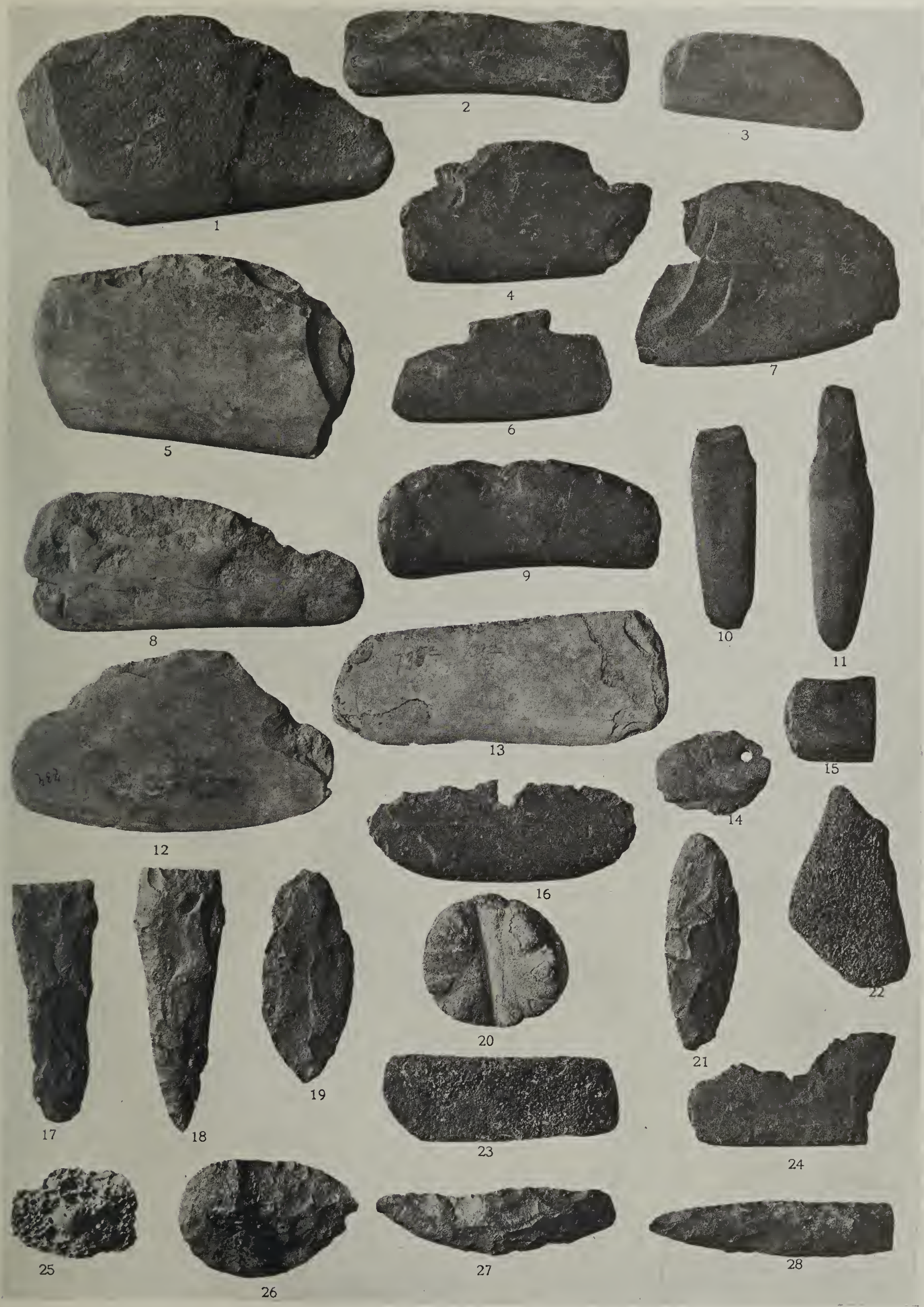

Knives and other implements of stone. About two-fifths natural size. 


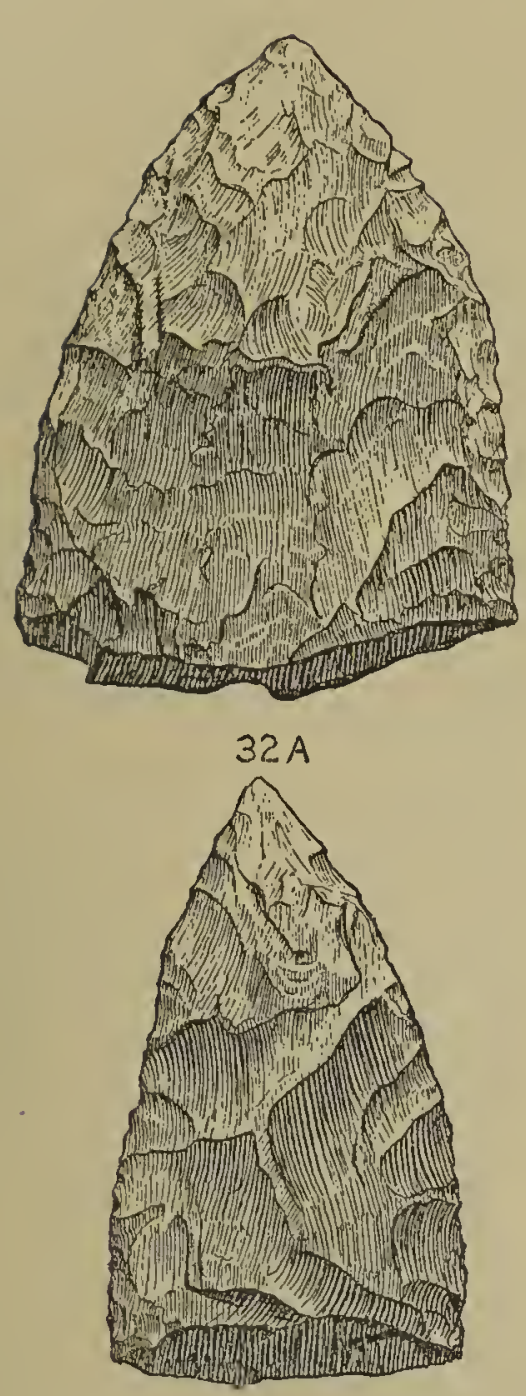

$32 B$

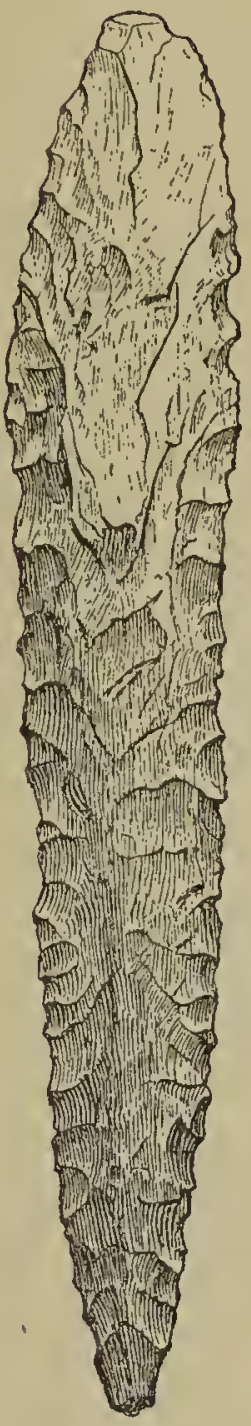

33

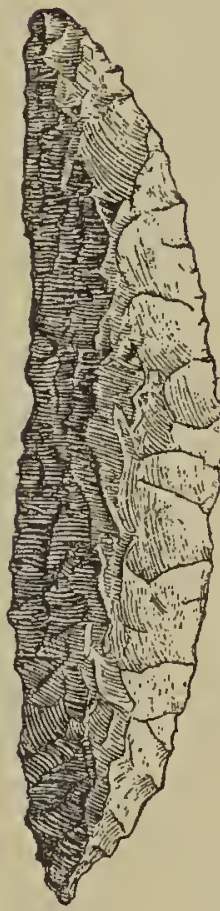

$34 \mathrm{~A}$
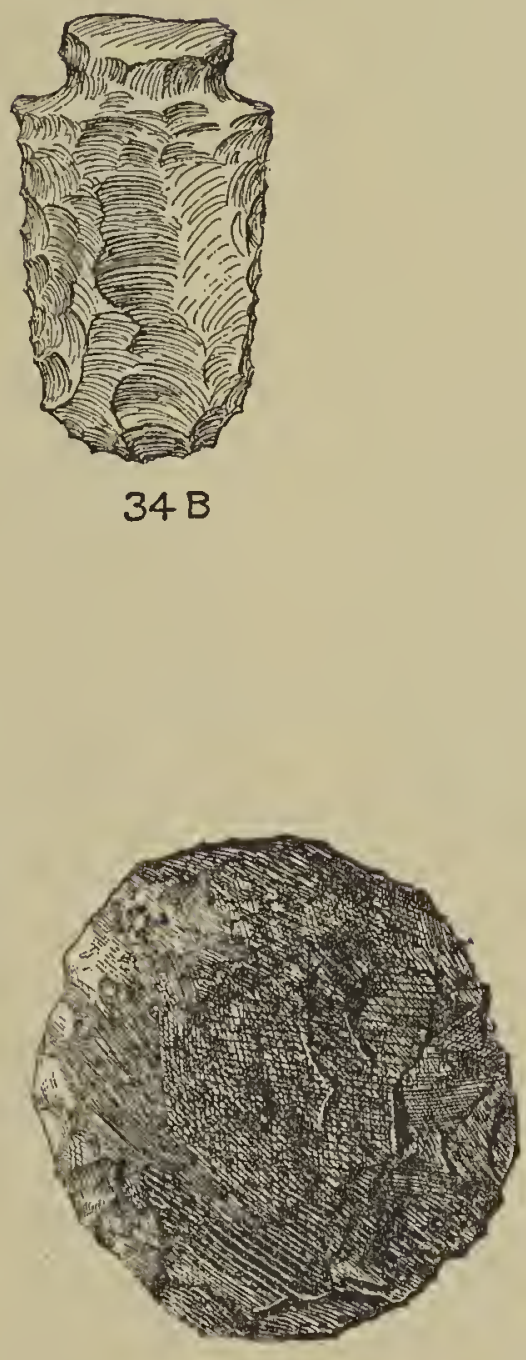

35

TEXr-FIG. $32 A$ (I23I) and $B$ (I233). Fragments of man's knives (cunu'six'). $A$ is of andesite; $B$ is of andesitic obsidian. These knives were used chiefly for cutting up sea mammals, but in war they were used as daggers. The Aleut kept them hidden in the sleeves of their overcoats and produced them when attacked. From Ukix, Umnak Island.

TExr-FIG. 33 (416). Lance-point of hornstone schist (hardness I, No. I). The lance was called qulgu'yax'. This stone point was fastened directly to the wooden shaft. The lance was used both in attacking sea mammals when in their rookeries and men. Found at a depth of 4.7 meters (see p. 26), Pit 4, Nani'kax', Attu Island.

TEXT-FIG. $34(A, B) . A(643)$, in $A$ plement of andesite for sawing small bones. From Cave 2, Atxa'lax', Atka Island. B, small knife with a convex upper end. It had had a bone or wooden handle and was used for cutting off thin longitudinal splints from the leg bones of birds for making awls and needles (see also fig. 66). From Cave 2, Atxa'lax', Atka Island.

TEXT-FIG. 35 (I3I4). Disk-shaped implement of andesite which had evidently been used as a scraper. From Natxu'kax', Umnak Island. 


\section{Description of Plate 17.}

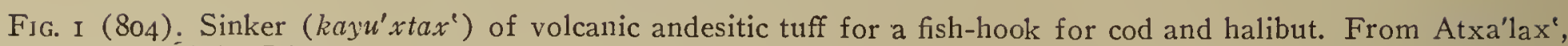
Atka Island.

FIG. 2 (I665). Head-piece of a quartzite drill (hardness I, No. 4). Head-piece of a drill is called qitqu'yax $x^{\mathrm{C}}$, on Umnak; kixtu'gyax $x^{\prime}$, on Unalaska; and umu'six', on Attu. From Ukix, Umnak Island.

FIG. 3 (1628). Fish-hook sinker of tachylitic tuff (basaltic, glassy) with a perforation made by drilling. From Pit I, Agla'gax site, Umnak Island.

FIG. 4 (2005). Fish-hook sinker of altered andesitic lava, with a drilled hole for fastening to the line. Found at a depth of 2.6 meters, at Xata'ctan, Amaknak Island.

FIG. 5 (I463). Fish-hook sinker of micro-granular quartz diorite with an unfinished groove. From Uglu'dax', Umnak Island.

FIG. 6 (I910). Fish-hook sinker of diabase porphyrite, much weathered. From Amaknax, Amaknax Island.

Fig. 7 (1235). Small grooved ball, part of a bird bolas, made of volcanic andesitic tuff. The implement, which consists of several balls to which thongs are attached, is called sanaga'sin, and each ball is called kayu'xtax $x^{2}$, the name for a fish-hook sinker. From Ukix, Umnak Island.

FIG. 8 (I464). Fish-hook sinker of altered andesitic tuff. It was also used as a hammer (itmagu'six') for rude chipping or flaking of stone implements. Uglu'dax', Umnak Island.

FIG. 9 (2006). Implement for grinding paints, made of enstatite-augite andesite (hardness 2, No. I4). Xata'cxan, Amaknax Island.

FIG. Io (1450). Small fish-hook sinker of tuff of tachylite, used for catching Cottus aleuticus Gilb. From Ukix, Umnak Island.

FIG. II (2I42). Whetstone (cumli'six') for polishing stone implements of tuff of tachylite (hardness 4, No. 23). From Tanaxta'xax', Amaknax Island.

FIG. 12 (2079). Fish-hook sinker of augite andesite. Found at a depth of 4.6 meters at Xata'cxan, Amaknax Island.

FIG. I3 (407). Hammer ( $t u g a^{\prime}$ six $\left.^{\prime}\right)$ used in the manufacture of stone lamps and for grooving stone sinkers. It is made of micro-granular quartz diorite (hardness 2, No. I2). From Nani'kax', Attu Island.

FIG. I4 (196). Fish-hook sinker of altered tuff of andesite: From Sin, Áttu Island.

FIG. I5 (2128). Small fish-hook sinker, used also as a polishing implement, made of andesitic lava. From Tanaxta'xax', Amaknax Island.

FIG. I6 (365). Piece of vesicular andesitic lava, used as a polishing-implement (ska'gix ${ }^{2}$ ) for bone, wood, and stone. An implement of microgranular andesitic lava was called cuktu'six*. From Nani'kax*, Attu Island.

FIG. I7 (270). Stone drill-head of quartz limestone (hard marble), used in making fire. From Nani'kax', Attu Island.

FIG. I8 (504). Piece of red ocher used for paint. From Nani'kax', Attu Island.

FIG. I9 (895). Paint grinder (ikica'six ${ }^{\circ}$ ) of augite andesite. From Atxa'lax', Atka Island.

FIG. 20 (I405). Ball of tachylite tuff which had evidently belonged to a bird bolas, although it appears too large for that purpose. It had served also as a hammer for rude chipping of stone lamps and fish-hook sinkers. From Uglu'dax', Umnak Island.

FIG. 2I (297). Small flat fish-hook sinker of hornstone schist. Nani'kax', Attu Island.

FIG. 22 (I908). Paint grinding stone, called ikica'six, meaning "implement for grinding," or hinkulu'gim-cā, i. e., the arm of hinkulu'gix", or an anvil-stone, on which the paint is ground. It is of enstatite augite andesite. From Amaknax, Amaknax Island.

FIG. 23 (2008). Hammer for chipping lamps and grooving fish-hook sinkers, made of volcanic andesitic tuff. From Xata'cxan, Amaknax Island.

Fig. 24 (1454). Hammer for chipping stone implements, semiopal (hardness I, No. 6). It had served also as a paint-grinder (ikica'six $x^{\prime}$ ). From Ukix, Umnak Island.

FIG. 25 (355). Fish-hook sinker of volcanic andesitic tuff. From Nani'kax', Attu Island.

FIG. 26 (I629). Fish-hook sinker of volcanic andesitic tuff with three perforations made by drilling. From Agla'gax', Umnak Island.

FIG. 27 ( $1636 d)$. Round stone of tachylite tuff used in the game called $a^{\prime}$ gixt. The game consists in throwing three or four stones up, one after another, with one hand, and catching them in the same hand. From Agla'gax', Umnak Island.

FIG. 28 (I45I). Fish-hook sinker of altered andesitic tuff for catching Cottus aleuticus Gilb. From Ukix, Umnak Island.

FIG. $29(1636 a)$. Round quartz pebble used in playing $a^{\prime}$ gix' (see No. 27). From Agla'gax', Umnak Island. 


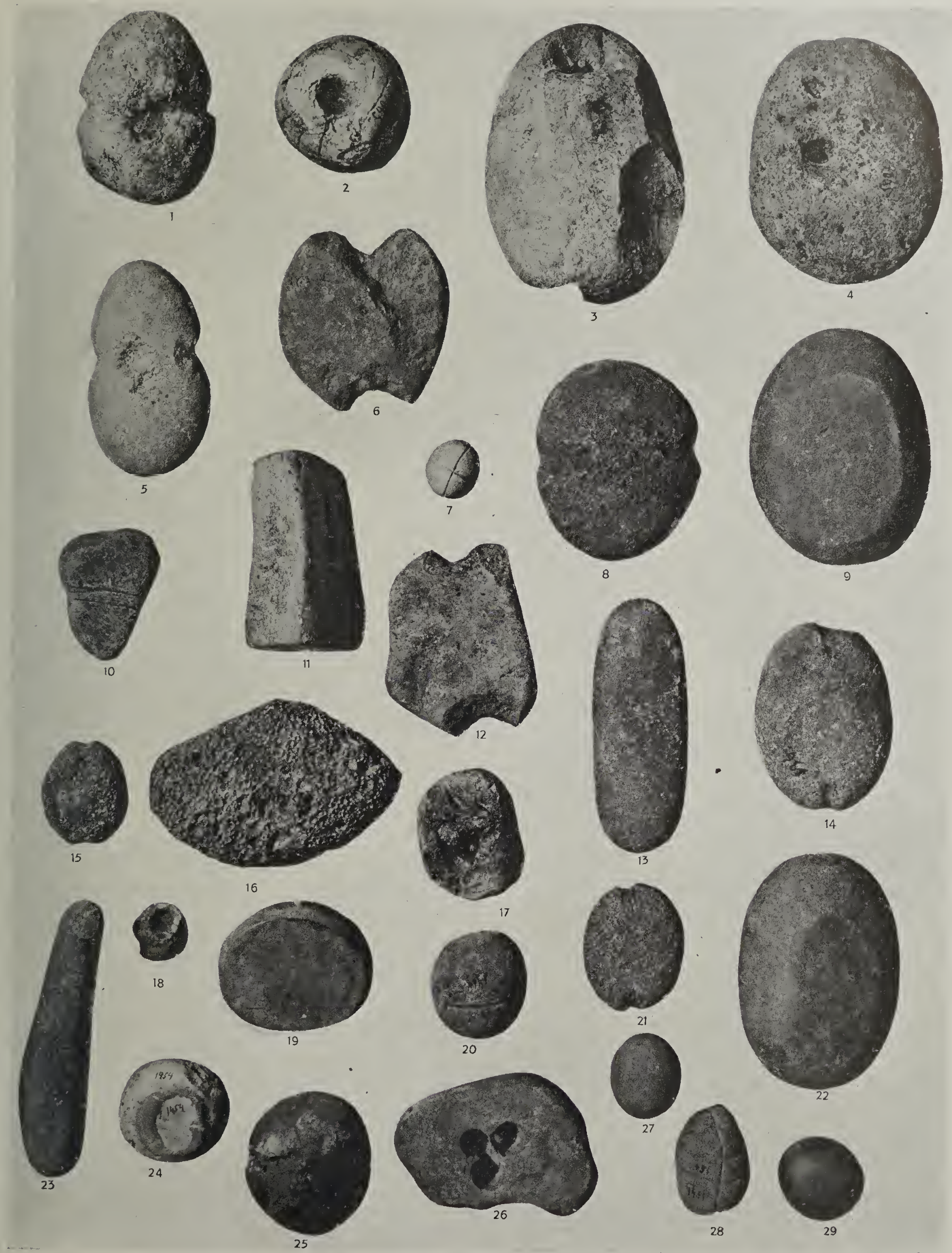

Hammers, sinkers, paint grinders, and other implements of stone. About two-fifths natural size. 


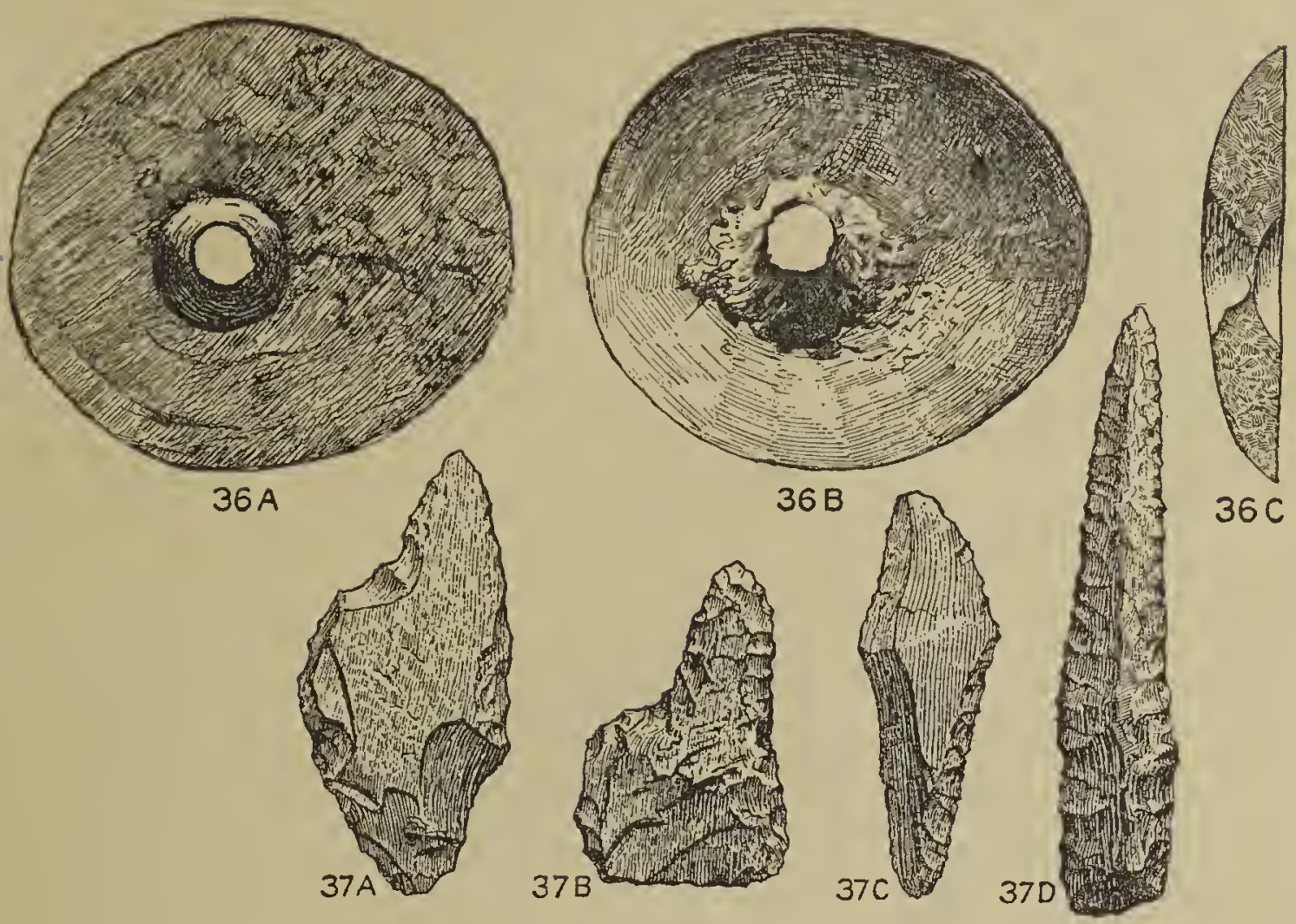

Text-FIG. $36 A-C$ (96r). Stone disk of volcanic andesitic tuff (hardness 3 , No. 20) with a central perforation. The disk appears to be too light for a fish-line sinker and is too large for the ring used in tightening the belt of the waterproof shirt made of sea-mammal guts. $A$ shows the convex side and $B$ the flat side of the disk. $C$ is a transverse section through the middle of the perforation. On the flat side $(B)$ may be seen evidence of drilling, while on the convex side $(A)$ the perforation had been enlarged by flaking with a chisel. The most likely use of this disk was as an ornamental pendant. Found in Pit I, Agla'gax', Umnak Island.

TEXT-FIG. $37 A$ to $D(A, 886 ; B$, I $495 ; C, 2102 ; D$, II 54 $)$. Drill-points; $C$ is of hornstone schist, the remainder are of andesite. These drills had had wooden handles and were operated by means of small bows. $A$, from Hala'ca, Atka Island; $B$, from Uglu'dax', Umnak; $C$, Tanaxtaxax, Amaknax Island; $D$, Pit I, Ukix, Umnak Island.

TEXT-FIG. 38 (1048). Slate whetstone for grinding and polishing bone needles and awls. Traces of grinding may be seen in the deep grooves of the soft stone. Found at a depth of 5.2 meters, in Pit 2 , Aglagax, Umnak Island.

\section{Processes in Working Stone Implements.}

Of stone objects found in the course of excavations on the Aleutian Islands, it remains but to describe stone lamps, stone ornaments, and a few household objects of stone. However, before entering into a description of the implements themselves, it may be well to describe their method of manufacture. The following data are based not only on the implements themselves, but on statements of old Aleut, particularly those on Umnak Island, who seemed to know more about the primitive techniques of their forefathers than any of the other islanders. Some stone implements, such as fish-hook sinkers and stone blades for throwing-lances used in hunting, were still in use. Because of this it was possible to establish the use of all the objects of the lithic industry of the old Aleut.

The following processes were employed in working stone implements:

1. Breaking off fragments, of which the implements were made from the core or boulder.

2. Rude chipping of the flakes to give them the desired shape, either of a point, blade, knife, or dagger

3. Fine chipping of the sides of the flakes.

4. Trimming the edges. This process is called "retoucher" by the French archrologists.

5. Polishing the blade or the whole implement. 


\section{HAMMER-STONES.}

Two kinds of hammer-stones, consisting of boulders picked up on the seashore or taken from the rock, are distinguished by the Aleut. One, called tuga'six', meaning "implement for striking," was an oblong rounded boulder found on the shore. The tuga'six' was used for processes I and 2. There were tuga'six of differing hardness, used in accordance with the hardness of the material to be beaten. It was used for the grooving of fish-hook sinkers and for the rude pecking out of stone lamps. As lamps and sinkers were made of stone of medium hardness, so the hammer-stone was not of the hardest minerals, as shown in plate I7, figures I3 and 23 .
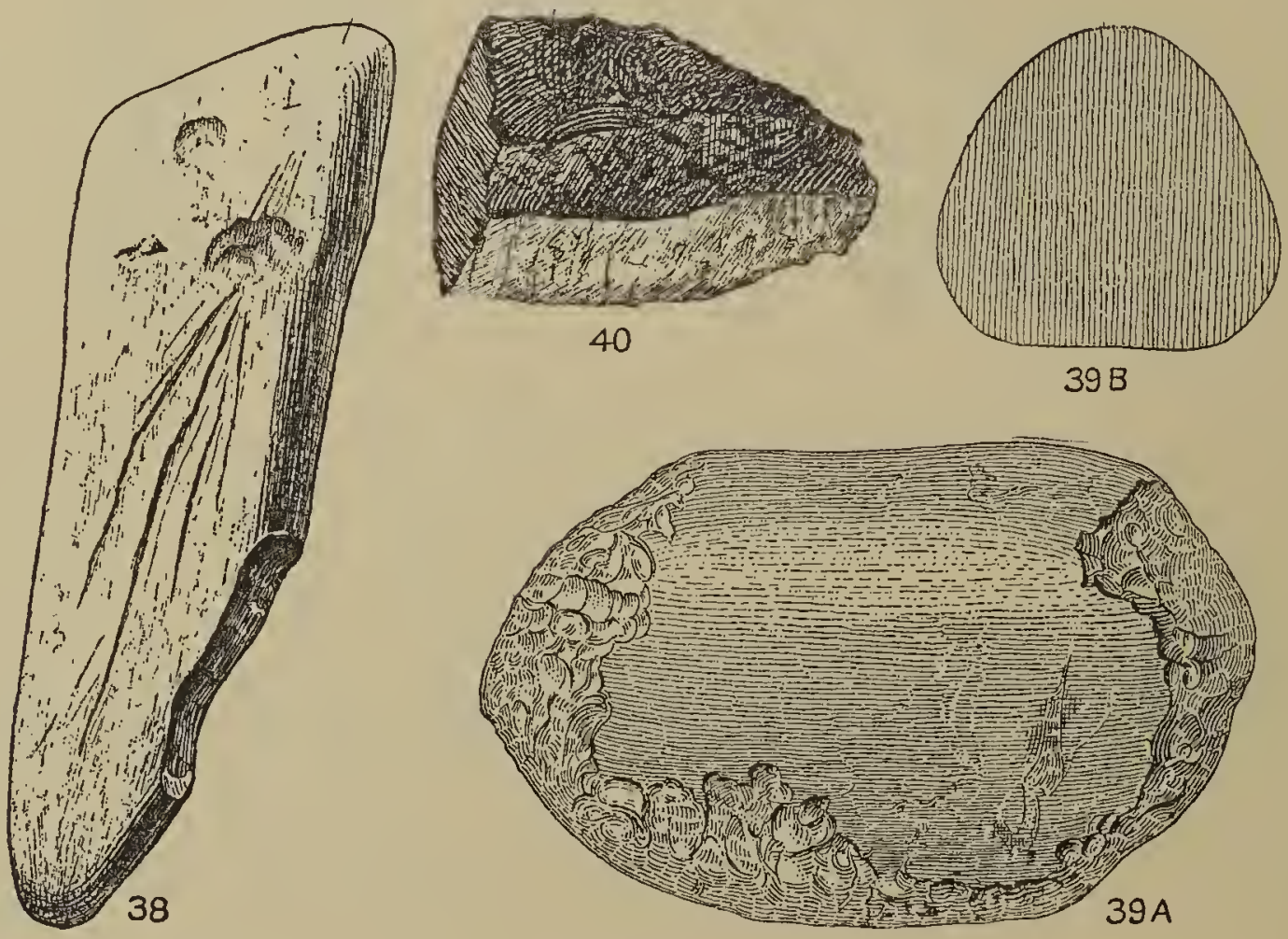

FIG. 38.-Whetstone for grinding and polishing bone implements.

FIG. 39.-Hammerstone for working stone implements; $A$, side view; $B$, transverse FIG. 40.-A core.

The second type of hammer-stone was called itmagu'six, i. e., implement for pecking, or delicate hitting, and was manufactured of the hardest minerals. It was egg-shaped, round, or discoidal in form, and served for the final chipping of stone implements and for hollowing out stone lamps. To use the hammer-stone, tuga'six', it was held in the right hand at one end, while the other was used to give a vertical stroke from above. The stone being worked lay on the edge of another flat stone or a piece of whale-bone. A long hammer augmented the power of the stroke.

The short hammer-stone, itmagu'six', was held in the right hand; in working with this implement, skill in handling it was more important than a powerful stroke. The stone to be shaped was held in the left hand and by cautiously striking and chipping with the itmagu'sixi', the irregularities of the edges and the borders of conchoidal cleavages were removed. Thus the edges were made thin and the protuberances from the sides were removed before the implement was trimmed and polished. 
Text-figure $39, A, B$ ( $145^{2}$ ) illustrates a hammer stone (itmagu'six') in natural size, with fine scarring on 3 sides-the marks of use. It is a water-worn boulder of green hornstone schist, with thinnest veins of quartz, hardness I of our scale. The back of the hammer-stone, which, when in use, is covered by the palm, has no scars; every other part of the implement was used. This specimen was found at Ukix, Umnak Island; $A$, is a view from the side; $B$, is a lateral section. Such an implement is also shown on plate 17 , figure 24 , and the collection contained many more of the same type.

It should be noted that our conclusions as to the shape of this hammer-stone does not agree with those arrived at by Professor W. A. Gorodtzov, of Moscow, who has made many experiments in the manufacture of stone implements. $\mathrm{He}$ states that all types of Stone Age hammer-stone must have been oblong in form. ${ }^{15}$ Illustrations in well-known works on American archæology, such as those of Professor Holmes, show hammer-stones of the type of the itmagusix; ; in other words, an egg or ball-shaped form. ${ }^{16}$ Such illustrations as are shown by Dr. Thomas Wilson ${ }^{17}$ are to be found in all hand-books on prehistoric archæology. ${ }^{18}$

In figure 40 (895) may be seen a core of andesite from which flakes had evidently been obtained by striking with a hammer-stone of the itmagu'sixt type vertically from above. In the lower part are also marks of side-strokes apparently made to obtain a point. In the opinion of the Aleut, this was a point for a throwing-lance in the early stages of its shaping.

\section{Retouching Stone Implements.}

The final shape to a stone implement was given it by trimming or retouching after the form had been thinned out with the itmagu'six' hammer-stone. As an implement for trimming the edges, a bone chipper or flaker $\left(c a^{\prime} t u x^{*}\right)$ was employed. Some European archæologists are of the opinion that Stone Age man of the Old World, that is, man of the palæolithic period, before bone implements were used, employed stone flakers for retouching his implements. ${ }^{10}$ In France they were called ecrosoirs, but M. de Mortillet prefers the name retouchoir. Sir John Evans calls stone flakers also fabricators. ${ }^{20}$ Judging by the implements found on the Aleutian Islands, and, according to the statements of the present Aleut, the forefathers of

$15 \mathrm{~W}$. A. Gorodtzov, On the Technics of Stone Implements (in Russian). Yearbook for Geology and Mineralogy of Russia, vol. XVI, part I, I9I4, p. I \&-20.

${ }_{10}$ W. H. Holmes, Stone Implements (Fifteenth Annual Report, Bureau of American Ethnology, Washington, I897, p. 59) ; Handbook of Aboriginal American Antiquities, Part I, Introductory, The Lithic Industries, Bull. 60, Bureau of American Ethnology, Washington, I9I9, pp. I80, 22I; 33I.

17 Thomas Wilson, Arrow-points, Spear-heads, and Knives of Prehistoric Times (Report National Museum, Part I, I899, p. 880).

18 J. Déchelette, Manuel d'Archéologie préhistorique, Paris, I908, p. 21. British Museum. A guide to the Antiquities of the Stone Age, London, I9II, p. 57, fig. 76.

${ }_{19}$ J. Déchelette, 1. c., I, pp. 33I, 538; Mortillet, L'homme préhistorique, p. 5I7; British Museum, A Guide, etc., p. I37.

20 John Evans, Ancient Stone Implements, p. 367. 
the latter used only bone-flakers for chipping the edges smooth. Leading American archæologists also believe bone to have been the retouching material. ${ }^{21}$

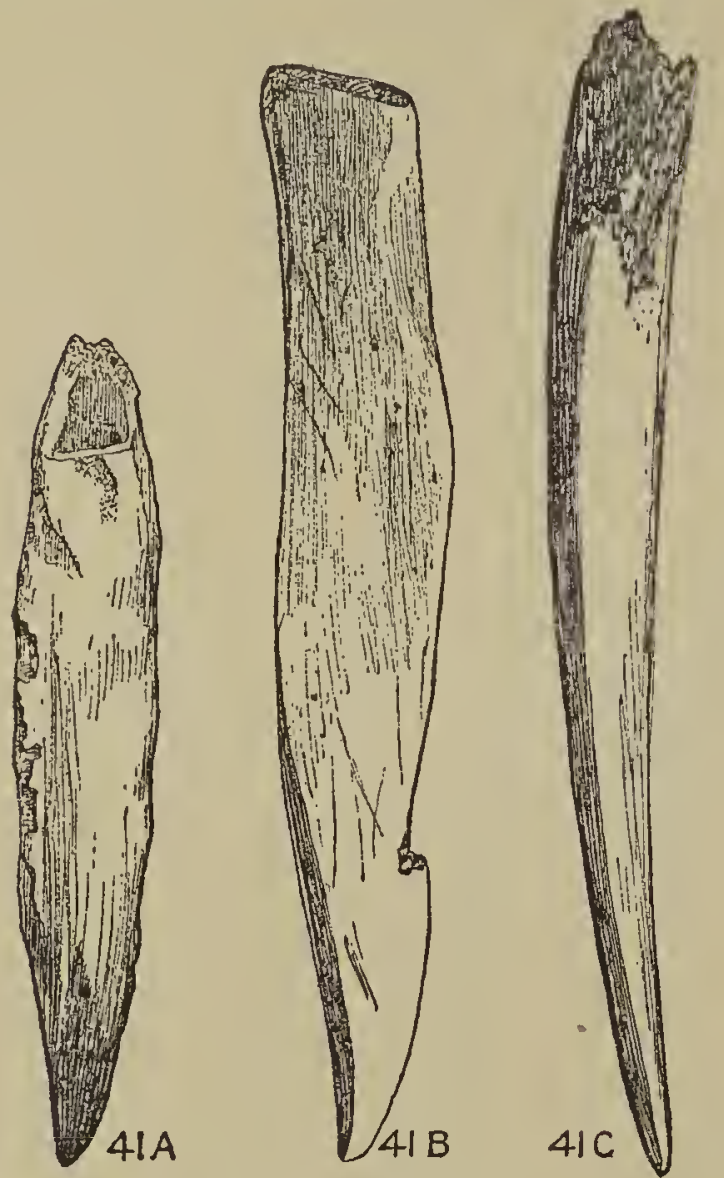

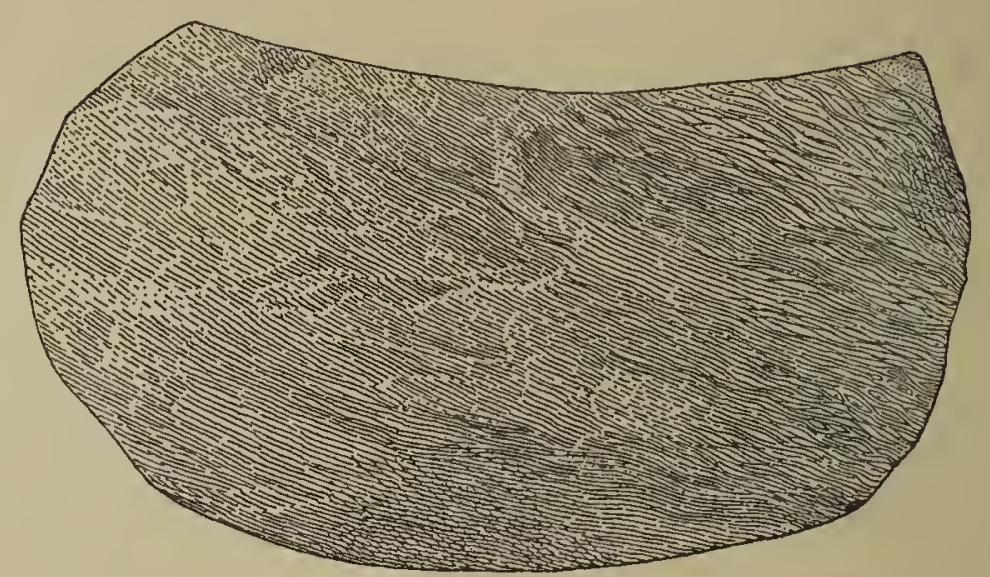

42

FIG. 42.-Piece of sea-lion skin.

FIG. 4I.-Bone flakers.

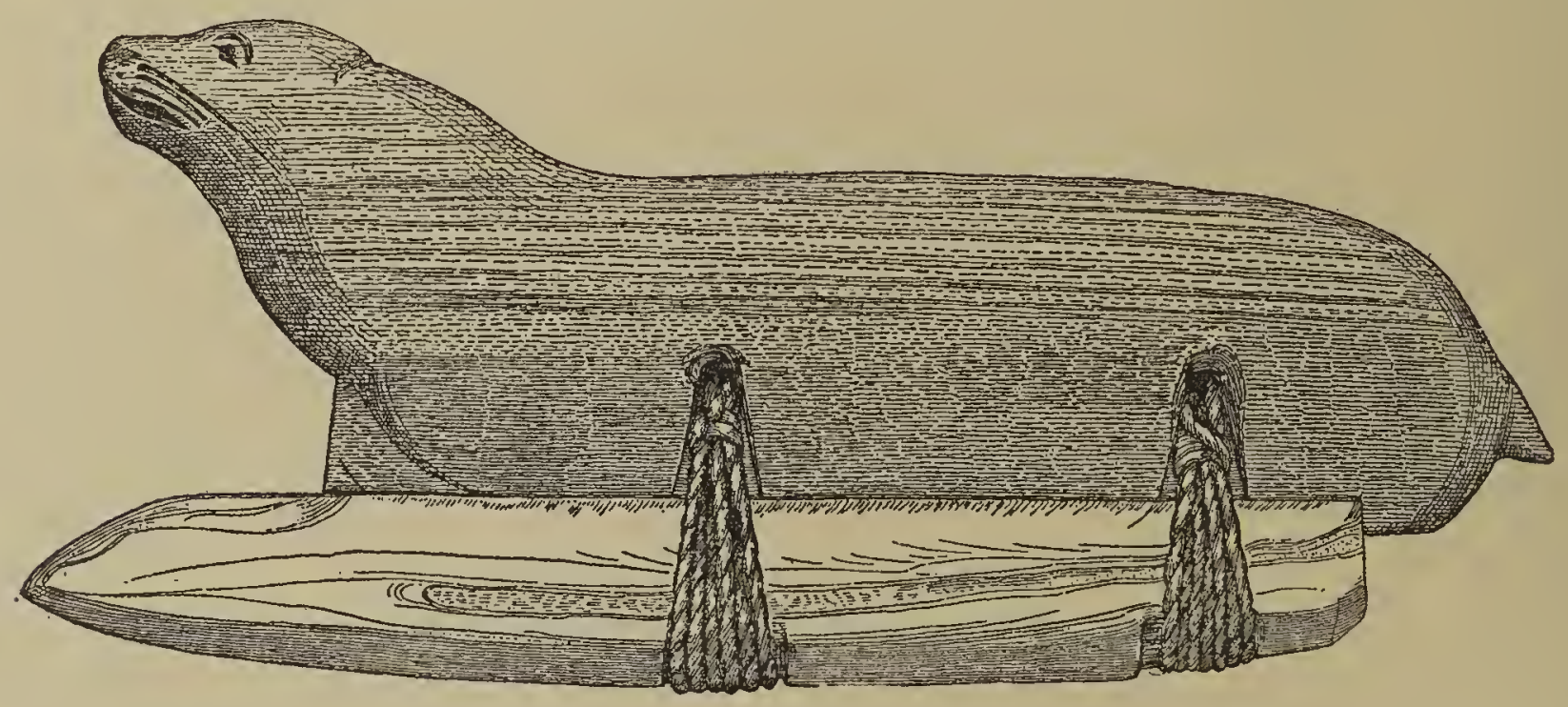

43

FIG. 43.-Bone flaker with handle.

The bone-flaker, $c a^{\prime} t u x^{i}$, was usually made of the penis-bone of a sea-otter ( $\left(\tilde{n} a^{\prime} t u m-u n \tilde{n}^{\prime} \tilde{i}^{\prime}\right.$, see plate 22, figs. I5, I6). It is a very dense and hard bone substance, but, in distinction from stone, possesses a certain degree of elasticity, so that with its somewhat curved form, the sea-otter's penis-bone was the best material for a bone flaker. These bone flakers usually had a thin, rounded, somewhat bent

21 W. H. Holmes, Handbook of Aboriginal American Antiquities, part I, pp. 305-308; Thomas Wilson, Arrow-points, etc., pp. $88 \mathrm{I}, 882$. 
and polished point. When the point broke off or split in retouching the sharp edges of stone implements, the flaker was ground down on a whetstone.

According to an old Aleut saying, a lad had no right to marry before he had ground off a penis-bone flaker to its base in the manufacture of stone implements. This proverb does not imply that all other kinds of dense and hard bone were excluded as material for making flakers. They were also made of the outer layer of a walrus-tooth and of the incisors of the killer whale.

The edges of stone implements were retouched with bone flakers, giving them an even or serrated form. In the first case, the weapon inflicted a cutting wound; in the second, a laceration. A serrated blade served also as a saw for filing bone and wood. With the bone flaker the stem, notches, barbs, and spurs of stone blades and points were chipped out.

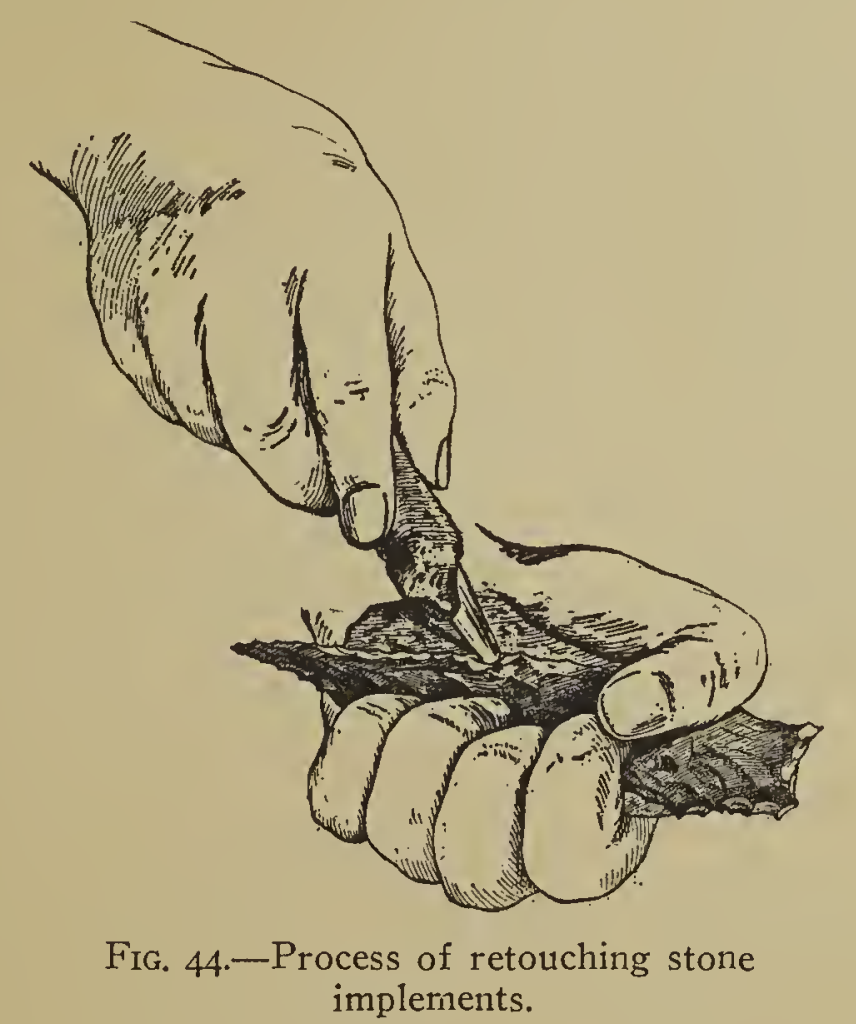

Three bone flakers are shown in figure 4I, $A$ to $C$. Figure 4I $A$ (1097) is of walrus-tusk and was found in Pit 2, Agla'gax', Umnak Island; $B$ was found at Ukix on the same island; while $C$ was found at Nani'kax', on Attu. In the Attu dialect a bone flaker is called catu'sixe.

For retouching large stone blades or knives, the bone flakers were fitted with a wooden handle called $u^{\prime} t u x^{\prime}$. This type of flaker is shown in text-figure 43 (I742). It is a model made on Umnak Island by the old Aleut, Boris Besyasykov. 'The bone is that of a killer's tooth. The wooden handle is fastened to the flaker by sinew threads and represents a sea-lion. To retouch a stone implement it was held in the left hand on a piece of thick sea-lion skin, while the flaker was manipulated with the right hand. In figure 42 is shown a piece of thick sea-lion skin, with an incision for the thumb. This covered the palm of the left hand during the retouching process, which may be seen in figure 44 . The small, sharp splinters fall on the thick sea-lion 
skin and not on the hand. Besides, the sea-lion skin prevented pressure on the hand with the flaker while chipping.

Many of the stone implements illustrated were retouched by the flaker, but not polished; the retouching was the final process; then the implement was ready for use. According to European archæologists, the retouching process was already known to man of the later palæolithic period. However, in the neolithic age, the implement which had to be polished must have been retouched by a flaker before the grinding and polishing.

\section{Polishing Stone Implements.}

Grinding and polishing of stone implements were known to the ancient Aleut, but very few of the implements found appear to have been polished. For the most part, the stone implements shown on plates i 5 to i 7 were only retouched.

As has been mentioned before, two kinds of polishing implements, made of andesitic lava, of fine and rude vesicularity, are shown on plates I6 (figs. 23 and 25) and I7 (fig. I6). The polishing implement of coarse vesicular andesitic lava, called by the Aleut sñ gixi or ska'gix', was used in the first phase of the process. For the second step, after the coarse unevenness of the stone was removed by the sina'gix', an implement of fine vesicular andesitic lava, called by the Aleut cuktu'six', was used. The third stage consisted in grinding with a smooth whetstone, called cumli'six', chiefly made of volcanic tuff (see plate I7, fig. II). With this implement the edges were also sharpened. In order to polish the surface the Aleut used the horsetail, Equisetum nyemale, which they called qi'lim alucaya'ñin, $i . e$. , the needles of the mythical monster, Qilixi. Chiefly, however, bone objects received their final polish with this plant.

Judging from the excavated implements, only stone adzes and axes of quartz and hornstone schist and large flat knives (man's knife, utu'gnux and woman's $\left.i g a^{\prime} d a x^{\circ}\right)$ were polished. On adzes, chiefly the edges and the places over the edges

\section{Description of Plate i8.}

FIG. I (1652). Lamp of altered diabase porphyrite (hardness 3, No. I8). Ukix, Umnak Island.

FIG. 2 (2II9). Lamp of andesitic lava (hardness 3, No. I7), found at a depth of 2.8 meters. Tanaxta'xax', Am'aknax Island.

FIG. 3 (I64I). Lamp of diorite (hardness 2, No. 12). Ukix, Umnak Island.

Fig. 4 (1648). Lamp of serpentine of an antigorite type (hardness 4, No. 26). Ukix, Umnak Island.

Fig. 5 (1657). Lamp of serpentine of an antigorite type. Ukix, Umnak Island.

FIG. 6 (I650). Lamp of volcanic andesitic tuff (hardness 4, No. 20). Ukix, Umnak Island.

FIG. 7 (899). Lamp of serpentine of an antigorite type (hardness 4, No. 26), Cave 2, Atxa'lax', Atka Island.

FIG. 8 (Igo6). Lamp of diorite (hardness 2, No. I2). Am'aknax', Am'aknax Island.

FIG. 9 ( I646). Lamp of serpentine of antigorite type. Ukix, Umnak Island.

FIG. Io (1658). Lamp of serpentine of an antigorite type. Ukix, Umnak Island.

FIG. I ( I694). Lamp of diorite. Found by the Aleut while digging a garden on site of a small ancient village. Cuni'xsux', which is about 3 miles north of present village of Nikolskoye, Umnak Island.

FIG. I2 (217). Lamp of volcanic andesitic tuff (hardness 3, No. 20). Sin, Attu Island; outside is painted black.

FIG. I3 (I30). Lamp of antegoritic serpentine. Hog Island.

FIG. I4 (I695). Lamp of volcanic andesitic tuff, made on Atka Island, after the advent of the Russians.

FIG. I5 (I67I). Lamp of antegoritic serpentine. Natxu'kax'. Umnak Island.

FIG. I6 (I65I). Lamp of volcanic andesitic tuff. Ukix, Umnak Island. 

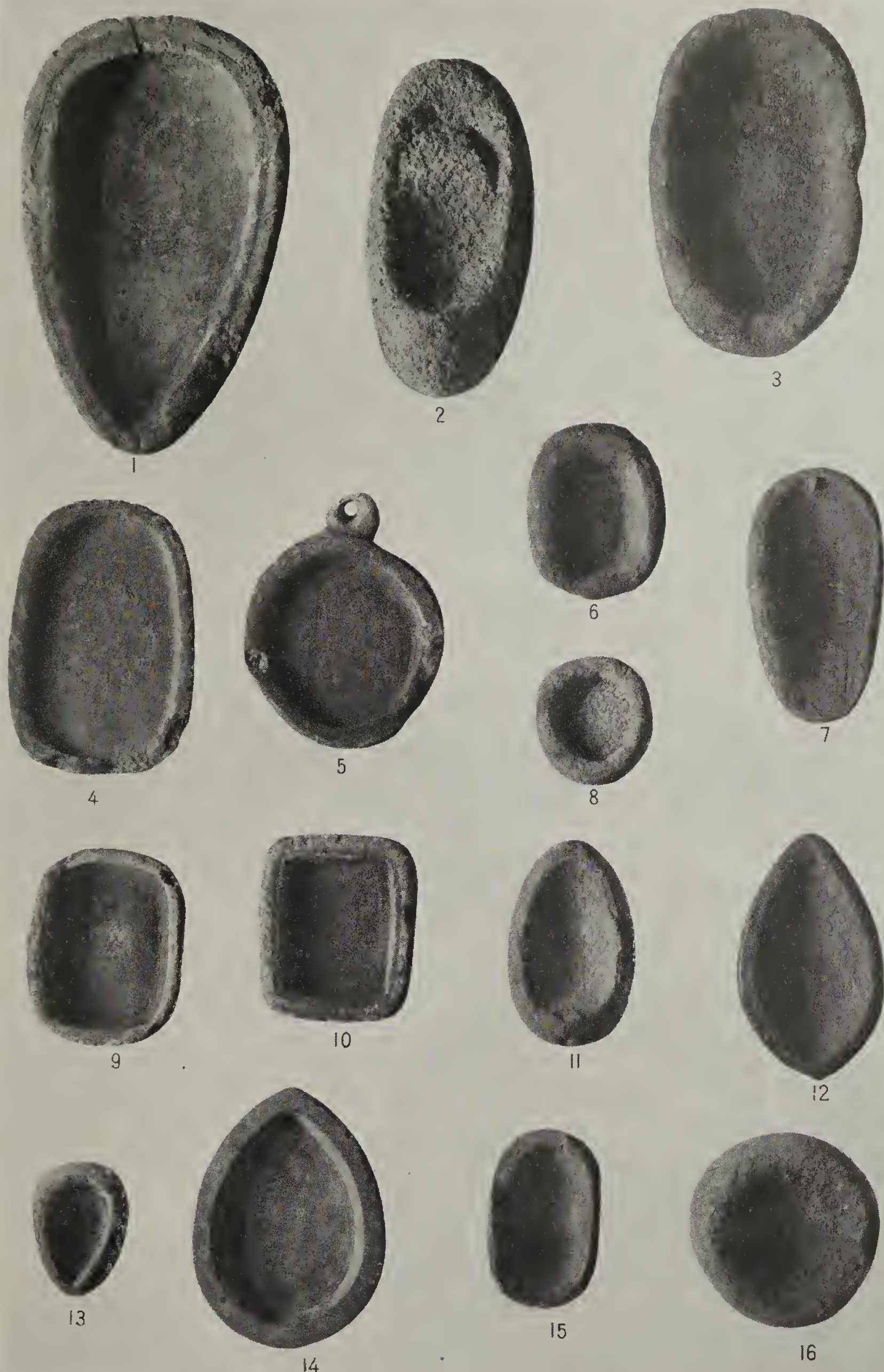

13

15

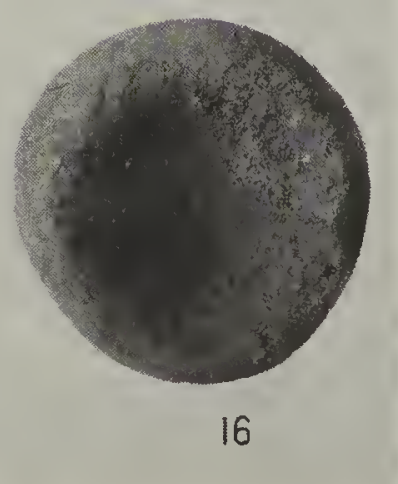

Stone lamps. About two-sevenths natural size. 

were polished, but seldom the entire implement. On flat knives, both men's and women's, of slate and hornstone schist, the whole surface on both sides was usually polished, but not quite smoothly. Of long knives, called cunu'six', there appeared 2 polished (see plate $\mathrm{I} 6$, figs. IO and II). Adzes for working in wood seem not to be polished (see plate I 5, figs. 35 and 34). As will be seen later, some of the lamps had the sides and lower surface polished.

\section{STONE AND BONE LAMPS.}

\section{Peculiarities of Aleut Stone and Bone Lamps.}

Aleut stone lamps were used for the light and warmth they afforded. There were two types, distinguished-by their size, names, and use: illuminating lamps were of small size and were called $i^{\prime} x t a x^{i}$, while those used for warmth were larger and were called, $a^{\prime} \tilde{n} u x^{\prime}$.

The wick, called $i^{\prime \prime} \tilde{n} i x^{\prime}$ or $h^{\prime} \tilde{n} i x^{\prime}$, for both types of lamp, consisted of a bunch of dry grass placed in the middle of the lamp, which was filled with tallow, melted fat, or oil obtained from sea animals. The lamp usually stood on a piece of sea-lion skin, from which drops of oil or fat, which occasionally fell from the lamp, were gathered. During a scarcity of fat, the wick was made thin and placed slantwise near the edge of the lamp. No special grooves or bridges were carved for wicks. The illuminating lamp served also to warm the dwelling, but this was an additional use of the lamp. Generally, no attempt was made to warm the dwellings. No fireplaces were built, neither did the Aleut cook over their lamps as do the Eskimo. For example, the southern Eskimo hang soapstone kettles over their lamps and in these food is cooked or snow melted. When the Aleut made a driftwood fire it was usually in the open air or in special semiunderground kitchen huts. There they fried meat of sea animals, birds, and fishes on flat stone frying-pans called cu' $\tilde{n} l u x^{\prime}$. Many such stone frying-pans were found on all the islands. One is shown in plate 2I, Fig. 2 ( 1697 ), from Uglu'dax', Umnak Island. It is of volcanic andesitic tuff blackened by smoke on the lower side and with grease on the upper. In use, the edges of the frying-pan were supported by stones, so wood could be burned under it.

The lamp called $a^{\prime} \tilde{n} u x^{\prime}$ was used, chiefly by hunters, for warmth. Women, too, warmed themselves over it, after working in the fields, gathering berries, grasses, or edible roots, or after searching on shore for echini, mollusks, or edible sea-weeds.

$A^{\prime} \tilde{n} u x$ " means "warmer," also the process of warming; the verbal form is $a^{\prime} \tilde{n} u$, to warm oneself over a lamp. The use of the "warmer" was as follows: People stood over the burning lamp or sat over it in a squatting position, covering it with their shirt-like coats. The ancient Aleut wore footwear only or a breechcloth and footwear under their coats, so the naked body could easily be warmed. Before getting in skin-boats the Aleut took off their footwear. Sick people were also seated over the $a^{\prime} \tilde{n} u x^{i}$ to make them perspire. Generally, the warming-lamp served in place of the sweat-bath, which was unknown to the Aleut before the coming of the Russians. As was in later days the case with the sweat-bath, visitors were always offered the use of a warming-lamp. 
Of the lamps shown in plates 18 to 20 , it is difficult to distinguish the $a^{\prime} \tilde{n} u x^{\prime}$ from the $i^{\prime} x t a x^{\prime}$. However, the size was generally an indication of their use. Thus, according to information obtained from the Aleut, the following large lamps were regarded as "warmers": Figures I and 3, plate I8; figures I and 2, plate I9, and figures 3 and 9, plate 20. The Attu chief, Prokopyev, who gave us information about the exceedingly large stone lamp, referred to a legend about a former chief of the southern part of the island who ordered his slaves to make the lamp for his daughter.

Without doubt, however, large lamps were used for lighting and the smaller ones for warmth. Thus, for example, the old Aleut say that during social festivities and plays the ulaga'max', $i$. e., the large underground dwelling of the chief, was lighted by large stone lamps usually used for warming. In such case several wicks were placed in the lamp for better lighting. On the other hand, hunters took with them, in their skin boats, small stone lamps, $i^{\prime} x t a x^{\prime}$, or carried them attached to their belts by means of a perforation. These served to light the caves or temporary tents in which the hunters lived, but more important still, these were carried by the hunters so that when overtaken by cold and humidity they might be able to warm and dry themselves. A lamp with an ear or handle by which it may be attached to the hunter's belt is represented on plate 18 , figure 5 .

Aside from the lamp, the hunter had to be supplied with fire-making implements, a drill, bow, head for the drill, dry grass or wood, pieces of sulphur, and a bladder filled with oil. The lamp fuel could also be augmented by pieces of fat from the sea mammals killed.

Judging by the specimens excavated, which numbered 69, the Aleut stone lamps are distinguished by a considerable diversity of types as to their size as well as their form. The length of lamps shown on the plates ranges between $45 \mathrm{~mm}$. and $310 \mathrm{~mm}$. There were also lamps less than $45 \mathrm{~mm}$. long, but these were probably toy or mortuary lamps. On the other hand, there were also lamps longer than $310 \mathrm{~mm}$. A lamp I meter long has already been mentioned.

For the plates different types of lamps were chosen. Those circular in outline are figures 5,8 , and $\mathrm{I} 6$ on plate $\mathrm{I} 8$, and figures 3,5 , and 8 on plate 20 . In figures 2 , 3,6 and I 5 on plate I8, and figures I and 2 on plate I9, are shown lamps of elliptical shape. Oval or egg-like shapes may be seen in figures 7 and I I on plate 18 , sad iron in outline are figures $1,12,13$, and 14 on plate 18 , while rectangular or nearly

Description of Plate i9.

FIG. I (409). Diorite lamp, found at Nani'kax', Attu Island, the largest in the collection. Length 3Io mm., width $220 \mathrm{~mm}$., height $180 \mathrm{~mm}$. It weighed about 40 pounds. We were told by the chief of Attu, Prokopyev, that on the southern part of the island there has been preserved a stone lamp 3 times as large as this. It may be added also that the author has examined a diorite lamp from Kodiak Island now in the U. S. National Museum (90476) which weighed $67 \frac{1}{2}$ pounds.

FIG. 2 (787). Large stone lamp of diabase porphyrite, from Cave 2, Atxa'lax', Atka Island.

FIG. 3 (I857). Bowl made of a whale's vertebra, for keeping edible roots, Fritillaria kamtschatica Ker Gawl (Aleut, alu'gax ${ }^{\prime}$ ) and Polygonum viviparum L. (Aleut, qugcu'dax and ka'gucudax'), found at Uglu'dax', Umnak Island.

FIG. 4 (80I, 90I, 677). Stone (80I), augite andesite, on which paints were ground called hink $u^{\prime} l u x^{\circ}$ by the Aleut. Found in Cave 2, Atx'alax', Atka Island. Stone pestle (901) for grinding paints (hinkulugim căa', $i$. e., the hand of hinku'lux or ikica'sixi, i. e., the grinder). It could also be used for polishing the edges of stone implements. It was made of andesitic tuff. Found in Cave 2, Atx'alax', Atka Island. A piece of red ocher (677) found in the same cave. 

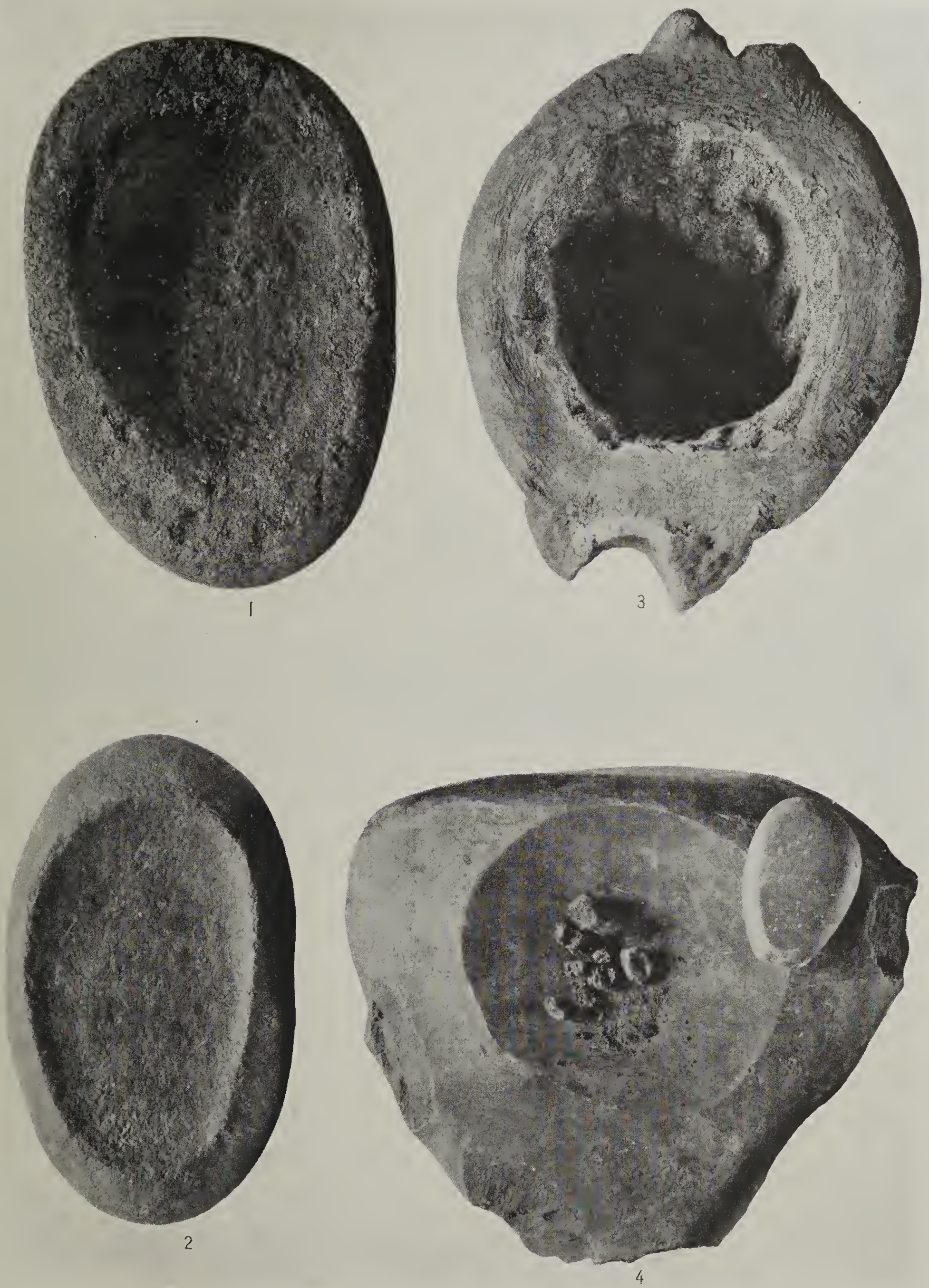

rectangular forms are illustrated in figures 4,9 , and Io on plate I8. No lamps of crescentic outline, like those of the Eskimo of Cumberland Gulf or Point Barrow, were excavated.

Most of the lamps are flat-bottomed, so they stand without support; however, some of them have rounded bottoms, as may be seen in the large lamps of elliptic shape shown in figures I and 2 on plate I9 and some of those circular in outline.

The cavity for oil in some lamps (as, for instance, in figs. I, 4, 5, 9, Io, and I4, plate I8) represents a flat bottom with straight sides, while in other lamps the bottom is rounded. In both cases the oil cavity is quite shallow, from to to $25 \mathrm{~mm}$., and in most cases the cavity, sides, and base are smoothly polished.

In the manufacture of stone lamps the processes employed in stone working heretofore described were employed. First, a stone was chosen and the cavity was rudely pecked out with a hammer-stone (tuga'six'). In plate $2 \mathrm{I}$, figure I, may be seen a stone in this stage of manufacture. In the same way, the sides and base of the lamp were rudely shaped by fracture. In case the lamp material was a waterworn boulder, the entire process was thereby facilitated. Generally, the gross outlines of the lamp depended on the original form of the material.

The second stage of shaping a lamp consisted in the finer chipping of the cavity, sides, and bottom by means of the stone hammer (itmagu'sixi). Then followed the polishing by the methods described before. The straight rims of some of the lamps were chiseled out with hard quartz or hornstone-schist chisels.

Doctor Walter Hough, ${ }^{22}$ curator of the Ethnology Division of the U. S. National Museum, attempted to classify Eskimo lamps with reference to their types, based on the specimens deposited in the National Museum. However, his conclusions, though based on a considerable amount of material, do not agree with those of the present author. For example, Doctor Hough states that the northern Eskimo use larger lamps than do the southern Eskimo. We have shown that the Aleut used both very small and very large lamps.

According to Doctor Hough, the most widespread type of lamp was of clamshell shape. This type, in a wider or narrower form, is distributed from Labrador to Alaska and Eastern Siberia. Often it has a bridge spanning the concavity, thus separating the wick from the oil reservoir. The oil flows to the wick through cuts in the sides of the bridge or through its middle. Bridged lamps were found in localities at great distances from each other-in northern Greenland, on the Mackenzie River, on St. Lawrence Island, at Point Barrow, and on the Chukchee Peninsula. According to Doctor Hough, circular lamps were found in Bristol Bay, while the lamps of the Kodiak and Aleut were ovate.

His description of Aleut lamps is based on those brought from the island by Doctor Dall. However, these lamps, in their size, form, and rude appearance, represent too uniform material. Most of them are roughly worked out boulders, or sometimes boulders with a natural cavity not even worked. Probably these were

22 Walter Hough, The Lamp of the Eskimo (Annual Report U. S. National Museum for the year 1897 , Washington, 1898, pp. 1027-1057). 
merely the carelessly worked lamps which hunters carried with them. However, lamps for lighting dwellings were made more carefully.

The late Prince Ookhtomsky, a Russian ethnologist, tried to revise this division of the Eskimo lamps by Doctor Hough, and for comparative purposes included also Chukchee, Koryak, and Kamchadal lamps. ${ }^{23} \mathrm{He}$ divides the lamps of the Arctic regions into three types. Two of the types segregated by Prince Ookhtomsky are: lamps semilunar in outline and with bridges, coincide with types of lamps which Doctor Hough finds similar in form to a clam-shell. In the third, most primitive type, Ookhtomsky includes the lamps of the southwestern Eskimo, the Aleut, Koryak, and Kamchadal. But this study of lamps is based on unsufficient material; we have seen that, for the most part, Aleut lamps are far from being primitive; they are carefully worked and even polished. Neither can the Koryak or Kamchadal lamps be considered primitive. It is hoped that we may be able to discuss this question when the material excavated in Kamchatka is published.

On the other hand, some of the Aleut lamps may be compared in shape with the lamps of the southwestern Eskimo. Thus, for instance, the ovate lamps of the Kodiak, the circular lamps of Bristol Bay, and the sad-iron-shaped lamps of Norton Sound are similar in outline to many of the Aleut lamps. The Aleut lamps may be distinguished from the above, not only by the absence of the bridge, but also by the position of the dry-grass wick in the middle of the lamp cavity. In none of the Aleut lamps was there a cut or groove for the wick, such as is found in the Kodiak lamps. Only the pointed border of the sad-iron-shaped lamps would serve as a leaning place for the wick, but the old Aleut asserted that the wick was placed in the center in all lamps. The considerable number of bone lamps found in the course of the excavations corroborates the statements of the Aleut that the wick was in the center of the cavity; otherwise the borders of the bone lamps would have been burned off by the flame of the wick.

\section{DESCRIPTION OF BONE IMPLEMENTS.}

The preceding divisions of this chapter were devoted to a general description of the construction of the most typical weapons for war and hunting implements. It is

Description of Plate 20.

FIG. I (414). Bone lamp made of a vertebra of a small whale. From Nani'kax', Attu Island.

FIG. 2 (I794). Bone lamp similar to preceding. From Agla'gax', Umnak Island.

FIG. 3 (216). Porphylite lamp. From Sin, Attu Island.

FIG. 4 (4I I). Porphylite lamp. From Nani'kax', Attu Island.

Fig. 5 (415). Bone lamp, found in the lowest layer of kitchen refuse amid a heap of echini (see above, p. 26) in Pit 4, Nani'kax', Attu Island.

FIG. 6 (1795). Bowl made of a whale's vertebra. From Uglu'dax', Umnak Island.

FIG. 7 ( 363 ). Lamp of whale's vertebra, found in the uppermost layer of kitchen refuse, Pit 4, Nani'kax', Attu Island.

FIG. 8 (I94). Unfinished lamp of diorite. From Sin, Attu Island.

FIG. 9 (1670). Stone lamp of volcanic andesitic tuff. From Ukix, Umnak Island.

FIg. Io (4). Tobacco mortar made of a whale's vertebra. It was used after the advent of the Russians, but was in the possession of an old woman in Unalaska and was considered by her an ancient object.

23 Prince D. E. Ookhtomsky, The Oil Lamps of the Arctic and Subarctic Tribes (Memoirs of the Russian Anthropological Society of the Petrograd University, vol. IV, I9I3, Petrograd, pp. I5I-I58) (in Russian). 

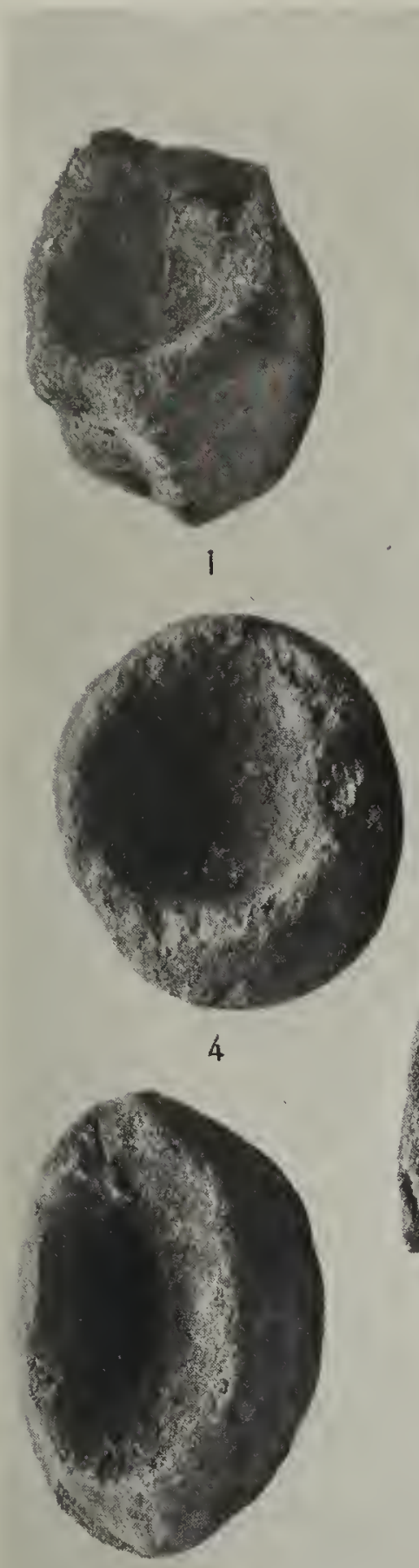

5
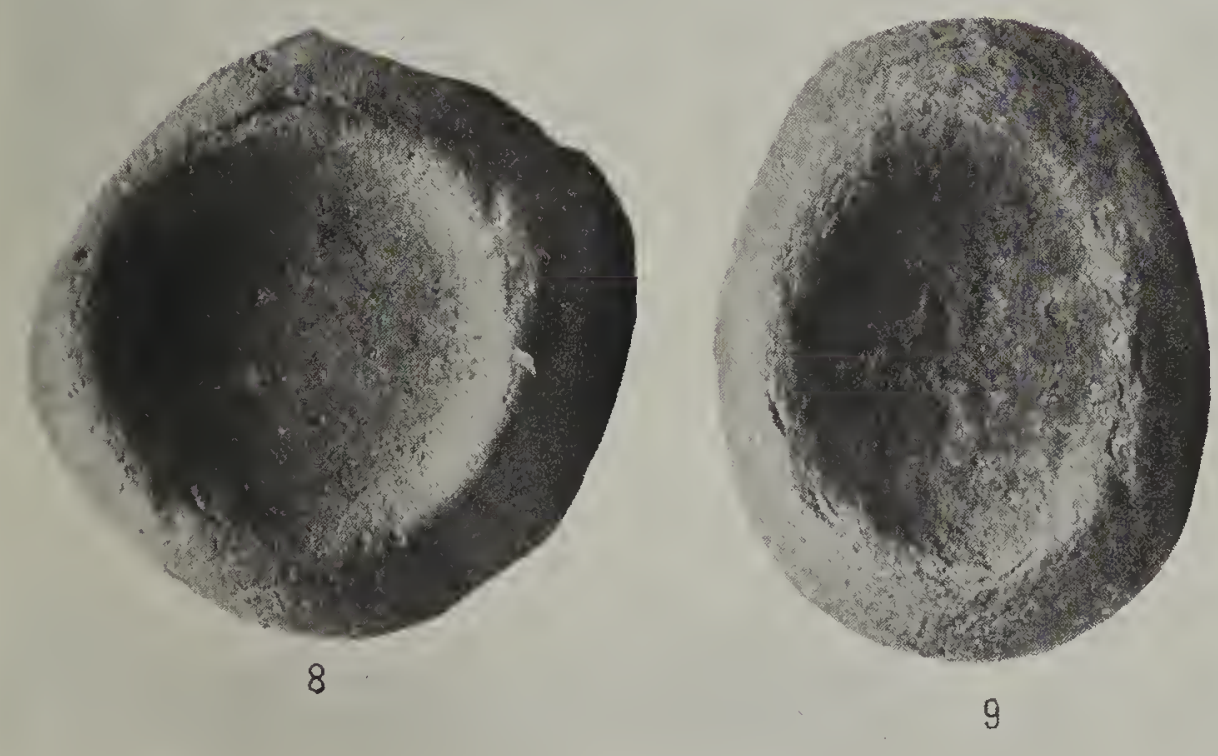
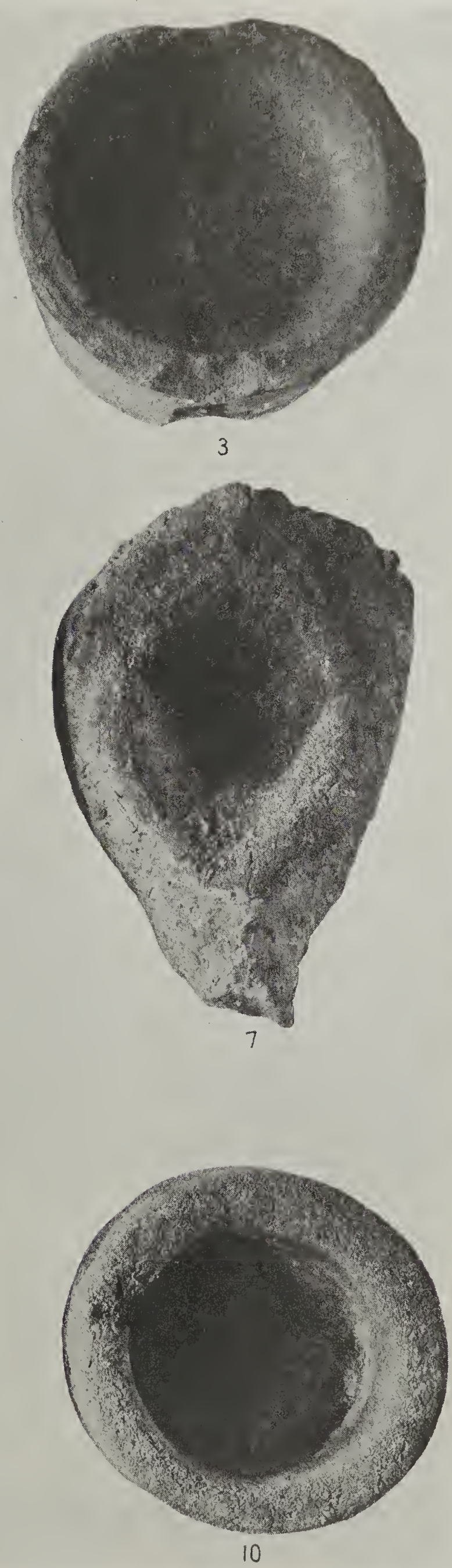


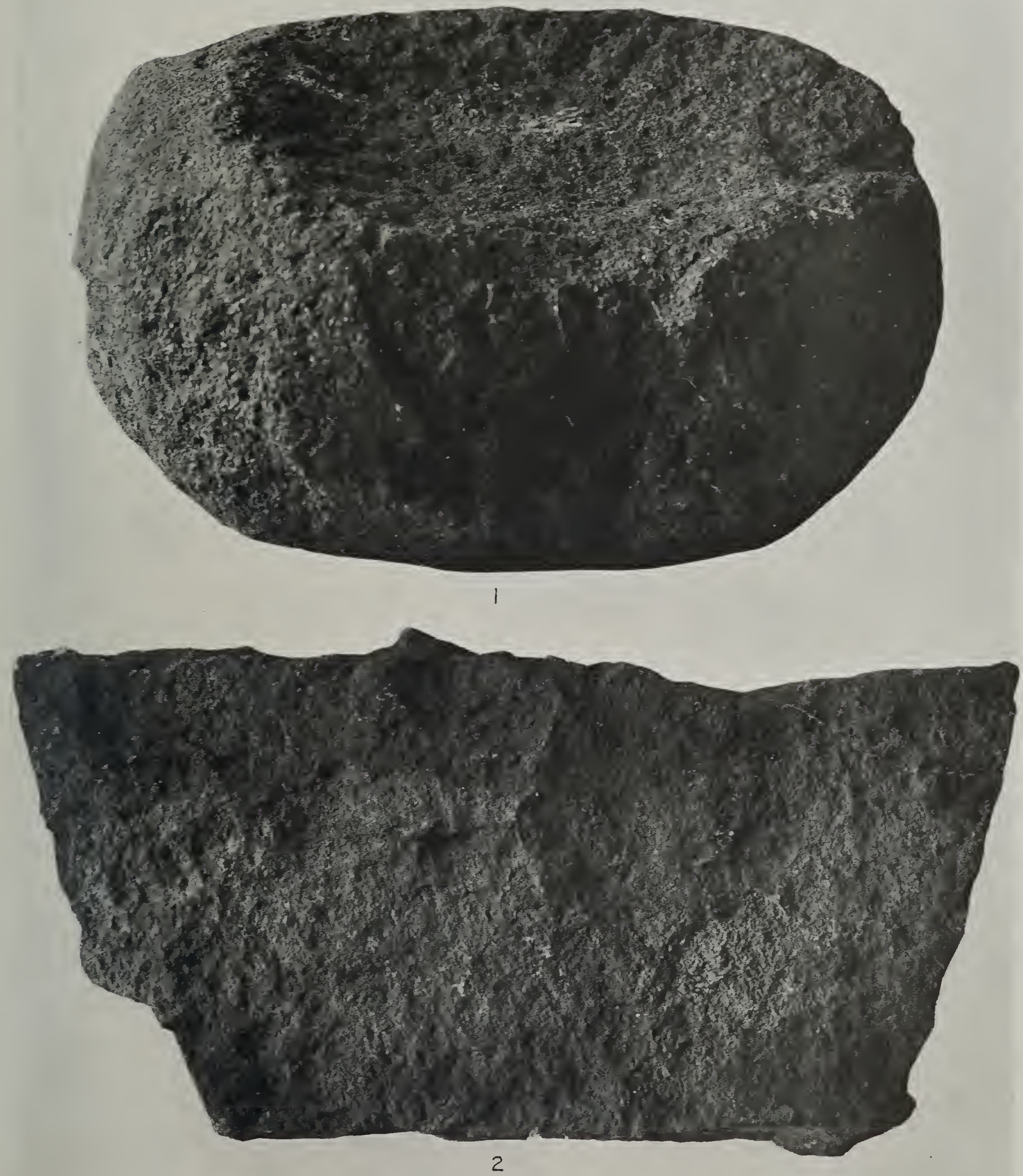

I. Stone lamp in process of manufacture.

2. Stone frying-pan. 

here our aim to describe bone sections of these implements, or fragments of them. Among the bone objects to be described are included implements, or portions of them, used not only in war and hunting, but as household utensils among the Aleut. The stone implements used in the manufacture of these objects of bone have already been described. Bone implements were polished with andesitic lava, but more glossy and fine vesicular, with andesitic tuff, and with horse-tail (Equisetum nyemale), as were implements of stone.

Considerable attention should be here given to the foreshafts. Many of them shown here are made of walrus-tusk ivory. Tusks of walrus, mammoth, and elephant, as well as the teeth, horns, and antlers of other animals, consist of layers of bony substances of differing density. The outer layer or crust is considerably harder and thicker than the inner portion, or pulp cavity, called cmix ${ }^{2}$ by the Aleut. In order to make long foreshafts and heads for throwing implements of walrus-tusk, it was necessary to saw or cut the tusk along its length, and thus only one side of the material contained the dense bone substance. In the course of time the side, with bone of lesser density, the cmix', contracted in drying, thus curving the implement. To prevent this bending, the Aleut made deep incisions in the cmix'. In the specimen shown in plate 23 , figure 22 , the incisions did not help, as they were not sufficiently deep. It should be noted, however, that the foreshaft was straight when excavated and became curved after exposure to the air.

In the course of excavations on the Aleutian Islands, as well as in Siberia, we found innumerable bent bone-implements which were originally straight, for otherwise they could not have been aimed either in warfare or hunting. According to the laws of ballistics, the path of any projectile depends on its form and partly on the manner of throwing it. For example, the Australian boomerang and the curved knives of some African tribes may fly in a complex curve and return to strike the ground behind the thrower. This is the result of the curved form of the weapon and also of the mode of throwing it with the hand from beneath upwards. The boomerang strikes, not with its pointed end, but with the sharpened outer edge of the curve. But in the case of an arrow discharged by a bowstring or of a spear cast with a throwing-board, it is necessary that the forward part of the missile, as well as the shaft, be quite straight, otherwise the weapon would change its path and strike the object, not with the pointed end, but with its flat or rounded curved side.

That primitive hunters knew that arrows and spears must be quite straight may be inferred from the use of special straighteners for the shaft. They also have a sharp eye to the condition of the weapon. We have seen Aleut or Yukaghir hunters verifying the straightness of their arrows or throwing-spears, before leaving for a hunt, by closing one eye and looking along the weapon with the other.

We refer to our field observations in order to show that there can be no curved projecting weapons, except of the boomerang type. Nevertheless, in every ethnographical museum curved bone-implements may be found. One European museum curator, who had not been in the field, inquired whether the author knew the mode of using curved spears. On the other hand, when the Aleut or Kamchadal were 


\section{Description of Plate 22.}

FIG. I (385). Bone foreshaft of a simple harpoon called igi'kax' by the Attu Aleut, and the foreshaft, igi'kam $q a g n \bar{a}^{\prime}, i$. e., the bone of the harpoon, igi'kax'. This, as well as the following 4 foreshafts on this plate, may perhaps be designated as heads, judging by their thickness. ${ }^{24}$ Such foreshafts were found only on Attu Island and are distinguished from the bone foreshafts of other simple harpoons

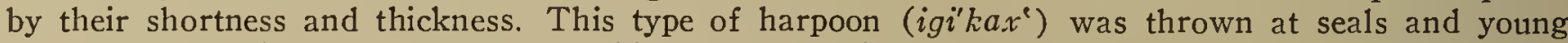
sea-lions from shore and not from a skin boat. Two kinds of $i g i^{\prime} k a x^{\prime}$ were distinguished, according to their size. The heavier one, called kala'gax', was thrown at animals not far from shore. The point of this harpoon was of bone, barbed on both sides, and when an animal was hit, the point was pulled out and remained in the wound when the shaft and the foreshaft were released. The base of the point had a hole for the attachment of a sinew string or thong, the other end of which was fastened to the shaft. The base of the bone foreshaft was bifurcated to receive the wedge-shaped upper end of the wooden shaft which was firmly fixed in this socket with fish-glue reinforced by a lashing of sinew cord. Directly over the bifurcation of the foreshaft was a perforation to which was attached a sinew cord, the other end of which was fastened to the lower, tapering, end of the shaft. Should the shaft be broken when the animal is struck, the heavy foreshaft remains attached to it and thus is secured from sinking. The foreshaft in the illustration (I) is made of a tooth of the whale called by the Aleut ayigi'gixi. It was found in Pit 4 , Nani'kax', Attu Island, at a depth of 1.7 meters, among the bones of whales.

FIG. 2 (3I8). Bone foreshaft similar to figure I, but smaller. It was found in the same pit.

FIG. 3 (3I6). Foreshaft similar to figure I, distinguished from it by its upper part, which is carved in the form of bird wings. Found at Nani'kaxe, Attu Island.

FIG. 4 (386). Foreshaft with a wedge-shaped base fitted into a slit at the end of the shaft. In the base of the foreshaft is a perforation to receive the bone peg which fixed it to the shaft. In addition, the end of the shaft was lashed with a sinew cord. The foreshaft has a lateral hole, similar to that in figure I, to which was attached a thong called unuxsuli'max', the other end of which was tied to the shaft. Found at Nani'kax', Attu Island.

FIG. 5 (453). Bone foreshaft similar to the preceding specimens, but with the lower end broken off. Traces of straight-lined ornamentation still remain. The head is carved like the wings of a bird, as in figure 3 . The foreshaft is distinguished from the others by a groove around the upper edge, to which the cord of the point had evidently been attached. Found at Nani'kax', Attu Island.

FIG. 6 (I855). Harpoon foreshaft made of a sea-lion's penis-bone. Its lower end was placed in a socket at the end of the shaft and was held in place by a bone ring. Found at Ukix, Umnak Island.

FIG. 7 (I5I7). Fragment of a bone handle $\left(u^{\prime} t u x^{\circ}\right)$ for a stone knife or adze. From Uglu'dax', Umnak Island.

FIG. 8 (I42I). Bone handle similar to the above, I $88 \mathrm{~mm}$. long. From Agla'gax', Umnak Island.

FIG. 9 (II66). Knife or adze handle, $170 \mathrm{~mm}$. long. From Ukix, Umnak Island.

FIG. Io (I5I4). Small bone shovel (kasi'gum takadu'ca) for removing from rocks and reefs, during low tide, the chiton Katharina tunicata Wood (Aleut, kasiguxi'). A wooden handle was attached to the grooved end. From Uglu'dax', Umnak Island.

Fig. II (1943). Fragment of an unfinished head of a simple harpoon. From Amaknax, Amaknax Island.

FIG. I2 (I244). Handle of a man's knife (cunu'six). Length, I70 mm. From Ukix, Umnak Island.

FIG. I3 (I347). Shovel similar to figure Io, but longer, and used without a handle. From Natxu'kax', Umnak Island.

FIG. I4 (483). Scraper (capta'six) for dressing guts. From Nani'kax', Attu Island.

FIG. I5 (280). Sea-otter's penis-bone ( $\left(\tilde{n} a^{\prime} t u m-u n \tilde{n}^{\prime}\right.$-qagna $\left.\bar{a}^{\prime}\right)$ which served as material for a flaking implement (see above, p. 70) or for points for small harpoon-darts. From Nani'kax', Attu Island.

FIG. I6 (285). Bone similar to the preceding, found at the same site.

FIG. I7 (I68I). Scraper for dressing seal-skins. From Agla'gax', Umnak Island.

FIG. I8 (I422). Knife (cumu'six) handle which had evidently served previously as a wedge for splitting wood, judging from the marks of hammer-strokes. The battered and pecked surface of the upper portion also bears evidence that the handle had been used as a hammer for breaking echini shells. Length, I43 mm. From Agla'gax', Umnak Island.

FIG. I9 (1243). Shovel like figures Io and I3. From Ukix, Umnak Island.

FIG. 20 (II7I). Skin-dressing scraper. Length, I60 mm. From Ukix, Umnak Island.

FIG. 2I (692). Fragment of a foreshaft of a harpoon called aga'lgits, for hunting seals and sea-otters. From Cave 2, Atxa'lax', Atka Island.

24 Because of the absence of barbs at the side, these have been designated as foreshafts. 

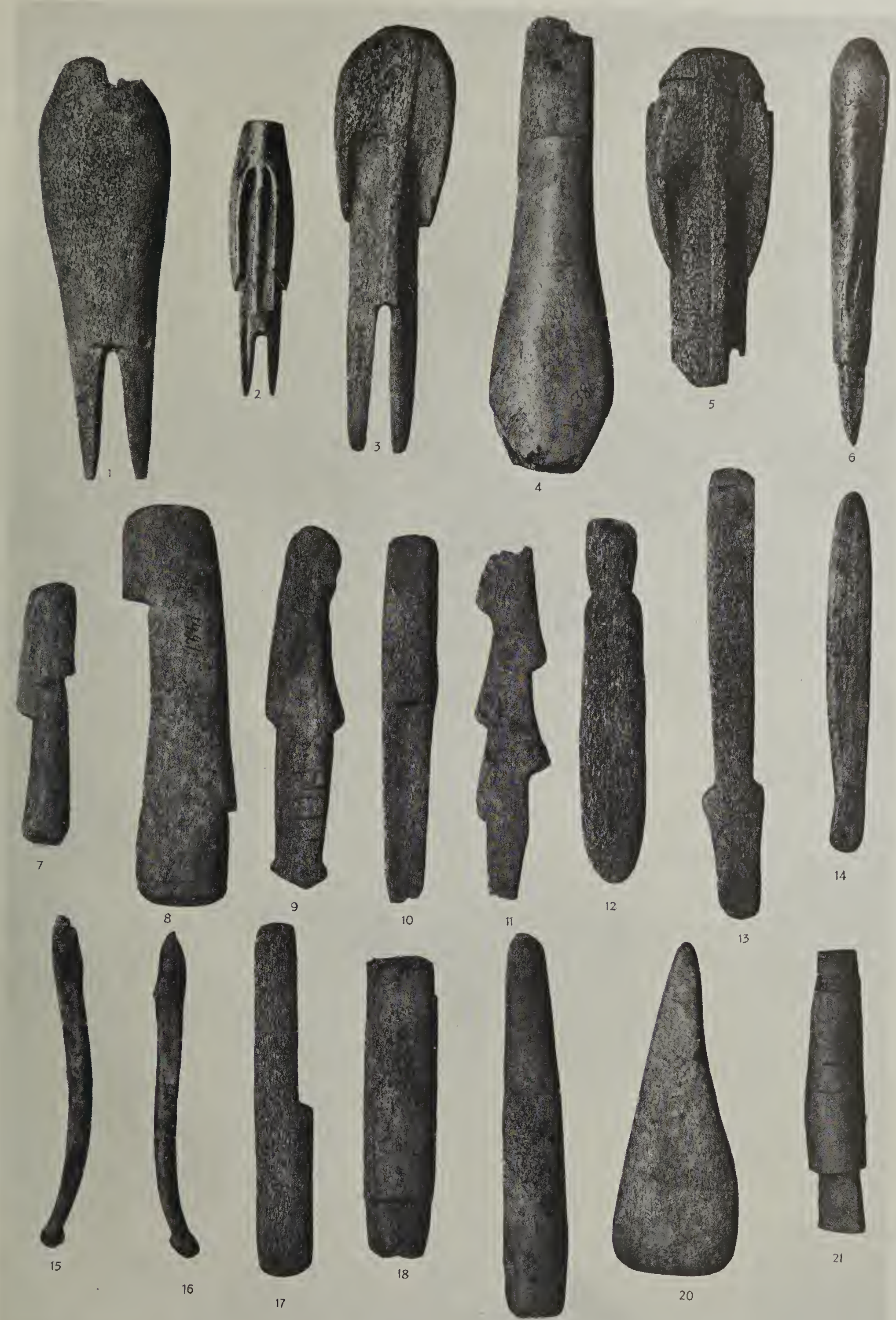

asked to explain the curved weapons found in excavations, they said that they were made straight, but became curved, owing to the unfitness of the material or the lack of skill of the maker.

The following text-figures belong with plate 22 :

FIG. 45 (315). Foreshaft of a simple harpoon (igi'kax', see plate 2I, figs. I to 5), made of the tooth of a whale (ayigigi ${ }^{\prime}$ ). The notches in the middle of the foreshaft are the marks of strokes with a stone adze. Evidently it had been intended to make some other implement from this foreshaft. The Aleut who assisted in the excavations believed that it was intended to cut off the fractured upper part to make a wedge of the lower part, but it is possible that the notched foreshaft, reminding one of a human figure, served as an amulet.

FIG. 46 (453). Foreshaft, illustrated also on plate 22, figure 5, showing the cavity for holding the point of the harpoon. This cavity is too large and had evidently been wedged with wood to decrease its size to receive the base of a bone point. From Nani'kax', Attu Island.

FIG. 47 (268). Bone knife used for smoothing the ribs of the frame of a skin boat. The handle is engraved and scratched to roughen its surface that it may not slip from the hand. From Nani'kax', Attu Island.

FIG. $48 \mathrm{~A}$ (1005). Much-decayed bone plate which had evidently served for removing mollusks from sea rocks. From Pit 2, Agla'gax', Umnak Island.

FIG. $48 B$ (1070). Scraper ( $q$ itqu'six ${ }^{\prime}$ ) for dressing bird-skins and guts of sea mammals. From Pit 2, Agla'gax'. Umnak Island, found in the lowest layer of kitchen refuse.
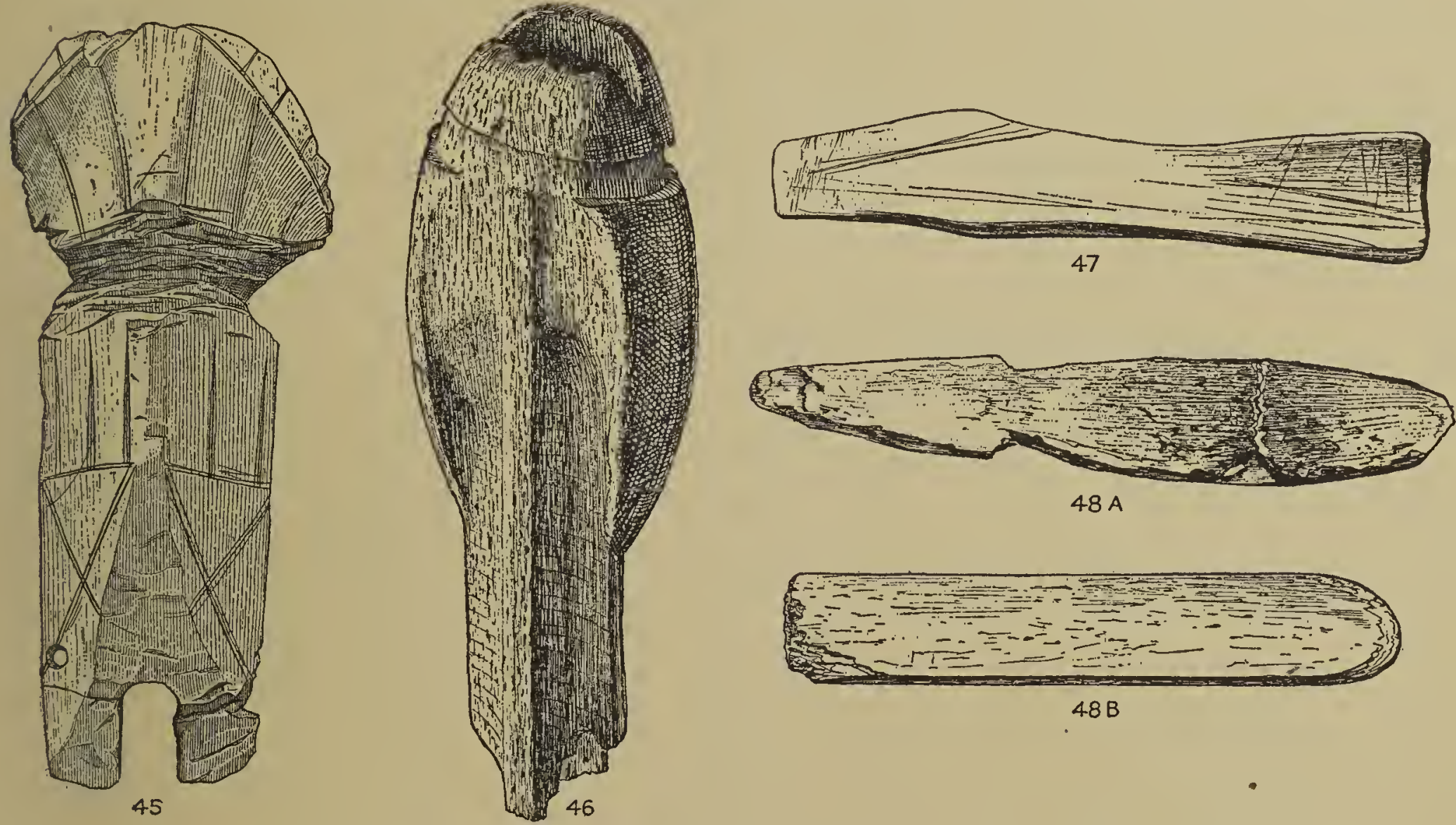

The knife shown in text-figure $49 A, B$ was cut out of a walrus-tusk in such a manner that the dentine is on one side and the pulp cavity on the other, and so the latter, in drying up, shortened and curved the knife. Figure $49 B$ presents a side view of the curved knife. Another knife (fig. 50) made from the same tusk, but only of the dentine, remains straight. Both knives are in the possession of the author. Figures $5 \mathrm{I}$ and 52 show 2 ice-picks which serve also as spears and are fastened to the butt end of the wooden shafts of Eskimo sealing-harpoons. These specimens (I-228I and 60.I-39I9) are in the American Museum of Natural History. The latter (fig. 52 ) is curved, owing to the cause before mentioned. Figure $5 \mathrm{I}$, however, has remained straight as a result of the groove in the pulp cavity. ${ }^{25}$

(Text continued on p. $8 I$.)

25 Similar specimens ma'y be found in every museum. Particularly worthy of mention are the ice-picks of harpoons in the U. S. National Museum, Washington, 


\section{Description of Plate 23.}

FIG. I (I75I). Walrus-tusk head of a war throwing-lance, with a sharpened point and without a stone blade. From Ukix, Umnak Island.

FIG. 2 (II47). Head of a war throwing-lance (anga'gim igiga'gan tumgä', i. e., a bone of a throwing-lance for man) with backward-pointing barbs and engraved ornament. For the method of attaching the head to other parts of the throwing-lance, see text-figure 53. The head was fastened to the shaft by means of the perforation above its base. This specimen was found together with figures 3 to 6 and 8 on the skeleton of a warrior in Pit I, Ukix, Umnak Island (see plate I I, fig. 3).

FIG. 3 (I I44). Lance-head similar to that shown in figure 2. The rounded stem of a stone blade was fitted into the ladle-like cavity in the bone head, which bore painted ornamentation, as evidenced by a few remnants of the paint (black and red) which still remained.

Frg. 4 (II46). (See fig. 3.) Stem of the bone head is broken off. In the cavity for receiving the stone point may be seen a yellow powder, the remains of glue yielded by a cod-fish eye.

FIGS. 5 (II45) and 6 (II47a) are similar to figure 2.

FIG. 7 (I5I). Bone harpoon-head used for hunting whales. A stone point was inserted in the bifurcated upper end. The peculiarity in this bone consists in the method of cutting deep into it over the barbs in order that some part may break when a whale is struck and thus become embedded in it. The lower rounded end swung freely in the socket of the shaft and was not attached. In striking, the shaft is entirely separated from the head. Found on Hog Island.

FIG. 8 (II48). See figure 2 (II47).

FIG. 9 (4I9). Bone head of a throwing-lance used in war as well as in hunting sea mammals. A stone blade was inserted in the bifurcated upper end. As was usual for throwing-lances, its head had backwardpointing barbs. It is shown on the plate in reverse position. From Nani'kax', Attu Island.

Figs. I I $(628)$, I2 $(656)$, I3 $(657)$, I4 (1345), I5 (629), I6 (936), and I7 (630) represent bone heads, or fragments of bone heads, of throwing-lances $($ cunilgixi $)$. With the exception of figure I4 (1345), found at Agla'gax' on Umnak Island, all the others were found, together with figure ro (627), in the layer containing skeletal remains in Cave 2, Atxa'lax', Atka Island.

Fig. I8 (4I7). Bone harpoon ( $\left.a k l i^{\prime} g a x^{\circ}\right)$ head, barbed only on one side. The harpoon was supplied with a bladder and was thrown at a sea mammal already wounded with another throwing-weapon. Found in Pit 4, Nani'kax' site, Attu Island, at a depth of 3 meters, in a layer of fish-bones.

FIG. I9 (69I). Unfinished foreshaft of a harpoon (aga'lgix'). From Cave 2, Atxa'lax', Atka Island.

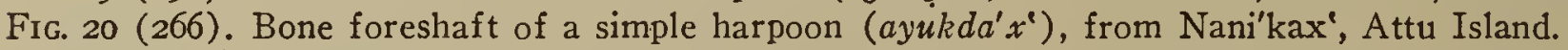

FIG. 2I (I359). Foreshaft, similar to the preceding, $260 \mathrm{~mm}$. long. From Ukix, Umnak Island.

FIG. 22 (I075). Foreshaft of a simple harpoon ( $\left.a y u k d a^{\prime} x^{\prime}\right)$ used for hunting sea-otters. The foreshaft appears bent in the illustration, but this was not its original form, it was curved afterwards. It is $264 \mathrm{~mm}$. long. Found in Pit 2, Agla'gax', Umnak Island.

FIG. 23 (1358). The foreshaft of a simple harpoon called ayukda' $x^{\prime}, 350 \mathrm{~mm}$. long. According to the Aleut, foreshafts in olden times were still longer. The specimen in this illustration is unfinished: the pocket to receive the bone head is not carved. From Ukix, Umnak Island.

FIg. 24 (II32). Bone foreshaft for a large and heavy harpoon called aga'lgix'. It was thrown at seals and seaotters in their rookeries. The end of the thong attached to the bone head was held by the hunter. The length of the foreshaft is $280 \mathrm{~mm}$. From Ukix, Umnak Island. 


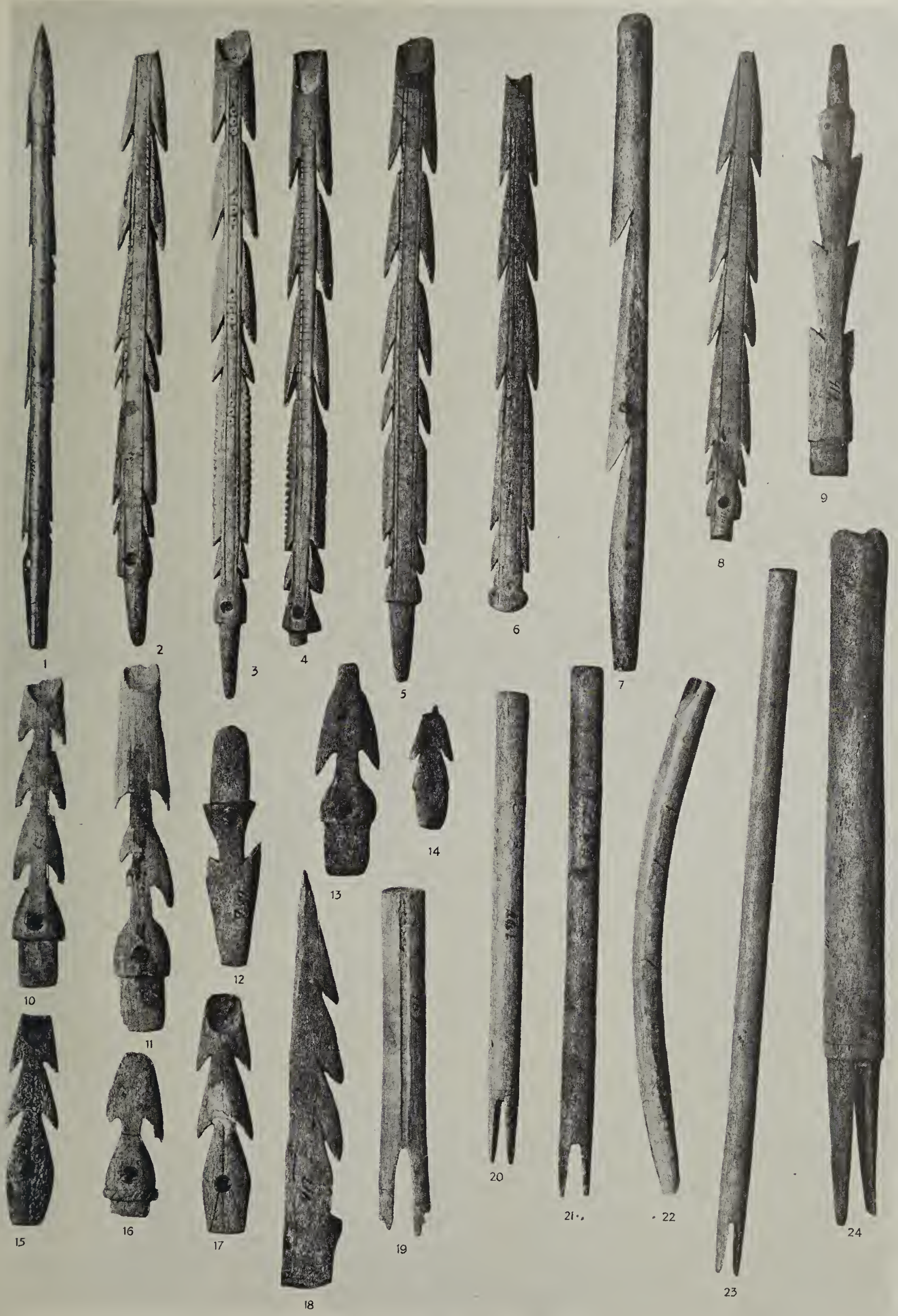

Bone heads of war and hunting-darts and foreshafts of harpoons. About two-fifths natural size. 

The best way to prevent implements from bending is to make them of bone of the same density throughout. Arrows and spears made of such material never curve. If, however, on account of lack of material, both layers of a tusk must be used, there are technical ways to prevent curving. Deep incisions are made on the side of lesser density. Ordinarily, such incisions are made at regular intervals, so that they look like ornamental lines. In this way we see how objects made for utility may eventually satisfy the esthetic sense. On some bone implements we have seen incised parallel lines, zigzags, dots, and circles on one side only, all made to prevent curving. Some arrow and spear heads were barbed on one side only, on the side of lesser density, to prevent curving. In this case, however, the barbs may have 2 practical ends in view: the technical one, and another, to inflict a severe, extraordinarily painful wound.
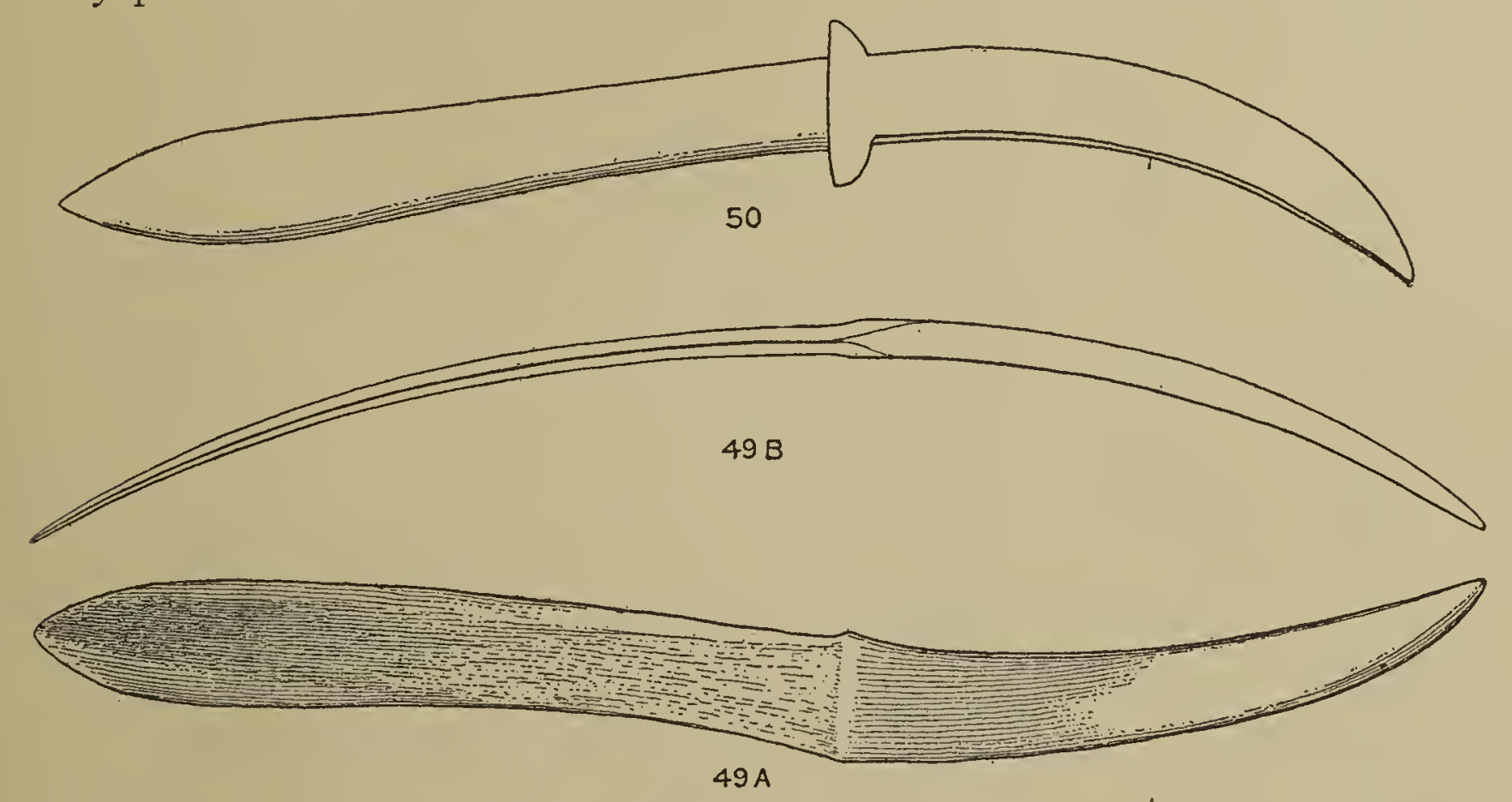

Frg. 49.- $A$, curved bone knife; $B$, side view.

FIG. 50.-Straight bone knife.

In connection with the foregoing, reference should be made to some Eskimo and Siberian bone spears with deep longitudinal grooves called "blood-channels," from the German, "Blut-Rinne." It has been suggested that the blood-channel may have been intended to serve as a channel through which to receive the blood from the wound. It appears to the writer that this idea has no foundation whatever. First, the spear is not a faucet, and the body of the animal is not a barrel. On the contrary, the form of the wound quite corresponds to the form of the weapon and the latter often appears rather as a spigot or plug stopping up the wound. ${ }^{26}$ Then, if some important deep-lying blood-vessels are hit, like the heart blood-vessels, there may be only internal bleeding. We have frequently observed the reindeer breeder killing reindeer for food. They stab them in the heart with a spear and there is no external bleeding at all, except for a few drops of blood. But abundant external bleeding takes place when blood-vessels nearer the surface are hit, like the neck

26 Some hunting tribes, for instance, the Eskimo, use bone plugs to close the wounds of animals, but this is done after the spear is removed (see Franz Boas, The Central Eskimo, p. 479; idem. The Eskimo of Baffin Land and Hudson Bay, pp. I8, I9.) 
arteries; but in this case the grooved spear is useless. The blood will spurt as from a fountain and the natives, eager not to lose it, put a vessel under the wound to catch it. The purpose of the so-called blood-channel, therefore, is made merely to prevent the spear from curving. This may best be shown by the illustrations in figures $5 \mathrm{I}$ and 52 .

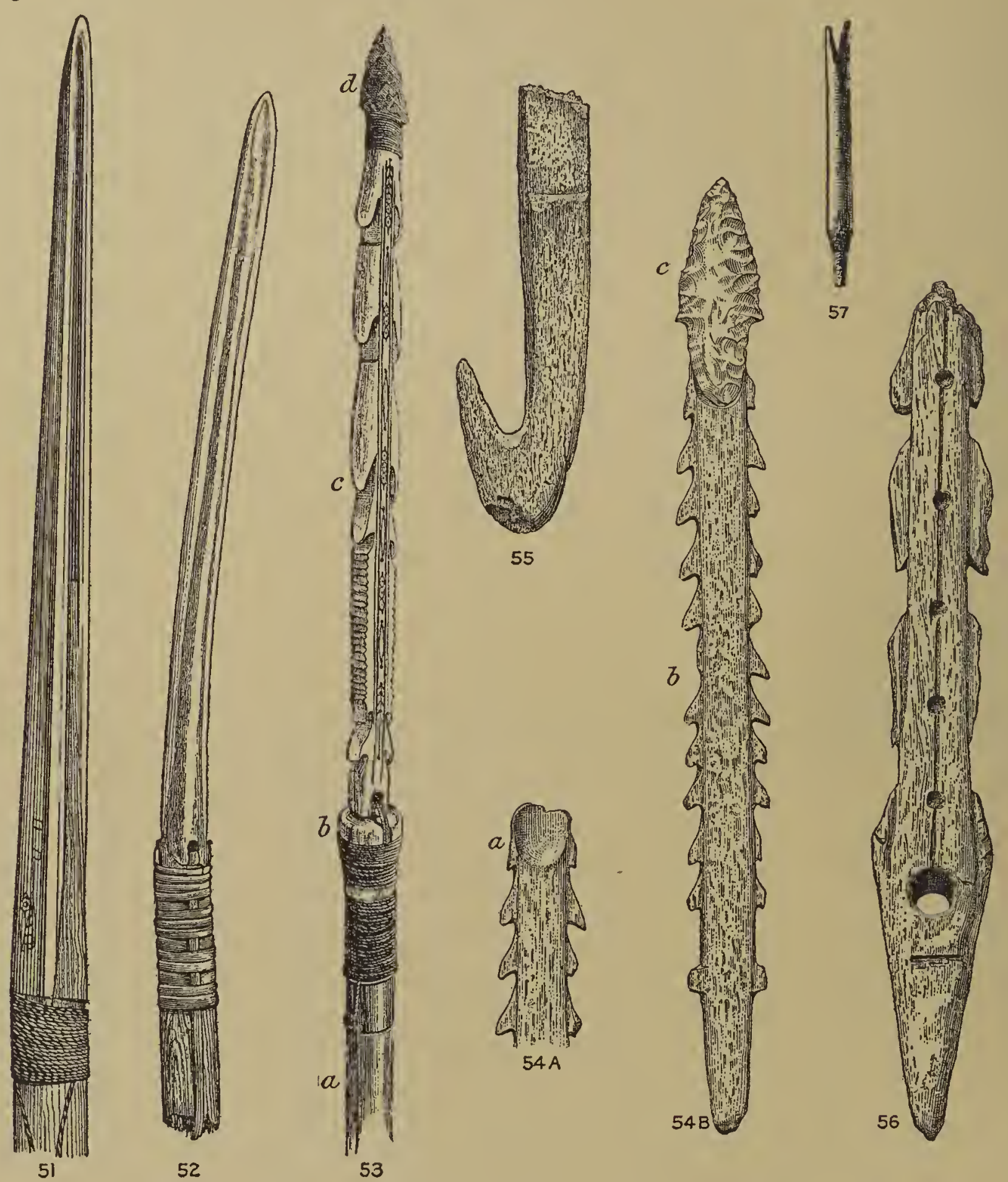

FIGS. 5I to 57--5I, straight ice-pick of a harpoon; 52, curved ice-pick of a harpoon; 53. throwing-lance for war; 54, sections of a throwing-lance for war; 55, bone point of fish-spear ; 56, harpoon-head; 57 , foreshaft of bow-arrow.

Evidently this method of preventing curvature in bone implements was known to Stone Age man in Europe. Obermaier, when illustrating bone spear-heads of the late palæolithic period in France, calls the grooves on some of them "Blut-bzw. Giftrinnen." We can say nothing about poison, but these grooves were certainly not made for the purpose of obtaining blood from the wound. ${ }^{2 T}$

27 Dr. Hugo Obermaier, Der Mensch der Vorzeit. Allgemeine Verlags Gesellschaft, Berlin-MunchenWien, p. 296, and p1. 22, figs. 10, 16, 20. 
This applies also to some specimens found by Rivière at a palæolithic station at Laugerie Haute, France, and at present in the Peabody Museum at Yale University. Doctor G. G. MacCurdy, in his article on that collection, gives illustrations of " pointed implements of reindeer horn, two with longitudinal grooves (presumably for the outflow of blood) and one with small oblique grooves." ${ }^{28}$ In the opinion of the writer, there can be no doubt that the longitudinal grooves in the 2 specimens are the result of removing the inner bone substance to prevent their bending and that the oblique grooves of the third specimen were made to the same end, but without removing the pulp-cavity.

It should be added that grooves often appear on swords, daggers, and knives of bronze and steel which, like those on bone weapons, are called blood-channels. These certainly are not made to receive blood, but in imitation of bone weapons, since there seems no doubt that with the coming of the metal age man imitated in metal the implements of the stone age.

The following text-figures belong with plate 23:

Text-figure 53 ( 1699 ) demonstrates how different parts of the war throwinglance were joined (see figs. 2 to 6 and 8, plate 22). The lance was called anga'gim igiq $\bar{a}^{\prime}, i$. e., a throwing-spear for man, or ali'txum igiqa $\bar{a}^{\prime}, i . e .$, a war throwing-spear. $a$, shaft $\left(i^{\prime}\right.$ glax $\left.{ }^{i}\right) ; b$, bone ring or bone belt (tu'mux $\left.{ }^{i}\right)$ consisting of 2 halves; $c$, bone foreshaft called igi'qax', as the whole weapon; $d$, stone point $\left(k a^{\prime} d a x^{*}\right)$ of andesite.

The bone belt, into which the stem of the foreshaft enters, is placed on the wedge-shaped end of the shaft. Through a perforation in the foreshaft above its stem and by means of a sinew cord, the foreshaft is fastened to the bone belt. This cord is lashed all around the belt, covering it altogether. The lashing is continued also below the belt around the shaft and the end, stretching forth along the shaft, is fastened to its lower end. The stone point or blade is received by the ladle-like cavity in upper end of the foreshaft to which it is attached with glue made from a cod-fish eye or by gum resin and fastened with a sinew thread lashing. The length of the barbed foreshaft corresponds to the distance between the planes of chest and spine of an adult. The spear, when hitting the chest, had to pass through the body and perforate the spine. The backward-pointing barbs ( $t a^{\prime} l i n$, plural from ta'lix', twig) were made so that the spear could not be extracted from the wound. The barbs have sharpened edges and are hollowed out inside. The ornaments on the foreshaft were incised with a stone implement, and the engraved figures were filled with black or red paint. The general name for engravings is cuñ'sin from $c u^{\prime} \tilde{n} a n$, dam of a river. Separately engraved figures are called: the notched ornament at the sides, $c u^{\prime} \tilde{n} a x^{i}, i . e$. , a stick of a dam or weir; $c u^{\prime} d u x^{i}$, ornament of incised lines; cu'mix', dots; qixma'dgux', circular dots or punch-marks; all other figures are called anugna'sin. This type of throwing-spear was cast at a distance of 20 fathoms; a dextrous warrior could throw at a distance of 25 fathoms. Made by Boris Besyasykov, an old Aleut on Umnak Island.

(Text continued on p. 85.)

${ }^{28}$ See George Grant MacCurdy, Certain Specimens from the Rivière Collection, American Anthropologist, vol. 25 , No. I, I 923, p. 8 I. 


\section{Description of Plate 24.}

FIG. I (989). One of the circular prongs of a dart for water birds (cata'six $\left.x^{\prime}\right)$. It consisted of a shaft ( $\left.i^{\prime} g l a x^{\prime}\right)$ and of 4 barbed bone prongs ( $n u^{\prime} g i n, c a t a^{\prime} \sin$, or cata'sim kada'ñin). One of the prongs, the central one, was straight. The other 3 , the circular ones, were curved. Found in Pit I, Agla'gax', Umnak Island.

FIG. 2 (2113). Similar to figure I, made of walrus ivory. Length $197 \mathrm{~mm}$. Found at a depth of 0.7 meter at Tanaxta'xax', Amaknax Island.

FIG. 3 (2II4). A fragment of a circular prong of a fish-spear. Found at a depth of 2.2 meters at Tanaxta'xax', Amaknax Island.

FIG. 4 (I5I9). A fragment of the central prong of a fish spear. Found at Uglu'dax', Umnak Island.

FIg. 5 (2III). A circular prong of a fish spear of walrus ivory. Length $25 \mathrm{~mm}$. Found at a depth of 0.7 meter, at Tanaxta'xax', Amaknax Island.

Fig. 6 (2:II2). A specimen similar to figure 5 ; length $240 \mathrm{~mm}$.

FIG. 7 (I577). Awl (axsila'six', i. e., that by which holes are made) made of an albatross wing. From Uglu'dax', Umnak Island.

FIG. 8 ( (1570). Bone awl for splitting sinews of sea mammals into threads for sewing, called iga'cim-caglisi ${ }^{\prime}$, i. e., implement for splitting sinews. From Uglu'dax', Umnak Island.

Figs. 9 (350) and io (44I). Bone awls similar to the preceding. Found at Nani'kax', Attu Island.

FIG. II (839). Piece of bone of an albatross's wing cut off for making needles. From Hala'ca, Atka Island.

FIG. I2 (442). Similar to figures 9 and 10.

FIGS. I3 (2108), I4 (2038), I5 (973), I6 (I270), I7 (204I), I8 (984), I9 (II 84), 20 (I960), 2I (IIII), 22 (I527), 23 (175), 24 (2150), 25 (1077), and 26 ( 1524 ) represent bone heads or points of a small harpoon, called ayukda'xi, used in the sea from skin boats in hunting sea-otters and seals. As distinguished from other heads and points called $k a^{\prime} d a x^{\prime}$, these heads also have a special name, saxsi'daxi or ayugda'gim saxsi'da. These bone heads vary with reference to the number and position of their barbs, which occur on one or both sides of the head. The flat tang is loosely fitted into the foreshaft and the harpoon cord is attached to the neck of the head above the tang. Judging from the fragment, only figure 2I had a perforation above the tang. It is possible that originally it was a head for a large simple harpoon of the aga'lyix type which was later sharpened off. Figures I3 and I4 were found in Tanaxta'xax' on Amaknax Island; figures 14 and 17 at Xata'cxan, Amaknax Island; figures 15, 18, 20, and 25 at Agla'gax', Umnak Island; figures 16 and 19 at Ukix, Umnak Island; figures $2 \mathrm{I}$ and 23 at Natxu'kax', Umnak Island; and figures 22 and 26 at Ugh'dax', Umnak Island.

FIG. 27 (1338). Foreshaft for a bow-arrow, from Agla'gax', Umnak Island. The top is turned down on the plate.

Fig. 28 (1057). Head of the harpoon ayugda'x [see fig. I3 (2108)], from Agla'gax', Umnak Island.

FIG. 29 (1552). Head of a small harpoon (akli'gixi) thrown at seals, sea-otters, and fur-seals, while in their rookeries, at a short distance. The head was called cuyini'lgix or akli'gin cuyinilgín. It was attached to a thong held by the hunter, was $87 \mathrm{~mm}$. long, and was found in Pit I at Agla'gax', Umnak Island.

FIG. 30 (III6). Fragment of the central prong of a bird throwing-spear from Natxu'kax', Umnak Island.

FIG. 3I (I078). Head of a harpoon ( $\left.a y u g d a^{\prime} x^{\prime}\right)$ with point broken off. Found in Pit 2, Agla'gax', Umnak Island.

FIG. 32 (2042). Fragment of the central prong of a bird throwing-spear from Xata'cxan, Amaknax Island.

FIG. 33 (II43). Bone prong of an implement by which sea-urchins were obtained from the water. This implement was called cuniga'sixe and consisted of a long shaft to the end of which four circular bone prongs (cuniga'sim agat $\bar{u}^{\prime}, i$. e., tooth of the implement, cuniga'six') were tied. From Ukix, Umnak Island.

Fig. 34 (I45). Bone point $\left(k a^{\prime} d a x^{\prime}\right)$ of an arrow $\left(a g a^{\prime} d a x^{\prime}\right)$ used with a bow (sa'yigix $)$, according to information obtained from the Aleut assisting with the excavations. Unbarbed points or heads were not used for hunting birds or mammals. Found on Hog Island.29

Fig. 35 ( I 107). Fragment of a circular bone prong for a bird throwing-spear from Natxu'kax', Umnak Island.

FIG. 36 (2039). Fragment similar to that in figure 35, from Xata'cxan, Amaknax Island.

FIG. 37 (I I96). Central prong of a bird-dart. Length $150 \mathrm{~mm}$. From Pit 3, Ukix, Umnak Island.

FIG. 38 (1009). Fragment of the central prong of a bird-dart. From Pit 2, Agla'gax', Umnak Island.

FIG. 39 (I542). Head of a bow-arrow (sa'yigim agada'gan kadā' or tumgä, $i$. e., a point or bone of an arrow for a bow). From Uglu'dax', Umnak Island.

FIG. 40 (1071). Central prong of a bird-dart. Found in the lowest layer of kitchen refuse in Pit 2, Agla'gax', Umnak Island. It is $176 \mathrm{~mm}$. long.

FIGS. 4I (IOI4) and 42 (IOI3). Fragments of the central prongs of bird-darts. From Pit 2, Agla'gax', Umnak Island.

Fic. 43 (428). Head of a harpoon called ayukda' $x^{\prime}$ from Nani'kax', Attu Island.

FIGS. 44 (775) and $45(764)$. Central prongs of bird-darts with points broken off. Found at a depth of 2.8 meters, under a layer containing skeletal remains, in Cave 2, Atxa'lax', Atka Island. On the plate. their bases are turned up.

${ }^{29}$ In connection with the statement of the Unalaska Aleut working on Hog Island, it should also be noted that the Atka Aleut told us of some unbarbed bone heads and of points of throwing-lances for hunting sea mammals. (See pl. 25, figs. 29, 30.) 


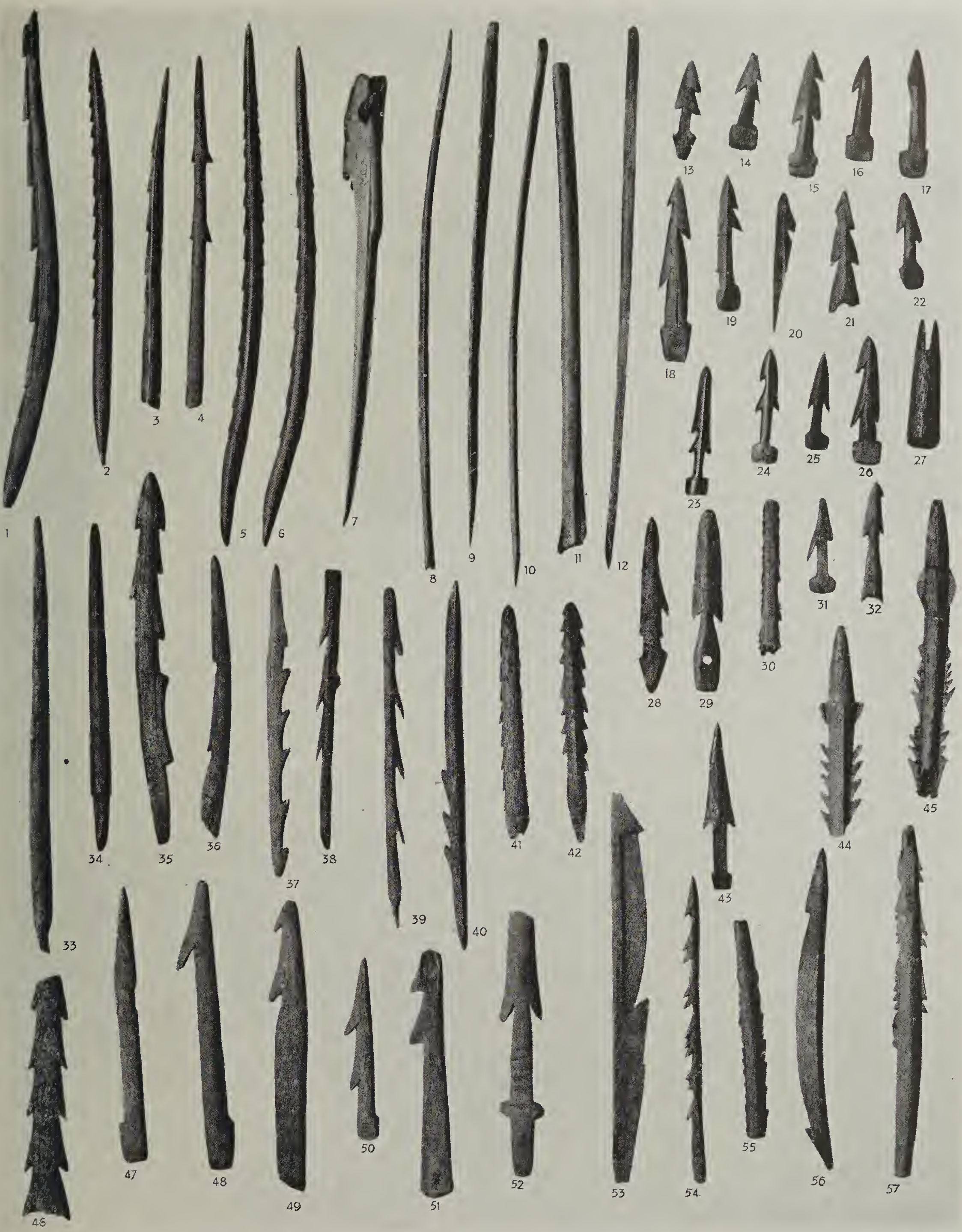

Bone points for throwing-implements, bird-darts, small harpoons, and sections of other bone implements. 

Description of Plate 24 (Continued)

FIG. 46 (32I). Fragment of a head, evidently of a fishing-lance. From Nani'kax', Attu Island.

FIG. 47 (III7). Head of a fishing-lance with the barbs broken. From Amaknax, Amaknax Island.

FIg. 48 (I929). Head of a fishing-lance in the form of a hook, from Natxu'kax', Umnak Island.

FIG. 49 (IOI I). Head of a fishing-lance from Agla'gax', Umnak Island.

FIG. 50 (I5I9). Harpoon-head ( $\left.a y u k d a^{\prime} x^{2}\right)$ from Uglu'dax', Umnak Island.

FIG. 5I (I030). Head ( $\left(a^{\prime} q a x^{\circ}\right)$ of a fishing-spear ( $\left.a y a^{\prime} k u x^{\circ}\right)$ with the point broken off. Found at a depth of 5.2 meters, in Pit 2, Agla'gax', Umnak Island.

FIG. 52 (I5II). Head of throwing-lance used for hitting seals and fur seals when sleeping on surface of water. At such times they may be closely approached in skin boats. The bone head of these lances had stone points. The engraved cross-lines are property marks (ana'tix $\left.{ }^{i}\right)$. From Uglu'dax', Umnak Island.

FIG. 53 (435). Unfinished section of a throwing-implement, possibly the circular prong of a bird-dart (see fig. 56). From Nani'kax', Attu Island.

FIg. $54(769)$. The central prong of a bird-dart. From Cave 2, Atxa'lax', Atka Island.

FIG. 55 (I049). Fragment of the central prong of a bird-dart. From Pit 2, Site Agla'gax', Umnak Island.

FIG. 56 (277). Circular prong of a bird-dart, according to the statements of the Aleut. The prong was tied to the shaft by one of the end barbs. From Nani'kax', Attu Island.

FIG. 57 (76I). Central prong of a bird-dart found at a depth of 2.8 meters in Cave 2, Atxa'lax', Atka Island.

Figure 54 $(A$ to $C)$ represents another kind of bone head with a stone point used in war. Both parts of this war throwing-spear were found in Cave 2, Atxa'lax', Atka Island. On Atka Island, as on the islands of Attu and Umnak, the stone point of a war spear was received by a ladle-like cavity in the barbed bone-head. $A$ shows the upper end of the head with the cavity for receiving the stem of the stone point; $B$, the natural size of the whole bone head. The stem of the bone head was placed in the bone belt on the upper end of the shaft and fastened to it by means of projecting spurs over the stem and a sinew cord. The bone of the head was much decayed and the backward-pointed barbs are blinted or have fallen off. $C$ (905) is a stone point of light-green hornstone schist with thin veins of quartz.

Figure 55 (II70). Bone point ( $\left.s a^{\prime} q a x^{\prime}\right)$ of a fish-spear ( $\left.a y a^{\prime} k u x^{\circ}\right)$. The point was attached directly to the shaft. A piece was cut from the lower end. A piece was also cut off the shaft to receive the point. The joint was lashed by a sinew cord and strips of whalebone. The end of the point was decayed in the earth. With this lance fish were speared near the dam or weir. Found in Ukix, Umnak Island.

The following text-figures are connected with plate 25:

Figure 56 (I774). Head (cuyini'lgix ${ }^{\circ}$ ) of the harpoon (aga'lgixi) which was cast at sea mammals, chiefly sea-otters, when they were asleep on rookeries and when the hunters could steal upon them under cover of the darkness. When an animal was struck the hunter tightened the sinew thong attached to the harpoon-head; the other end of the line was held by the hunter, who after having drawn the animal within reach, clubbed it to death. The barbs on the head decayed in the earth. The head is ornamented with dots engraved on a line. A notch under the cord perforation is a property-mark (ana'tix ${ }^{\circ}$ ). Found in Cave 2, Atxa'lax', Atka Island.

Figure 57 (I90r). Foreshaft of a bow-arrow into the bifurcated upper end of which a stone point was inserted. The foreshafts of bow-arrows shown in plate 24, figure 27 , and on plate 25 , figures $19,20,33,35$, and 37 were attached to the shaft at the bifurcated end, and a bone point was inserted in the socket at the other end. Found at Amaknax, Amaknax Island.

(Text continued on p.87.) 


\section{Description of Plate 25.}

FIG. I (I374). Head of a small harpoon for hunting fur-seals. On Atka Island, the harpoon was called $t i^{\prime} n i x^{*}$

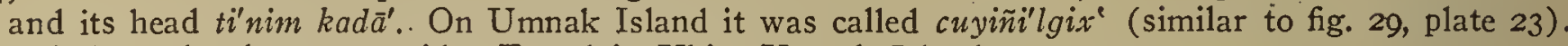
It. is barbed only on one side. Found in Ukix, Umnak Island.

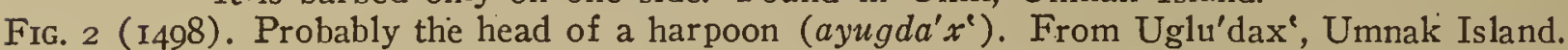

FIGS. 3 (906), 4 (I543), and 5 (772). Central prongs of a bird-dart. Figures 3 and 5 were found in Cave 2, Atxa'lax', Atka Island, and figure 4 in Uglu'dax', Umnak Island.

FIG. 6. (Io14). Head of a harpoon (cuyiñilgix') for hunting seals and fur-seals. From Pit 2, Agla'gax', Umnak Island.

FIG. 7 (767). Central prong of a bird-dart. From Cave 2, Atxa'lax', Umnak Island.

Figs. 8 (I69I) and 9 (427). Harpoon (cuyiñilgix') heads for hunting seals and fur-seals. Figure 8 was found in Uglu'dax', Umnak Island, and figure 9 at Nani'kax', Attu Island. In the Attu dialect, the harpoon (cuyiñi'lgixi) is called agalga'yaxi.

FIG. Io (I9I3). Harpoon-head similar to figure I. Found at a depth of I meter at Amaknax, Amaknax Island.

FIG. II (2073). Fragment of a fish-spear found at a depth of 3.7 meters at Xata'cxan, Amaknax Island.

FIG. I2 (418). The head of a throwing-lance (igi'qax ${ }^{\circ}$ ) with barbs on both sides. This type of lance was cast at sea mammals in the water from a position on shore. It is a light weapon and is capable of being thrown for considerable distances. According to the Attu people, the throwing-lance (igi'qax ${ }^{i}$ ) was used in war and particularly in battles with the first Russian invaders. From Nani'kax', Attu Island.

Figs. I3 (998), I4 (999) and I5 (776). Fragments of the central prongs of bird-darts. Figures I3 and I4 were found in Pit 2, Agla'gax', Umnak Island, and figure I5 at a depth of.2.8 meters at Atxa'lax', Atka Island.

FIG. I6 (IOI5). The head of a harpoon (cuyinilgixi) for hunting seals and sea-otters. It is barbed on one side only. The barbs are.carved out in a particular way and hollowed out inside (see text-fig. 83 ).

FIG. I7 (1520). Circular prong of a bird-dart. From Uglu'dax', Umnak Island.

FIG. I8 (1366): The head of a broken arrow-point, evidently for a bow arrow. From Ukix, Umnak Island.

FIGS. I9 (1206) and 20 (I012). Foreshafts of bow-arrows, shown with the bases turned up. The tapering end of the shaft is inserted in the bifurcated end while the upper end contains a socket to receive the point. From Ukix, Umnak Island.

FIGS. 2I (I335) and 22 (I0I2). Circular prongs of bird-darts. Figure 21 is a fragment. Found in Pit 2, Agla'gax', Umnak Island.

Fig. 23 (768). Harpoon-head similar to that shown in figure:I6.: Found in Cave 2, Atxa'lax', Atka Island.

FIG. 24 (i i 80 ). Unfinished central prong of a bird-dart. From Ukix, Umnak Island.

Fig. 25 (I935). Fragment of a fish-spear. From Amaknax; Amaknax Island.

FIG. 26 (2029). Fragment of a harpoon-head (áyuqda'x). From Xata'cxan, Amaknax Island.

FIGS. 27 (I282) and 28 (1356). Fish-spear heads. The projections at the lower ends are for tying the head to the shaft. The points had" decayed." From Ukix, Umnak Island.

FIGS. 29 (1204), 30 (1038) and 31 (I203). (See.fig. I.) Figures 29 and 31 were found in Ukix, on Umnak Island, and figure 30 in Pit 2, Agla'gax', Umnak Island.

FIG. 32 (1692). Foreshaft of a throwing-lance (igi'qax $x^{\circ}$ used in war as well as in hunting sea mammals. The bone is slightly decayed. From Agla'gax', Umnak Island.

FIG. 33 (I75). Foreshaft of a bow-arrow. From Ukix, Umnak Island.

Fig. 34 (990). Head of a fish-spear ( $a y a^{\prime} k u m$ saq $\left.\bar{a}^{\prime}\right)$. From Agla'gax'; Umnak Ișland.

FIg. 35 (I47). Foreshaft of a bow-arrow. From Hog Island.

FIG. 36. (I352). Harpoon head (cuyiñi'lgixi) for hunting fur-seals. It is $15 \mathrm{I} \mathrm{mm}$. long and is distinguished from other harpoons of this kind by the perforation in the tang for a thong. Ukix, Umnak Island.

FIG. 37 (II87). Walrus ivory foreshaft of a bow-arrow (sa'yigim agada'gan tumga'kix), $97 \mathrm{~mm}$. long. From Ukix, Umnak Island.

Figs. 38 (III5) and 39 (2075). Heads of fish spears. Figure 38 was found in Natxu'kax', Umnak Island, and figure 39 in Xata'cxan, Amaknax Island, at a depth of 3.7 meters.

Figs. 40 (934), 4I (II83), 42 (I090) and 43 (I089). Points for fish-hooks. Figure 40 was found in Cave 2 , Atxa'lax', Atka Island. Figure 4I, made of a sea-lion's tooth, was found at Ukix, Umnak Island. Figures 42 and 43 were found in Pit 3 , Agla'gax '; Umnak Island.

Figs. 44 (I260, I I93, 9I I ), 45 (I 26I ), 46 (I087, I550, I088), 47 (I583, I 55 I, I 255), 48 .(I259, I69I, I072), 49 (I254 I673, I258), $50^{\circ}$ (910, 762, I369), and 51 (851, I218, I857). Points and bow-shaped parts of hooks for fishing-lines. For a detailed description of such a hook see text-figure 58: These specimens:were found at the following sites: Ukix, Umnak, I254, I255, I257, I258, I259, .I260, I26I, I278, I I93, I367, I69I ; Uglu'dax', Umnak, I550, I55I, I583; Agla'gax', Umnak, I072 (found in Pit 2, in the lowest layer of kitchen :refuse); 1087 and "I088 (in.Pit 3), I673; Atka Island, at Atxa'lax', 762, 9I0 and 9II (in Cave 2, at a depth of 2.8 meters); Hala'ca, 85 I. 

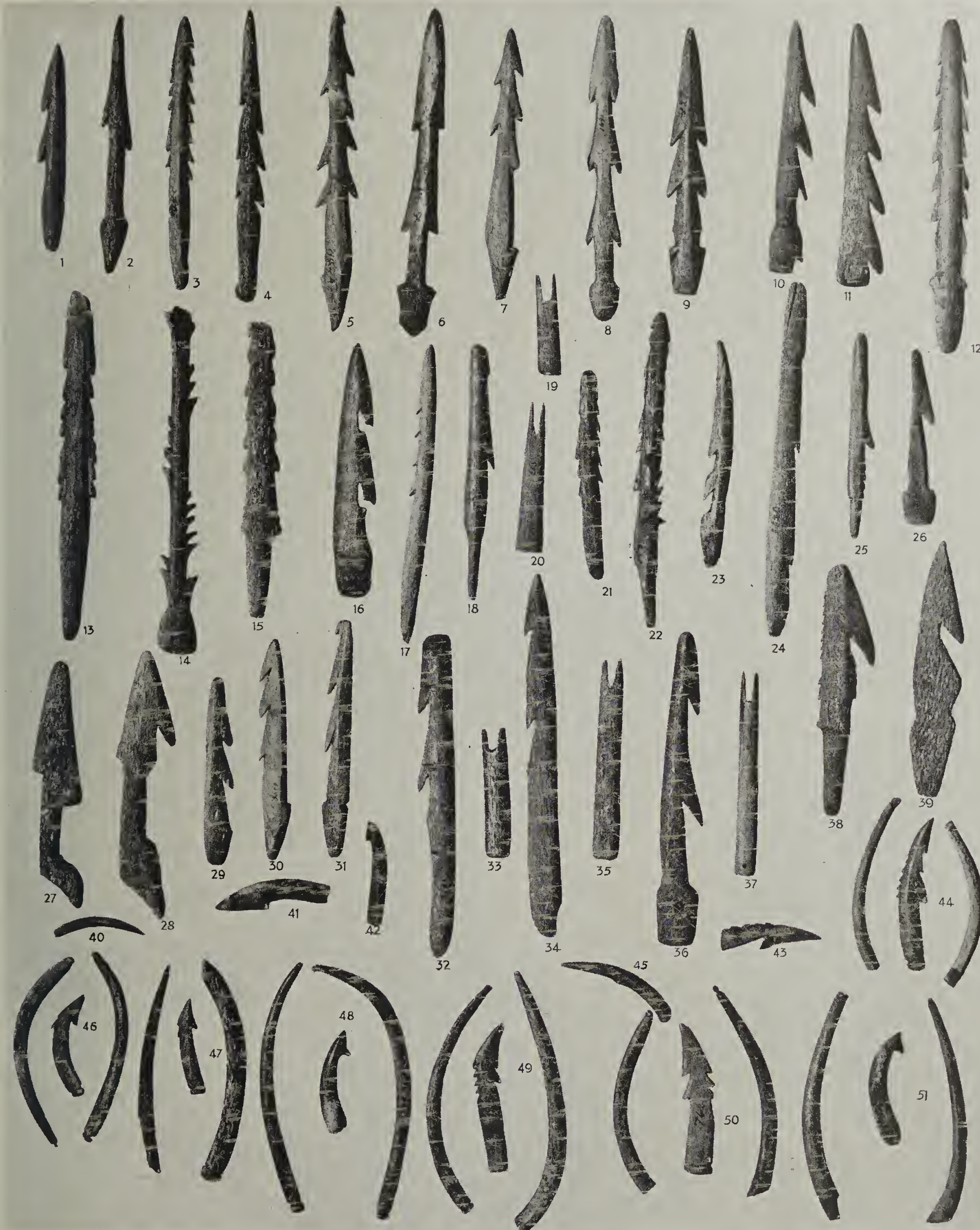

${ }^{19}$
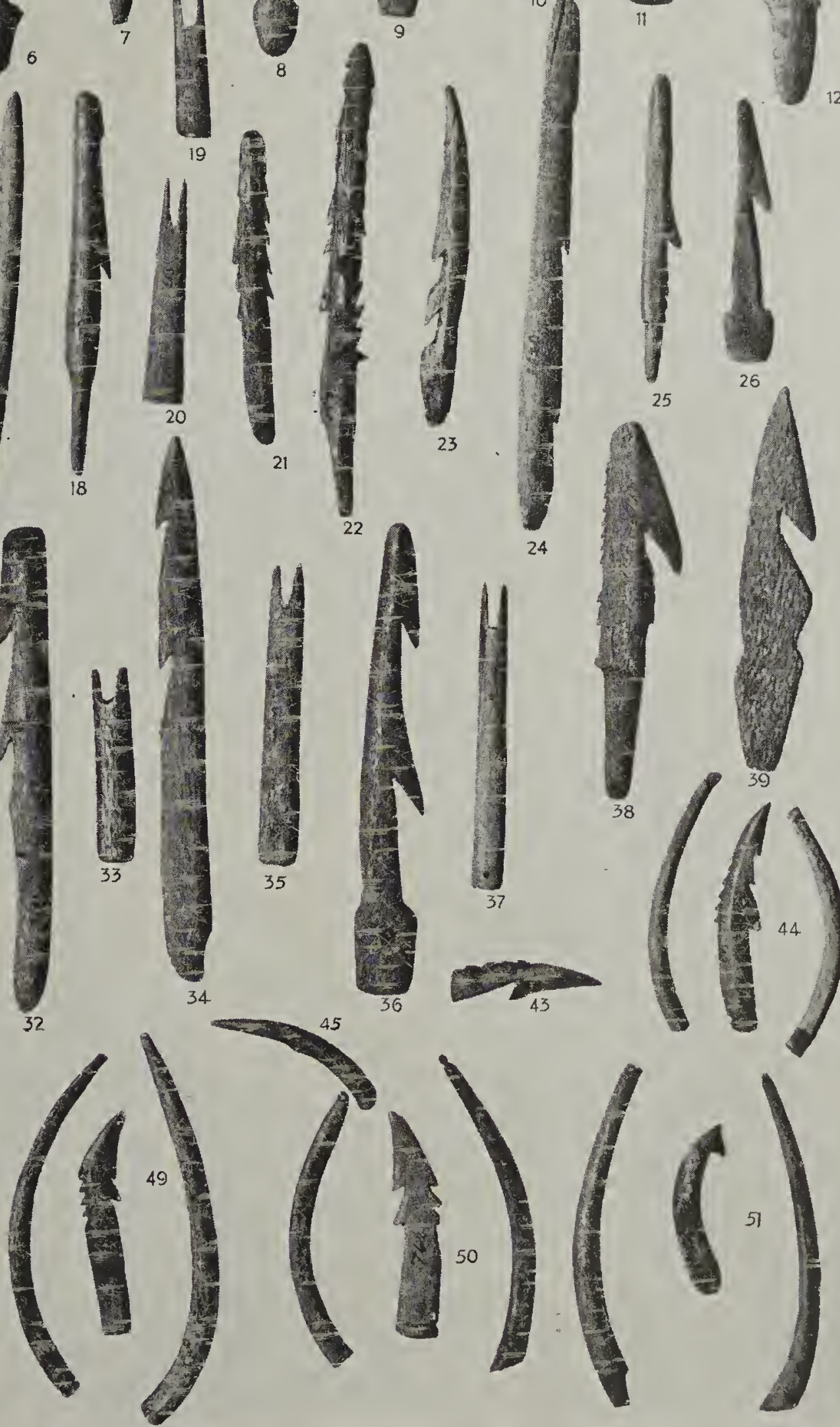

Bone points for throwing-implements, foreshafts of bow-arrows, sections of fish-hooks and other bone implements. 

In text-figure $58, A$ ( 1088 ) and $B$ ( 1550 ) represent two parts of a bone hook for a fishing-line: $A$, the bow-shaped section $\left(u^{\prime} m x^{\prime} x^{\circ}\right)$, and $B$, the curved point (qix $x^{\circ}$; $C$ shows the hook in natural size. ${ }^{32}$ For catching fish of smaller size, the hooks were of smaller size, as shown on plate 25 .

Text-figure $59 A$ (I 529) and $B$ (I954). For catching small fish in shallow water, there were simple hooks of one piece of bone $\left(d u x t a^{\prime} d a x^{*}\right)$. A shows such a hook (Text continued on p. 89.)

Fig. 58.- $A, B$, sections of bone fish-hook; $C$, fishhook entire.

FIG. 59.- $A$, simple bone fish-hook; $B$, a simple fish-hook in process of manufacture.
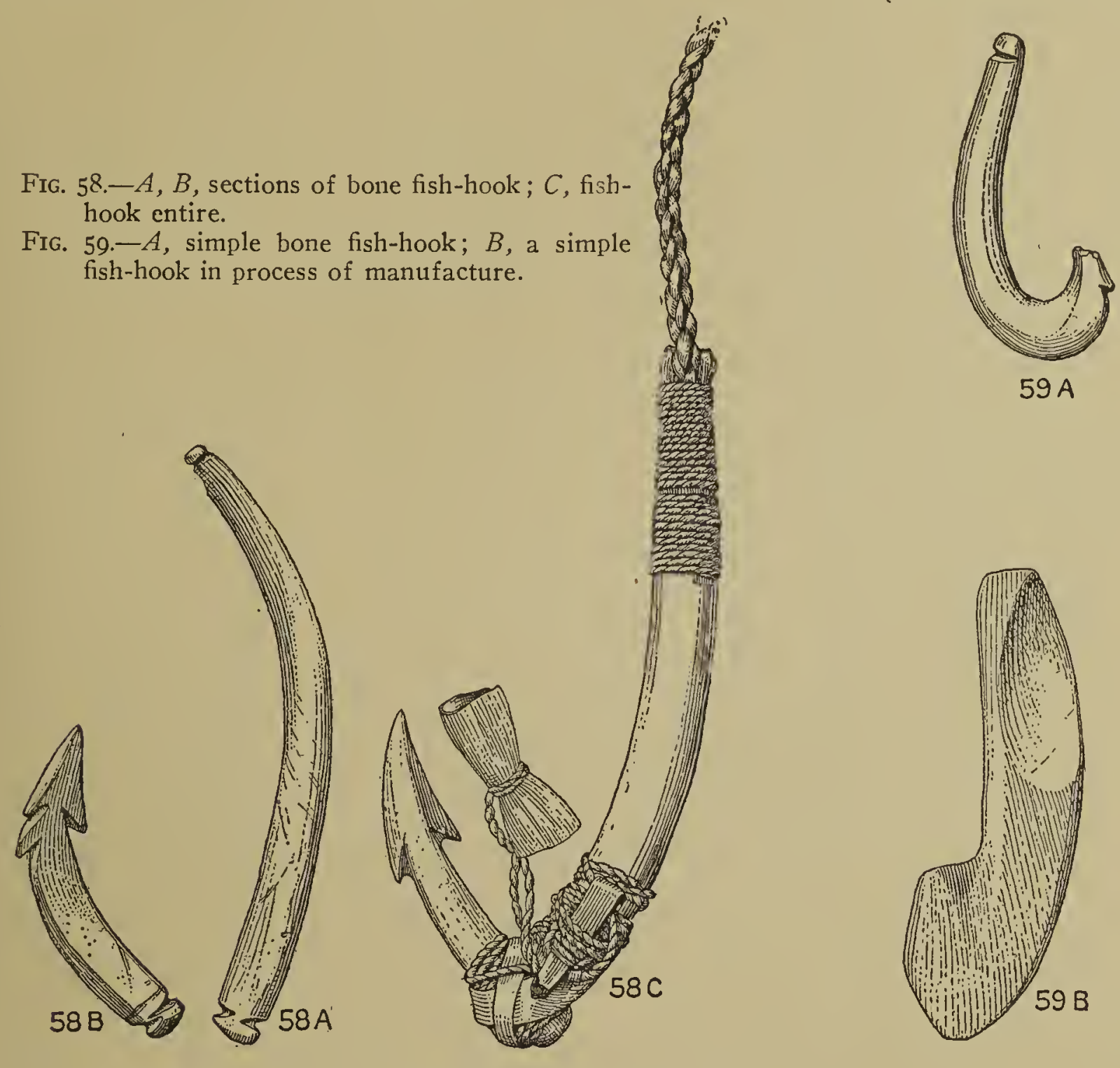

Description of Plate 26.

FIG. I (I676). A bone pick for digging edible roots (igu'lax or caxu'sixe, $i$. e., that with which one digs).

FIGS. 2 (2016), 3 (I458), 4 (568), 5 (1460), 6 (1409), 7 (665), 8 (892). Whalebone wedges made with stone adzes. The bone wedge was a very important implement in the prehistoric life of the Aleut. With the wedge the Aleut split driftwood logs for various household uses. Stone adzes or small axes were used only to notch the wood, but not to split it. The scratches on the wedges and their ruggedness were intentional, so that they might not slip from the split log. On the upper ends of the wedges may be seen the marks of stone hammers. Throughout the excavations were found a great number of bone wedges. Only 100 were removed. Figure 2 was found in Xata'cxan, Amaknax; figures 3 and 5, at Ukix, Umnak Island; figure 4, in Sin, Attu Island; 6, at Agla'gax', Umnak Island; 7 and 8, in Atxa'lax:, Atka Island; figure 7, in Cave 2, and figure 8 in Cave I, Atka Island.

FIG. 9 (340). Bone club (sagiyagu'six in Attu and $a^{\prime} n n a x^{*}$ in the eastern dialect) for killing small sea mammals, like seals, sea-otters, and fur-seals, when the hunter is drawing them toward himself with the line of a harpoon after striking the animal with the barbed head. Large fish, like halibut and cod, caught by a hook were also clubbed with the $a^{\prime} n n a x^{2}$. Found in Nani'kax', Attu Island.

32 A similar fish-hook made of 2 slightly curved pieces of bone pointed at each end and firmly tied together at the lower end was found at San Miguel Island, California. (See G. G. Heye, Certain Artifacts from San Miguel Island, California, p. 84, fig. I0, Indian Notes and Monographs, Museum of the American Indian, vol. 7 , No. 4, New York, I92I, and St. Bowers, Fish-hooks from southern California, Science, Cambridge, Massachusetts, 1883, p. 575 .) 


\section{Description of Plate 26 (Continued)}

FIG. IO (I558). Spoon (atgu'six') of reindeer antler. Reindeer antlers were brought to the islands west of Unimak from Unimak Island, Shumagin Islands, or the Alaskan peninsula. Found in Uglu'dax', Umnak Island.

FIG. II ( 1632 ). Fragment of an unknown implement, evidently a bone handle for a stone knife or dagger. From Uglu'dax', Umnak Island.

FIG. I2 (336). Rounded piece of bone which might serve as a club to stun small fish like salmon or to break echini shells. From Nani'kax', Attu Island.

FIG. I3 (343). Piece of a rib of a small whale of which a pick for root digging was being made. From Nani'kax', Attu Island.

FIG. I4 (207). Fragment of a pick. From Nani'kax', Attu Island.

FIG. I5 (156). Club of a whale's rib with broken ends. From Hog Island.

FIG. I6 (639). Long, thin foreshaft of a simple harpoon (ayukda' $x^{2}$ ) for hunting sea-otters. From Cave 2, Atxa'lax', Atka Island.

FIg. I7 (484). Bone shovel (Attu dialect, kilta'sim cañayucī'; in the eastern dialect, katmu'sim cañaducī') for putting a boot stretcher into footwear for drying after sewing. Skins or leather are moistened before sewing. From Nani'kax', Attu Island.

FIG. I8 (1236). Spoon (atgu'six') of reindeer antler. From Ukix, Unnak Island.

FIG. I9 (352). Spoon with a handle (ablula'six', i. e., that by which one draws up) found in the upper layer at Sin, Attu Island. Evidently made after the advent of the Russians.

FIG. 20 (I559). Spoon made of the breastbone of an urile. Two holes show that it was attached to some kind of a handle. Uglu'dax', Umnak Island.

FIG. 2I (474). Fragment of a bone slab with round perforations and scratches over the whole surface, possibly a woman's tailoring board. Nani'kax', Attu Island.

FIG. 22 (208). A bone skin-scraper. It is called a'ngim-camtasi'. Found at Sin, Attu Island. On Atka Island this implement is called qitqi'six'.

FIG. 23 (IOgI). A peg-topped-shaped bone object with cross-like figures engraved on one side, from Pit 3 , Agla'gax', Umnak Island.

FIG. 24 (120I). A bone handle for an engraver on stone. On one side the handle has a sharpened point which could serve as an awl. From Ukix, Umnak Island.

FIG. 25 (500). The blunted head of a throwing-weapon for practice in casting. It is made of a sea-lion's tooth. From Nani'kax', Attu Island.

FIg. 26 (I355). A whale-bone handle similar to figure 24. From Ukix, Umnak Island.

FIG. 27 (272). The head-piece of a drill for making fires and drilling holes. It is called ci'xtim-umusi ${ }^{\prime}, i . e .$, the squeezer of the drill, from $c i^{\prime} x t i x^{*}$, drill, and $u m u^{\prime}$ six $x^{2}$, implement for squeezing. It is made of a whale's tooth called ayigi'gix'. From Nani'kax', Attu Island.

FIG. 28. Half of an implement used in sewing. Both halves which may be called a presser are loosely tied around the middle, which is attached by a string 0.25 meter long to the top of a carved small upright post 0.5 meter high. The post is firmly fastened to a board, usually painted and carved, on which the woman sewing sits in a squatting position and which she presses down with her foot. The material to be sewed is placed in the squeezer on one side and at the other is inserted a bone wedge so that it is held fast. When it is thus tightened, the woman can hold the free end with her left hand and continue to sew. The whole stand is called $k a^{\prime} x$ six $^{\prime}$ or ciy' 'six' in the Attu dialect, in the eastern dialect, $q i^{\prime} q \operatorname{six}^{\prime}$, and the squeezer is called $k a^{\prime} x \operatorname{sim-agal} \bar{u}^{\prime}$, or ciyu'sim agat $\bar{u}^{\prime}, i$. $e$., the tooth of the implement, $k a^{\prime} x$ six or ciyu'six'. Found in the course of excavations at Sarana Bay, Attu Island. As a similar appliance used in sewing, called shveika, was known to the old-time Russians there is a possibility that it was adopted from them.

FIGS. $29(694), 30$ (695). Two unfinished heads for throwing-lances (iduga' $\left.y a x^{*}\right)$. They were cast at sea-lions when in their rookeries and were approached from the sea in order to prevent their escape into the water. From Cave 2, Atxa'lax', Atka Island.

FIGS. 3 I and 33 (II50) $A$ and $B$. Two halves of a belt of a throwing-lance for war (igi'qam tumu'kix) into which the head was inserted (see above, pp. 82,83 ). Length $88 \mathrm{~mm}$. Ukix, Umnak Island.

FIG. 32 (935). Evidently the foreshaft of a bird-dart with sockets for 4 circular prongs. From Cave 2, Atxa'lax', Atka Island.

FIG. 34 (1239). The bone foreshaft (tumga'kix) of a simple harpoon for hunting fur-seals and sea-otters. The harpoon is called tumumu'lgux'. From Ukix, Umnak Island. The figure is shown on the plate in reverse position.

FIG. 35 (223). Bone knife for scraping guts (see fig. 22). Sarana Bay, Attu Island.

FIG. 36 (I44I). Bone shovel (adgu'six or asu'gasixi, i. e., a pit-digger). From Agla'gax', Umnak Island.

FIg. 37 (339). A pick (igu'lax') for digging edible roots. From Nani'kax', Attu Island.

FIGS. 38 (1238) and 39 (1167). Two fish-spear heads. The bones were much decayed.

FIg. 40 (210). Half a bone belt for war throwing-lance. (See figs. 3I and 33.) From Tanaxta'xax', Amaknax Id. FIG. 4I (234). A fragment of a spoon made of a whale's bone. Sarana Bay, Attu Island.

FIG. 42 (IO2I). Foreshaft of a small harpoon used in hunting sea-otters. The narrower part was set in the shaft. Length II4 mm. From Pit 2, Agla'gax', Umnak Island.

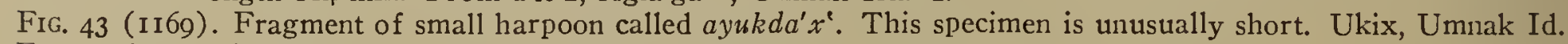

FIG. 44 ( I924). Fragment of a pick for digging edible roots. Amaknax, Amaknax Island. 


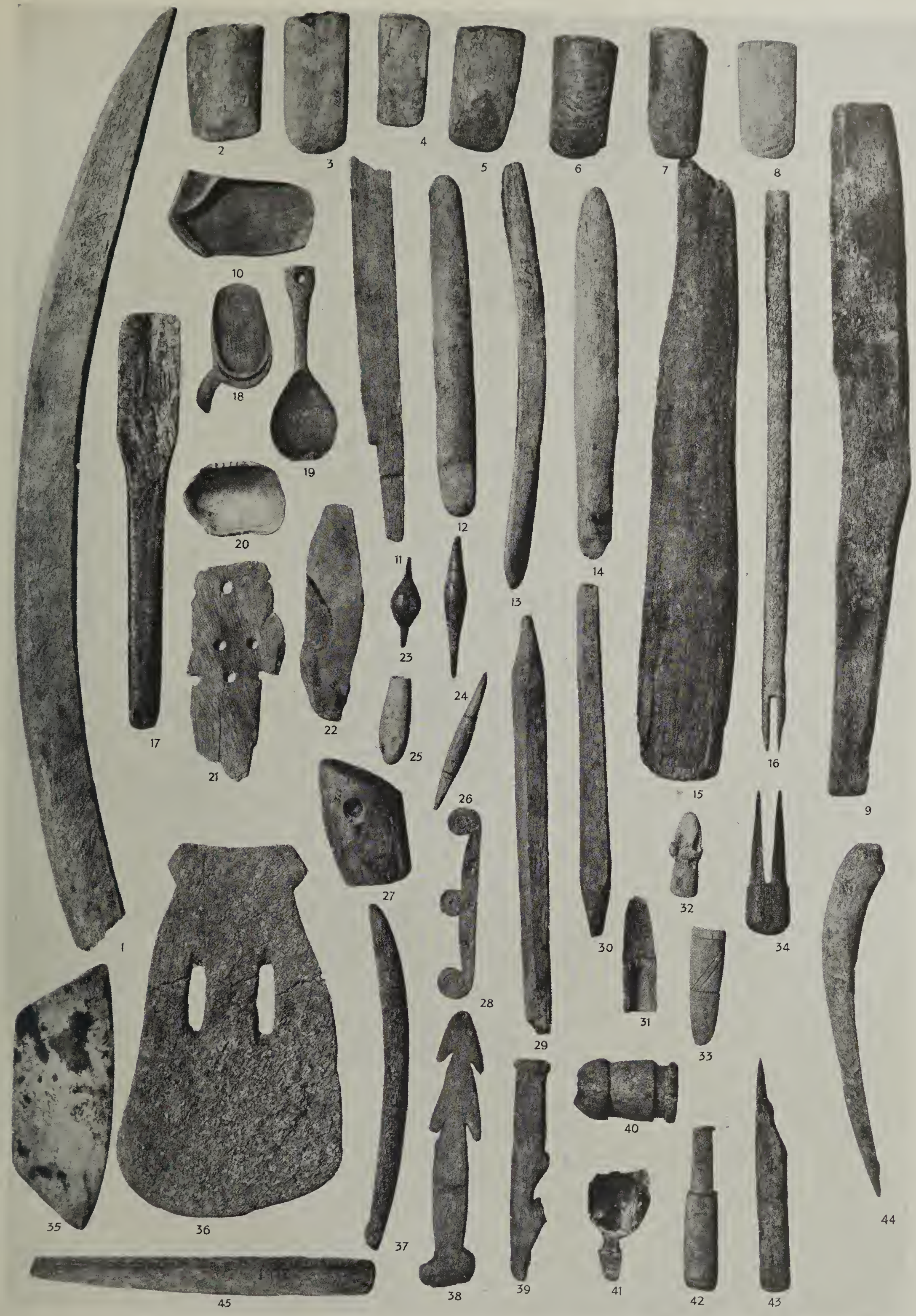

Bone spoons, wedges, root-diggers, and other bone implements. About two-sevenths natural size. 

found in Pit I, Uglu'dax', Umnak Island, at a depth of 3 feet; $B$ is a piece of bone in the process of manufacturing a hook. From Amaknax, Amaknax Island.

Both sections of this fish-hook were found in the excavations on all the islands. At present the Aleut use imported American iron fish-hooks and the Aleut of Atka and Attu were unable to explain the use of these bones. They were confused by the sight of a curved arrow-point "which is not available" for casting weapons or bows. There appears to be no doubt that this fish-hook was in use long after the coming of the Russians and shows how easily and rapidly the use of an implement may vanish from the memory of a people when a more convenient implement is substituted..$^{30}$ It is of interest to point out that Doctor Dall found similar sections of fishing implements but could obtain no information as to their use. Bone hooks found in a cave on Kagam-Ilan Island are illustrated in one of his works. ${ }^{31}$

It was only on Umnak Island that we learned that these bone objects are parts of fish-hooks. Although the people on Umnak now use only imported iron hooks, the old people still remember the use of the composite bone hooks. $A$ was found in Pit 3, Agla'gax', Umnak Island; $B$ at Uglu'dax', Umnak Island; $C$ ( I693) is a representation of the compound fish-hook. The implement was made on Umnak Island by Boris Besyazykov. Like every other fishing-implement, the hook was called qanaga'six'; but it had a special name, $u^{\prime} x t a x^{\prime}$, or a more ancient one, aqa'nax'.

$U^{\prime} x t a x^{\prime}$ or aqa'nax' consisted of the following sections:

(I) $U^{\prime} m x i x^{\circ}$, a curved long bone of the hook made of a sea-lion's tooth.

(2) Qix or $q i^{\prime} g i x^{2}$, a curved point of the hook, made also of a sea lion's tooth.

(3) I' $\tilde{i} k l u x^{2}$ or $a k a^{\prime} g d a x^{*}$, the line, plaited of several sinew threads.

(4) Umqilgagu'six', a sinew thread for attaching bait.

(5) Antami'kux', a small root of a plant called ami'dux which was tied to the hook and which, according to the beliefs of the Aleut, attracted fish to it, particularly halibut. The root was first wrapped in birchbark ( siti $\left.^{\prime} k n a x^{\circ}\right)$.

(6) A'kax', a bird-quill covering the lashing of sinew threads which bound parts I and 2, in order that the fish teeth may not spoil the lashing.

(7) $U^{\prime} x \operatorname{tam}$ tutusi $\bar{i}^{\prime}$ (i. e., the ear of the fish-hook) a folded piece of urile quill, which is tied to the hook from the side, to which the end of the thread is attached by which the bait is fastened to the $u^{\prime} m x i x$.

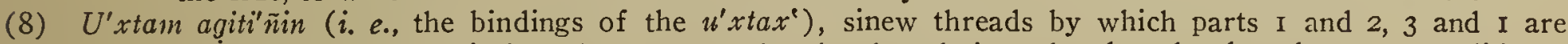
fastened. Pieces of birch-bark are put under the threads in order that the threads may not glide on the smooth bone surface.

The following text-figures belong with plate 26 :

FIG. $60 a-b$ (I24I). A bone skin-scraper. It is of walrus ivory ornamented with notches, which are also intended to give the implement a firm hold. Both sides are shown in the figure. From Ukix, Umnak Island.

FIG. 6I (450). Fragment of a back-scratcher (iblaga'six', in the eastern dialect imlaga'six', $i$. e., scratcher). It was tied to a stick in order to shove it along the back under the clothing. On Umnak Island this implement was called qaku'qix'. From Nani'kax', Attu Island.

FIg. 62 (47I). Piece of a bone comb made of a whale's tooth. Found in the upper layer of kitchen refuse in Nani'kax', Attu Island. This is evidently an imitation of imported Russian combs. Old people on Atka Island have stated that the ancient Aleut combed their hair with a wing of the urile, the feathers of which are very hard.

FIG. 63 (I280). Fragment of a comb (itxu'sixic) found at Ukix, Umnak Island.

FIG. 64 (2I24). A back-scratcher made of a whale-killer's tooth (see fig. 6I). From Tanaxta'xax', Amaknax Island.

30 Another example of how peoples with no written records may lose all knowledge of a custom is that of some of the Siberian tribes, who since their acquaintance with metal vessels have lost all memory of their ancestral pottery making.

${ }^{31}$ See W. H. Dall, Remains of later prehistoric man from the caves of the Aleutian Island (Smithsonian Contributions to Knowledge, Washington, 1878). On plate 10, figure I7260, $a$ to $c$, are shown 3 points (qix). In the text Doctor Dall suggests that "they might have been used in some way connected with sewing work." He also says: "Three curious implements ( $17260, a$ to $c$ ), 2 of them an inch long, and the other, 2.5 inches long, made of ivory. I have never seen anything like these elsewhere. They are shaped like a small arrow-head with the point curved to one side" (p. 23). 
FIG. 65 (IIO2). Bone mouthpiece for a bladder, used to keep fresh water in the skin boat. The bladder was made of the stomach of a two-year-old sea-lion. One end of the mouthpiece, called $u m a^{\prime} l u x^{2}$, was inserted in the bladder and lashed by a sinew thread, and the other was covered by a stopper. At present the Aleut carry fresh water in their boats in small wooden kegs or flasks. Found at Natxu'kax: on Umnak Island, in Pit 2, where 6 skeletons were discovered.

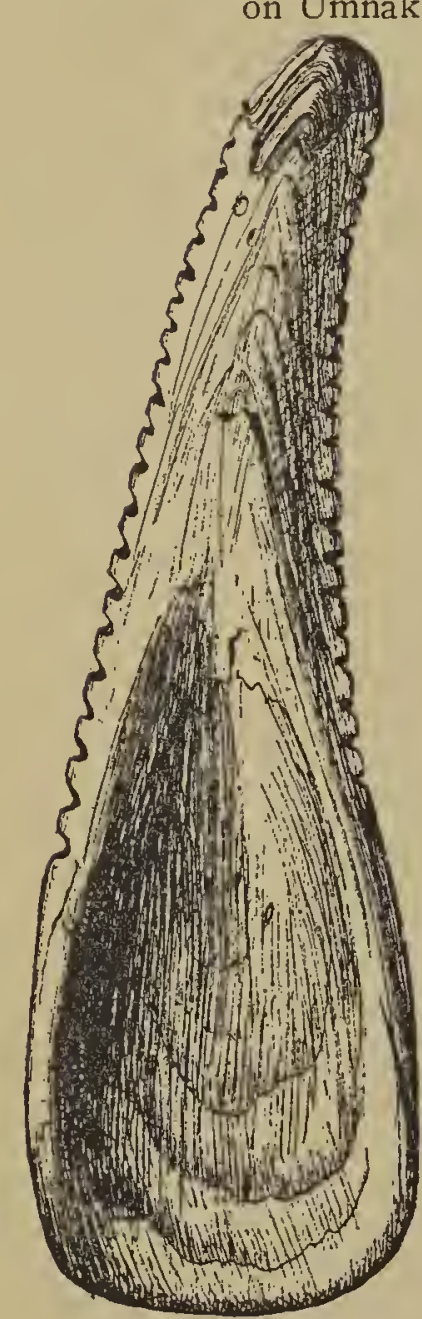

$60 \mathrm{~B}$

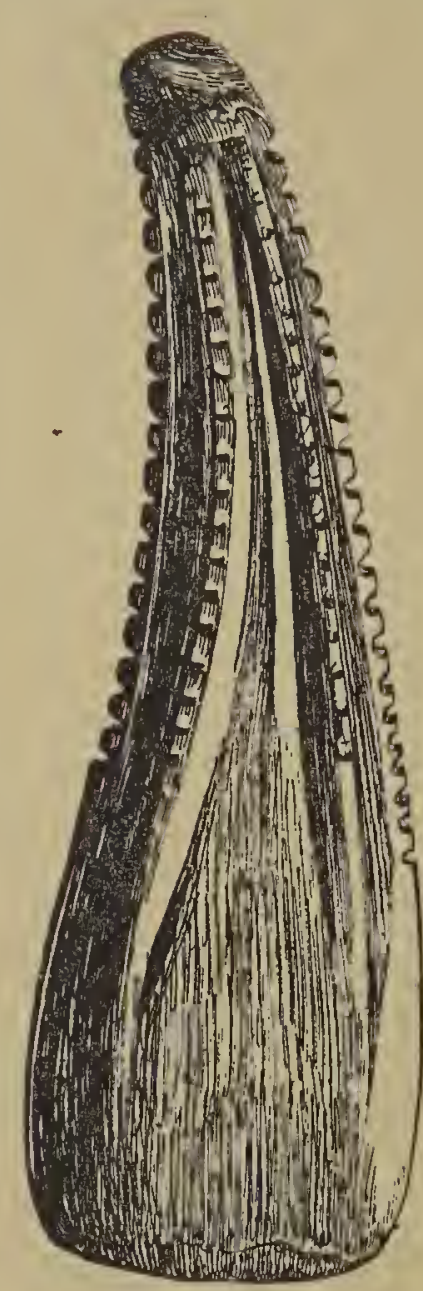

$60 \mathrm{~A}$

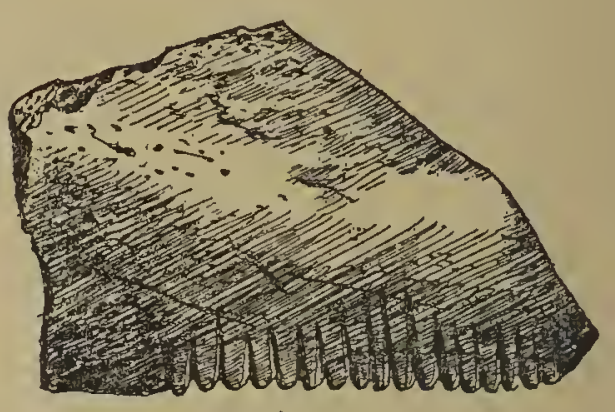

61

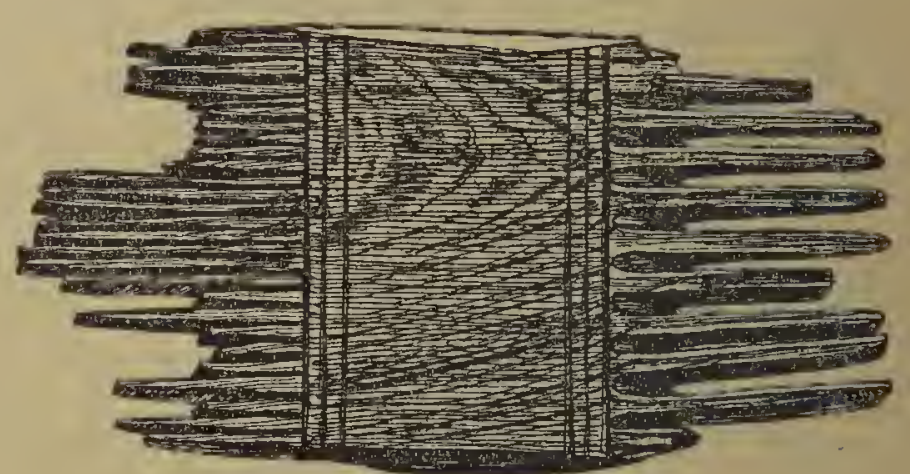

62

Description of Plate 27.

FIG. I (I4I7). A large bone wedge ( $\left.a n \cdot g u^{\prime} q a x\right)$ used for splitting logs. From Agla'gax', Umnak Island.

Figs. 2 (I9I7), 3 (I40I), 4 (444), 5 (I402), 6 (939), 7 (980), and 9 (I920) represent wedges, called $q u^{\prime} x s u x^{\circ} .35$ In some places these are called $u \tilde{n} a^{\prime} q a x^{\imath}, i$. e., splitter, or cagya'sixi, i. e., wood-working implements. Figures 2 and 9 were found at Amaknax on Amaknax Island; figures 3, 5, and 7, at Agla'gax', Umnak Island; figure 4 at Nani'kax', on Attu Island; figure 6, in Cave 2, Atxa'lax', Atka Island. Figures 2, 3, 4, 5 and 9 served also as head pieces ( $q$ itqu'yax $x^{\prime}$ ) for drills (igda'kax').

FIG. 8 (846). A piece of whalebone which had evidently served as an ax or chopping-knife for edible plants. The median groove for attaching to a haft was made with a stone ax. From Hala'ca, Atka Island.

FIGS. Io (II05), II (I9I4), I2 (2045), I4 (99I), and I5 (I576). Bone awls made of the wing-bones of albatrosses. These specimens were found at the following sites: Figure Io at Natxu'kax', Umnak Island; figure II, in Cave 2, Atxa'lax', Atka Island; figure I4 at Agla'gax', Umnak Island; figure I5 at Uglu'dax', Umnak Island.

FIG. I3 (755). Bone knife ( $u^{\prime} \operatorname{tax} x^{2}$; $u^{\prime} \operatorname{tax}$ means also thumb) for removing pieces of meat from guts before dressing. Found in Cave 2, Atxa'lax', Atka Island.

FIG. I6 (II06). Awl made of the wing-bone of an eagle with notches to assist in holding securely. From Natxu'kax', Umnak Island.

FIGS. I7 (45I), I8 (I350), I9 (448), 20 (899), 2I (I56I), 22 (986), 23 (2040), 24 (429), 25 (I349), 26 (II75), 27 (I35), 28 (658), and 29 (catalogue No. not given) represent heads of a compound harpoon (akagu'six). Figure $I 7$ is unfinished, and figure 26 is evidently a fragment of an unfinished head. Figure 27 reminds one of an unfinished qacagi'luxi, $i$. e., a bone, usually of the shape of a sea-otter, which is fastened to the side of the skin boat to prevent the paddle from falling when it is laid on top of the skin boat instead of a special noose in front of the hatch. This specimen was found in Cave 2, Atxa'lax', Atka Island; figures I8, 25, 26, and 27 at Ukix, Umnak Island; figures I7, I9, and 24 at Nani'kax', Attu Island; figure 20 in Hala'ca, Atka Island; figure $2 \mathrm{I}$ in Uglu'dax', Umnak Island ; figure 22 at Agla'gax', Umnak Island; figure 23 at Xata'cxan, Amaknak Island. The variety in the sizes of these heads point to the fact that harpoons were not of uniform size, but were in accord rather with the size of the animal to be hunted.

\footnotetext{
${ }^{35}$ See plate 26.
} 


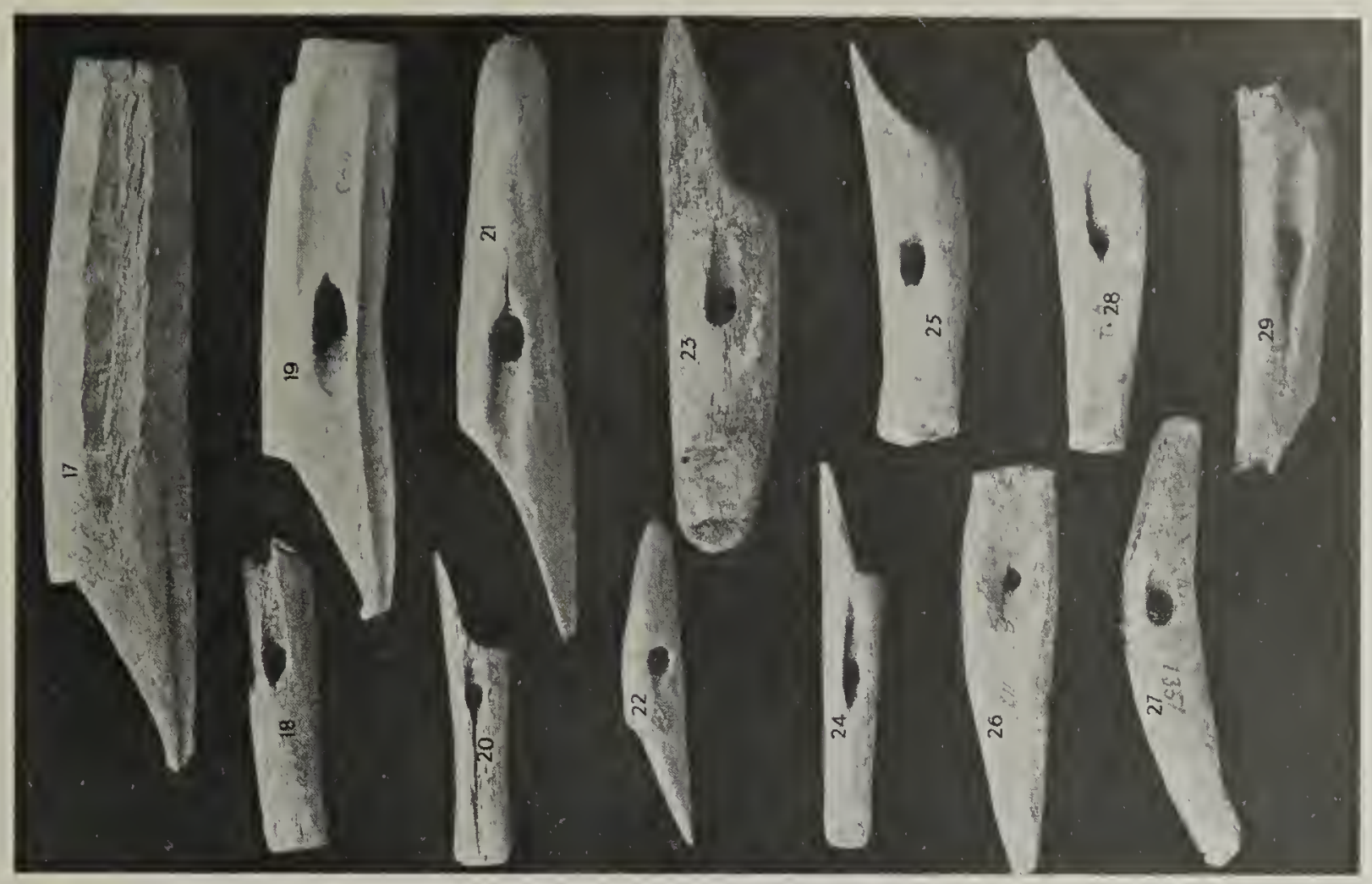

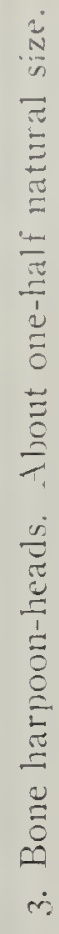
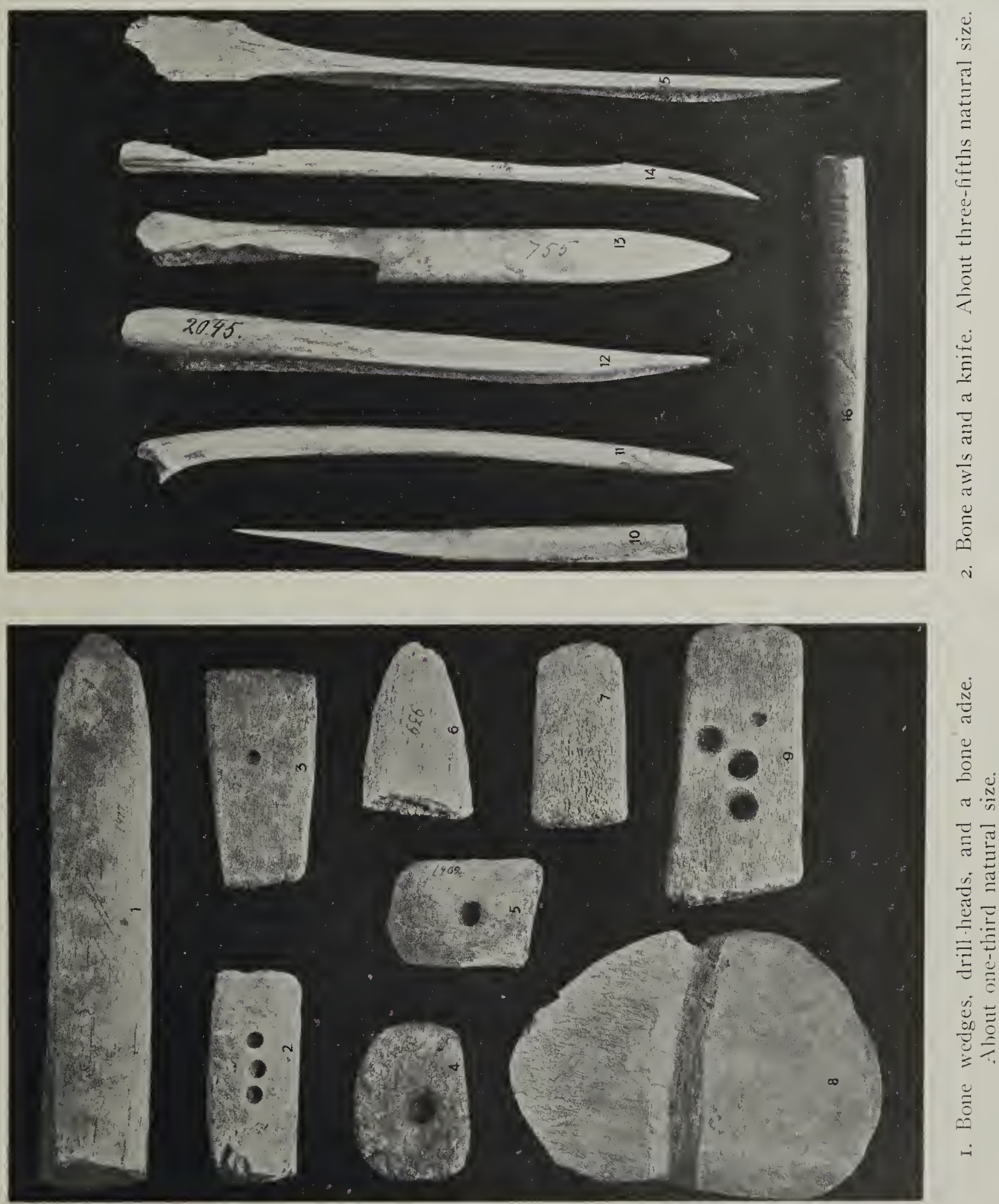


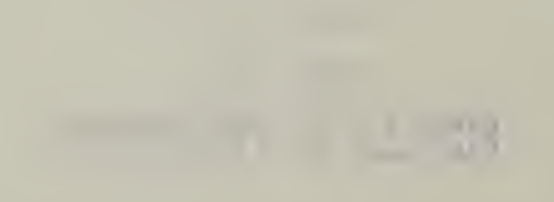


The same kind of bone mouthpieces, but somewhat shorter, are used by Eskimo as mouthpieces of seal-floats in hunting sea mammals. ${ }^{33}$ In olden times the Aleut also used seal floats in hunting.
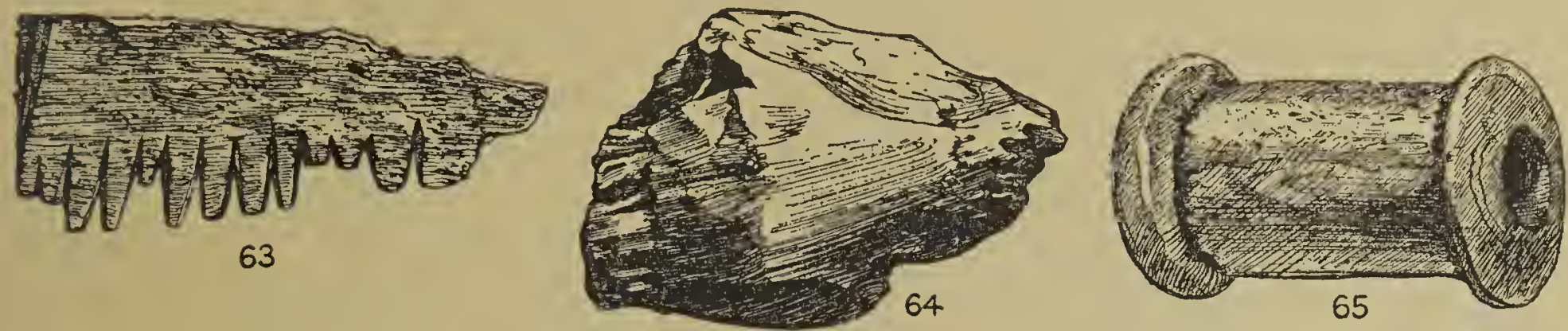

Stomachs or bladders of reindeer, seal, white whale, or walrus, provided with mouthpieces and stoppers, are used for carrying water or seal oil by the Bering Strait Eskimo. ${ }^{34}$

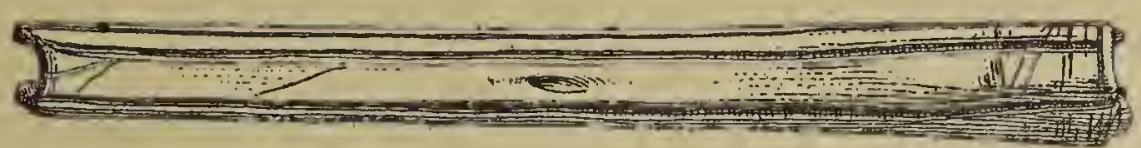

66

The following text-figures should be considered with plate 28 :

FIG. 66 (1560). A piece of albatross humerus with a longitudinal groove made with a stone knife demonstrating the method of splitting bone for making needles and awls. Found in Pit I, Uglu'dax', Umnak Island.

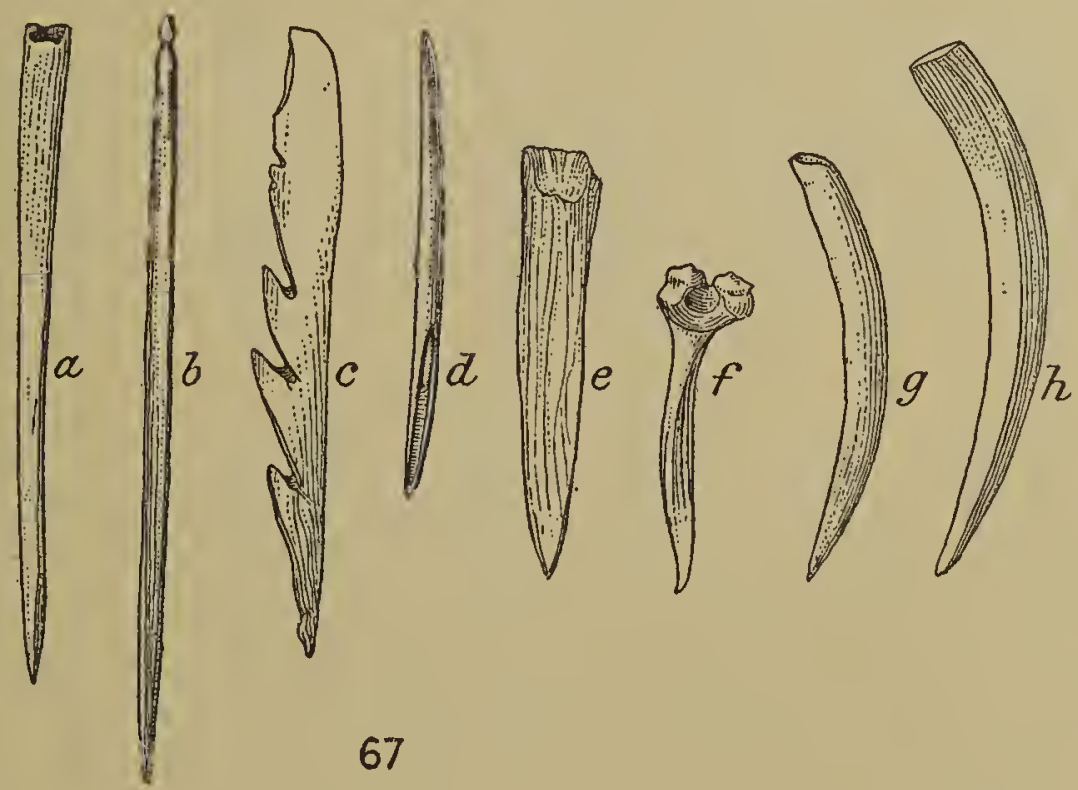

FIG. $67 a$ to $h . a$ (9I9) and $b$ (426). Needles (alu'sixi, i. e., implement for sewing). $a$ was found in Cave 2 Atxa'lax', Atka Island; $b$ at Nani'kax', Attu Island. Ancient Aleut bone needles had no perforations; the thread was tied to a notch in the upper end. $c$ (I28I). A flat point made of a bird's breast bone. The Aleut suggested that it was a point for a fish-spear used by children to catch trout. Found at Ukix, Umnak Island. $d$ (ro93). An awl found in Pit 3, Agla'gax', Umnak Island. $e$ (836). A toothpick (cimcili'six'). From Hala'ca, Atka Island. $f$ (I530). A small awl made of the leg-bone of a sea-parrot. From Uglu'dax', Umnak Island. $g$ (934) and $h$ (125I). Unfinished points of hooks for fishing sculpins, without barbs. $g$ was found in Cave 2, Atxa'lax', Atka Island, and $h$ at Ukix, Umnak Island.

${ }^{33}$ Franz Boas, Central Eskimo, p. 493; Eskimo of Baffin Land and Hudson Bay, p. 428.

${ }^{34}$ E. W. Nelson, The Eskimo about Bering Strait, p. 73, and plate XXXIII, fig. Io. 
Of throwing-weapons, war-lances were particularly ornamented. The names for ornamental figures on such lances have been noted previously (p. 83 ).

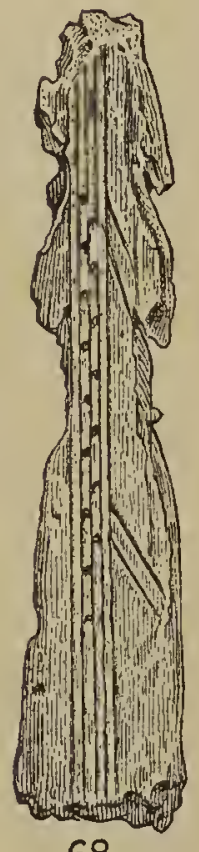

68

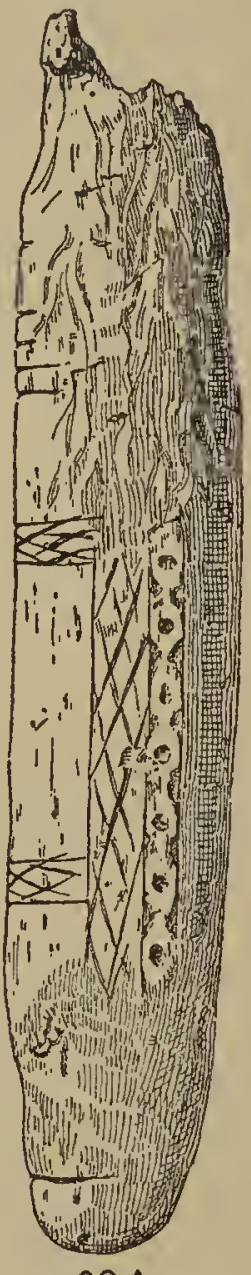

$69 \mathrm{~A}$

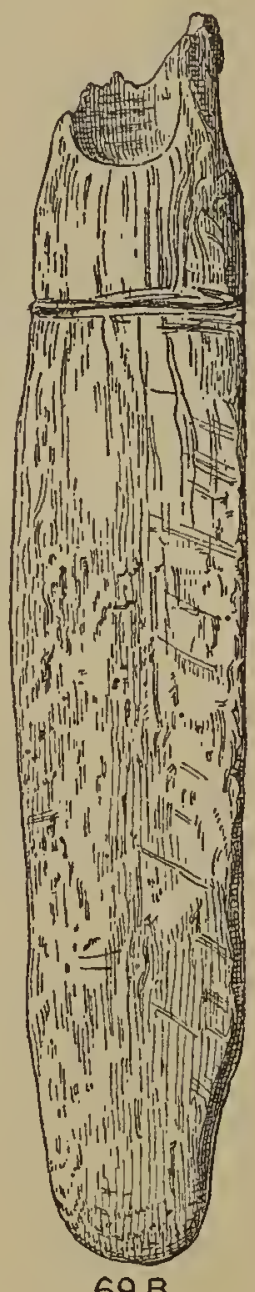

$69 \mathrm{~B}$

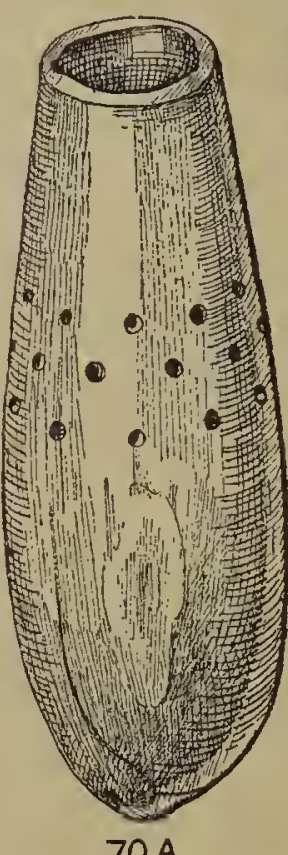

$70 \mathrm{~A}$

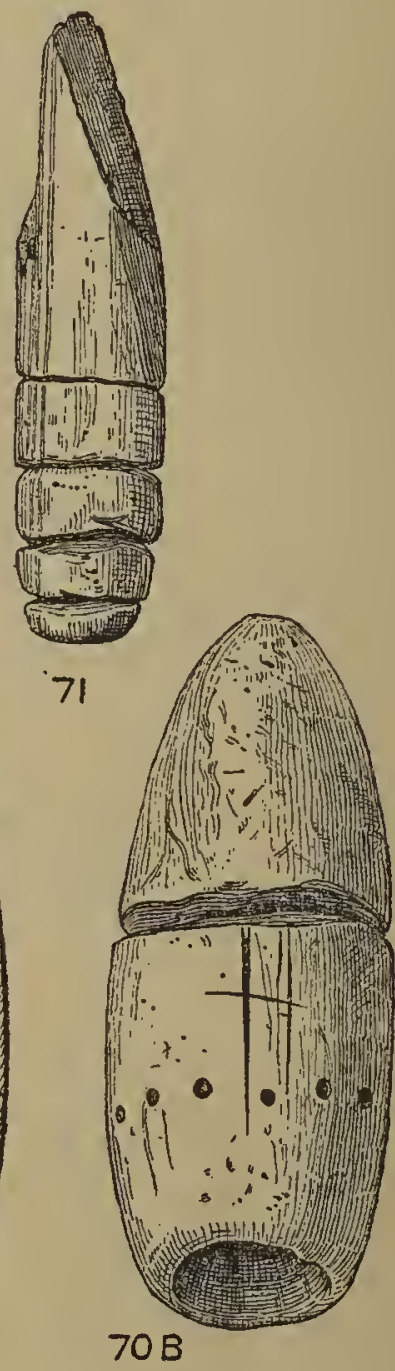

$70 B$

FIG. 68.-Fragment of bone head for a throwing-lance.

FIG. 69.-Fragments of bone haft for stone knife, both sides.

FIG. 70.-Two blunt-shaped heads of casting-lances for drilling.

FIG. 71.-Fragment of a bone haft (783), found in Cave 2, Atxa'lax', Atka Island.

\section{Description of Plate 28.}

FIGS. I (II03), 2 (I575), 3 (I320), 4 (I578), 5 (42I), and 6 (I326). Awls (ax sila'six') made of the wing-bones of uriles. Figures I and 6 were found at Natxu'kax', Umnak Island; figures 2 and 4 at Uglu'dax', Umnak Island; figure 3 at Agla'gax', Umnak; and figure 5 at Nani'kax', Attu Island.

FIGS. 7 (1330), 8 (I043), 9 (937), IO (9I3), I I (I33I) and I2 (9I2). Bone chisels (qada'ñix) for working wood, especially for making grooves and perforations in wood; for instance, the grooves and cavities on throwing-boards. These are all made of the wing-bones of uriles. Figures 7, 8, and II were found at Agla'gax', Umnak Island; figures 9, ro, and 12 in Cave 2, Atxa'lax', Atka Island.

Figs. I3 (I58I) and I4 (2047). Awls. Figure I3 was found in Uglu'dax', Umnak Island, and figure I4 at Xata'cxan, Amaknax Island.

FIGS. I5 (276), I7 (438) and 20 (437). Awls used for splitting sinew into thread (iga'cim caglimaga'ca). The perforation in the middle of the implement was made so that it could be hung on a thread from the left wrist. For use the implement was manipulated with the right hand. With this awl as well as with the type called axsila'sixt perforations were made preparatory to sewing. These three awls were made of the wing-bones of albatrosses and were found at Nani'kax', Attu Island.

FIGs. I6 $(680 a)$ and I8 $(680 \mathrm{~b})$. Split sections of bone used for making needles. Found in Cave 2, Atxa'lax', A tka Island.

FIG. 2I (I020). Bone needle (cunku'six) used in sewing the cover of a skin boat to the rails of its frame. Length $98 \mathrm{~mm}$. Found in Pit 2, Agla'gax', Umnak Island.

FIGS. 22 (920), 23 (922), 24 (I57I), 25 (645), 26 (924), 27 (I25I), 28 (422), 29 (923), 30 (104I), 3I (9I8), 32 (1250), 33 (647), $34(77 \mathrm{I}), 35(92 \mathrm{I}), 36(9 \mathrm{I} 6)$ and 37 (917). Thin bone awls (axsila'six' or si'lax'; in the Attu dialect, isila'six). Figures 22, 23, 25, 26, 27, 31 and 33-37 were found in Cave 2, Atxa'lax', Atka Island; figure 24 at Uglu'dax', Umnak Island; figures 27 and 32 at Ukix, Umnak Island; figure 28 at Nani'kax', Attu Island; figure 30 in Pit 2, Agla'gax', Umnak Island. 

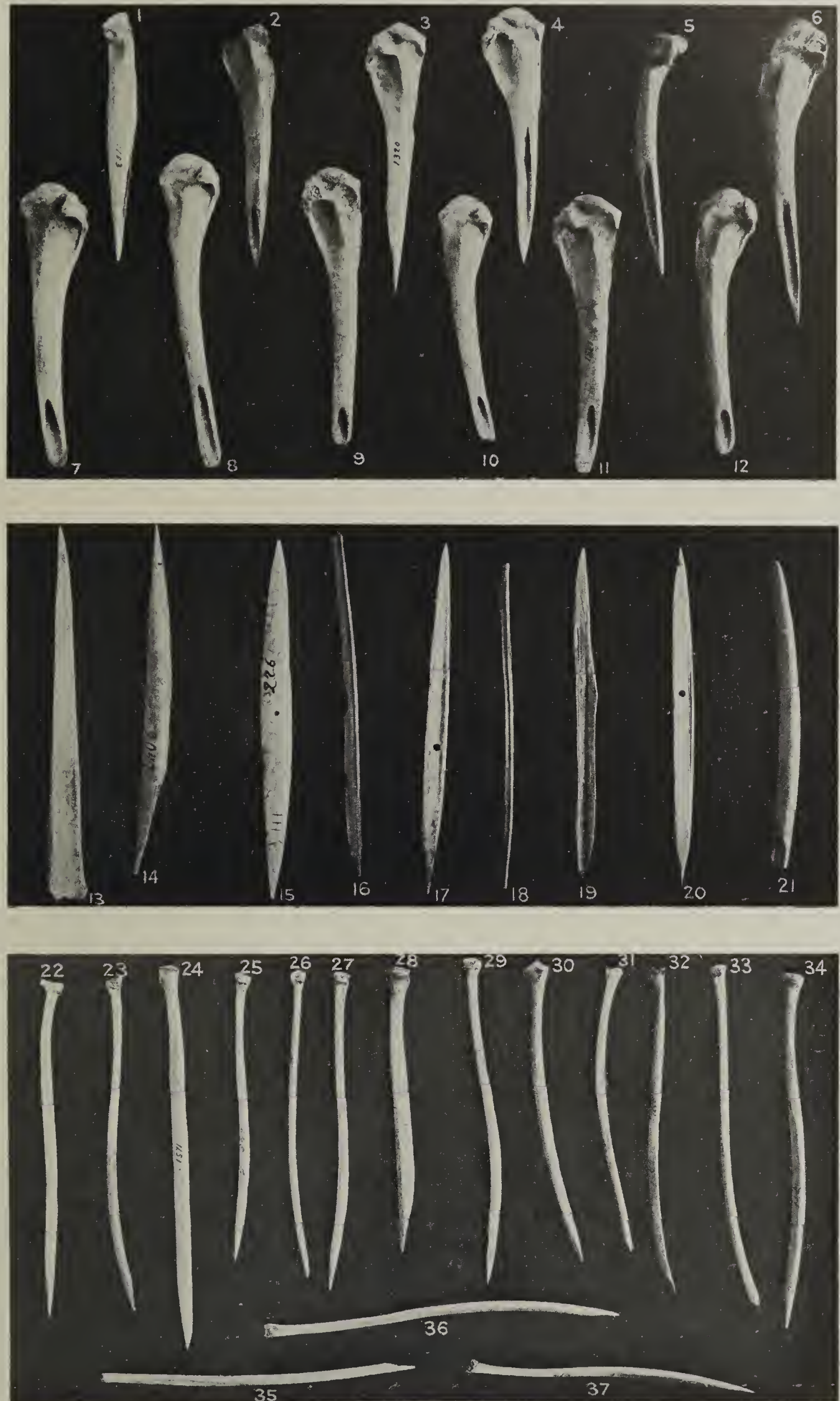

A. Bone awls and chisels. About one-half natural size.

$B$. Bone awls and needles. About three-fourths natural size.

C. Bone awls. About one-half natural size 



\section{ORNAMENTATION OF BONE IMPLEMENTS.}

A large proportion of the bone objects secured were ornamented with geometrical designs formed by symmetrically-arranged notches, lines, dots, and circles. In many cases notches or lines appeared, not as decorations (anagna'sin), but as property-marks (ana'tix ${ }^{\prime}$ ). In some cases possibly the geometrical patterns had some magical significance. Irregular incised lines and scratches were often made to meet a practical end: to prevent the smooth bone implement from slipping from the hand. Ornamental lines, dots, and circles were engraved on the flat or curved surface of bone implements with the points of small stone knives or with lancets used by the old Aleut medicine men. The engraved grooves were filled with black, red, or other mineral paint.

On the bone implements of the present-day Aleut may be seen ornamentation consisting of engraved and colored figures of animals, mostly aquatic, birds, and other realistic motives. No realistic decorations were noted on bone objects secured in the course of excavation, but realistic designs in very low relief, as well as the paint, may have been rubbed off in contact with the earth. Geometric ornamentation also was not entirely preserved. Nevertheless, it should be pointed out that on no one of the bone objects obtained from the excavations were traces of realistic. patterns found.

The bone, figure $68(687)$, is much decayed. The ornamentation consists of 5 longitudinal parallel lines incised in the middle with 2 rows of alternating points located between the inner parallel lines. At the sides, parallel lines formed sharp angles with the longitudinal lines, though at the left, these horizontal lines had been rubbed off. The side lines may represent the flippers of a sea mammal and the longitudinal lines with dots may represent the spinal column and vertebræ. A similar symbolic representation of human figures is met with in the love-letters of the present-day Yukaghir, which are incised on birch-bark and in which parallel lines and dots represent the human spine. ${ }^{36}$ It should be added, however, that such a conventional interpretation of ornamentation should be regarded merely as hypothetical, particularly since the engravings and carvings of the present Aleut represent naturalistic motives. Found in Cave 2, Atxa'lax', Atka Island.

Obverse and reverse of fragment of a bone haft for a stone knife is shown in text-figure 69 (I I I4) $A$ to $B$. On $A$ we see traces of a socket to receive the rounded tang of the knife. Under the socket is a notch for the sinew thread by which the end of the haft and the stem of the knife were lashed together. At some points in $B$ may be seen traces of engraved decoration, representing 2 motives; rhomboidal lozenges and circular punch marks. Found at Natxu'kax', Umnak Island.

Two blunt-shaped heads for throwing-weapons are shown in figure $70 A$ (500) and $B$ (619), with which young boys practiced casting lances. The heads were of sea-lion's teeth and had sockets to receive the wooden shaft. The throwing-weapon

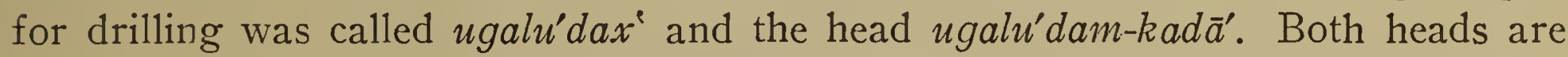

${ }^{36} \mathrm{~W}$. Jochelson, The Yukaghir, part IJI, Material Culture (Memoirs, American Museum of Natural History, Vol. IX, in press). 
decorated with circular dots, painted black and red; on $B$ there is also a property mark in the shape of a cross and a circular groove in the middle. A was found at Nani'kax', Attu Island, and B in Cave I, Atxa'lax', Atka Island.

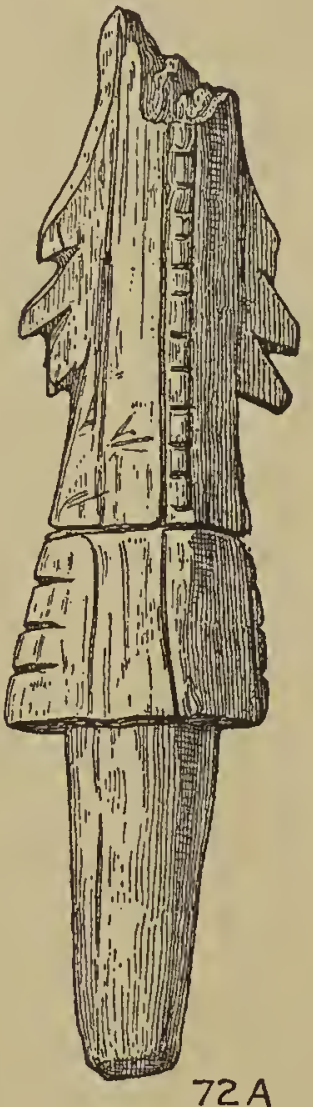

$72 \mathrm{~A}$
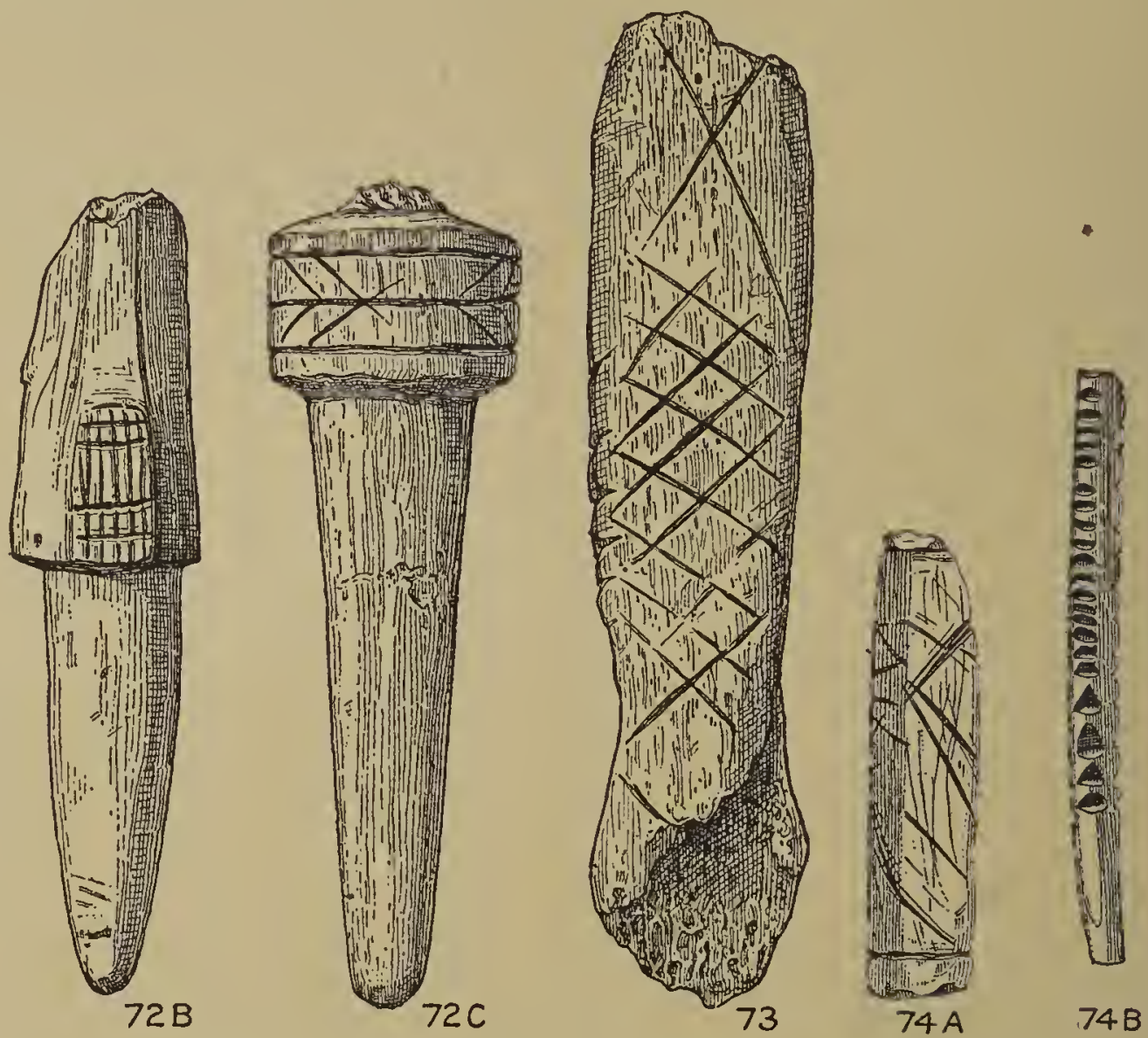

Fig. 72.- $A$ to $C(A, 777, B, 778, C, 779)$. Fragments of the lower ends of bone heads of throwing-lances bearing traces of lineal and notched decoration. Found in Cave 2 , Atxa'lax', Atka Island.

Fig. 73 (782).-Fragment of a decorated bone haft of a stone knife. Found in Cave 2, Atxa'lax', Atka Island.

FIG. 74.- $A$ (IOr8) and $B$ (III3). $A$, piece of a wing-bone of an urile which had evidently served as a haft for a stone chisel. From Pit 2, Agla'gax', Umnak Island. $B$, Notched piece of a bird-wing with the point broken off. It had evidently served as an awl. From Natxu'kax', Umnak Island.
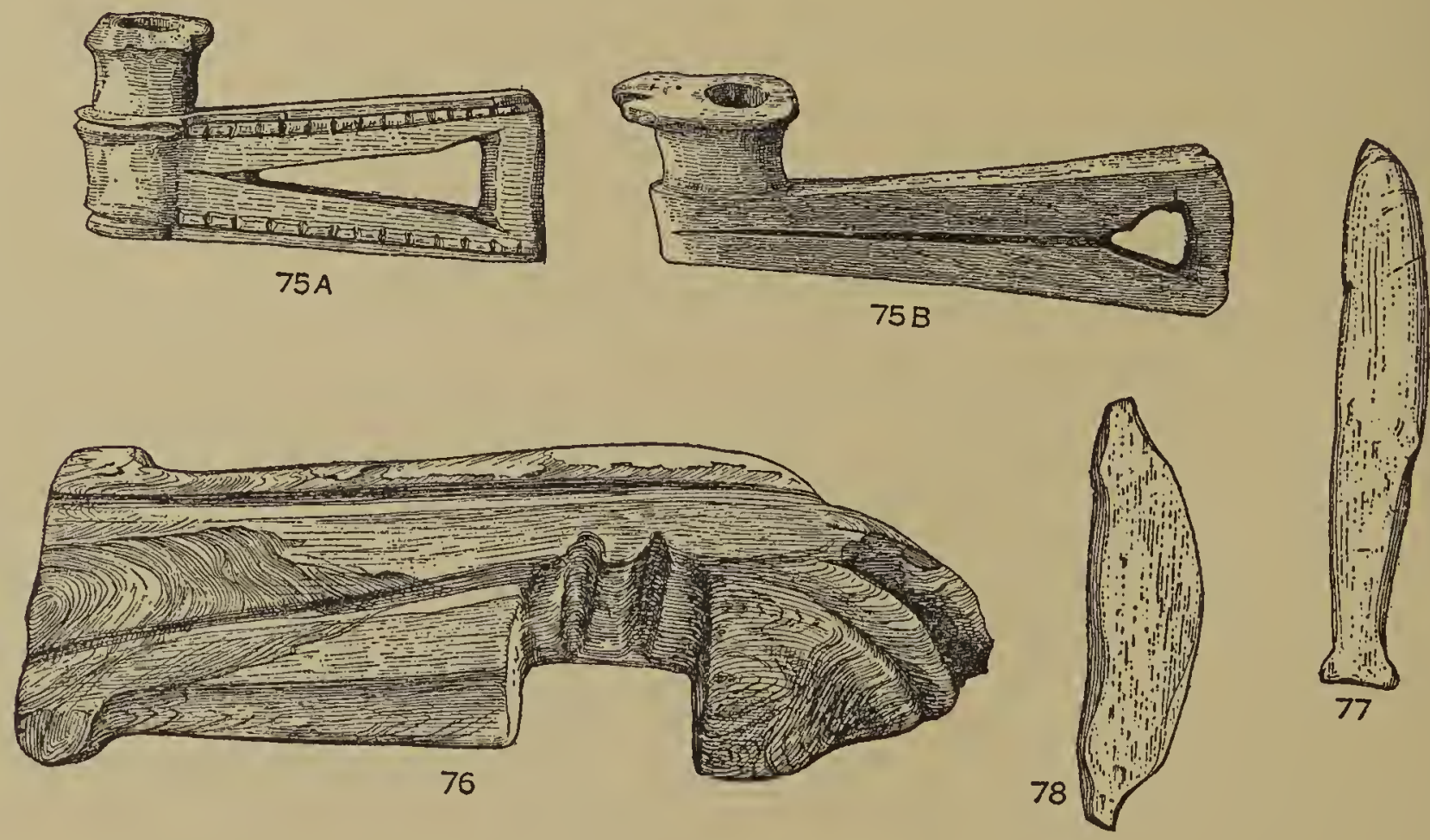
Fig. 75.-A, B. Ivory mouthpieces (uma'lux', from $u^{\prime} m a$, to blow) for bladdered harpoons (ayasa'qaxi). ${ }^{37} A$ (IIgS) is decorated with notches, and $B$ bears the carving of the head of some animal. From Ukix, Umnak Island.

Fig. 76.- $(760)$. Bone handle probably for drum, decorated with a carved fox-paw.38 Found in the layer containing skeletal remains in Cave 2, Atxa'lax', Atka Island.

FIG. 77.-(425). Bone carving representing a fish. It may have served as a toy or amulet. From the middle of the section in Pit 4, Nani'kax', Attu Island.

Fic. 78.-(IIIg). Unfinished carving representing a sea animal. From Natxu'kax', Umnak Island.

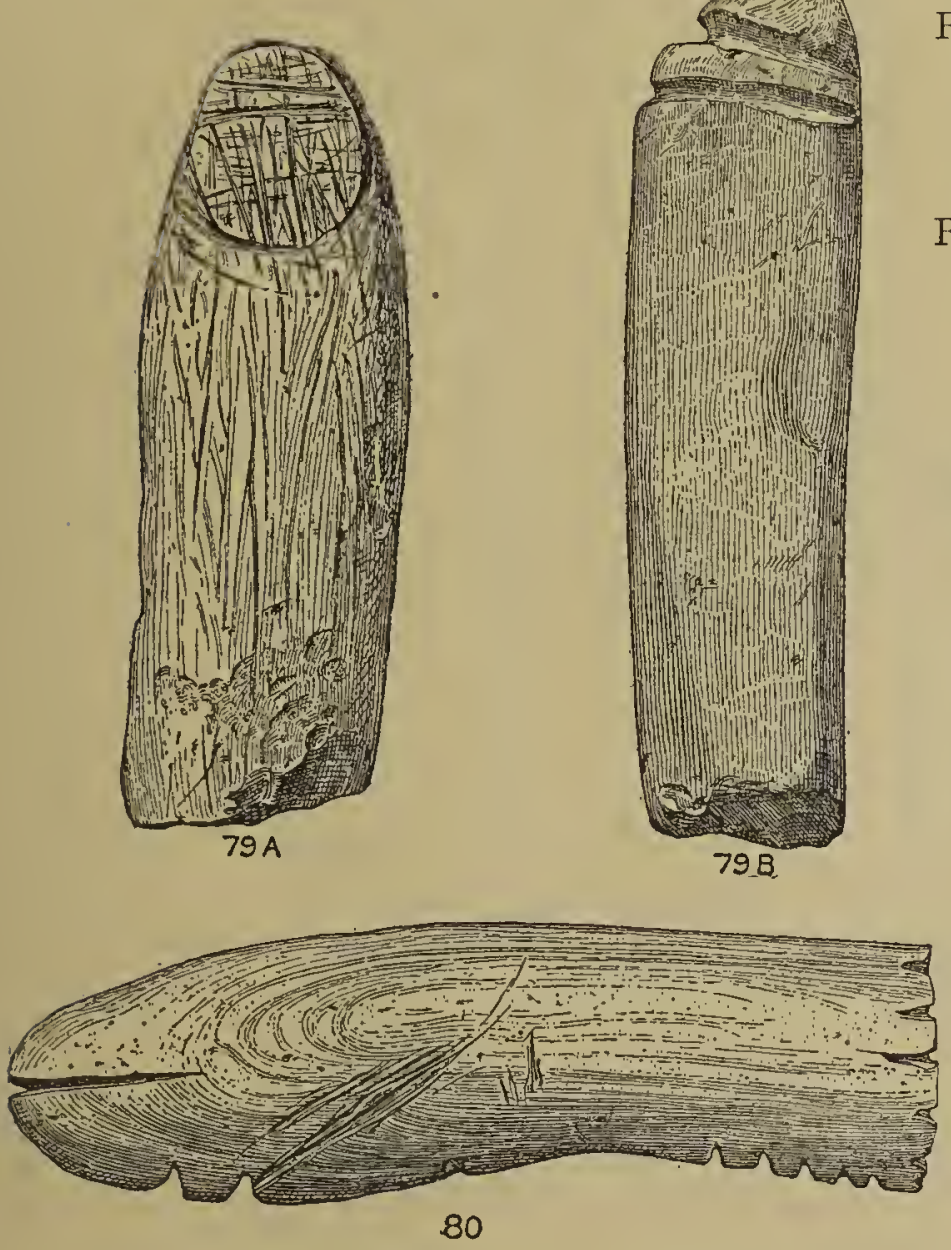

FIG. 79.- $A$ (983) and $B$ (I059). Amulets (kadga'dax $x^{\prime}$, the rudely carved human figures in stone, also used in divination. $A$ is of volcanic andesitic tuff; $B$ is of slate. Both figures were found on Umnak Island; $A$ at Agla'gax $^{\prime}$ and $B$ in Natxu'kax'.

FIG. 80.-(IOOI). Figure of a whale of volcanic andesitic tuff. It also served as an amulet, like the figures of men. Found in Pit 2, Aglą'gax', Umnak Island.
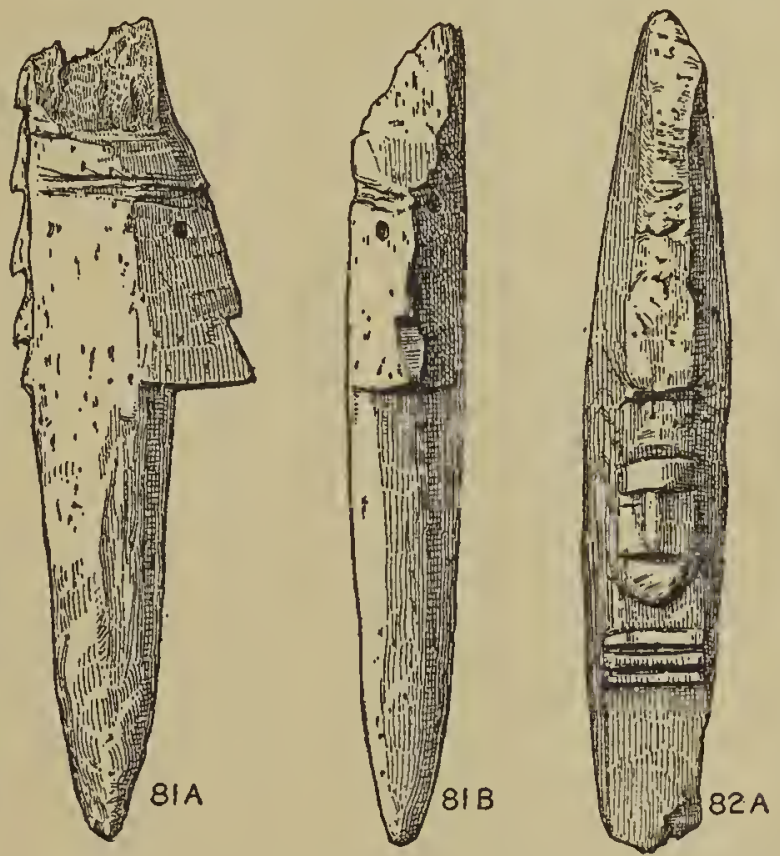

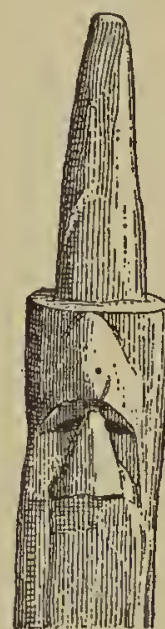

828

FIG. 8I.- $A$ and $B$ (I036). Front and side views of a fragment of a head of a warharpoon. The face is turned toward the shaft. From Pit 2, Agla'gax, Umnak Island.

FIG. 82.- $A$ (I037) and $B$ (I038). Two fragments of bone heads with carved human faces facing the point. Found in Pit 2, Agla'gax', Umnak Island.

A rudely carved human face was found on many fragments of the bone sections of casting-weapons. Evidently these faces were intended as guardians of the weapons and to help them in striking the animal. The following are figures of this character:

A bone harpoon-head (fig. 83 (1242) $A$ to $C$ ) much decayed. Two barbs have fallen off. $A$ shows the flat side of the head; $B$ is a side view with a carved human face facing in the direction of the point; $C$, a barb hollowed out inside, with three sharp points which became blunted during burial. A head with such barbs can not be removed from a wound. Such a head was used with war throwing-lances, as well as with throwing-spears when hunting seals and sea-lions asleep ashore.

37 For similar mouthpieces, see E. W. Nelson, The Eskimo about Bering Strait, plate LVI, and John Murdoch, The Point Barrow Eskimo, fig. 202, p. 215.

38 For similar drum handles see Murdoch, The Point Barrow Eskimo, pp. 386, 387. The notch is to secure the handle to the rim of the drum, but there are no holes, as in Murdoch's specimens, for attaching the handle. Murdoch's handles have carved human or animal faces. 


\section{LABRETS.}

The ancient Aleut painted their faces and wore labrets and ear ornaments. Labrets and other stone and bone ornaments were worn by the Aleut in holes made in the lips, nasal cartilage, cheeks, and ears. In a hole in the middle of the lower lip the Aleut inserted a labret in the form of a skin boat, grooved all around to keep

( Text continued on p. 99.)

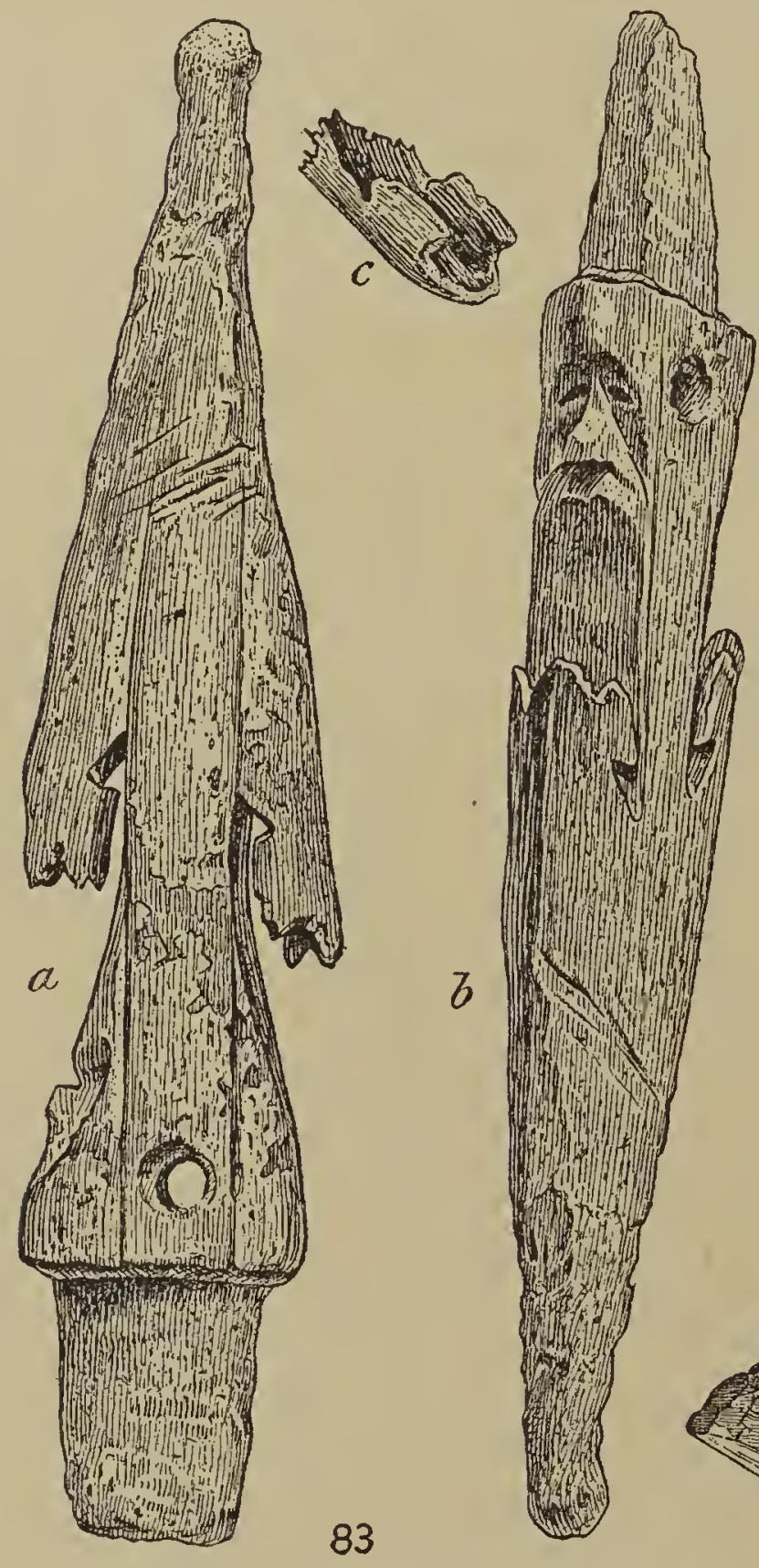

FIG. 83.-Bone harpoon-head; $a$, flat side; $b$, side view; $c$, a barb.

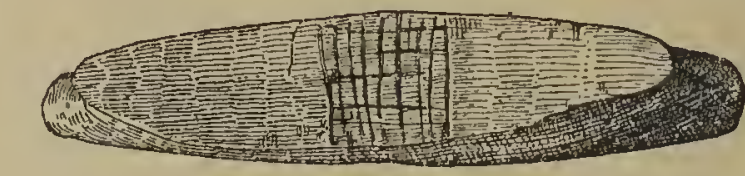

84
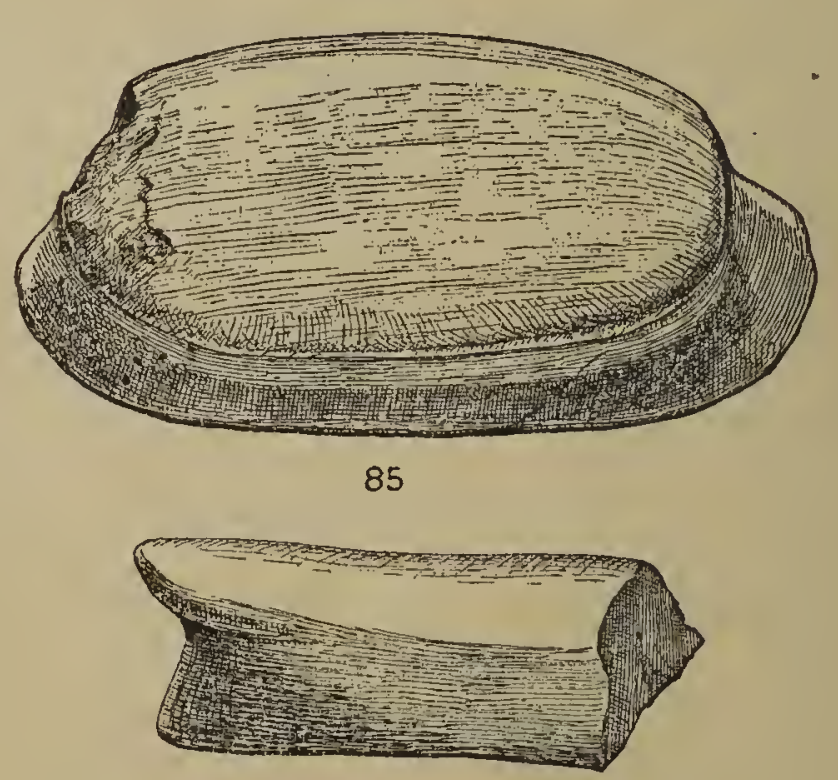

86

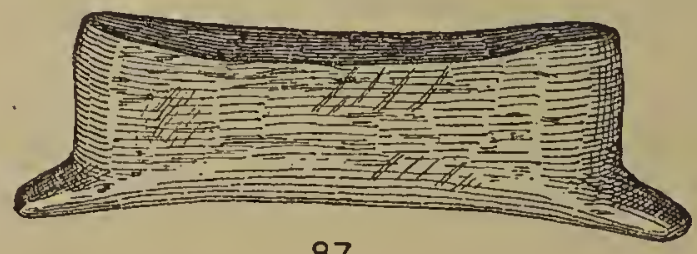

87

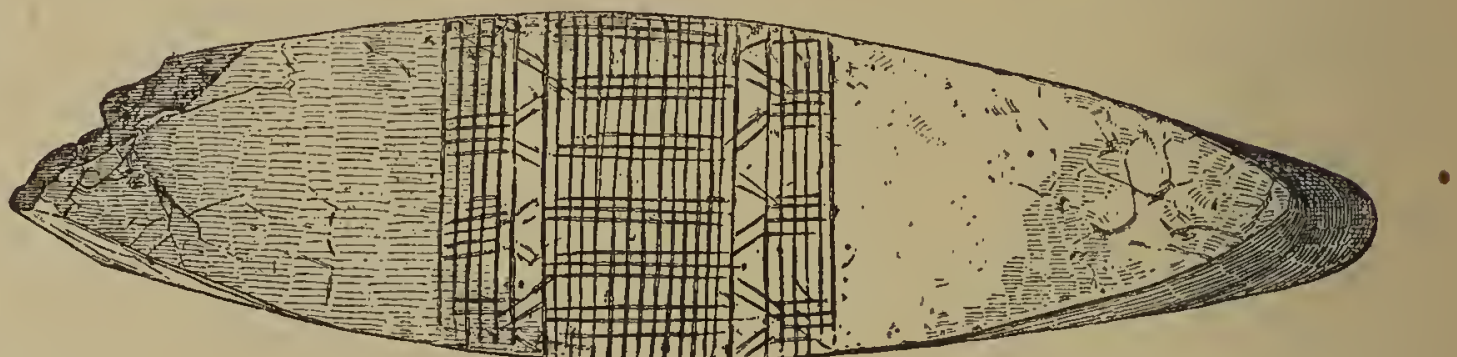

88

Fig. 84.- (954). Marble labret with a chess-like decoration in front. Found about 2 meters deep on a skeleton in Pit 2, Agla'gax', Umnak Island.

FIG. 85.- (I52I). Oval marble labret, smoothly polished. A piece has been broken off. Found in Pit I, at a depth of 3.I meters, in the lower layer of sea urchins, at Uglu'dax', Umnak Island.

Fig. 86.-( I300). Fragment of a marble labret found at Agla'gax', Umnak Island. It is interesting because of its resemblance in shape to bone labrets collected by Murdoch among the Eskimo at Point Barrow. ${ }^{39}$

FIG. 87.- (997). Bone labret of the same shape as the preceding stone labret. Found in Pit 2 , in the same layer as figure 82, Agla'gax ${ }^{\circ}$ Umnak Island.

39 John Murdoch, Ethnological Results of the Point Barrow Expedition (Ninth Annual Report, Bureau of Ethnology, Washington, 1892, p. I48, fig. 96). 


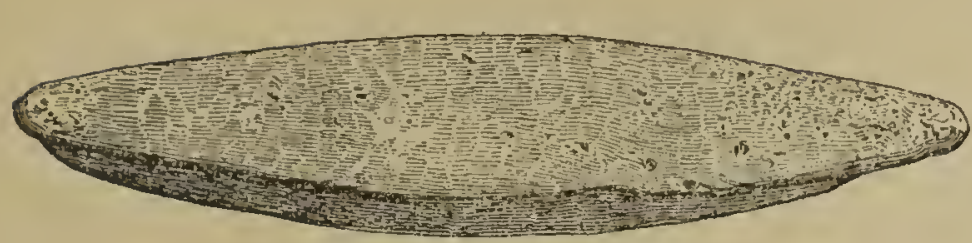

$89 \mathrm{~A}$

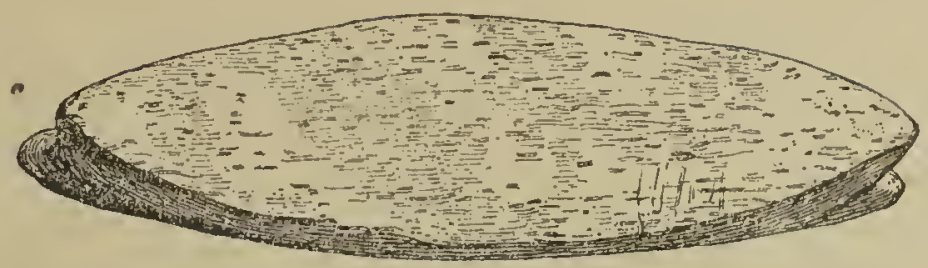

$89 B$

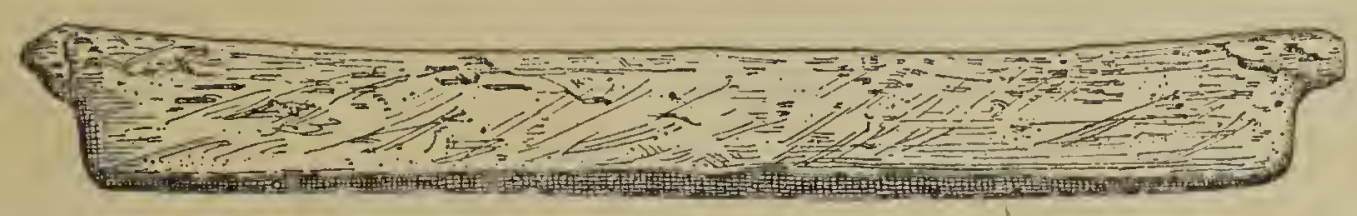

$90 \mathrm{~A}$

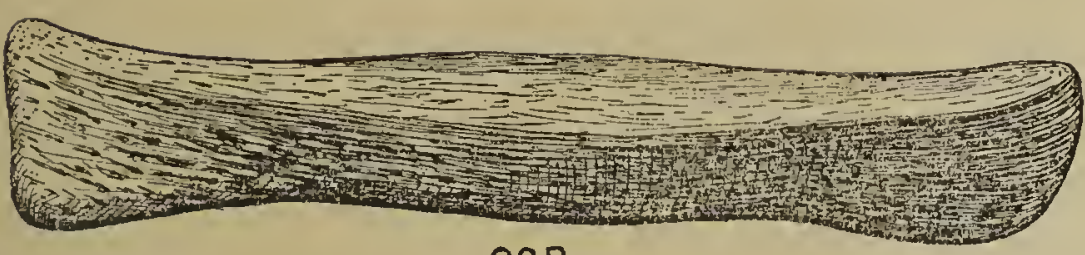

90.8

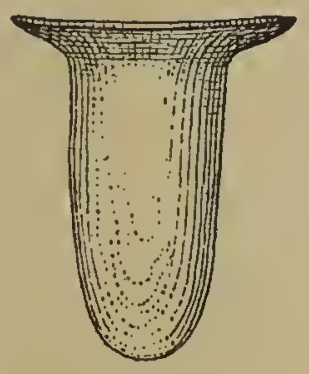

$92 \mathrm{~A}$

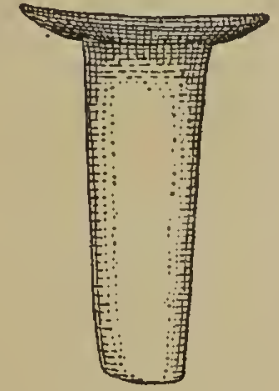

$92 \mathrm{~B}$
$92 \mathrm{C}$

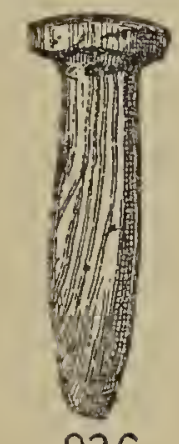

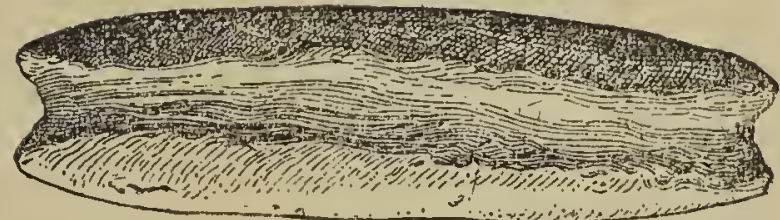

91

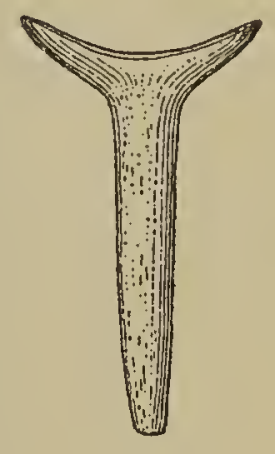

$93 \mathrm{~A}$

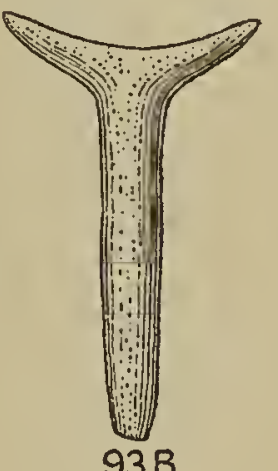

$93 B$

FIG. 88.-(624). Large marble labret $\left(k u l i^{\prime} t a x^{\circ}\right)$ found in Cave 2, Atxa'lax', Atka Island, in the layer of skeletal remains. It may be noted that the engraved ornament on the front surface of the labret is quite similar to that on figure 84 found on Umnak Island.

FIG. 89.- $A$ (625) and $B(626)$. Two large bone labrets, found in the layer of skeletal remains in Cave 2, Atxa'lax', Atka Island.

FIG. 90.- $A$ (II35) and $B$ (2076). Bone labrets, larger than those shown in figure 89 $A$ was found at Ukix, Umnak Island, and $B$ at Xata'cxan, Amaknax Island, at a depth of 13 feet.

FIG. 9I.-(2I07). Oblong bowlder of volcanic andesitic tuff with an artificial groove all around the stone. Judging from its shape as well as from its material, it could scarcely have served as a labret. It may rather be a shaft straightener for throwing weapons.

FIG. 92.- $A$ (II95), $B$ (I275), and $C$ (I522). Examples of paired bone labrets. $A$ and $B$ were found in Pit 3 , Ukix, Umnak Island, and $C$ in Pit I, Uglu'dax', Umnak Island, at a depth of 3.I meters. $A$ and $B$ have the inner side smoothly excavated and polished to fit the gum. ${ }^{40}$

FIG. 93.- $A(908)$ and $B$ (909) bear some resemblance to paired labrets, worn in the corners of the mouth, but according to the explanation of the Umnak Aleut these are small bone pieces in the form of crutches (canaya'six') on which the upper rail of the frame of the ancient Aleut skin boat rested loosely. This supplied a skin boat with a particular elasticity and swiftness. Stone and bone labrets were worn by the ancient Aleut also in incisions of the cheeks.

40 Similar small labrets made of white quartz are shown in Nelson's work on the Eskimo about Bering Strait (P!. XXII, figs. 19-22). 


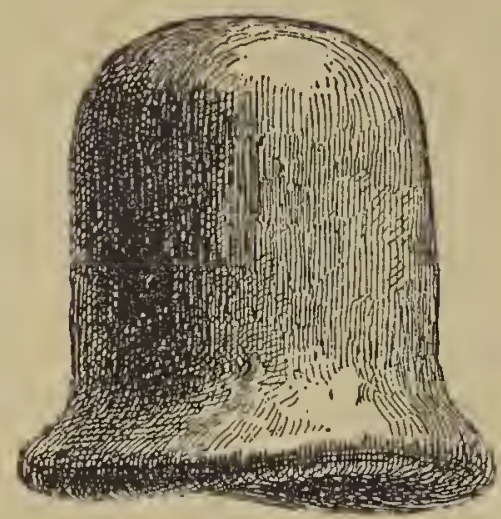

94

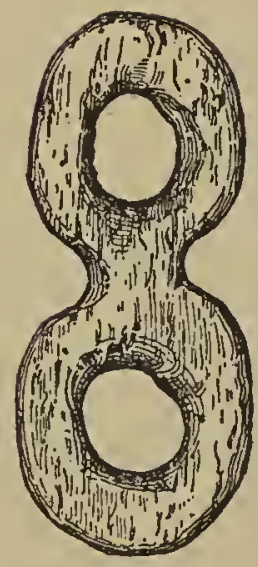

96

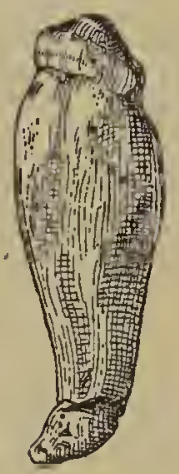

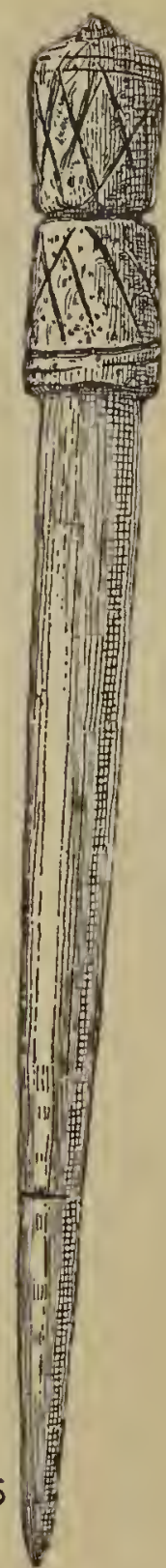

FIG. 94.-(I739). Hat-shaped labret of bone. It was called ulu'gam cimitit', $i$. $e$., cheek stopper. Found at Uglu'dax', Ummak Island.

FIG. 95-(623). Bone pin worn in a perforation of the nasal cartilage and called qusi'dax' (in the Atka dialect, icimi'$\left.k l u x^{2}\right)$. On both sides of the pin, on the ornamented head and in the notch near the point, were hung small bone pendants attached to sinew threads. These bone pendants were usually seal's teeth and dangled over the upper lip. These pendants bore the very unesthetic name of su'klun, $i$. e., snots. ${ }^{41}$ After the advent of the Russians the Aleut made suklun of beads strung on sinew threads. The bone pin was found in Cave 2, in the layer containing skeletal remains, at Atxa'lax', Atka Island.

FIG. 96.-(I534). Type of qusi'dax' in the shape of a figure 8. It was attached to a perforation of the nasal cartilage by a sinew thread and su'klun hung from both sides. Found in Pit 4, at Uglu'dax', Umnak Island.

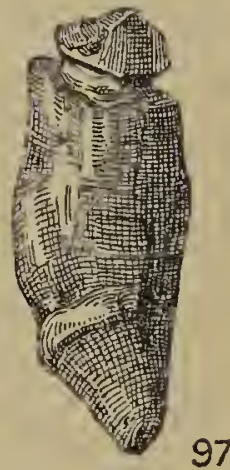

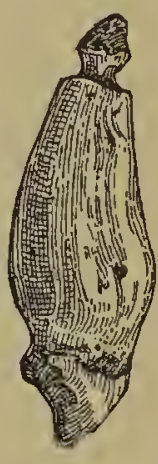

FIG. 97.- $A$ to $D$ (IO98 to IIOI). Four suklun made of seals' teeth, bearing notches to hang them to the qusidax?. One of the teeth (IIOO), in addition to the notch, bears a perforation made by drilling. All four pendants were found in the burial pit of the skeleton of a woman and child, at Natxu'kax', Umnak Island.

41 Doctor Dall has reported that the Tananah Indians wear an ornament made of dentalium. A hole is pierced through the skin of the nose, below the cartilage, in infancy. The name of the ornament, sookli, he regards as a Russian word (see W. H. Dall, Alaska and its Resources, Boston, 1870, p. 95), but, as we have seen before, it is an Aleut word, su'klux , i. e., snot. Evidently the Russians of the Yukon region adopted it from the Aleut. We wish to add, however, that the Russian word for snot, soplya (plural-sopli) sounds like sookli. 

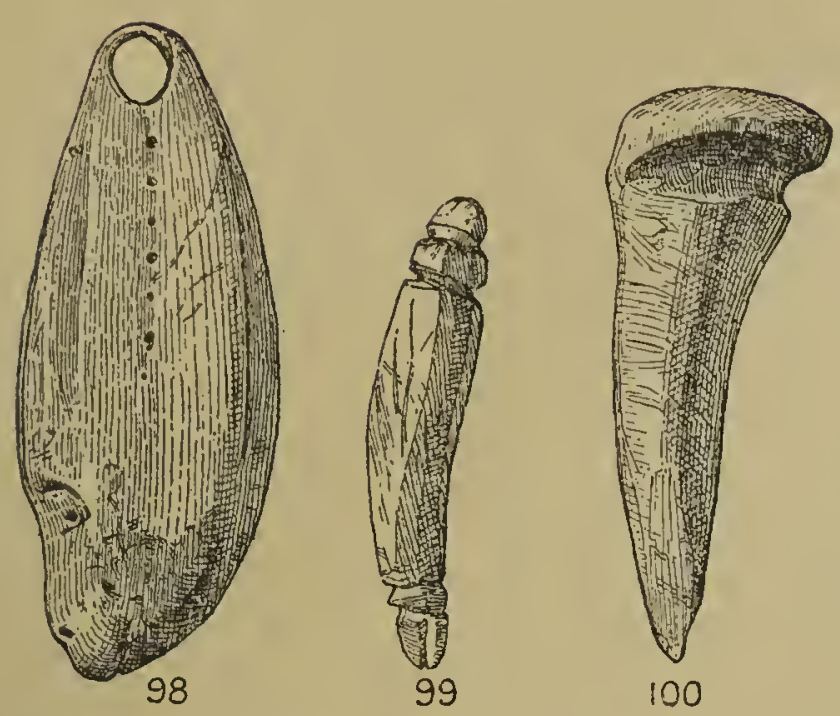

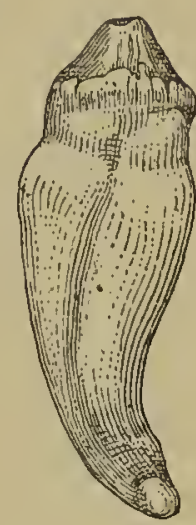

101
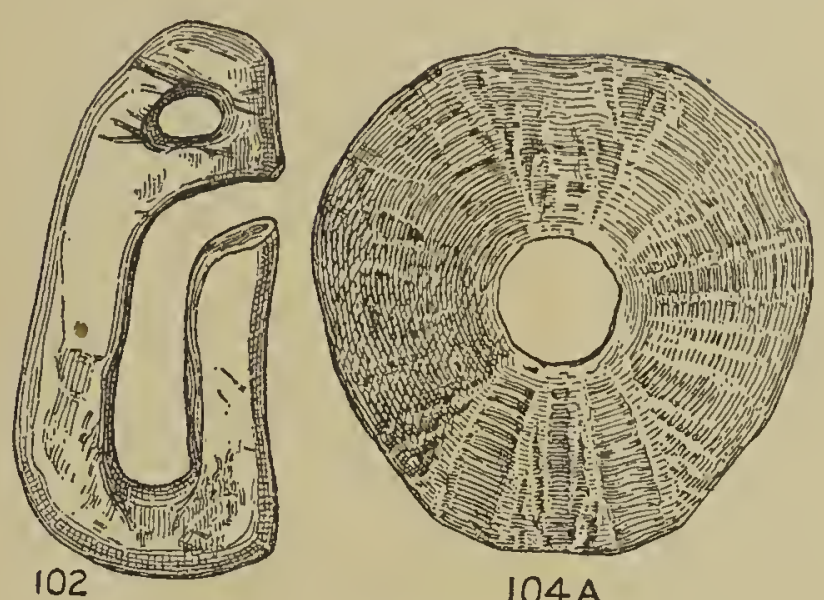

$104 \mathrm{~A}$

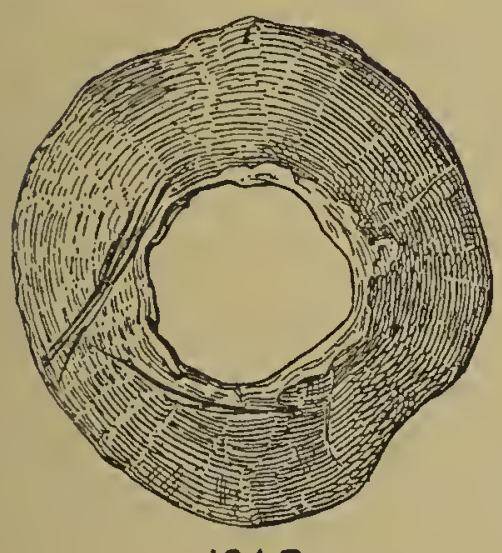

$104 \mathrm{~B}$

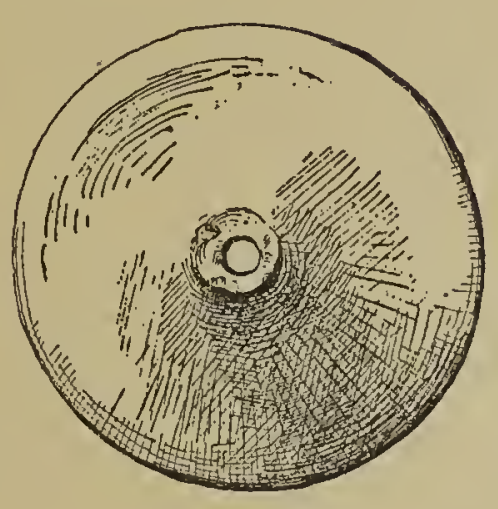

$103 \mathrm{~A}$
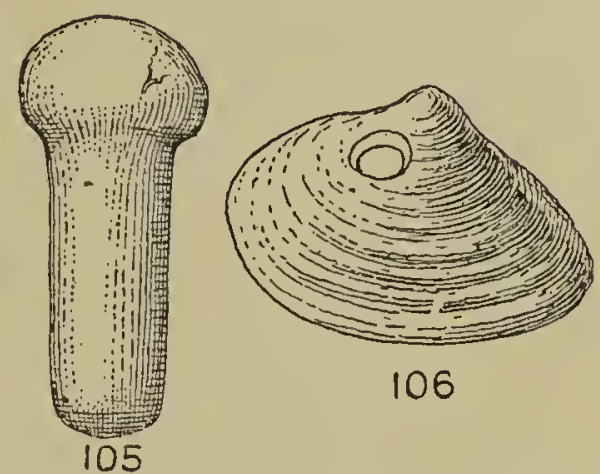

106

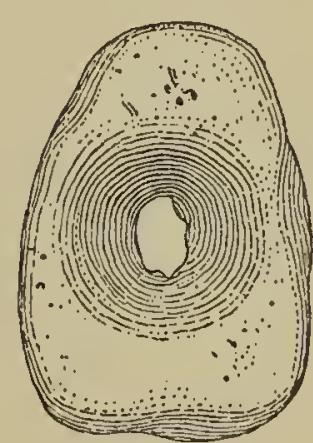

$103 \mathrm{~B}$

FIG. 98--(1097). Bone ear-ring called $t u^{\prime} t a x^{\circ}$. On the lower part of the ear-ring is the carved head of a sea-lion and at the sides it is ornamented with painted dots. It was hung on a sinew thread. The Aleut wore $t u^{\prime} t a n$ (plural of $t u^{\prime} t a x^{\circ}$ ) not only in the lobe of the ear, but all around the ear-shell. The soft edges of the earshell were perforated and small bone pendants were worn on sinew threads, like the pendants over the upper lip. Sea-lions' whiskers were also worn in the perforations of the ear-shell and after the advent of the Russians, beaded strings. Found in the same pit as figure 93

FIG. 99.- ( I525). Nose pendant $\left(s u^{\prime} k l u x^{e}\right)$ or ear pendant ( $\left.t u^{\prime} t a x^{\circ}\right)$ made of an incisor of a young sea-lion. Found in Pit I, Uglu'dax', Umnak Island.

FIG. IO0.-(IIVI). Plug made of a sea-lion's tooth which had served evidently for enlarging the perforations for labrets. The notch at the thicker end was made to keep the plug in the perforation for a certain time. Found in Pit 3, Ukix, Umnak Id.

FIG. IOI.-(33I3). Sea-lion's tooth to be used as a pendant, shown before perforation or notching. Found together with figure Ioo.

FIG. I02.- (I523). Bone object, too large to be a nose or ear pendant; it may possibly be a buckle for short breeches or for the breech-cloth belt. Found in Pit I, Uglu'dax', Umnak Island.

FIG. I03.- $A$, bone ring; $B$, stone ring, called $u k a^{\prime} m l u x$.

Fig. I04.- $A, B$. Two $u k a^{\prime} m l u x^{*}$. $A(97 \mathrm{I})$ consists of a halibut's vertebra and was found in Pit I, Agla'gax', Umnak Island. $B$ (I549) is made of a vertebra of a small species of shark. (Description, see p. I00.)

FIG. I05.-(274). Marble stopper (cimiyu'six ${ }^{\circ}$ ) for the bone mouthpiece of a bladder used for carrying fresh water in skin boats. Found in Nani'kax', Attu Island.

FIG. I06.-Shell of the mollusk Tellina calcarea, which may possibly have been worn as an ornament. However, as determined by Professor N. M. Knipovich, the perforation was not drilled by man, but was made by a carnivorous snail of the Naticidæ family. Found at Agla'gax', Umnak Island.

it in the hole. Such a labret was called kulitax'. The lower lip was pierced in childhood and the perforation gradually enlarged by special plugs. In adults the perforation of the lower lip reached 5 or $6 \mathrm{~cm}$. All the stone kuli'tax of the Aleut were of marble which was imported, according to information received from them, from the continent. Marble is easily cut and may be well polished.

The labrets shown in figures 84 to 87 were worn single in an incision in the middle of the lower lip. In addition we found similar labrets, but of such large size 
that they could hardly be worn in the lip. We believe the particularly large labrets, shown in figures 88 to 90 , were made to put in the perforations of the painted wooden masks which covered the faces of the dead or which were worn by dancers during festivals or religious ceremonies. The Aleut of Umnak Island, who assisted in the excavations, were of the same opinion. All the labrets illustrated here are shown in their natural size.

It is of interest to note that no labrets were found in the excavation of Attu Island; that the Attu people asserted that their ancestors did not wear such ornaments, and that the custom of wearing labrets was known only to the east islanders. The first specimens of labrets were found on Atka Island and the local Aleut did not recognize them. This is another instance of how easily a people will forget an old custom when it is no longer in use (see above p. 89). It is, therefore, possible that no credit should be given to the testimony of the Attu people. Detailed data as to the ornaments for the face, their names, and the methods of wearing were obtained only from the Umnak Aleut.

The Aleut had another shape of labret which was worn in pairs, one at each corner of the mouth. These were also called kuli'tax. (See figure $92 A, B$.) A hatshaped labret was worn in incisions of the cheeks. (See figure 94.)

Two circles or rings $\left(u k a^{\prime} m l u x x^{i}\right.$ ) (fig. I03, $A, B$ ) are tied to one end of the cord of su'tax. Su'tax is part of a hunter's clothing when in the skin boat. It is a skirt made of seal-guts about 0.75 meter long. The lower edge of the su'tax' is tied around the projecting rim of the hatch in which the occupant sits; the upper edge is tightly drawn under the arm pits of the hunter, and the ends of the cord, one of which is thrown over the left shoulder, may be instantly untied by touching the $u k a^{\prime} m l u x^{\prime}$ on the chest if there is danger of capsizing. When the su'tax is tied on both sides no water can penetrate the interior of the boat. Under the su'tax the hunter wears a water-proof shirt, also made of seal-guts. This is securely tied at the wrists and the hood is tied around the face. Doctor Dall, in describing the skin boat of the Yukon Inuit, says that the edge of the water-proof shirt itself is tied to the rim of the kayak hole. ${ }^{42}$ The same is reported for the Bering Strait Eskimo by E. W. Nelson ${ }^{43}$ and in the guide to the Museum of the American Indian. ${ }^{44} A(273)$ is of walrus ivory and $B(27 \mathrm{I})$ is of stone. Evidently $B$ was formerly used as a headpiece for a drill. In rotating, the drill-stick pierced a hole in the head-piece, making it unfit for drilling. Both $u k a^{\prime} m l u x x^{`}$ were found at Nani'kax', Attu Island.

42 See W. H. Dall, Alaska and its Resources, Boston, 1870, p. I5.

43 See E. W. Nelson, The Eskimo about Bering Strait, Washington, I899, p. 37.

${ }_{41}$ Guide to the Museum of the American Indian, Heye Foundation, First Floor, New York, I922 (p. 217 ). 


\section{CHAPTER VI.}

\section{CRITICAL SURVEY OF PREVIOUS WORK IN ALEUTIAN ARCHAEOLOGY.}

This chapter will be devoted to a brief critical survey of previous investigations of Aleutian archæology. The two outstanding names connected with the study of the Aleut are the late French ethnologist, Alphonse Pinart, and the American naturalist, William H. Dall. In I87 I, Pinart visited Unga Island, the largest of the Shumagin group, and in a burial-cave on Delaroff Bay named by him "la caverne d'Aknañh" found the remains of 4 skeletons, fragments of wooden masks, human figures carved in wood, and other painted objects of wood. Evidently these finds were not very old, and from the point of view of Aleut antiquities, they are not as important as are the investigations of Doctor Dall. Two points in the brief descriptions offered by Mr. Pinart should be noted. He informs us that the dead lay at full length, on beds of moss; further, that these were the remains of whalers, who, among the Aleut, were of a specially honored group and consequently were buried in this posture in caves and not in earth huts. However, Mr. Pinart fails to add a more detailed description of the position of the bodies; for example, whether they were laid on their backs or on their sides. ${ }^{1}$

In 1874 Doctor Dall visited the same cave. In this connection he states that Mr. Pinart " had secured the cream of what was contained there, though much that was valuable remained behind," $i$. e., he took what came to his notice at first sight. ${ }^{2}$ Doctor Dall's investigations cast some doubt as to the authenticity of Pinart's report. After removing many fragments of rocks which had fallen from above, Doctor Dall discovered the remains of 13 skeletons. In another crevice he found additional remains of mummies wrapped in decayed grass-mats. All these skeletons were in a squatting position. Besides, there were skeletons not only of adult men, but of women and children, and these could not belong to a company of whalers. ${ }^{3}$

Doctor Dall, in I87I-I874, was engaged in a hydrographic and geographical reconnaissance of the Aleutian Islands, under the auspices of the U. S. Coast and Geodetic Survey, and during enforced intervals of leisure, made necessary by

1 Alphonse L. Pinart, La Caverne d'Aknañh, Ile d'Ounga (Archipel Shumagin, Alaska), Paris, I875, pp. I-II, plates I-VIII. The transcription of the name of the cave is scarcely correct; it should be $A^{\prime} k$ nax ${ }^{*}$ or Akna'ñix', since all nouns in Aleut end with $x^{*}$. (See also: Catalogue des collection rapportées de l'Amérique Russe, par Alphonse Pinart, exposées dans le Musée d'Histoire Naturelle de Paris. Paris, r872. In the course of the description of the objects found on Unga Island, Pinart remarks as follows as to the skeletons: ". . . . les corps avaient été deposés sur une litière en mousse, dans une position allongée (différent en cela de la manière dont les Esquimaux occidentaux enterrent leur morts en repliant les membres sur le corps)" (p. 25).

2 Before Doctor Dall's visit the cave had been examined by other persons unqualified to do so and in consequence the remains were considerably disturbed.

3 W. H. Dall, On the Remains of later Prehistoric Man obtained from caves in the Catherina Archipelago. Alaska Territory, and especially from the caves of the Aleutian Islands, Smithsonian Contributions to Know1edge, Washington, I878, pp. 28-3I. 
weather conditions which interfered with surveying operations, he undertook excavations of ancient Aleut village sites. Thus, he excavated on the islands of Attu, Atka, Amaknax, Unalaska, Adax, and Amchitka. The author also excavated on the first 3 of these islands. Doctor Dall also gives a list of islands (Amchitka, Agattu, Kyska, Amlia, Umnak, Sannax, Unga, and other Shumagin Islands) and other points on the Alaska Peninsula (Port Möller and Chignik Bay) where shell-heaps may be found. Of the last-named places the author made excavations only on Umnak Island. Thus our work overlapped sufficiently for a review of results.

In the main, Doctor Dall and the author are agreed in the facts observed, but differ in our interpretations. For this reason it seems advisable to discuss Doctor Dall's conclusions in some detail. He concluded that the Aleut, beginning with their first appearance, left on the islands traces of 3 stages or periods of culture. These periods are: (I) The Littoral Period, represented by the Echinus layer; (2) The Fishing Period, represented by the fish-bone layer; (3) The Hunting Period, represented by the mammalian layer."

Naming the first period "littoral" does not appear to be quite accurate, as it implies that the two following periods represent an inland and not a coastal culture. The third period would be more accurately described as a sea-mammalian culture, since under "mammals" land animals are usually understood.

Doctor Dall further illustrates the periods he designates as follows: In the littoral period the islanders had an extremely primitive culture which left no trace of manufactures of any kind. They had no houses, clothing, fire, lamps, ornaments, weapons (unless of the most primitive kind), implements of the chase or for fishing or for cooking the food they found on the shore. If they possessed any of these things, they must have been of such rude or perishable materials as to have left no traces." "It would appear," he says further, "that they must have had rafts or rude canoes of some kind, but no trace of them is left." He found no skeletal remains of the Aleut of the echini period, so he concludes they were cannibals. Also that the Echinus layers represent a definite cultural stratum, as shown by the finding of stone hammers for cracking the sea-urchins and that only near the uppermost surface of the Echinus layer, where it joins the fishbone layer were there found stone net-sinkers, very rude in form. Further, the broken test and spines of the echini "presented the aspect, until closely examined, of fine, pure, uniform, greenishwhite sand. With it were found sparingly the shells of some edible mollusks. This bed varied in thickness from a total of 2 feet to 3 feet in a vertical direction. The deposit extended everywhere underneath the shell-heaps, covering 3.5 acres at Attu, about 4.75 acres at one of the Amchitka villages, and at Adakh 0.5 acre or more, by measurement." Doctor Dall does not, however, point out more specifically where the echini beds he describes may be found.

${ }^{4}$ See W. H. Dall, On Succession in the Shell-Heaps of the Aleutian Islands (Contributions to North American Ethnology, vol. r, Washington, 1877, pp. 4r-9r). See also by the same author: Notes on Prehistoric Remains in the Aleutian Islands and On further Examination of the Amaknax Cave, Captain's Bay', Unalaska (Proceedings California Academy of Sciences, November 4, 1872, and November 17, 1873).

${ }^{5}$ W. H. Dall, On Succession in the Shell Heaps of the Aleutian Islands, p. 55. 
In the opinion of Doctor Dall, the Aleut who left behind them the Echinus layers did not possess even the embryonic beginnings of culture and did not have even the edged-stone implements of the so-called eolithic period; yet the possession of some implements has been ascribed even to man of the Acheulean and the Chellean period, while the use of fire has been established nearly throughout the entire palæolithic period, beginning with the Acheulean, and some archæologists believe that man of the eolithic period knew the use of fire, although, as yet, we have no proof of it. Later we shall see that Doctor Dall estimates the time required for the formation of the mound of kitchen refuse on the islands as 3,000 years. Now, since the Aleut came to the islands, as Doctor Dall justly supposes, from the American continent, it would follow that 3,000 years ago, when Europe was passing from the later Neolithic period to the Bronze Age, there still lived in northern America a people without any culture. On the other hand, the presumption that the Aleut of the sea-urchin period navigated rafts or very primitive boats is quite incompatible with the supposed absence of any implements, save boulders for breaking echini shells. It is also difficult to imagine navigation by rafts in the stormy waters of Bering Sea and how people could live under the climatic conditions of the Aleutian Islands without clothing, dwellings, and fire.

Leaving for a moment this hypothesis of Doctor Dall, let us turn again to his characterization of the culture-periods among the Aleut. He assumes that the stratum of the Fishing Period may be sharply distinguished from that of the Echinus Period, since the Fishing Period layer, though showing some mollusk shells and bird-bones, gives but occasional remains of sea-urchins. This seeming sudden change in the mode of living is assigned by Doctor Dall to a new immigrant wave of fishingpeople from the continent. However, the thickness of the stratum ascribed to the Fishing Period is said to be the same as that of the Littoral Period. No lamps, no evidences of fire, or of underground dwellings occur in the Fishing Period layer. On the other hand, the earliest skeleton remains were found here.

Turning to the next assumed culture horizon, it was noted that the stratum of fish-bones was not so sharply separated from the Mammalian layer, as from the Echinus layer, but that this layer imperceptibly passes over into that for the Hunting Period. Further, Doctor Dall divides the mammalian layer, which is from 2 to Io feet thick, into 3 strata. In the lowest of these strata are principally bones of seals, fur-seals, sea-otters, sea-lions, and small whales. In the middle mammalian layer, in addition to the aquatic mammals mentioned as occurring in the lowest layer, were remains of the whale Megaptera versabilis and the bones of many species of sea-birds. In the topmost mammalian layer, to the bones found in the first two were added bones of large whales and of various species of unidentified birds.

The first two culture layers, according to Doctor Dall, those of echini and fish, were assumed to represent pure kitchen refuse, while the upper layer, that of mammalian bones, was intermingled with other organic remains. Traces of underground or half-underground dwellings were found only beginning with the second stratum of the upper layer, where were also indications of the use of fire and lamps. This 
he explains by the acquisition of sufficient quantities of oil as a result of improved methods of hunting sea mammals.

As to the development of implements, with special reference to their form and the material of which they were made, Doctor Dall assumed them to appear in the following order: in the fish-bone layers were found only rudely chipped stone knives and heads; bone implements appearing in the upper part of the fishing layer,
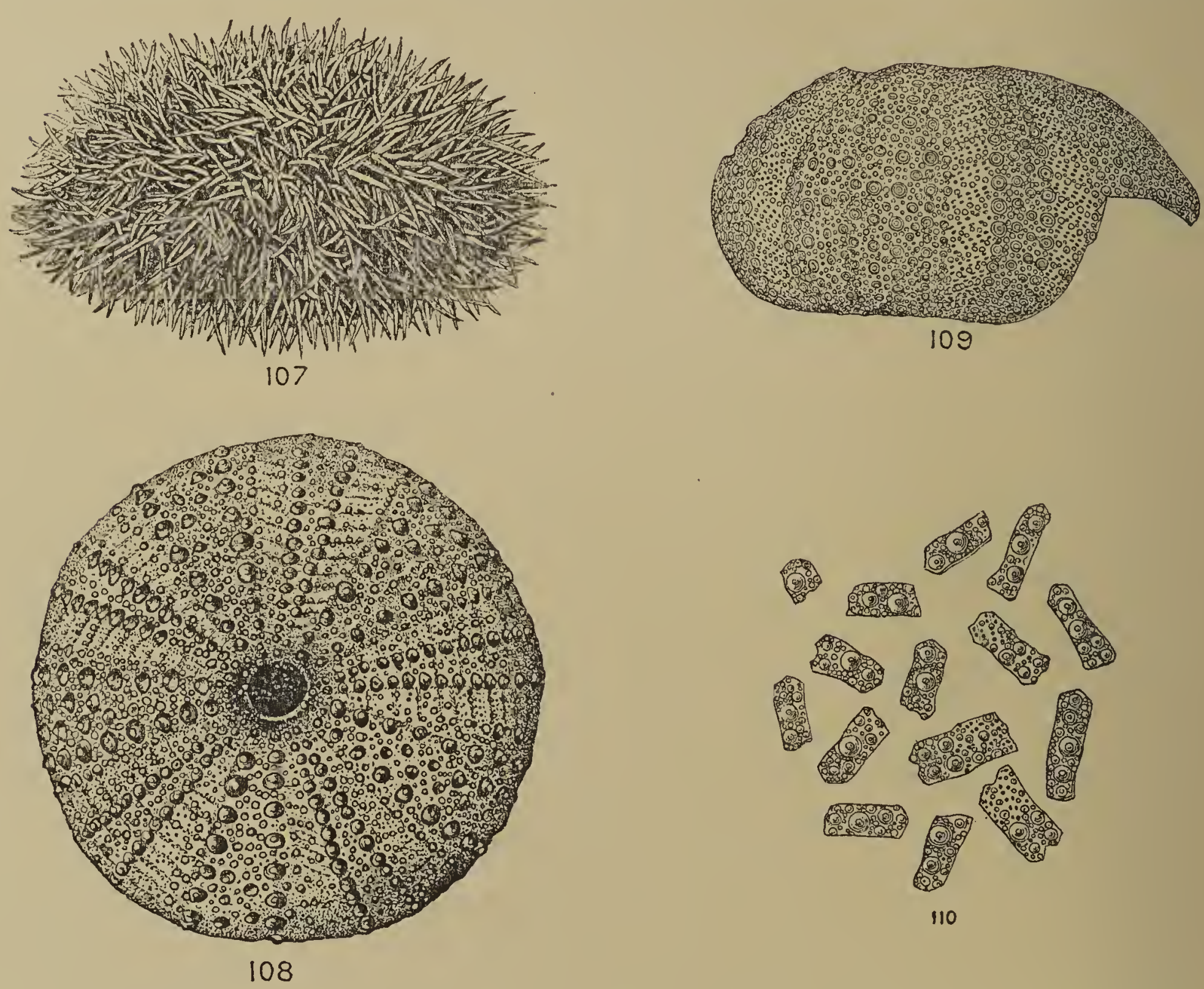

FIG. I07.-Sea-urchin.

FIG. 108.-Sea-urchin without needles.

FIG. I09.-Fragment of sea-urchin shell without needles. FIG. I IO.--Split pieces of sea-urchin shell.

as follows: first, bone heads with barbs on one side, and later, in the layer containing bones of sea mammals, there appeared bone heads barbed on both sides and better finished and polished stone implements.

Such is the general picture of the development of culture on the Aleutian Islands based on excavations made by Doctor Dall. The results of our own diggings, as may be inferred from the preceding chapters, particularly Chapter III, differ considerably from these conclusions. First of all, it should be noted that nowhere in the course of our excavations were the shells of echini ground down to such a condition that they had the appearance of "greenish white sand." This con- 
dition holds in spite of the fact that in some of our diggings the culture bearing layers were considerably deeper than those reported by Doctor Dall. The greatest depth of the three layers reported by Doctor Dall was I4 feet, while our excavations reached a depth of 2I feet in some places (see Agla'gax' site on Umnak Island, especially Pit 2). However, on the shore of Lastova Bay on Attu Island, we did observe ground echini shells in a comparable condition. Thus, while walking to the ancient Nani'kax' village site, we sank into soft sand, consisting in great part of well-ground shells and needles of echini, which gave it a greenish appearance. But this was an alluvial layer, the result of action of the sea and not of man.

On the contrary, the fragments of sea-urchin shells uncovered in our excavations, even in the lowest layers, consisted of split five- to six-angled lamellar pieces, into which the armor of the sea-urchin falls in drying or under mechanical pressure. From constant rubbing against each other, these pieces lose the form of regular polygons. This is clear from our collected examples of fragments of echini shells taken from various depth. Thus, in figure 107 may be seen a side view of a seaurchin with the needles, while figure 108 represents the sea-urchin, without needles, as seen from the side of the mouth opening. In figure Iog is shown a fragment of the shell of a sea-urchin without the needles, and in figure I Io the split pieces of the shell in natural size. Such split pieces were found in all our excavations quite independently of the depth of the layer. Of course, among these split pieces were smaller fragments of the shell and parts of the needles, but layers containing the remains of the sea-urchin had by no means the appearance of "pure, fine sand."

Further, Doctor Dall's estimate of the number of acres covered by sea-urchinshell refuse is not clear, for the writer observed no such uniformly continuous deposits as his statement implies. A sedimentary deposit may be uniform throughout and its continuity may be taken for granted, but the continuous spread of kitchen refuse could be determined only by removing the entire upper surface of the locality in which such refuse occurs. In any case, our experience was that a given layer of kitchen refuse, if taken separately, does not cover, without interruption, a large space. Thus, in one pit of a site, the lower layers may consist of echini or shell-fish, while in another pit the order of layers may be different. Even in the same pit, one section may show one order of layers and another section quite a different one. On the borders of a site were usually found very scant kitchen remains, and then in spots only. Thus, one could hardly speak of acres covered by kitchen middens. Occasionally the space between two pits, if excavated, yielded a very small amount of kitchen refuse. Hence, in order to present a clear idea of the succession of the layers of kitchen refuse in our excavations, we have given in detail the greater part of the sections made.

In our first diggings at the Nani'kax' site, on Attu Island, the successive layers in the pits were as follows: Echini, shellfish, and fish, while in the upper layer appeared the bones of sea mammals. However, later excavations made it appear that the succession of layers in the pits of Nani'kax' must be regarded as a casual occurrence, since elsewhere heaps of echini and of mollusk shells were often found 
above the layers of mammal bones. In such cases where mammal bones were rare in the lower layers, account should be taken of the fact that bones of mammals decay more rapidly than shells of echini and mollusks.

In order to determine approximately the period of time necessary for the formation of a layer of echini of a given thickness, Doctor Dall dried an echini of the largest size and reduced it to coarse grains. He found that it had a capacity of I.75 cubic inches. At this rate, it would take 988 echini to make a cubic foot of the layer and 87,000,000 of echini-shells would form a stratum 2 feet deep and covering an acre. Assuming a village of 20 inhabitants and supposing roo echini as necessary per diem to feed one person, Doctor Dall calculated that the time needed for the formation of the stratum of echini previously described on the island of Amchitka would be 2,200 years; but on the average he assumed a period of 1,000 years as necessary to form the so-called Littoral period for the Aleutian Islands.

The arbitrary character of Doctor Dall's calculations could easily be demonstrated, even if one accepted the echini layer as marking a distinct chronological period. But such a period could never have existed, simply because sea-urchins can not serve as food throughout the whole year. The tissues of the Echinus, which form a rough, hard cartilage, are inedible and only the bright-yellow ovaries are eaten. According to information obtained from the Umnak people, the minute eggs of echini are fully developed from April to May and September to October. During February and March there are no eggs and the inedible tissues of the Echinus contain " only water." Yet we were told by the Attu people that some echini have fully developed eggs in June. At that time one adult Echinus furnishes a full tablespoon of eggs. According to the Aleut, 6 or 7 echini are then sufficient for a meal and may satisfy an adult man. Echini roe is sweetish, but taken with lemon juice, as we did, is a palatable food. So in some respects the assertions of Doctor Dall do not agree with the statements of the Aleut. For example, he says that the ovaries, "when in full condition, which occurs in some individuals at all seasons of the year, offer 2 or 3 tablespoonfuls of really palatable minute eggs. It would require 40 or 50 adult individuals to afford a good meal for a man." ${ }^{6}$

The present-day Aleut also gather echini in the months indicated above, even on the Pribilof Islands, where other food, local and imported, may be had in abundance. The greater number of echini are gathered by the women in shallow pools on shore during low tide. They hold them on a stone with one hand and crack them open with a stone hammer or bone club; but before removing the eggs, they place the sea-urchins in grass bags and wash them in fresh water. This is done to kill the echini and not to remove the salty water, as might be supposed. They die in fresh water." There is also a special implement (cuniga'six') for gathering echini in high tides or in deep places generally. ${ }^{8}$ This consists of a long shaft with 4

${ }^{6}$ See W. H. Dall, On Succession of Shell Heaps, etc., p. 5 r.

${ }^{7}$ When the Aleut catch an octopus the process is the same. Octopi are caught in shallow places from boats by means of hooks tied to long shafts. After dragging an octopus out of the sea-water it is plunged into fresh water and in a moment the legs and feelers cease to move.

8 See above, p. 84 , fig. 33 , plate 24 . 
blunted circular bone or wooden prongs attached to it. This may be distinguished from a bird-dart by the absence of the central prong and of barbs on the prongs.

Doctor Dall believes that the echinus eaters "might have secured their food with hand nets or scoop nets" and that with the beginning of the Fishing Period, the larger and more effective seine had been added. But we know certainly that nets and seines became known to the Aleut only after the advent of the Russians and the stone sinkers found in the excavations were used for fishing with line and hook. On Attu and Umnak we were afforded many opportunities to observe how the women and children gathered the echini during every low tide. For one thing, the present-day Aleut do not throw the echini shells close to their dwellings, as did their ancestors, but carry them to pits especially dug for this purpose at some outlying point near the village. Hence, at some future day, the remains of echini, mollusks, fish, and other food thrown out by the present Aleut will serve as objects for study by palæoethnologists, but they can be distinguished from the ancient deposits by noting that the kitchen middens of the present Aleut will be found apart from the dwellings and, essentially, apart from skeletal remains. ${ }^{9}$

On Attu Island we found fragments of shells of echini and mollusks on the top of a mountain pass between Sarana and Lastova bays, at a height of 800 meters. On January 8, I9I0, while on Umnak Island, we experienced a serious volcanic shock. The following morning the shore was covered with a layer of stunned fish, sea-urchins and shellfish, about 2 feet high and 2 feet wide, but in several days these were carried to the neighboring hills and mountains and eaten by gulls and ravens.

The fish-bone layer, Doctor Dall stated, was so hard that a bar and pickax were required to disintegrate it. He also asserted that because of these fish remains the deposits could be exported for use as fertilizer. This was not our experience. As to the hardness of the fish-bone layers, reference may have been made to layers accumulated in hard clay, such as we found on Amaknax Island. The fish-bone layers we found in sandy deposits, and particularly pure layers of fish-bones, without an admixture of earth, were as soft while digging as were layers of echini and mollusks. The fish-bones found by us were of a dark-brown color and consisted chiefly of the bones of the head and spine of cod-fish (Gadus macrocephalus Tilarius; Aleut, atxi'dax') and of halibut (Hippoglossoides Hord. a. Gilb.; Aleut, ca'qix'). There were found also the bones of sculpins, of Cottus aleuticus Gilb., Aleut sxix, or agu'gim-qa, i. e., " fish of the high tide," and of a small species of shark (Semniasus microcephalus; Aleut, qaci"kux'). However, Doctor Dall states that he found also the bones of two kinds of salmon, "hoikoh of the Russians, and another Salmo sp." Hoikoh is evidently the Russian haiko or keta (Oncorhynchus lagocephalus). But the keta rarely ascends the Aleut rivers from the sea. The salmon most frequently ascending the Aleut rivers is the Russian "red fish" or

9 It may be of interest at this point to call attention to the following: On hills or plains far from the present villages or from ancient sites were seen, often in considerable quantity, fragments of shells of echini and mollusks, which could be assumed to be the remains of man's food, and sometimes might even be regarded as testimony in favor of the rising of the sea bottom. As a matter of fact, these were simply the remains of birds' food. 
"nerka" (Oncorhynchus lycaodon), Aleut a'nux'. But we found no bones of salmon. The Aleut explained this by saying that the salmon bones decayed very rapidly, falling to pieces in 2 or 3 years. This is easily conceivable when the softness of salmon bones is taken into consideration, as compared with the hard bones of sea fishes which do not ascend the fresh waters of rivers and lakes. ${ }^{10}$

The characteristic peculiarity of kitchen remains attributed to prehistoric man in the palæolithic or neolithic period is that these deposits accumulated around his dwelling and that in them he interred his dead. The same is true of the Aleut. Remains of food, dwellings, and skeletons were found together. Our conception of the accumulation of kitchen refuse by the Aleut is, then, as follows: All uneatable parts of animals and other refuse were taken from their semiunderground dwellings and thrown out near the outer walls. These heaps of kitchen refuse grew until they reached the tops of the dwellings and also filled the pits of the abandoned huts adjoining. Eventually new dwellings were built amid these kitchen remains, but necessarily at a higher level than the old ones. Thus, after repetitions of this process, the village sites were elevated. In repairing a ruined dwelling or building a new one, the Aleut often used old pits, raising their bases in accordance with the level of the whole site. Also, the pit walls were drawn nearer to one another or placed farther apart, according to the size of the dwelling needed. So there might be occasion to dig amid kitchen remains in erecting a new underground dwelling and in consequence displacement of the midden layers may have taken place, causing later remains to lie deeper than the earlier ones. The soil containing plant roots, etc., which had originally covered the kitchen refuse might, under such circumstances, be so displaced as to lie beneath the shell-heap itself. Nevertheless, in spite of these possibilities, the deeper-lying layers of kitchen refuse appear to be the more ancient. Particularly is this true with reference to spaces between the dwelling pits where the refuse was thrown out. Most of our sections were made on the edges of pits or along the walls which separated one pit from another. Besides, in cases of dislocation or displacement of layers, the disturbance of their horizontal form and regular succession is easily noticed (see, for instance, plate 3, fig. 2). Generally, then, it may be said that the deeper layers of kitchen refuse on the Aleutian Islands are the more ancient. This is true also of skeletal remains, implements, and other traces of man's activities disclosed in the course of the excavations.

We have previously observed that in all layers of kitchen refuse, even in the lowest, objects were found which testify to a much higher culture than that described by Doctor Dall, but it may be well here to point out the most conspicuous

10 It is of interest to note that the well-known Russian geologist, the late Professor Inostrantzev, failed to find the bones of salmon and pike among fish remains in the excavations on the shore of Ladoga Sea, in spite of the fact that they are at present abundant in that sea (see A. A. Inostrantzev, Prehistoric Man of the Stone Age on the shore of the Ladoga Sea, Petrograd, I882, p. 90, in Russian). In the Danish Kjökkenmöddings anong mollusk shells were also found bones of sea fishes like cod, flounder, and herring (see Doctor Hugo Obermaier, Der Mensch der Vorzeit, Allgemeine Verlags-Gesell., Berlin, Munchen, Wien, p. 47I). We wish, however, to mention that "in one of the Mentone caves Rivière found a paleolithic necklace composed of twenty-four salmon vertebrae." (G. G. MacCurdy, The field of Paleolithic Art. American Anthropologist, vol. 26, No. I, JanuaryMarch, 1924, p. 4I.) It would be extremely interesting to verify whether the mentioned vertebrae are really of salmon fishes, which usually ascend rivers for spawning. 
items. That the Aleut used fire in the earliest period of the accumulation of the kitchen refuse is shown by the discovery of stone and bone lamps in all the layers. Thus in Pit 4, Nanikax, Attu Island, at the bottom of the lowest layer, and at a depth of 4.8 meters (the section was excavated to a depth of 5 meters) a bone lamp was found (plate 20, fig. 5); a similar bone lamp was found in the same section in its upper layer at a depth of I meter (plate 20, fig. 7). This bears testimony to the fact that not only the people who accumulated the lowest layer of kitchen refuse used bone lamps for lighting and warming, but the same type of bone lamp was preserved to the end of the Stone Age of the Aleut. Stone lamps were also discovered in layers at different depths, not excluding the lowest ones. For instance, at Atxa'lax', Atka Island, a large stone lamp was found at a depth of 3.4 meters (plate I9, fig. 2). The pit was dug out to 4.2 meters. At the Agla'gax' site, on Umnak Island, a small stone lamp was found in Pit 3 in the lowest stratum of the last layer of kitchen refuse, at a depth of 4.3 meters. The pit was excavated to a depth of 4.5 meters (see p. 32 ).

That the Aleut used fire in the earliest period of the accumulation of kitchen refuse is shown by the discovery of stone "frying-pans" and traces of charcoal and ashes of fire-places in the lowest layers of remains. Thus, a stone frying-pan was found in Atxalax, Atka Island, in the lowest culture layer, at a depth of 4 meters, in Pit A, the whole depth of the pit being 4.2 meters (see p. 27).

The use of lamps in the earliest period of man's existence on the Aleutians, for which the blubber of sea mammals is necessary, might of itself serve as evidence that the Aleut were hunters at the time of their arrival at the islands. This conclusion may well be corroborated by the discovery of bones of aquatic mammals in all the culture layers of the excavations. Even the bones of the largest sea mammals, the whales, were found in the lowest layers of kitchen remains. Thus, for example, bones of a large whale were found in the lowest culture layer, at a depth of 4.5 meters, in Pit 4 , Nani'kax' site, Attu Island (see p. 25). On Umnak Island bones of a large whale were found in the lowest culture layer in Agla'gax', Pit 2, at a depth of 6.2 meters; the total depth of the pit was 6.5 meters (see p. $3 \mathrm{I}$ ).

It is true that whales' bones were not necessarily derived from whales killed by hunters, but may have been obtained from stranded dead whales killed by killer whales. In this case, however, whalebones would not be so frequently found throughout the excavations. In addition, bones of other sea mammals were also found in the lowest layers of kitchen-middens. Finally, fragments and parts of implements for hunting sea mammals were also discovered in the lowest layers of the excavations. Of these may be noted, the stone blade of a throwing-lance found at Nani'kax', Attu Island, in the lowest culture layer (fig. 33) at a depth of 4.7 meters; the stone point of a throwing-lance found under the last culture layer, on a clay bed, in Pit 4, Uglu'dax', Umnak Island (fig. I4); the stone point of a war-lance found at a depth of 5.I meters in Pit 2, Agla'gax', Umnak Island (plate I5, fig. 22). 
Doctor Dall illustrates two stone sinkers. ${ }^{11}$ One is rude in character and the other is of better workmanship, with a regular groove in the middle. According to his opinion, the first belongs to the Fishing Period and the second is a present-day net-sinker. In these two examples he sees the assumed progress the Aleut have made in the manufacture of stone implements. But if we consider the specimens illustrated in plate $\mathrm{I} 7$, it will be seen that rudely worked sinkers were also found in the upper layers. Even now the Aleut make sinkers as rude as those found in the lowest layers of the excavations; these they use for the seines adopted from the Russians. So, in general, notwithstanding Doctor Dall's opinion to the contrary, the Aleut were acquainted with fishing on their arrival at the islands. Bone heads for fishing-spears and parts of bone hooks for fishing-lines were found in the lowest culture layers. One bone head for a fish-spear was found at a depth of 6.2 meters (see plate 24, fig. 5I ). This appears to refute Doctor Dall's opinion that the earliest inhabitants of the Aleutian Islands had no bone implements. In the lowest layers of remains we found fragments of bone heads and bone points of arrows and throwing-darts. And again, Doctor Dall's assertions that the earliest bone heads were distinguished by being barbed on one side only, also remain uncorroborated by the results of our excavations, for in all layers we found bone heads of both types, with barbs on one or both sides. Further, the discovery, in the lowest layers, of bone awls and needles, of bone and stone scrapers, of whetstones, of paints and pestles for grinding them, show conclusively that the Aleut were sewing clothing and painting skins in the early days of their inhabitation of the islands.

Returning to the question of the use of fire by the ancient Aleut, it should be pointed out that in the lowest culture layers we found bone and stone heads for firemaking drills and bone wedges for splitting logs of driftwood (see p. 87).

Finally, Doctor Dall's supposition that the Aleut began to build semiunderground dwellings only at the time of the middle stratum of the "Hunting Period" layer remains uncorroborated, since we found, in the different layers, whale bones which had served as posts in ancient Aleut dwellings or as parts of the roof frame (Chapter III).

It is thus that a critical survey of the suppositions of Doctor Dall concerning: the history of the development of the culture of the inhabitants of the Aleutian Islands leads one to the assertion that the Aleut came to the islands with a comparatively high primitive culture, not far removed from that found by the Russian invaders. Of course during the period of occupation changes in the native material life did occur, partly as the result of adaptation to changes in the environment, partly as a matter of culture progress, but these changes were trivial.

${ }^{11} \mathrm{He}$ calls them net sinkers, but in fact they are sinkers for fish-hooks. 


\section{CHAPTER VII.}

\section{ARCHAEOLOGICAL AND ETHNOLOGICAL INFERENCES.}

Before presenting the conclusions based on our own data on the prehistoric Aleut, we wish to give critical consideration to those of earlier explorers. It has already been stated that theories as to the origin of the Aleut are at great variance; though most writers on the subject believe that the Aleutian Islands were peopled by immigrants from Asia.

It should be noted that the Aleut, in distinction from the northwestern Eskimo of America, had had no intercourse with Siberian natives before the islands were discovered by the Russians. The Aleut became acquainted with the Kurilians, Kamchadal, and other Siberians through Russian traders and hunters who transported them on their vessels to colonize the Komandorsky Islands.

Despite this, Weniaminoff supported the theory of the Mongolian origin of the Aleut, basing his conclusion on a doubtful tradition dealing with the arrival of the Aleut on the islands from a "big land " or "country" from the west. Furthermore, he believed the "big land" of the tradition to be Japan. ${ }^{1}$ Baron Wrangel was also of the same opinion, laying particular stress on the Mongoloid appearance of the Aleut. ${ }^{2}$ Associated with Weniaminoff and Wrangel was the well-known explorer, Professor Schrenk, who believed that the Aleut could have reached the Aleutian Islands from the west with no other means of navigation (small and large skin boats) than those they had when discovered by the Russians. Their further expansion to the American continent on the east was prevented, according to Professor Schrenk, by the resistance of the Konyag and Kolosh (Tlingit). For these reasons Schrenk ranked the Aleut among the Palæasiatics. ${ }^{3}$

So it may be inferred that Schrenk believes this migration of the Aleut from Asia occurred during recent time, or, in other words, when the present geographical conditions existed. Following Schrenk, a recent investigator, S. K. Patkanoff, who worked out the statistical materials of the census of 1897 of the Siberian natives, also placed the Aleut among the Palæasiatics. ${ }^{4}$ Again, the belief in a possi-

1 I. Weniaminoff, Notes on the Islands of the Unalaska Division, St. Petersburg, Part II, p. 272 (in Russian). It may be noted that Aleut give the name "Big Land" (Ta'nam Añunā' or Ta'nax-Añu'nax") to one of the Four Volcano Islands, which are at present uninhabited, but in the days before the advent of the Russians were inhabited. It is possible that some of the old villages on Umnak Island or even on the island of Unalaska were founded by immigrants from Ta'nam-Añunā'.

2 See Wrangel, Voyage in Siberia and in the Arctic Sea, Part II, p. 124. (In Russian.)

${ }^{3}$ L. Schrenk, Die Völker des Amur-Landes, Band III, pp. 25I-252. According to Schrenk, the Aleut came to the Aleutian chain from Asia and were prevented from expanding to the Continent by the resistance of the Konyag, who stopped their advance. Weniaminoff, however, recognizes the affinity of language, physical type, and culture between this group and the Aleut.

${ }^{4}$ S. Patkanoff, Essay d'une statistique et d'une Géographie de peuples Palaasiatiques de la Siberie, St. Pétersbourg, I903; Statistical Data showing the Tribal Compositoin of Siberia's Population (in Russian), vol. I, pp. I07, I65, Petrograd, I912. 
ble migration from Asia to America over the Aleutian chain is favored by Professor W. J. Sollas, but he gives no indications of the time during which this assumed migration could have taken place. ${ }^{5}$ We also note that the Russian ethnologist, Leo Sternberg, ${ }^{6}$ refers to an instance of Gilyak on a small island not far from the mouth of the Amur River, having come in contact with Aleut, and expresses his belief in the common origin of both peoples.

Finally, the Danish explorer, H. P. Steensby, expressed the opinion " that the Aleut are members of an original independent tribe which adopted the implements and hunting methods of the subarctic Eskimo." " But it should be stated that Steensby based his conclusions on Doctor Dall's designation of the three periods of Aleut culture.

The first traveler to express the supposition that the Aleut came from the American continent was Captain P. Saikoff. He visited the Aleutian Islands in I772-I778 on the ship St. Vladimir. ${ }^{8}$ Among travelers of the latter part of the last century it was Doctor Dall ${ }^{9}$ who combated the idea that the Aleutian chain was a bridge for emigrants from Asia to America, referring to the fact that Commander Islands were uninhabited before the Bering Expedition, that the distance between Kamchatka and the Commander Islands is very considerable ( 138 statute miles) and that the distance between these islands and Attu Island is still greater (253 statute miles). On these grounds Doctor Dall finds it improbable that the Aleut came from the west. It should be added that even in their present skin boats they are unable to navigate such long stretches of rough, foggy, and tempestuous seas. Besides, skin boats were and still are unknown to the Aino and Gilyak, as well as to the Kamchadal.

The Russian zoologist, Suvoroff, who studied the seal fisheries on the Commander Islands, estimates the distance between Copper Island and Attu at about I 80 nautical miles and between Bering Island and the Kamchatka headland at about 90 nautical miles. Professor Suvoroff also gives the data for various depths: that between Bering and Copper Islands is about 70 fathoms, but between Copper Island and Attu it reaches I,996 fathoms. Between Bering Island and the Kamchatka Peninsula the depth is still greater, being 3 , I I 7 fathoms. ${ }^{10}$

The idea that the islands were peopled by Japanese junks occasionally carried to the east by gales, Doctor Dall justly finds unreasonable, first, because they would be carried by the Japanese and great easterly Pacific currents to the coast of America in latitude 50 before the northerly branch of the current would cast them up on land;

5 W. J. Sollas, Ancient Hunters and their Modern Representatives, London, r9II, p. 379. $6 \mathrm{I}$, and 63 ).

${ }^{6}$ L. J. Sternberg, The Gilyak, Moscow, 1905, p. 9 (a separate from the "Ethnographical Survey," parts 60,

7 H. P. Steensby, An Anthropogeographical Study of the Origin of the Eskimo culture, Kobenhavn, r9r6, p. $15 \mathrm{r}$.

8 P. S. Pallas, Neue nordische Beytrage, Vol. III, 1782, p. r84.

9 W. H. Dall, On the Origin of the Inuit (Contributions to North American Ethnology, Vol. I, Washington, 1877, pp. 95-97); On the Geological Aspects of the Possible Human Immigration Between Asia and America (American Anthropologist, vol. 14, No. r, rgr2, p. I2).

10 See Suvoroff, The Commander Island's and Fur-Hunting Trade on them. Publication of the Russian Geographical Society, Petrograd, 1912. 
secondly, no migrations were ever effected by accidental shipwrecks. It must also be remembered that women did not accompany parties of primitive sea-going hunters. ${ }^{11}$

The author agrees fully with the theoretical considerations of Doctor Dall concerning the impossibility of a direct peopling of the Aleutian Islands from Asia under geographical conditions like the present and with the prehistoric means of navigation. However, some attention should be given to the past status of the islands, $i$. $e$, the geological basis for considering the Aleutian Islands at one time or another as a land bridge from Asia to America.

This general question has three aspects: (I) Did the land bridge between northeastern Asia and northwestern America, which undoubtedly existed, reach as far to the south as the present latitude of the Aleutian chain? (2) Can the present Aleutian chain be regarded as a remnant of the ancient land bridge? The significance of an affirmative answer to this second question is obvious. In any case it is the question in which we are exclusively interested, namely, (3) was this junction of the two continents still in existence during the Pleistocene Period, $i . e$., during the time of the earliest possible migration of man from the Old World to the New ? ${ }^{12}$

Unfortunately, the geology of the Aleutian Islands is not sufficiently well known to give a definite answer to these questions. Even with the help of the general descriptions of different explorers, it is difficult to form a definite opinion as to the basal rock of the Aleutians. As yet it is known to us only in isolated localities, remote from one another. ${ }^{13}$ Plutonic rocks of diorite and granite; quartzite, and other ancient rocks are mentioned as occurring on Unalaska as well as on Attu. Professor Jaggar refers to slates found on Unalaska Island. ${ }^{14}$ But generally the ancient rocks occur among more recent eruptive minerals of andesite and among the tertiary eruptive basalts as blocks raised by volcanic processes. Suess ${ }^{15}$ regards the arc of the Aleutian Islands as a continuation of the Alaskides, mountains of a comparatively recent origin. Judging from the changes observed on Bogoslof Island,

11 We wish, however, to point out that Steensby (An Anthropogeographical Study of the Origin of the Eskimo Culture, pp. 208, 209) regards it as plausible that the Eskimo could have been influenced by Japanese navigators before the beginning of the seventeenth century, after which date the Japanese government prohibited all navigation beyond its home waters. Professor Haddon (Wanderings of Peoples, p. 74) believes that the Aleutian Islands, like Bering Strait, could have served as stepping-stones for migrations. The same is maintained by Foy (Zur geschichte der Eissentechnik) and admitted by Weule (Leitfaden der Völkerkunde, Leipzig und Wien, I912, p. 30).

12 Some anthropologists believe in the existence, previous to the Palæolithic age, of the so-called Eolithic Age, which carries us back to the Tertiary Period. But since the remains of Tertiary man himself have not been discovered as yet, the idea of an Eolithic Man remains a conjecture. It may be remembered that a land bridge between North America and Eastern Asia existed during the whole Tertiary Period, and if a Tertiary man did exist he could have followed the Tertiary mammals in their migrations from the Old to the New World.

13 C. Grewingk, Beitrag zur Kenntniss der orographischen und geognostischen Beschaffenheit der Nordwestlichen Küste Amerikas, St. Petersburg, I850, p. I23; G. F. Becker, Reconnaissance of the Gold Fields of Southern Alaska, with some notes on general Geology (I8th Annual Report, U. S. Geological Survey, I897-98, part 3, p. 25I); Dall and Harris, Correlation Papers, Neocene (Bulletin, U. S. Geological Survey, I892, p. 968).

14 T. A. Jaggar, Jr., Journal of the Technology Expedition to the Aleutian Islands, Igo7 (Technology Review, Vol. X, No. I, Boston, I908). Although the ancient minerals, which served for making the stone implements before described, were obtained on the islands themselves, they are not referred to as material taken not in situ. According to Becker (see footnote I3) the whole range of active volcanoes on the Aleutian Islands produces andesitic lava exclusively, while basaltic lava predominates in Tertiary beds.

15 Ed. Suess. The Face of the Earth, Oxford, I909, vol. 4, p. 374 (English translation). 
the formation of mountains on the Aleutians is still in process. ${ }^{16}$ Smoking craters are still to be found on all the islands of the chain, from Unimak to the west to Small Sitkin (long. $178^{\circ} 30^{\prime}$ E.). Kiska Island ( $177^{\circ} 20^{\prime}$ E. long.) to the west of Small Sitkin, consists of andesites. The configuration of most of the islands, with their pairs of deep bays on both sides and their low and narrow necks of land, clearly shows that they were formed by a junction of separate rocks or small volcanic islands. The presence in many localities of petrified shells of the Tertiary Period shows that these places were still under water in the Tertiary age. As has been stated before, Doctor Dall cites the distance and the depth of the sea between the Commander Islands and Attu as proof that migration from Asia to America by the Aleutian route was impossible. These considerations can not refer to the earliest geological periods, as the great depth of the sea between these islands may have resulted from a more recent sinking of the sea-bottom. For our purpose it is important to know in what geological period this sinking took place. The time of the sinking of the sea-bottom, which reaches a depth of 3, I I 7 fathoms between the Commander Islands and Kamchatka, is placed by Professor Bogdanovich in the Post-Pliocene or in the early Pleistocene, $i$. e., in the period which preceded the appearance of man on the American continent. ${ }^{17}$

It is true that on Attu, the most westerly of the Aleutian Islands, volcanic rocks have not as yet been found. However, andesite, of which many of the stone implements were made, was brought, according to the statements of the Aleut, from Agatu, another island of the same group, located to the south of Attu. It is not without interest to note that in none of the lakes on the Aleutians, including Attu, were fresh-water fish found. Neither have we authentic data as to the finding of Pleistocene fossils on the islands. Weniaminoff states that in 1836 a mammoth-tusk was discovered on St. Paul Island, ${ }^{18}$ but he does not state who found it and where.

Mr. Stanley Brown, of the U. S. Geological Survey, in his account (I89I) of the Pribilof Islands, writes as follows:

"There are two fragments of palæontologic evidence connected with these islands which, as they have been used by writers, demand a cautionary word. The tusk of a mammoth was found in the sands of northeast point on Saint Paul island, and the tooth of one is reported as coming from the shores of Saint George. As there is not a foot of earth upon either island, save that which has resulted from the decomposition of the native rock and the decay of the vegetation, the value of such testimony is questionable." (Bull. Geol. Soc. Amer., vol. III, p. 499.)

We have information also that mammoth tusks and teeth were found on Unalaska Island in I80r, ${ }^{19}$ evidently based on the statements of hunters, but these can be given little weight. But even if the finds of isolated bones of diluvial animals had actually taken place, they would not be incontrovertible evidence of the existence of the

${ }^{16}$ T. A. Jaggar, Jr., The Evolution of Bogoslof Volcano (Bull. American Geographical Society, Vol. XL, July 1908).

${ }_{17}$ C. Bogdanovich, Geologische Skizze von Kamtschatka (Petermann's Mitteilungen, 1904).

${ }_{18}$ Weniaminoff, Notes on the Islands of the Unalaska Division, vol. I, p. 196.

${ }^{18} \mathrm{~F}$. Stein, On the time of the appearance of the Aleutian Islands (Memoirs of the Mineralogical Society, vol. I, I830, St. Petersburg, p. 383, in Russian). 
animals themselves in former times. Separate bones could be brought by man or be washed out by the sea. Of the bone objects excavated, there was not a single instance of an object made of mammoth bone; this in itself may suffice to show the absence of the remains of the mammoth on the islands.

G. M. Dawson made depth measurements with a deep-sea lead, and discovered a shallow submarine plateau beginning near Unimak Pass and running northwestward to the vicinity of Cape Navarin in Siberia. He sees in this traces of a wide terrestrial plain which connected North America with Asia and which existed during a long period in later geologic time. ${ }^{20}$ However, the arc of the Aleutian Chain lies to the southwest of this line.

Thus, it may be said, when geological conditions are taken into consideration, that the Aleut could not have come to the islands from the west. The question of their origin must, therefore, be merged with that of the origin of the native population of America, in general, i. e., the Eskimo and Indians.

Setting aside the question of the relation of the Eskimo and Indians, we will consider the relations of the Aleut and Eskimo as shown by their linguistic, cultural, and somatological connections. The Aleut language belongs, without any doubt, to the Eskimo stock. It has not been possible, as yet, to make a detailed comparative study of my extensive Aleut dictionary and published Eskimo vocabularies, but even a superficial survey of the latter showed many common elements. However, a detailed grammar of the Aleut language in its three dialects has been worked out and it was found that its structure is based on the word formations common to Eskimo. The modification of the Aleut verb, with its two formal processes of incorporation and polysynthesis characterizes, perhaps in the best way, the Eskimo-like structure of the Aleut language.

The half-underground dwellings, the skin boat, the harpoon, the throwingboard and lances, the former use of different kinds of labrets, the method of disposal of the dead, the use of paints and of ceremonial and dancing masks, the woman's tailoring-knife, fur clothing, and other objects of culture bear witness to the close connection of Aleut and Eskimo culture. These resemblances are independent of the origin of Eskimo culture, whether in Hudson Bay or elsewhere, and of the items of Eskimo culture which may have been adopted from Siberian or other sources. At present we shall consider only the Aleut cephalic index, one of the most important indices of physical type.

Of the 79 Aleut skulls excavated, only 50 were sufficiently complete for measuring. They gave an average cephalic index of 82.I with a standard deviation of 2.7; individually the cephalic index of the skulls ranges between 78 and 88. As all the skulls were taken from graves undoubtedly of the pre-Russian period, it may be concluded that they were not a pure race.

The measurements of 138 living people (men and women) gave a cephalic index of 84 , with a standard deviation of 3.3 , as individually the cephalic index

${ }^{20}$ G. M. Dawson, Geological Notes on some of the Coasts and Islands of Bering Sea and Vicinity (Bull. Geol. Soc. Am., vol. 5, I894, pp. I44, I45). 
ranges from 76 to 94. Thus, we see that mixture with the Russians did not influence the head measurements of the Aleut. According to Broca, 2 units may be added to the cephalic index of skulls to obtain the cephalic index of the living. Adding 2 units to 82.I (cephalic index of our Aleut skulls) we have 84.I. Thus, we see that the average cephalic index of ancient Aleut may be regarded as similar to the cephalic index of the present Aleut. ${ }^{21}$

If we compare the cephalic index of the Aleut with that of several Eskimo groups, Indians nearest to them, and the Palæasiatics, we shall see that they exceed all of them with reference to the relative width of the head. Thus, the Greenland Eskimo show a dolichocephalic index of 76 ; the Alaska and Siberian Eskimo have a mesocephalic index of 79 and 8o, respectively. The Koryak, Kamchadal, and Yukaghir are also mesocephals showing cephalic indices of 78,79 , and 80 , respectively. The Indian tribes nearest to the Aleut, the Tlingit, Tsimshian, etc., have a cephalic index not exceeding 82 .

The high cephalic index of the Aleut can not be regarded as the result of their blending with their present American or Asiatic neighbors. Two possible explanations may be given. First, the Aleut, as suggested by Doctor Hrdlička, ${ }^{22}$ became mixed with some division of Athapascans when, as a branch of the Eskimo stock, they came to the Aleutian Islands at a time when a part of some Eskimo group migrated to the south of Alaska from the place of origin of the Eskimo culture. Some of the divisions of the Athapascan tribe show an average cephalic index of $84 .^{23}$

A second possibility is that the Aleut, during long isolation on the islands, gradually acquired a superbrachycephalic index. The much discussed observations of Doctor Boas ${ }^{24}$ on the bodily changes of American immigrants under the influence of new surroundings and nutrition is now corroborated by Russian anthropologists who investigated the somatic changes undergone by individuals under the influence of a starvation diet. ${ }^{25}$

Turning to other physical traits, it should be pointed out that in skin-color, broad face-width, and Mongoloid eyes, some of the Aleut remind us more of Mongolians than they do of Palæasiatic or Indian types. Professor Virchow, who measured some Labrador Eskimo skulls, pointed out the Mongoloid character of their facial bones, in spite of the dolichocephaly of the skulls. ${ }^{26}$ This is equally true of the physical type of the Aleut who have a brachycephalic head index. However, some Aleut faces bear witness to mixture with Russians.

21 I wish here to point out, however, that the average cephalic index of 27 skulls collected by Doctor Dall on various islands of the Aleutian Chain is 84.3 (see Dall, On Succession in the Shell-Heaps of the Aleutian. Islands, Contributions to North American Ethnology, Washington, I877, pp. 66-68).

22 In a discussion of a paper on the Aleut read by the author at a meeting of the Anthropological Society of Washington in December 1923.

${ }^{23}$ C. Wissler, The American Indian, p. 330.

${ }^{24} \mathrm{~F}$. Boas, Changes in Bodily Form of Descendants of Immigrants, New York, Columbia University Press, I912; The Head Form of the Italians as influenced by Heredity and Environment (American Anthropologist, vol. I5, April-June I913, pp. I63-I88).

${ }_{25}$ Professor A. Ivanovsky, Physical Modifications of the Population of Russia under Famine (American Journal of Physical Anthropology, Vol. VI, No. 4, October-November, 1923, pp. 330-353).

${ }^{26}$ Rudolf Virchow, Eskimo von Labrador (Zeitschrift für Ethnologie, vol. I2, Berlin, I88o). 
If we turn now to the conclusions to be drawn from the description of the prehistoric objects excavated, there appears first of all the question of the antiquity of the Aleut kitchen middens. The relative antiquity of prehistoric finds is generally judged by the geological strata in which they are discovered, by the presence of bones of extinct animals, by the remains of vanished plants, by the skeletal remains of man, and finally by the material, shape, and types of implements discovered.

In general, all shell-heaps or kitchen remains of the type of Danish "Kjökkenmöddings," with which the Aleutian remains may be ranked, do not belong to very remote geological time. Thus, the Danish shell-heaps, the most ancient known, even in Europe, belong to the early neolithic or protoneolithic period which existed approximately about $8000 \mathrm{~B}$. C. This is proven by the finding of shells of the so-called Litorina period, charcoal of oaks which grew at that period and are now extinct, and bones of exterminated animals, such as the wild ox, lynx, beaver, and wildcat. The coastal accumulations of shell-heaps in France, Portugal, Ireland, and other European countries are also assigned to the beginning of the neolithic age.

Shell-heaps in the New World, in Brazil, Patagonia, Chile, Louisiana, Florida, California, etc., belong to a later period, since the mollusks, fishes, and other animal remains found belong to present-day species. However, some data have come to light that bear witness to the considerable age of American kitchen middens.

Thus, for instance, the investigation of some of the California shell-heaps showed that their lower layers lie several feet below the water-line. The shore-line has been slowly sinking. While the rate of depression is not yet known with certainty, the conditions are such as to infer a considerable age for the lower layers.

There is another example. The lower strata of the shell-heaps in Florida show, by their compactness and the contraction of their organic substance, a considerable antiquity. Huge oaks growing on the surface of the shell-heaps show that the latter were accumulated long before the advent of Europeans. Traces of different types of culture bear still more evidence of the considerable age of the shell-heaps.

The Aleut kitchen middens, like the other American shell-heaps, belong to a recent geological period. All the remains of animals found in the excavations belong to species still living. Although some of the ancient village sites seem to be slightly above sea-level, no marked changes were discovered on the surface. Some of the ancient village sites are found near smoking volcanoes, but the foundations of the villages evidently were begun after the volcanoes ceased their destructive activities.

Unfortunately, we have no definite criterion by which to determine the length of time necessary for the accumulation of the shell-heaps on the Islands. There are even no trees to give us an idea of the time of their growth. The calculations made by Doctor Dall as to the age of separate layers are founded, as has been mentioned before, on incorrect estimates and on a faulty conception of the strata. Nevertheless, the extreme age of many Aleut shell-heaps is shown by the following data.

We have already seen that in many of the lower layers were found decayed kitchen remains, and the bones of whale's jaws, which consist of bone of a particular hardness. In many places, where decayed bones of other animals were found, 
whale's bones were so well preserved that the Aleut carved from them arrow-heads, points, and other objects which are in our collection. It may be of interest to point out that whale's bones which have crumbled into soft powder were found in deeplying layers of kitchen middens which consisted mostly of shells of echini and mollusks, where sedimentary waters were not retained. Thus they could have only a slow effect on the decay of the whale's bones. Other factors furthering the process of decay, as oxygen, light, and heat of the sun could not effect them at all.

The depth of some of the shell-heaps which reached to 6.5 meters may also demonstrate their considerable age. A long period of time was necessary for the accumulation of such heaps of kitchen refuse.

We will consider, for example, the Agla'gax' village site, where the depth of cultural layers reached 6.5 meters. This site, taking into consideration all the traces of dwellings and other pits, occupied I6,800 square meters (about I4O meters long and about $\mathrm{I} 2 \mathrm{O}$ meters wide. If, considering the unevenness of the surface, we should take the average depth of kitchen midden for the whole village as 5 meters, then the strata containing kitchen refuse will form 84,000 cubic meters or about 74,372 tons (counting a ton not by weight but by volume, equal to I.I 3 cubic meters). It is true that one-third of the volume is occupied by earth with which kitchen remains are mixed, but we must remember that kitchen middens do not contain all the refuse of the inhabitants of the sites. A considerable number of the animals killed were eaten at the killing-places or in caves in which the hunters took shelter when they were overtaken by tempests and gales.

It has been pointed out before that the ancient villages were located on open isthmuses. In summer, to catch the migrating fishes, the people had to go to the river valleys, where they spent several months, and there they lived on salmon.

It is also of interest to point out that among the bones of aquatic mammals found in the shell-heaps the skull-bones were missing, except for the lower jaws of whales, which served as posts and beams for the earth dwellings. The absence of the skull-bones of sea mammals may be explained by the religious attitude of the ancient Aleut to the animals hunted. The skulls were thrown back into the sea in the belief that the animals would come to life again or, as a mark of honor, they were set up on elevated places, where they were allowed to decay. According to Krasheninnikoff, ${ }^{27}$ the Aleut carefully gathered all the bones of the sea animal first killed on a hunting trip and threw them back into the sea. So we see from the foregoing that a considerable part of the kitchen remains did not reach the shell heaps.

The volume of the kitchen remains has been further reduced from the original as a result of the working of other factors. A considerable portion of the mammalbones, and those of birds and fishes, have fully decayed and their components have mingled with the soil or they have been carried into the sea by subsurface waters.

In our sections there often occurred, between strata containing kitchen refuse, narrow, horizontal layers of black earth. Formerly these layers were, perhaps during long periods, the upper soil, which afterwards became covered with shells of

${ }^{27}$ H. Krasheninnikoff, The description of Kamchatka, Vol. II, p. 29I. (In Russian.) 
echini, mollusks, and other kitchen remains. In the course of decay, the latter added mold to the soil.

It must also be remembered that the ancient Aleut settlements were not very populous. The Aleut $t u^{\prime} k u x^{i}$ (i.e., master, elder, chief) often ruled over only a few families of relatives, consisting of 40 to 60 people, inhabiting two or three earth dwellings. That many more pits were found at all ancient village sites than would account for two or three dwellings does not mean that all the pits were inhabited at one time. Settlements with a population of 200 to 400 men were established by the Russian conquerors, who segregated small scattered groups of Aleut hunters in certain spots in order to facilitate control over them.

Thus the remains of millions of echini and mollusca were accumulated on the ancient village sites by a very small number of inhabitants. Besides, the same small group of people often had a separate summer settlement in some river-valley, not far from the river-mouth, and the kitchen remains were heaped up only during certain seasons and not in the course of a whole year.

All the foregoing considerations fail to give us a definite measure of time which could be expressed in figures; nevertheless, they show clearly that the Aleut came to the islands many centuries ago, if not during the earliest period of the peopling of northwestern America.

We may turn now to the question of the degree of culture possessed by the inhabitants of the islands who left us the remains of their food, manufactures, and dead. Of course, the Aleut of the shell-heaps lived in the Stone Age, but in what phase of that period? In this case the question concerns the degree of culture and not a period of time. Up to the present time it is only in the prehistoric archæology of western Europe that a definite correlation has been established between stages of primitive culture and time periods, between types of implements and other traces of man's activities and the age of the geologic strata or the fossils accompanying them. Such a corresponding parallelism does not occur in the prehistoric remains of regions retarded in their cultural development. A few centuries ago the Aleut were in the same stage of culture as the prehistoric Western Europeans were thousands of years ago. But considering only the stage of civilization, without regard to the time element, we are allowed or even obliged to make use of the terminology established by the archæologists of Western Europe when referring to prehistory of backward tribes. Even though until some 80 years ago implements of the Stone Age were not definitely classified and German archæologists combated the conclusions of Danish archæologists that the Bronze Age preceded that if Iron, ${ }^{28}$ nowadays no one hesitates to acknowledge the fact that the evolution of primitive

28 It should be noted, however, with particular reference to Africa, that the late Professor von Luschan contended that this continent was not only the place of origin of iron technics, but that the negroes knew the art of smelting iron before they began the manufacture of bronze (see Felix von Luschan, Eisentechnik in Afrika, in Zeitschrift fur Ethnologie, Band 4I, Berlin, I909; Völker, Rassen, Sprachen, Berlin, I922, p. 5). On the other hand, Doctor Foy combats the contention of Professor von Luschan that Africa is the place of origin of iron smelting and the blacksmith's art (see W. Foy, Zur Geschichte der Eisentechnik, und besonders des Gebläses. Ethnologica, Im Auftrage des Vereins zur Förderung des Städtischen Rautenstrauch-Joest Museums für Völkerkunde in Cöln. Vol. I, Leipzig, I909, pp. 185-222). 
techniques proceeded everywhere in one and the same manner, beginning with the use of unworked boulders and ending with carefully polished axes and knives. Thus, to judge by the types of stone implements of the ancient Aleut and by the methods of manufacture, the Aleut of the Shell-Heap period had already entered the neolithic age or age of polished stone implements. This may be corroborated by the specialization of forms for stone knives and points for throwing-weapons, by the use of bone flakers, by finds of stone points with serrated edges, made by the retouching method, by the use of the bow, and by the presence in the excavations of polished stone implements and lamps.

On the other hand, even in the upper layers were found rudely chipped stone implements, reminding us of Solutrian, Mousterian, or even Acheulian flint weapons. A few polished-stone objects were found. The polished-stone adzes and chisels, some of which have been previously illustrated, were ground only on their edges. Although everywhere we find that the use of crude chipped implements follows the invention of polishing methods, we may nevertheless state that the neolithic culture among the Aleut had not been fully developed before their first meeting with the Russians.

The absence of large stone axes may be explained by the complete absence of growing trees. For splitting pieces or logs of driftwood along their length, bone wedges and stone hammers were sufficient, and for chopping these splinters they used stone adzes. The only stone implement which could be termed an ax is shown on figure 26 , plate 15 .

It should be stated that the number of stone adzes found in the excavations was exceedingly small. Among the I,500 Stone Age objects obtained on the Aleutian Islands, only I 5 stone adzes were discovered. In his extensive diggings, Doctor Dall found only I adze. ${ }^{29}$ This can not be ascribed to accident alone. It seems that the Aleut rarely used even the adze. In manufacturing bone and wooden objects they used the large stone knives described above. Nevertheless, it should be added that we found many traces of bone worked with adzes.

As has been stated before, in the lowest layers of the kitchen middens were found vestiges of underground dwellings in the shape of lower jaws of whales, and we are justified in inferring from this that the Aleut were already acquainted with the building of underground dwellings upon their arrival in the islands. It should be pointed out, however, that no skeletal remains were found in the lower layers of kitchenmiddens. We must admit that at the time of their settling on the islands the Aleut placed their dead in caves only or in burial huts above ground, and these decayed leaving no traces.

The close cultural connection between the Aleut and the Eskimo has been remarked before. It should be added that the typical large woman's slate tailoringknife called $u$ 'lu occurred in all the excavations on the Aleutian Islands. The Aleut called it iga'dax'.

${ }^{29}$ W. H. Dall, On Succession in the Shell-Heaps on the Aleutian Islands (Contributions to North American Ethnology, vol. I, Washington, I877, p. 8I). 
The methods of ornamentation of bone objects, by engraving with stone gravers and awls, notches, parallel lines, dots, zigzags, circles, and other geometrical patterns, filled with paints of different colors, are the same as among the Eskimo. Of Eskimo type are also the present-day Aleut realistic representation of animals on bone objects and the realistic carvings in bone and wood.

The particular climatic conditions in the Aleut country and the formation of the islands contributed some specific traits to their material culture. As the inhabitants hunted only sea animals, mainly from skin boats, the use of the bow was very limited. The darts cast at sea mammals by means of a throwing-board were very light, so that they could be thrown with the right hand, while, with the left, the hunter steadied the boat, holding the double paddle with the left hand across the skin boat. For stringing a bow the use of both hands is necessary. Besides, the bowstring recoils when it is released, and if used in the light skin boat it might capsize. Eskimo hunters use the bow only when hunting land animals which will not stand, and the force of throwing-weapons when in flight is considerably less than that of the arrow shot from the bow. According to the present Aleut, their ancestors used the bow almost exclusively in war when the party on land met assailants nearing an island in boats. The Aleut of the Alaskan Peninsula, however, used the bow in hunting wild reindeer, bears, and other land animals. At present the Aleut do not use the bow at all. According to information obtained from the Umnak people, the old Aleut bow was of small size. The staff was about a yard long and the arrows were thin, with small stone points. ${ }^{30}$ The staff consisted of one piece of curved wood, rarely backed. In Captain Chirikov's report on his voyage with the second Bering expedition there is a drawing of an Alett bow. ${ }^{31}$ Its length is not given, and in comparison with other objects shown on the plate, it is small, but it appears to be a composite bow, backed with sinew and double-curved. In studying ${ }^{32}$ the weapons of the Eskimo and Aleut, I found in the Museum of the American Indian some bowstaves catalogued as Aleut. Their authenticity, however, is doubtful, since the localities where they were collected are not specified. In one case the locality is given as Woody Island, but this island is located near Kodiak Island and inhabited by Kodiak people and not by Aleut.

The Aleut methods of hunting sea mammals do not correspond entirely to those of the Eskimo. As the sea surrounding the islands does not freeze, the Aleut were not acquainted with the Eskimo method of hunting aquatic mammals through iceholes or from floating ice-cakes. Therefore some of the Eskimo winter hunting implements were not developed among the Aleut. These were the composite double fore-shafted bow, hooks for catching ice-blocks, ice-scrapers, bone picks for making ice-holes, snow-knives, snow-beaters, snow-shovels, ice-scoops, snow-goggles, and snowshoes. No crescentic lamps and no bridges for the wicks were found. The

30 See above, text-figures $16 e$ to $h$ (p. 60) and plate 25, figs. 19, 20, 33, 35, and 37.

31 Bering's Voyages, by F. A. Golder, edition of the American Geographical Society, New York, I922, p. 304, fig. 4 .

32 For that purpose the collections of the U. S. National Museum, Ámerican Museum of Natural History, the Peabody Museum of Harvard University, the University Museum of Philadelphia, and the Museum of the American Indian, Heye Foundation, were examined. 
Aleut did not cook over the lamps. As a result of the absence of driving dogs and sledges, the only means for moving from one rookery or hunting-place to another is the skin boat or $i^{\prime} q y a x^{\prime}$, a word very similar to the Eskimo $q a^{\prime} y a x^{\prime}$. Sometimes the Aleut hunter walks from one rookery to another.

Eskimo pottery consisted of vessels and lamps of burned clay. This also was not adopted by the Aleut, possibly as a result of the absence of clay. The ancient Alett, however, consumed food either raw or roasted on stone frying-pans, but not cooked. During all our diggings on the Aleutian Islands we found only one unbaked clay lamp; and this fell to pieces at the first touch. The same has been reported by Doctor Dall, who also found a lamp made of unbaked clay ${ }^{33}$ in a cave at Nazan Bay on Atka; this had also disintegrated.

As has been pointed out, the Aleut, when peopling the Aleutian Islands from the American continent, must have been already in possession of skin boats, stone and bone lamps, throwing-darts, and other stone and bone implements. It must, however, be admitted that to a certain degree the technique of the Aleut improved after their arrival in the islands. For instance, many bone heads for fishing-spears were found in the lower layers, while bone sections of the composite fish-hook were discovered chiefly in the upper layers. Polished stone lamps and adzes were also found mainly in the upper layers. The rainproof part of the Aleut kayak-man's costume called sutuxi ${ }^{34}$ seems to be an Aleut invention.

It should also be noted that the Aleut had some culture traits in common with the Indians of the northwest coast, such as the use of the labret, face painting, and other decoration. In general, we may say that the cultural, spiritual, and physical traits of the Aleut show closest connection with the inhabitants of the American continent and not with those of Asia.

In concluding this chapter, I wish to add that I do not regard the study of Aleut archæology as a finished piece of work. Under cover of the earth are still many remains of great interest in solving the details of the prehistoric life of the Aleut. These remains may supplement my conclusions or alter them, but it would nevertheless be desirable to make some further excavations. For this reason I regard it as my duty to indicate those ancient village sites and burial caves on the Aleutian Islands which were inaccessible to me, but which may be explored in the future.

(I) On Agatı Island is a grotto-like cave on the walls of which are many figures representing woman's sexual part. They were made by a shaman named Hani'kax?, which means "The one who is standing on the water's surface." Told by the Attu Aleut Philaret Prokopyeff and Michael Prosoff.

(2) On Simichi Island are traces of village sites and a burial-cave where remains of painted wooden masks are preserved. Told by the Aleut Ivan Artamonoff and Yegor Khudyakoff, of Attu Island.

(3) On the eastern end of Amlia Island is a burial cave.

(4) On Tanaga and Kanaga Islands are traces of large ancient village sites with burial-caves.

${ }^{33}$ W. H. Dall, On Succession in the Shell-Heaps on the Aleutian Islands, p. 80, fig. I302I.

34 See above, pp. 99 (text-figures 103 and 104) and 100. I wish to add, however, that I was told that the Kodiak people also used the $s u^{\prime} t u x^{i}$. 
(5) On Ilax is a burial-cave extending the whole width of the island. Information on Amlia, Tanaga, Kanaga, and Ilax was given by the Atka Aleut Peter Khoroshoff, Leonty Snegireff, Michael Mershenin, and Yegor Peshenkoff.

(6) On Kagam-Ilan there is another burial-cave, in the rock above the cave from which Captain Henning obtained mummies and other objects described by Doctor Dall. ${ }^{35}$ To get access to the upper cave it is necessary to have a ladder about 3 fathoms long, since it is located on a steep rock. More mummies could be obtained in this cave. The entrance to the cave is shielded by a high threshold of whale bones.

(7) On Ulagan Island there is a burial-cave in which the mummies of a man and his wife were placed.

(8) There is a burial-cave on Samalga Island. Information concerning the last three islands, situated to the southwest of Umnak, was given by the former chief of Umnak, Cyril Yermiloff.

In enumerating the localities where he observed ancient village sites, Doctor Dall remarks that on the islands to the east of Unalaska, shell-heaps are particularly numerous. This is also true concerning some localities on the Alaska Peninsula, as Port Möller. ${ }^{36}$ It must be admitted that in localities where land mammals were hunted, the composition of kitchen remains may differ in some respects from that on the islands where our excavations were made.

Professor Dixon, in discussing North American archæology, ${ }^{37}$ states that excavations on the western shores show everywhere a uniform culture and in all layers skeletal remains of one type. This may be true of the Aleutian Islands, but as far as it concerns the archæology of the western coast, from the Seward Peninsula to the territory of the Tlingit to the south, the statement should be corroborated by actual excavations, because there may have been an occupation of this territory by Indians before the Eskimo wandered south of Bering Strait.

Perhaps it may not be out of place to mention here that in one respect the excavations on the Aleutian Islands were greatly facilitated. In winter the ground freezes to the depth of a foot, sometimes even less, and sometimes not at all. Thus excavations may be made the year round. The specimens in the deeper layers are not subject to decay as far as it may be the result of continued freezing and thawing. On the continent, and particularly in the Arctic regions, conditions for digging are quite different. There the ground thaws out only late in the summer and regular diggings can be made only in August and September. Such, at least, was our experience in northeastern Siberia.

${ }^{35}$ See above, p. 45 .

36 W. H. Dall, On Succession in the Shell Heaps of the Aleutian Islands (Contributions to American Ethnology, vol. I, I877, p. 45).

37 R. B. Dixon, Some Aspects of North American Archeology (American Anthropologist, n. s., vol. I5, I913, pp. 549-577). 


\section{BIBLIOGRAPHY.}

Adler, Bruno. Die Bogen Nord-Asiens. (Internationales Archiv für Ethnographie, Band XV, Heft I, 1902.) Ameghino, F. Le Diprothomo platensis, un précurseur de l'homme du pliocène inférieur de Buenos Aires. (Anales, Museo Nacional, Buenos Aires, XIX, 1909.)

Anderson, J. Notice of a Cave recently discovered at Oban. (Proceedings, Society of Antiquarians of Scotland, Vol. XXIX, I895.)

Anuchin, D. N. Sledges and Boats as Accessories at Burial Ceremonies. Moscow, I89o. (In Russian.)

Baeltz, E. Die Menschenrassen Ost-Asiens. (Verhandlungen der Berliner Anthropologischer Gesellschaft, Igor, March, p. 202.)

Zur Vor- und Urgeschichte Japans. (Zeitschrift für Ethnologie, Berlin, 1907, pp. 287-310.)

Becker, G. F. Reconnaissance of the Gold Fields of Southern Alaska, with some Notes on General Geology. (Eighteenth Annual Report, U. S. Geological Survey, 1897-98, part 3.)

Birket-Smith, KaJ. Ethnography of the Egredesminde District with aspect of the general culture of West Greenland. Kobenhavn, Ig24.

Boas, Franz. The Central Eskimo. (Sixth Annual Report, Bureau of American Ethnology, Washington,

Th88.)

Die religiösen Vorstellungen und einige Gebräuche der Zentralen Eskimos. (Petermann's Mitteilungen, 1887.)

Die Jesup Expedition. (Verhandlungen des XVI. Internationalen Americanisten-Kongresses, Wien, I909.)

The Eskimo of Baffin Land and Hudson Bay. (Bulletin, American Museum of Natural History, Vol. XV, Parts I and 2, New York, I90I and 1907.)

Ethnological problems in Canada. (Journal, Royal Anthropological Institute, London, I9Io, Vol. XL.)

The History of the American Race. (Annals, New York Academy of Sciences, Vol. 21, 1912, pp. I27183.)

Changes in Bodily Form of Descendants of Immigrants. (New York, Columbia University Press, I9I2.)

The Head Form of the Italians as infuenced by Heredity and Environment. (American Anthropologist, n. s., Vol. I5, April-June, I913, pp. I63-188.)

Bogdanovich, C. Geologische Skizze von Kamtschatka. (Petermann's Mitteilungen, I904.)

- Sketches of the Chukchee Peninsula. (St. Petersburg, Ig0I. In Russian.)

Bogoras, Waldemar. Brief Account of the Investigation of the Chulkchee of the Kolyma District. (Bulletin of the East Siberian Division of the Imperial Russian Geographical Society, Vol. XXX, Part I, Irkutsk, I897.)

- Materials for the Study of the Chukchee Language and Folklore collected in the Kolyma District. (Part I, edited by the Imperial Russian Academy of Sciences, Petrograd, Igoo.)

The Folklore of Northeastern Asia. (American Anthropologist, 11. s., Vol. IV, No. 2, 1902.)

-. The Chukchee. (Jesup North Pacific Expedition, Vol. VIII, I905-I9Io.)

- Chukchee Language. (Handbook of American Indian Languages, Bulletin 40, Part 2, Bureau of American Ethnology, Edited by Prof. Franz Boas.)

Bowers, St. Fish-hooks from Southern California. (Science, Cambridge, Mass., I833.)

British Museum. A Guide to the Antiquities of the Stone Age. (London, Igir.)

Brown, Stanley. Account on the Pribilof Islands. (Bull. Geological Society of America, Vol. III, p. 499.)

CoXe, William. Account of Russian Discoveries between Asia and America. (London, I787.)

Czaplicka, M. A. Aboriginal Siberia, a Study in Social Anthropology. (Oxford University Press, 19I4.)

Dall, W. H. Alaska and its Resources. (Boston, 1870.)

-. On the Remains of Later Prehistoric Man obtained from Caves in the Catherina Archipelago, Alaska Territory, and especially from the Caves of the Aleutian Islands. (Smithsonian Contributions to Knowledge, Washington, r878.)

On the Succession in the Shell-Heaps of the Aleutian Islands. (Contributions to North American Ethnology, Vol. I, Washington, I877.)

Remarks on the Origin of the Inuit. (Contributions to North American Ethnology, Vol. I, Washington, I877.)

Notes on the Pre-Historic Remains in the Aleutian Islands. (Proceedings, California Academy of Sciences, Nov. 4, 1872.)

On Further Examinations of the Amaknax Cave, Captain's Bay, Unalaska. (Proceedings, California Academy of Sciences, Nov. 17, 1873.)

On the Geological Aspects of the Possible Human Immigration between Asia and America. (American Anthropologist, n. s., Vol. XIX, No. I, I9I2, p. I2.)

and G. D. Harris. Correlation Papers, Neocene. (Bull., U. S. Geological Survey, I8g2.) 
Dawkins, Boyd W. Die Höllen und die Urbewohner Europas. (Translated from English, I876.)

Dawson, G. M. Geological Notes on Some of the Coasts and Islands of Bering Sea and Vicinity. (Bull., Geological Society of America, Vol. V, I894.)

DÉchelette, J. Manuel d'Archéologie. (Paris, I908.)

Dixon, Roland B. Some Aspects of North American Archæology. (American Anthropologist, n. s., Vol. XV, No. 4, Oct.-Dec., I9I3, pp. 549-577.)

Duckworth, W. L. H., and B. H. PAin. An Account of some Eskimo from Labrador. (Proceedings, Cambridge Philosophical Society, Vol. Io, pp. 286-29I, Cambridge, I900.)

Elliotr, Henry W. Our Arctic Province, Alaska and the Seal Islands. (New York, 1887.)

Evans, John. Ancient Stone Implements. (London, I897.)

FEw Kes, J. W. Archeology of the Lower Mimbres Valley. (Smithsonian Miscellaneous Collections, Vo1. 63, No. Io, Washington, I9I4.)

Foy, W. Zur Geschichte der Eisentechnik, und besonders des Gebläses (Ethnologica, Im auftrage des Vereins zur Förderung des städtischen Rautenstrauch-Joest Museums für Völkerkunde in Cöln, I, Leipzig, I909, pp. $185-222)$.

Friedmann, M. Vorlage eines Gipsabgusses des Schädeldaches von Diprothomo platensis Ameghino. (Zeitschrift für Ethnologie, Berlin, Heft 6, igio.)

Gidley, J. W. Palæontological Evidence bearing on the Problem of the Origin of the American Aborigines. (American Anthropologist, n. s., Vol. I4, No. I, I9I2.)

Golder, F. A. Bering's voyages. (American Geographical Society, Research Series, No. I, New York, I922.) Gordon, G. B. In the Alaskan Wilderness. (Philadelphia, I917.)

Gorodtzov, W. A. On the Technics of Stone Implements (in Russian). (Yearbook for Geology and Mineralogy of Russia, Vol. XVI, Part I, I9I4, pp. I8-20.)

GrewingK, C. Beitrag zur Kenntniss der orographischen und geognostischen Beschaffenheit der Nordwestlichen Küste Amerikas. St. Petersburg, I850.

GRUBE, W. Giljakisches Wörterverzeichniss nebst grammatischen Bemerkungen. (Anhang zum III Band der Reisen und Forschungen im Amurlande v. Dr. Leopold v. Schrenk, Lief. I.)

Haddon, A. C. The Wanderings of Peoples. (Cambridge University Press, IgII.)

Handbook of American Indians North of Mexico. Edited by F. W. Hodge. (Bull. 30, Bureau of American Ethnology; 2 volumes, Washington, I907 and 1910.)

Harris, G. D. See W. H. Dall and G. D. Harris.

Hawkes, E. W. The Labrador Eskimo. (Memoir 9I, Geological Survey of Canada, Anthropological Series, No. I4, Ottawa, I916.)

Heye, G. G. Certain Artifacts from San Miguel Island, California. (Indian Notes and Monographs, Museum of the American Indian, Vol. 7, No. 4, New York, I92I.)

Hodge, F. W. Hawikuh Bonework. (Indian Notes and Monographs, Museum of the American Indian, Vol. III, No. 3, New York, I920.)

Hoernes, M. Natur und Urgeschichte des Menschen. (Wien, I909.)

Hoffman, W. J. The Graphic Art of the Eskimo. (Report, United States National Museum, Washington, I897.)

Holmes, W. H. Handbook of Aboriginal American Antiquities. Part I, The Lithic Industries. Washington, I9I7.

—. Stone Implements. (Fifteenth Annual Report, Bureau of American Ethnology, Washington, I897.)

Hough, W. The Methods of Fire-Making. (Report U. S. National Museum for I890, Washington, I892.)

-. Primitive American Armor. (Report U. S. National Museum for I893, Washington, I895.)

- The Lamp of the Eskimo. (Report U. S. National Museum for I89I, Washington, I892.)

HrdičKa, A. Origin of the American Aborigines, Historical Notes. (American Anthropologist, n. s., Vol. I4, Jan.-March, I9I2.)

- The Peopling of America. (Journal of Heredity, Vol. 6, No. 2, February, I9I5.) (Bull., American Museum of Natural History, Vol. XVI, New York, I902.)

Skeletal Remains suggesting or attributed to Early Man in North America. (Bull. 33, Bureau of American Ethnology, Washington, 1907.)

Early Man in South America. (Bull. 52, Bureau of American Ethnology, Washington, I912.)

Remains in Eastern Asia of the Race that peopled America. (Smithsonian Miscellaneous Collections, Vol. 60, No. 16, Washington, 1912.)

- Restes dans l'Asie oriental de la Race qui a peuplé l'Amérique. (Congrès International d'Anthropologie et d'Archéologie préhistorique, Compte Rendue de la XIV Session, Genève, I9I2.)

Immanuel, Fr. Nordwest-Amerika und Nordost-Asien. (Petermann's Mitteilungen, Band 48, 1902, pp. 49-58.)

Inostrantzev, A. A. Prehistoric Man of the Stone Age on the Shore of the Ladoga Sea, Petrograd, I882. (In Russian.)

Ivanovsky, A. Physical Modifications of the Population of Russia under Famine. (American Journal Physical Anthropology, Vol. VI, No. 4, Oct.-Nov., I923, pi. 33I-353.)

JAGGAR, T. A., JR. The Evolution of Bogoslof Volcano. (Bull., American Geographical Society, Vol. XL, July I908.)

- Journal of the Technology Expedition to the Aleutian Islands, I907. (Technology Review, Vol. Io, No. I, Boston, I908.) 
Jochelson, W. Preliminary Account of the Investigation of the Natives of the Kolyma and Verkhoyansk Districts. (Bull., East Siberian Division of the Imperial Russian Geographical Society, Vol. XXIX, Part I, I898.)

Materials for the Study of the Yukaghir Language and Folklore. (Part I, Edited by the Imperial Russian Academy of Sciences, Petrograd, I900.)

Ueber Asiatische und Amerikanische Elemente in den Mythen der Koryaken. (Verhandlungen des XIV Internationalen Amerikanisten Kongresses, Stuttgart, I904.)

The Koryak. (Jesup North Pacific Expedition, Vo1. VI, 1905-1908.)

Essay on the Grammar of the Yukaghir Language. (Annals New York Academy of Sciences, Vol. XVI, Part 2, March 1905. Reprinted as a Supplement to American Anthropologist, n. s., Vol. 7, No. 2, I905.)

Die Riabouschinsky Expedition nach Kamchatka. (Globus, No. 14, I908, pp. 224-225.)

-. The Riabouschinsky Expedition under the auspices of the Imperial Russian Geographical Society. (Science, New York, February 17, 1909, pp. 303-306.)

Scientific Results of the Ethnological Section of the Riabouschinsky Expedition of the Imperial Russian Geographical Society to the Aleutian Islands and Kamchatka. (Proceedings I8th International Congress of Americanists, London, 1912, pp. 334-343.)

The Aleut Language in the Light of Veniaminoff's Grammar. (Bull., Russian Academy of Sciences, I9I9, pp. 133-I53 and 287-315.)

Letters of the Leader of the Ethnological Division of the Kamchatka Expedition to the Secretary of the Imperial Russian Geographical Society. (Bull., Imperial Russian Geographical Society, Vol. XLV, Part IX, I909, and Vol. XLVII, Parts I-V, I9II.)

The Aleut Language and its Relation to the Eskimo Dialects. (Proceedings I8th International Congress of Americanists, London, 1912, pp. 96-104.)

The Yukaghir. (Jesup North Pacific Expedition, Vol. IX, parts I-2 (I9I0- I924. Part 3 in press).

Keller, K. Die Haustiere. (Hans Kremer's "Der Mensch und die Erde," I905, Vol. I.)

Komarov, W. L. Travels on Kamchatka in rg08-1909. (The Kamchatka Expedition of F. P. Riaboushinsky fitted out by the Imperial Russian Geographical Society, Botanical Division, Vol. I, Moscow, Igr2.) (In Russian.)

Kotzebue, O. Voyages, I815-1818. (Russian Edition.)

Krasheninnikoff, S. Description of the Land Kamchatka. (Vols. I, II, St. Petersburg, I8rg, in Russian.)

Kroeber, A. L. The Eskimo of Smith Sound. (Bu11., American Museum of Natural History, Vol. XII, 1899.)

-. The Archæology of California. (Putnam Anniversary Volume, New York, 1909.)

LANGSDORFF, von G. H. Voyages and Travels in Various Parts of the World during the years I803-1807. (2 vols., London, I8I4.)

Lemmann-Nitsche, R. El hombre foesil pampoans. (Bol. ofic. Nac., Estad. La Paz, Bolivia, VI, I9ro.)

-. Nouvelles Recherches sur la formation pampéenne et l'homme fossile de la Republique Argentine. (Rev. Mus. La Plata, Tome I4, I907.)

Homo Sapiens and Homo neogaeus aus der argentinischen Pampas formation. (Verhandlungen des XVI Internationalen Amerikanisten Kongress, I909.)

Luschan, Frlix von. Eisentechnick in Afrika. (Zeitschrift für Ethnologie, Band 4I, Berlin, I90I.)

- Völker, Rassen, Sprachen. (Berlin, 1922.)

… Zusammenhänge und Konvergenz. (Mitteilungen der Anthropologischen Gesellschaft in Wien, Band 48-49, I919.)

Lürke, TH. Journey around the World. Historical Section. Parts I, II, III. (St. Petersburg, I834, I835, 1836.) (In Russian.)

MacCurdy, G. G. Certain Specimens from the Rivière Collection (American Anthropologist, n. s., Vol. 25, No. I, I923, p. 81.)

The Field of the Paleolithic Art (American Anthropologist, Vol. 26, No. I, January-March, I924, pp. 27-49).

Mason, O. T. North American Bows, Arrows, and Quivers. (Annual Report Smithsonian Institution for I893, Washington, I894.)

Mooremead, W. K. The Stone Age in North America. (2 Vols., 191o.)

Mortillet, A DE. Essai d'une classification des cavernes et de stations sous abri fondée sur les produits de l'industrie humaine. (Compte Rendue Académie des Sciences, Paris, tome 68, I869, pp. 553-555.)

Mortillet, G. and A. DE. Le préhistorique origine et antiquité de l'homme. (Paris, 1900.)

MüLLER, F. R. Allgemeine Ethnographie. (Wien, I873.)

Murdoch, John. Ethnological Results of the Point Barrow Expedition. (Ninth Annual Report Bureau of Ethnology, Washington, I892.)

Nansen, Fridtjof. Eskimoleben. (Leipzig und Berlin, I903.)

Nelson, E. W. The Eskimo about Bering Strait. (Washington, I899.)

Nelson, N. C. Shell-mounds of the San Francisco Bay Region. (University of California Publications in American Archæology and Ethnology, Vol. 7, No. 4, Berkeley, 1909.)

The Ellis Landing Shell-mounds. (University of California Publications in American Archæology and Ethnology, Vol. 7, No. 5, Berkeley, 19ro.)

Chronology in Florida. (Anthropological Papers, American Museum of Natural History, Vol. 22, Part 2, New York, 1918.) 
Obermaier, H. Prehistoric Man. (Russian translation from the German. Petrograd, I9i3.)

- Der Mensch der Vorzeit. (Allgemeine Verlags-Gesellschaft. Berlin-München,Wien, I9I2.)

Oокнтомкку, D. E., Prince. The Oil-Lamps of the Arctic and Subarctic Tribes (in Russian). (Memoirs Russian Anthropological Society of Petrograd University, Vol. IV, Petrograd, I913.)

Osborn, Henry Fairfield. The Age of Mammals in Europe, Asia, and North America. (New York, IgIo.)

-. Men of the Old Stone Age; Their Environment, Life and Art. (New York, I9I5.)

- Proving Asia as the Mother of Continents. (Asia, The American Magazine of the Orient, Vol. 22, I922, pp. 72I-724.)

PaIN, B. H. See W. H. L. Duckworth and B. H. Pain.

Pallas, P. S. Neue nordische Beyträge. (i782.)

- Reise durch verschiedene Provinzen des Russischen Reiches, I-III. (Petersburg, I77I-76.)

Patkanoff, S. Statistical Data for the Racial Composition of the Population of Siberia, its Languages and Tribes. (In Russian.) (Petersburg, I912.)

- Essay on the Geography and Statistics of the Tungus Tribes of Siberia. (In Russian.) (Petersburg, I906.)

—. Essai d'une Statistique et d'une Géographie des Peuples Paléo-Asiatiques de la Sibérie. (Petersburg, I903.)

Peschel, O. Völkerkunde. (Leipzig, I876.)

Pinart, A. L. Catalogue des collection rapportée de l'Amérique Russe par Alphonse Pinart exposées dans le Musée d'Histoire Naturelle de Paris. (Paris, I872.)

- La caverne d'Aknañh, Ile d'Ounga, Archipel Shumagin, Alaska (Paris, I875).

Preuss, TH. Begräbnissarten der Amerikaner und Nordost Asiaten. (Königsberg, I894.)

Radloff, L. Ueber die Sprache der Tschuktschen und ihr Verhältniss zum Korjakischen. (Memoirs de 1'Academie, St. Petersburg, HI, No. I0, I86r.)

Rau, Chardes. North American Stone Implements. (Smithsonian Report for 1872, Washington, I873.)

2. Prehistoric Fishing in Europe and North America. (Smithsonian Contributions to Knowledge, Vol. 25, Washington, I884.)

Sarytcheff, G. Journey in the Northeastern Part of Siberia, the Arctic Sea, and the East Ocean during eight years with the Geographical, Astronomical, and Naval Expedition, under the Command of Captain Billings, from I785 to I793. (St. Petersburg, I802, in Russian.)

- Journey of Captain Billings through the Land of the Chukchee from Bering Strait to the Fort of Nishne-Kolymsk. (St. Petersburg, I8I I, in Russian.)

Sauer, Martin. An Account of a Geographical and Astronomical Expedition to the Northern Part of Russia, performed by Commander Joseph Billings in the years $1785-1794$. (London, 1802.)

Scharf, R. F. On the Evidence of a Former Land-Bridge between northern Europe and North America. (Proceedings, Royal Irish Academy, Vol. XVIII, Section B, I909.)

Schiefner, A. Ueber die Sprache der Jukagiren. (Bull. Hist. Phil. XVI, 1859, pp. 24I-253, and Mél. Asiat., III, pp. 595-612. Russian Academy of Sciences.)

-. Beiträge zur Kenntniss der jukagirischęn Sprache. (Bull. XVI, I87I, pp. 273-399, and Mél. Asiat., VI, pp. 409-446.)

- Ueber Baron v. Maydell's jukagirische Sprachproben. (Bull. XVII, I87i, pp. 86-103, and Mél. Asiat., VI, pp. 600-626.)

Schmidt, Emil. Vorgeschichte Nordamerikas im Gebiet der Vereinigten Staaten. (Braunschweig, I894.)

Schrenk, Leopold von. Reisen und Forschungen in Amur-Lande in den Jahren, 1854-56. 4 Bde. (Petersburg, I858-1900.)

- Die Völker des Amurlandes. (Petersburg, 189r.)

Srinner, Alanson. Archæology of the New York Coastal Algonkin. (Anthropological Papers, American Museum of Natural History, Vol. 3, New York, I909.)

Smitr, Harlan I. Archeology of the Thompson River Region. (Memoirs, American Museum of Natural History, Vol. 2, part 6, New York, 1900.)

- Shell-heaps of the Lower Fraser River, British Columbia. (Memoirs American Museum of Natural History, Vol. 4, part 4, I903.)

- Archæology of the Gulf of Georgia and Puget Sound. (Memoirs American Museum of Natural History, Vol. 4, Part 6, I907.)

Sollas, W. J. Ancient Hunters and their Modern Representatives. (London, I9II.)

Spinden, Herbert J. Ancient Civilizations of Mexico and Central America. (Handbook, No. 3, American Museum of Natural History, New York, I922.)

Steensby, H. P. An Anthropogeographical Study of the Origin of Eskimo Culture. (Kobenhavn, r9r6.)

Stefansson, V. On Eskimo Work, I908-1912. (Summary Report Geological Survey of Canada, Ottawa, I912.)

- The Stefansson-Anderson Arctic Expedition of the American Museum: Preliminary Ethnological Report. (Anthropological Papers, American Museum of Natural History, Vol. I4, Part I, New York, I9I4.)

- My Life with the Eskimo. (New York, r9ig.)

Stein, F. On the Time of the Appearance of the Aleutian Islands. (Memoirs Mineralogical Society, Vol. I, I830, St. Petersburg. In Russian.)

Steinmann, G. Das Alter des Menschen in Argentinien. (Berlin Prähist. Ves., Cöln, I908.)

Steller, G. W. Beschreibung von dem Lande Kamtschatka. (Frankfurt und Leipzig, i774.) 
Sternderg, L. J. Bemerkungen über Beziehungen zwischen der Morphologie der Giljakischen und Americanischen Sprachen. (Verhandlungen des XIV Internationalen Americanisten Kongresses. Stuttgart, I904.)

The Gilyak. (Moscow, Ig05.) (A separate from the "Ethnographical Survey," parts 60, 6I, and 63.)

Suess, Ev. The Face of the Earth. (Oxford, I909.) (English Translation.)

Suvoroff. The Commander Islands and Fur-Hunting Trade on them. (Publications of the Russian Geographical Society, Petrograd, I912.)

Schwalbe, G. Studien zur Morphologie der Südamerikanischen Primatformen. (Zeitschrift für Morphologie und Anthropologie, Band XIII, Heft 2, Stuttgart, I9Io.)

Thalbitzer, W. The Ammassalik Eskimo. (Copenhagen, IgI4.)

Thomas, Cyrus. Introduction to the Study of North American Archæology. (I898.)

TURNER, L. M. Ethnology of the Ungava District, Hudson Bay Territory. (Eleventh An. Report, Bureau of Am. Ethnology, Washington, I889-I890.)

Urle, Max. Die Muschelhügel von Ancon, Peru. (Proceedings, International Congress of Americanists, London, I9I3.)

- The Emeryville Shell-mound. (University of California Publications in American Archæology and Ethnology, Vol. 7, No. I, Ig07-I9Io, Berkeley.)

VIRchow, R. Eskimo von Labrador. (Zeitschrift für Ethnologie, Vol. I2, Berlin, I880.)

- Eskimo. (Ibid., Vol. I0, p. I85, Berlin, 1878.)

VIX. Die Totenbestattung in vorgeschichtlicher und geschichtlicher Zeit. (Leipzig, I896.)

Warde, H. Newell. Stone Implements of Surgery (?) from San Miguel Island, California. (American Anthropologist, n. s., Vol. I5, No. 4, Oct.-Dec., I9I3, pp. 656-66o.)

Weniaminoff, J. Notes on the Islands of the Unalaska District. (Published at the expense of the RussianAmerican Company, in Russian, 3 Volumes, St. Petersburg, I840.)

Wilson, L. Spuren des Vormenschen aus Süd-Amerika. (Korr.-Blatt der Deutschen Gesellschaft für Anthropologie, Ethnologie und Urgeschichte, XXXIX, Jahrgang, I908, Braunschweig.)

Wilson, Thomas. Arrowpoints, Spearheads, and Knives of Prehistoric Times. (U. S. National Museum Report, Part I, I897.)

Wissler, Clark. Harpoons and Darts in the Stefansson Collection. (Anthropological Papers, American Museum of Natural History, Vol. XIV, Part II, New York, I9I6.)

Archrology of the Polar Eskimo. (Anthropological Papers, American Museum of Natural History, Vol. XXII, Part III, New York, I9I8.)

Arctic Geography and Eskimo Culture. Review of Steensby's "An Anthropo-Geographical Study of the Origin of Eskimo Culture." (Geographic Review, Vol. IX, No. 2, pp. 125-I38.)

- The American Indian. (2d ed., New York, Ig22.)

Wrangel, F. von. Journey to the North Coast of Siberia and to the Polar Sea. (St. Petersburg, I84I.)

YARRow, H. C. Introduction to the Study of Mortuary Customs among the North American Indians. (Washington, I880.) 


\section{GLOSSARY OF ALEUT WORDS.}

The following alphabet is used in transcribing Aleut words :

$a, i, u$, have their continental sounds.

$\bar{a}, \bar{i}, \bar{u}$, long vowels.

$i$, short, almost a semivowel.

$\bar{a} \epsilon, i^{\epsilon}, u^{\epsilon}$, like $a, i, u$, with a deep laryngeal intonation. $b$ and $p$, bi-labials, used only in the Attu dialect and are pronounced by a very slight closure of the lips so that we have transient sounds between $b$ and $v$ and $p$ and $f$.

$c$, an intermediate sound between English $c h$ and German $c$ in ceder.

$d$, like English th in those.

$g$, like $g$ in good.

$g$, as an uvular $g$.

$h$, as in English, used in the Aleut dialect.

$k$, as in German.

$k^{\circ}, k$ with a spirant added.

$l$, as in English.

$l$, anterior palatal sound.

$m$, as in English.

$n$, as in English.

$n$, a palatal soft $n$.

$n$, with strong nasalization.

$\tilde{n}, n$ combined with a velar $g$.

$q$, a uvular $k$.

$x$, like ch in German Bach.

$x^{i}$, has a spirant added (gehauchter Absatz of Sievers). $t$, as in English.

$t^{t}$, is $t$ closure continued same time before explosion, only terminal with strong aspiration.

$t$, is used in the Attu dialect only; it is a cerebral sound, the tip of the tongue is turned back.

$t l$, lateral affricative sound used only in the Atka dialect.

hwe, like English wh in where.

$y$, like English $y$ as a consonant.

$z$, used in the Atka dialect only.

Words of the Attu dialect are marked with an asterisk.

* Ablula'sixं, spoon. See atgu'six'.

Adgu'six', shovel. See asuga'six'.

$A g a^{\prime} d a x^{\prime}$, bow arrow.

Aga'lgixi, large harpoon.

Aga'luxं, tooth, tusk.

Agama'xcix', small species of whale.

Agayux', urile (Phalacrocorax urile).

Agi'sax', observatory hill on which a guard was kept.

$A^{\prime}$ gix $x^{2}$ a game consisting in throwing up with one hand three or four round stones one after another and catching them in the same hand.

Agla'gax', ancient village site, Umnak Island.

* Agalga'yax', harpoon for hunting seals and fur-seals. See cuyini'lgix'.

Agli'gaxi, albatross (Diomedes albatros Pallas).
Agu'gim-qa. See sxix, fish species of Hexagrammus. Agu'nax', sea-urchin (Strongilocentratus drcbachiensis Müll.).

Agu'six', implement, tool.

Agya'x, whale species:

$A k a^{\prime} g d a x^{\circ}$. See i'nklux.

Akagu'six*, compound harpoon.

$A^{\prime} k a x^{*}$, bird quills which cover the lashing of the two bone sections of a fishing-hook.

*Akli'gaxं, harpoon provided with a bladder.

Akli'gix ${ }^{*}$, small harpoon.

Ala'max, a small whale.

Ali'txum igiqa,', war throwing-lance. See anga'gim igiq $\bar{a}^{\prime}$.

Ali'txuxं, war.

Alu'six', needle.

Amdi'xtixi, vesicular andesite lava.

Amgi'gnax", sentry, sentinel.

$A m i^{\prime} d u x^{i}$, root. See antami'kux'.

$A \tilde{n}$, long line of sinew threads attached to the harpoon head.

Anagna'sin, ornamental engravings, decorations; lineal ornamentation.

Ana'tix', property mark (on weapons and implements).

Anga'gim igiqa $\bar{a}^{\prime}$, throwing-spear for man. See ali'txum igiq $\bar{a}^{\prime}$.

Anga'gix', man.

* A'ngim camtasi $\bar{i}^{\prime}$, bone scraper for removing meat and fat from guts in dressing. See qitqi'six'.

An.gu'qax', large bone wedge for splitting logs. See $q u^{\prime} x$ sux'.

An.'kix', hard schists (hornstone and quartz schists).

An'nax, club, stick for clubbing. See *Sagiyagu'six'.

Antami'kux', the root $a m i^{\prime} d u x^{\circ}$ attached to a bone fishing-hook as a magical attraction.

Anugna'sin (plural from anugna'six), ornamental figures in general.

A'nux, salmon nerka (Oncorhynchus lycaodon).

$A^{\prime} n u x^{i}$, stone or bone lamp. See $i^{\prime} x t a x^{*}$.

$A q a^{\prime} n a x^{i}$, compound bone fishing-hook (ancient name). See $u^{\prime} x \operatorname{tax} x^{\circ}$

Asuga'six. See adgu'six'.

Asxinan, the dead.

Atgu'six', spoon. See ablu'lasix'.

*Atki'yax, cod (Gadus macrocephalus Til.). See atxi'dax?.

Atxi'dax'. See atki'yax.

Axsila'six', bone awl. See isila'six' and si'lax'.

$A^{\prime} x$ sixi', hematite; objects supposed to have miraculous power. See $c a^{\prime} g a x^{e}$.

Aya'kux', bone fishing-spear.

Ayasa'gax', bladdered harpoon.

*Ayigi'gix', a species of whale.

Ayukda'gim saxsi'da, head of the small harpoon ayukda'x. See saxsi'dax'

Ayukda' $x^{\prime}$, small harpoon. 
$C a^{\prime}$ gax $x^{\circ}$ hematite. See $a^{\prime} x$ six

Cagli'six'. Sce iga'cim ciglisī.

Cagya'six. See qu'qsux'.

Ca'lax', mollusk (Mactra ponderosa Phil. s. Ovalis Sav.).

Canaya'six', a small bone crutch attached to the keel of the skin boat on which the upper rails of the frame of an ancient skin boat were resting.

*Capta'six', bone scraper for dressing guts.

Ca'qix', halibut (Hippoglossoides elassodon Jord. a. Gilb.).

Cata'sim kada'ñin, prongs of a bird-dart.

Cata'sin, cata'sim kada'ñin.

Cata'sixe, bird-dart.

$C a^{\prime} t u x^{2}$, bone flaker for retouching stone implements.

Catu'sixi. See ca'tux'.

Caxi, arm.

*Ca'xtuxi, sea otter (Enhydris marina). See cña'tux ${ }^{2}$. Caxu'six', bone digger of edible roots. See igu'lax'.

Cayu'sux, a species of wild duck, black. See $s a^{\prime} k u x^{2}$ and $q a^{\prime} b s a x^{\prime}$.

$C i^{\prime}$ daxi, a small whale species.

$C i^{\prime} g d u m$ anugana $\bar{a}^{\prime}$, clay lamp. See $a^{\prime} n u x^{\prime}$.

$C i^{\prime} g d u x^{2}$, clay.

Cigu'nix', microgranular andesitic lava; whetstone of microgranular andesitic lava.

*Ciki'cax. See ci'knax'.

Ci'knax', mollusk (Acmea patina Esch.).

Cimcili'six', tooth-pick.

*Cimi'gixt. See cimka'yux

Cimitix', stopper.

Cimiyn'six". See cimi'tix'.

Cimka'yux, mollusk (Litorina sitchana Mid.). See cimi'gix.

Ci'xtim umusi'. See umu'six'.

Ci'xtixi, drill.

*Ciyu'sim agalü', bone squeezer of a sewing-stand. See ciyn'six', aga'lux'.

*Ciyu'sixt, wooden sewing-stand.

Cmix', pulp-cavity of a tooth, tusk, or other bone.

Cña'tum uniñ $\bar{i}^{\prime}$ qagna', bone of sea-otter's penis. See c $\tilde{n} a^{\prime} t u x^{*}, u^{\prime} n \tilde{n} i x^{\prime}, q a^{\prime}$ gnax'.

Cña'tux", sea-otter '(Enhydris marina). See ca'xtux

$C u^{\prime} d u x^{*}$, lineal ornament.

Cuktu'six', implement for polishing stone implements and lamps of microgranular andesitic lava.

$C u^{\prime}$ mix, dots, ornament.

Cumli'six", whetstone for polishing implements.

$C u^{\prime} \tilde{n} a n$, dam or weir of a river.

Cuña'sin, general name for ornamental engravings on implements.

$C u^{\prime} \tilde{n} a x^{\prime}$, rod of a dam or weir; ornamental notch.

Cuniga'sim agalü, prong of an implement for catching sea-urchins.

Cuniga'sixt, implement for catching sea-urchins.

Cuni'lgix", head of a large harpoon; throwing-lance (Atka).

$C u^{\prime} \tilde{n} l u x^{2}$, flat frying-stone.

Cunu'sixe, large man's knife of andesite.

Cu'sux', mollusk (Modiola modiolus L.). See kyux.

Cuyini'lgix, point of the harpoon called akligixs.

Duxta'dax', bone hook for a fishing-line.

Halac'a, ancient village site on Atka Island.

$H i^{\prime} n i x^{\prime}$. See $i \epsilon^{\prime} n i x^{\prime}$.

Hinkilu'gim $c \bar{a}$, stone for grinding paints. See $i k i c a^{\prime} s i x^{\prime}$, cax', hinku'lux'.
Hinku'lux $x^{2}$, flat large stone on which paints were ground.

$H i^{\prime} x \operatorname{tax} x^{2}$, species of whale. See $i^{\prime} x t a x^{\prime}$.

Hwa'yigix', mollusk (Mytilus edulis L.). See $m a^{\prime}$ yigixt.

*Iblaga'six, bone back-scratcher.

Icimiklux (Atka). See qusidax $x^{\circ}$.

Iduga'yax $x^{\circ}$, kind of a throwing-lance.

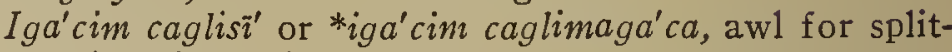
ting sinews into threads.

Iga'cixit, sinew.

Iga'daxe, woman's tailoring-knife.

I'gax, slate.

Igda'kax', drill.

*Igi'kam qagña', bone foreshaft of the harpoon, $i g i^{\prime}$ $k a x^{\circ}$.

*Igi'kaxi', simple harpoon.

Igi' $q a x^{\prime}$, barbed bone head of a spear without the stone point; any throwing-spear; bone belt on the shaft of throwing-weapons.

$I^{\prime}$ glax', shaft of throwing-weapons and arrows.

Igu'lax'. See caxu'six'.

Ikica'six', stone grinder for paints. See hinkilu'gim $c \bar{a}^{\prime}$.

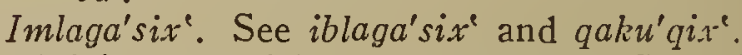

I' $\epsilon^{\prime} n i x^{\prime}$, grass wick of a stone lamp. See hi'nix'.

I'nklux, sinew cord of a fishing-line.

Iqu'luxe, Aleut name for Lastova Bay, Attu Island.

*Isila'six'. See axsilasix'.

I'sux, large seal species (Erignatus barbatus).

Itmagu'six', stone hammer for rude flaking of stone implements.

It $x u^{\prime} \sin$, comb.

$I^{\prime} x t a x^{2}$, lamp for warming. See $a^{\prime} n u x^{*}$.

$I^{\prime} x t a x^{\prime}$, whale species. Sce $h i^{\prime} x^{\prime} t a x^{\prime}$.

$K a^{\prime} d a x^{e}$, end, top; point of harpoons, spears, and arrows.

Kadga'dax', a stone amulet in the shape of a man's figure.

*Ka'gucudaxi. See qugcu'dax'.

*Kala'ga $x^{\prime}$, large simple harpoon, heavier than igi'qax'.

Kasi'gum takadu'ca, bone shovel for taking of reefs of the chiton kasi'guxi.

Kasi'gux', chiton (Katharina tunicata Wood). See qasu'gixi

Katmusim cañadu'ci, bone shovel for putting a boot stretcher into footwear for drying after sewing. See *kibta'sim tañayu'ci.

*Ka'xsix*. See ciyu'si $x^{*}$

Kayu'xtax', stone sinker; stone ball of a bird bolas $($ sanaga' $\sin )$.

*Kibta'sim tañayu'ci. See katmu'sim tañaäu'ci.

Kixtu'gyax', stone drill-head. See qitqu'yax' and umu'sixe.

Kula'max', Pacific right whale (Balcena siceboldii).

Kuli'tax $x^{2}$, labret of stone or bone.

*Kyux. See cu'suxt

Laku'dax', fur seal (Callorhinus ursinus).

$M a^{\prime}$ yigax'. See hwa'yigax'.

* Ma $a^{r} y i x^{i}$, a small man's knife.

Nani'kax', ancient village site on Attu Island.

$N u^{\prime}$ gim cidgay $\bar{u}^{\prime}$, green stone; hornstone schist of green color. 
$N u^{\prime}$ gin (plur. of $\left.n u^{\prime} g i x^{\circ}\right)$, prongs of a bird-dart. See cata'six'.

Nux, stone, mineral.

${ }^{*} Q a^{\prime} b s a x^{*}$, white species of wild duck. See cavu'sux' and $s a^{\prime} k u x^{*}$.

Qacagi'luxi, bone usually having the shape of a seaotter, which is fastened to the side of the skin boat in order to prevent the paddle from falling when it is put on the top of the skin boat.

Qacikux', species of small killer (Somniasus microcephalus).

Qada'ñxi', bone punch.

Qa'hwax', sea-lion (Eumetopias Stelleri)

Qaku'qix: (Umnak Island), bone back-scratcher. See iblaga'six, imlaga'six.

Qalgu'yax', spear with a stone point.

*Qama'xtix'. See utu'qmux'.

Qanaga'six', any implement for fishing.

*Qasu'gix'. See kasi'gux'.

Qida'nax', a kind of small auk (Sinthliborrhamphus antiquus Gm.). See sa'tax'.

Qi'gix'. See qix.

Qi'gsix'. See ciyu'six'.

Qi'lim alucaya'ñin, needles of the monster qi'lixi horse tail (Equisetum nyemale L.).

Qi'lix', a mythical cannibal monster.

Qitqi'six'. See a'ngim camtasi'.

Qitqu'six', scraper for dressing birdskins and guts of sea mammals. See capta'six'.

Qitqu'yax'. See kixtu'gyax'.

Qixma'dgux, ornamental circles.

Qix, bent point of a fishing-hook.

Qugcu'dax', edible roots of Polygonum viviparum L. (See $k a^{\prime}$ gucudax'.)

*Qu'lgax'. See uluga'six'.

$Q u \lg u^{\prime}$ yax', lance-point.

$Q u^{\prime} m a x^{*}$, any burial-place.

Qusidax, bone pin worn in a perforation of the nasal cartilage. See icimi'klux' (in Atka).

$Q u^{\prime} x s u x^{i}$, small bone wedge. See una'qax', cagya'six', and $a n . g u^{\prime} q a x^{\prime}$.

*Sagiyagu'six. See an'nax.

Saki'tax, arrie (Uria lomvia arra Pall. and Uria troile, California).

Sa'kux ${ }^{\prime}$, duck species (Somateria v. nigrum Gray). See cayu'sux' and *qa'bsax'.

Sanaga'sin, throwing-stone balls for .killing birds (bolas).

$S a^{\prime} q a x$, bone point of a fishing-spear called $a y a^{\prime} k u x^{*}$.

*Sa'tax. See qida'nax'.

Sax, a species of Hexagrammus.

Saxsi'dax, bone point for small harpoons. See $k a^{\prime} d a x^{\prime}$.

Sayigim agada'gan kada $\bar{a}^{\prime}$, point of a bow-arrow. See $a g a^{\prime} d a x^{*}$ and $k a^{\prime} d a x^{*}$.

Sa'yigix', bow.

* Si'bluxi. See si'mluxi.

Si'lax'. See axsila'six

Si'mlux, Pseuduria columba Pall. See si'blux.

Sin, ancient village site, Attu Island.

Siti'knax", birch-bark.

Skagix", piece of coarse vesicular andesitic lava for a rude, preliminary polishing of stone implements; also sña'gix.

Slu'kax', large sea-gull (Larus glaucescens Neum.?).
Sñagix $a^{\prime}$. See ska'gi. $x^{\prime}$.

Snasim-iga', stone edge or small ax without the handle.

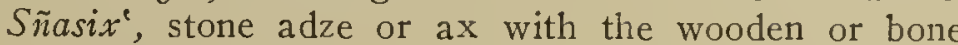
handle.

Su'klun, snots; pendants to qusi'dax ${ }^{\mathrm{e}}$, bone ornament in the nasal cartilage.

Su'tax, a part of a hunter's clothing while in skin boat.

Sxix, Cottus aleuticus Gilb.?. See agu'gim-qa and sa.x.

T'a'lin (plural from ta'lix', small branch) backwardlooking barbs of bone heads.

$T i^{\prime}$ nix $x^{e}$, small harpoon (Atka).

Tuga'sixe, stone flaker.

$T u^{\prime} k u x^{\prime}$, rich man; elder; host; official ; chief.

Tu'mgax $u^{\prime}$, bone foreshaft.

$T u^{\prime} m u x^{e}$, bone ring or belt which keeps the joint of the shaft and foreshaft or head of throwing-weapons.

Tunumu'lgux', simple harpoons for hunting sea-otters and fur-seals.

T'u'tax', ear-ring; any pendant worn in perforations around the ear-shell.

Ugalu'dax', throwing-dart for drilling, with a blunted head without a point.

*Uga'luxi', kind of a throwing-lance.

Ugama'xcax', bowhead whale (Balcena mysticetus).

$U k a^{\prime} m l u x^{\prime}$, bone ring for $s u^{\prime} t a x^{\prime}$ (which see).

Ulaga'max', the largest earth-lodge in a village, usually that of the chief.

Ula'kax', burial-lodge

$U^{\prime}$ lax', dwelling, house, earth-lodge.

Ulu'gam cimiti', cheek-stopper, $i$. e., labrets worn in the cheek perforations. See cimi'tix and ulu'gax'.

Uluga'six', a finch species, small bird (Leucosticte tephrocotis). See qu'lgax'.

Ulu'gax', cheek.

$U^{\prime} m a$, to blow.

$U m a^{\prime} l u x^{i}$, small bone-pipe for bladders to carry fresh water or for inflating seal-skin floats for harpoons.

$U m q i^{\prime} d a x^{i}$, andesite.

Umqilgagu'six', sinew thread for attaching the bait to a fishing-hook.

Umqisi'sixi, curved carving-knife.

*Umu'six.' See ki.xtu'gyar.

$U m n \cdot x i x$, part of the compound fishing-hook.

Un.guqaxi. See $q u^{\prime} x$ sux $x^{\circ}$.

*Unuxsuli'max', a thong tied to the foreshaft of a simple harpoon $u^{\prime} n \tilde{n} i x^{\prime}$, penis.

$U^{\prime}$ tax, thumb; bone knife for taking off meat from guts before dressing.

Utu'qmux', large broad knife (man's) made of andesite or slate.

$U^{\prime} t u x^{\prime}$, handle of a flaker, knife or adze.

$U^{\prime} x c u x^{i}$, Lunda cirrhata.

$U^{\prime} x t a m$ agiti' $\tilde{n} i n$, sinew threads by which the bone parts of a fishing-hook are tied.

$U^{\prime} x \operatorname{tam}$ tutas $\bar{\imath}^{\prime}$, noose made of an urile's quill and tied to a bone fishing-hook for attaching the bait. See $u^{\prime} \cdot x+a x^{2}$

$U^{\prime} x t a x^{\prime}$, compound bone fishing-hook. See $a q a^{\prime} n a x^{\prime}$

Uxtu'six, lancet for bleeding, of andesitic lava.

$U y a^{\prime} \tilde{n} i x^{\prime}$, andesitic tuff.

$Y a^{\prime} \operatorname{gax}^{\mathrm{i}}$, wood (as material).

$Y a^{\prime}$ gam-ñan agu'six', tool for working in wood. See agu'six'. 



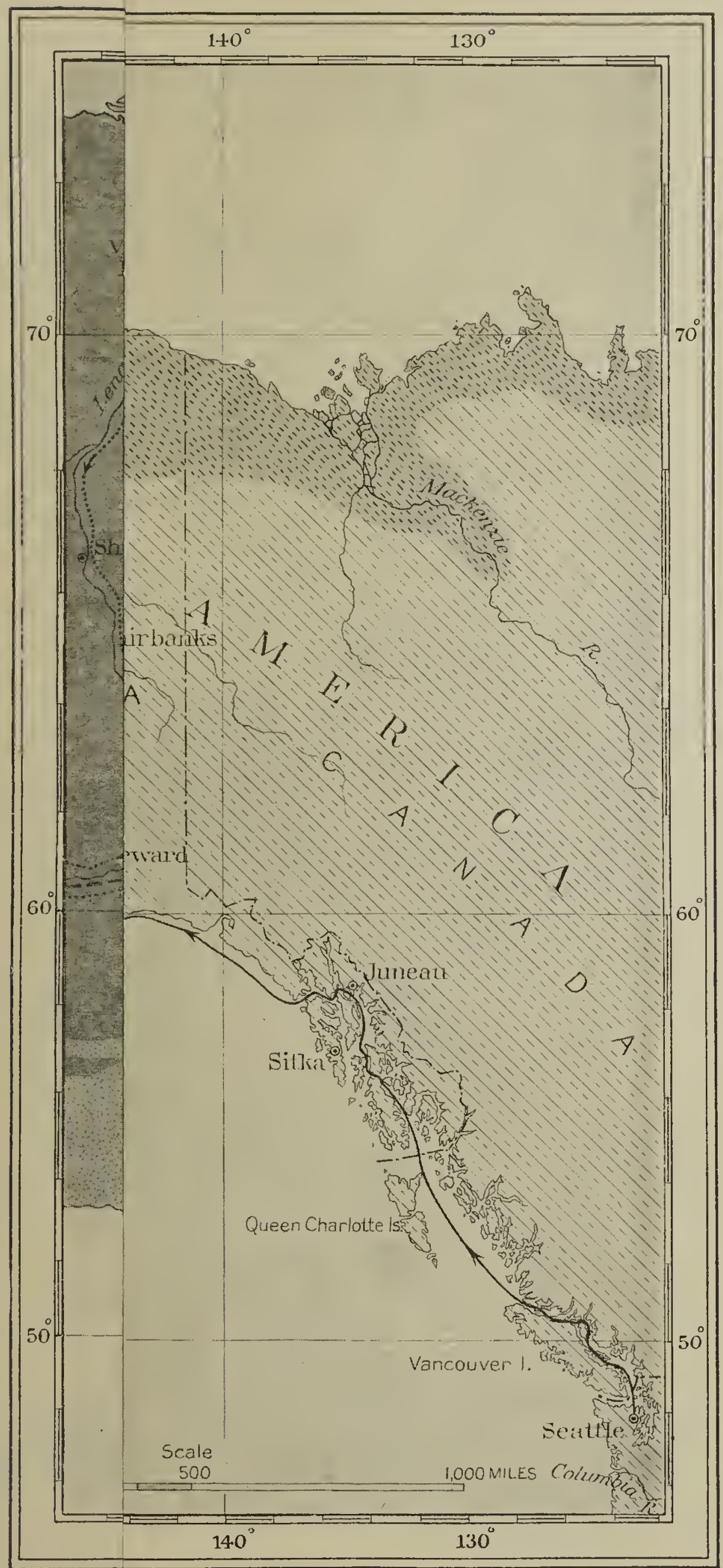

EXPLANATION
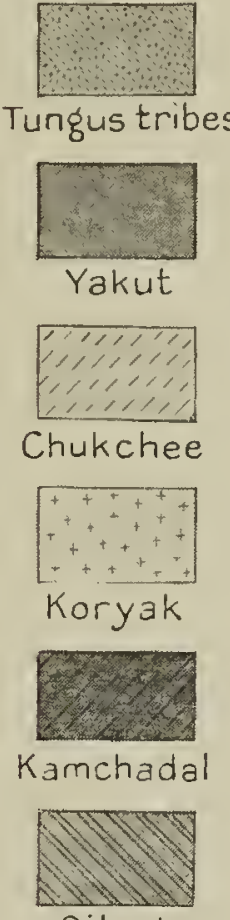

Gilyak

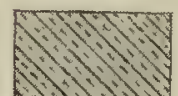

Ainu and

Kurilians
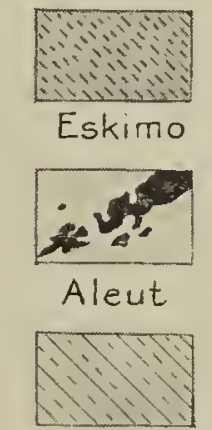

indian tribes

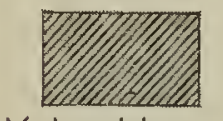

Yukaghir and

Chuvantzy

Routes of the Author

In the expedition

of Riaboushinsky

$1908-1911$

In the expedition of the American

Museum 1900-1902

In the expedition

of Sibiriakof 1894

1897 


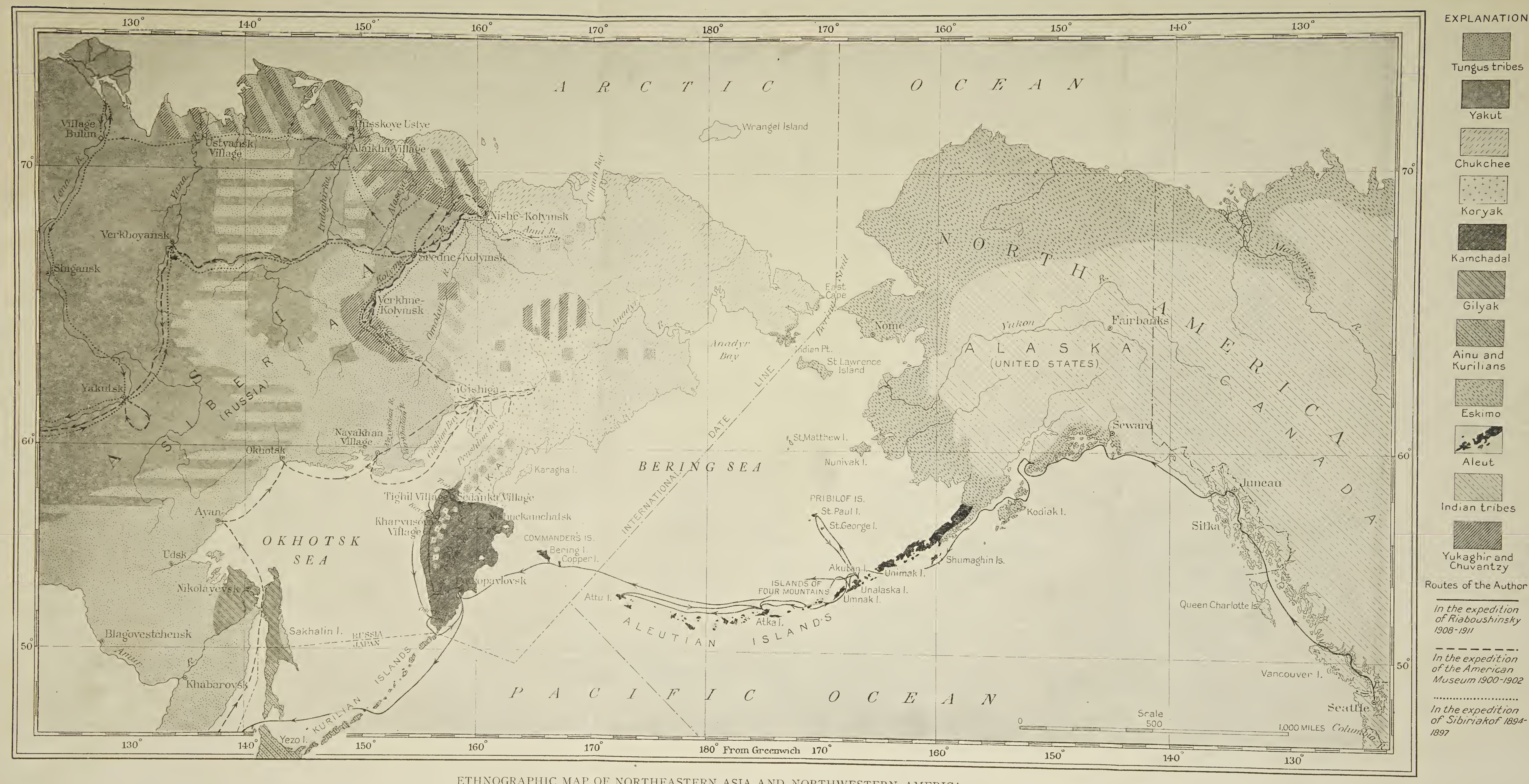

ETHNOGRAPHIC MAP OF NORTHEASTERN ASIA AND NORTHWESTERN AMERICA. 


\section{INDEX}

Acheulian flint weapons, I20

Adax Island, I02 period, I03

Adge, stone, I20 for working in wood, 73 found, $58,59,62$

Africa, 43, II9

African tribes, knives of, 77

Agattu Island, 57

andesite brought from, II4

cave on, I22

excavations of Dall on, I02

Age of village sites, 30

Agla'gax', ancient village site, Umnak Island, 29, 89, 105, I09, II 8

Aino, skin-boat unknown to, II2 tribe, 3

Akutan Pass, I3

Alaska Commercial Company, I2, I3, I6, I7, 44 Eskimo, 8 cephalic index of, II5 soapstone as material for lamps of, 57 . stone lamps of, 75

Peninsula, I3, I5, I9, 57, I21, I23 excavation on, 102

Territory, geological studies in, 18 Government officials in, I2 route of steamer Santa Clara to, I2 volcanic chain in, I8

Albatross (Diomedes albatros Pallas), 25, 47 beak of, used as pincers, 54

Aleut, cephalic index of, II5, II6 -Kamchatka Expedition, 53 lamps of, 75 language, grammar of, II in relation to Eskimo dialects, I medicine men, 93 study of, I5

problems, 3

reason for investigation of, 2

theory of origin of, II I

tribe, 3,14

village sites, excavations of ancient, 2

woman resting, 44

Aleutian chain, II5 weaving basket, 44

Islands, 3, I5, I8

accessibility of, II

as a continuation of the Alaskides, I I3

future investigation on, I8

journey to the, II

natural features of, I9

period, I06

traveling in the, 18

Algonkin Indians as a division of Cro-Magnon, 9 Alpine mountains, beauties of, I2

Ama'knax ${ }^{e}$ Island, 37, 38, 39, 46, 49, 52, 85, 87 excavation by Dall on, I02 excavations by the author on, 37 village, 37,38 map of, 37

Amchitka Island, excavations by Dall on, I02
Ameghino, F., Professor, I24

America, Eskimo in, 2

hypothesis of, 5

natives of northwestern, 4

people in, I03

Pleistocene period in, 6

taken for India, 4

American and Asiatic races, variety in type of, 6 Siberian tribes, 3

archaeologists, 70

archaeology, works on, 69

-Asiatic tribes, comparative investigation of, 6

Eskimo, 4

Geographical Society, I7

Indians, 4I

Museum of, I00

iron fish-hooks, 89

kitchen middens, age of, II7

Museum of Natural History, v, 2, II, I2I officials, I4

origin, 8

population, origin of, Io

race and Palæ-Asiatic tribes, relation between, Io

migration from Asia, 7

origin of, 4

Revenue Cutter Service, I5

scientific institution, assistance from, II

Americanists, International Congress, I

Americanoid tribes of Siberia, 7

Americans, I4

Amlia Island, 28

Amulets, 95

burial cave on, I22

excavations by Dall on, I02

Anderson, J., author, 6, I24

Andesite, 56 and passim

Anemones, 2I

brought from Agatu, II4

Animal decoration, 93

Animals, Asia as place of origin of domestic, 9

Anthropological Society of Washington, I 6 study, 9

Antiquity of Aleut kitchen middens, II7

Anuchin, D. N., professor, I24

Applegate, Captain, I4, I5, I7, I8

Aquatic animals as decorations, 93 mammals, passim

Archaeological investigations, on Aleutian Islands, future, I22 problem, 2I, 22

Archaeologists, American, 70

Danish, II9

European, 69, 72

German, II9

Archaeology, American, works on, 69

North American, by Dixon, I23, I25

writers on prehistoric, 55

Arctic or hyperborean races, 3 region, lamps of, 76

regions, digging difficult, I23

Sea, 6 
Arrow, 77

bone, 28

-head, 3I, 89

-heads from whales' bones, II 8

Artamonoff, Ivan, Aleut, I22

Aryan Languages, 4

Asia, I I5

as place of origin of higher civilization, 9 High, 8

immigrants from, 4, III

(Indo-China and Japan), 43

natives of northeastern, 4

Asian-American bridge, 6

Asiatic and American races, variety in type, 6

Eskimo lamps, 57

origin of American aborigines, theory of, 7 peoples, 4

Athapascans, I I6

Atka Island, I5, I6, I7, 28, 44, 46, 89, I09

excavations on, 26

map of, 27

merchandise to, once a year, $\mathrm{I} 4$

people, 57

skulls on, 47

temperature, I

Attu Island, I 5, I7, 23, 57, 89, I00, I02, I06, I09, 24 andesite on, II 4

bird-bones on, 25

bones found on, 25

excavation by Dall on, I02

excavations on, 24

fish-bones on, 25

map of, 24

merchandise to, once a year, I4

revenue cutter at, 16

sea otters found on, 25

seals on, 25

Atxa'lax', 26, 27, 29, 46, 47

spear found at, 85

Australian boomerang, 77

Awl, bone, 28, 3I, 84, 9I, 92

$\mathrm{Ax}$, iron, 33

stone, $57,58,120$

Azilian stage in Scotland, 6

Back-scratcher, bone, $89,9 \mathrm{I}$

Baeltz, E., professor, 3, I24

Baffin Land, Eskimo of, 57

Baranof Island, I2

Bartering, soapstone as object for, 57

Basalt, 59

Baskets and mats made of grass, 46

Beads, glass, 33

Beams, jaws and bones of whales served as, 32

Bear, revenue cutter, at Nazan Bay, I7 commander of, 18

Bears, 6 hunting, I2I

Beaver, I I7

Becker, G. F., author, II3, I24

Belt, bone, section of hunting and war weapons, 55,83 of hunters, 74

Bending of bone implements, 8I

Bering Expedition, I7, I12

Island, distance between Kamchatka and, II2 Sea, 6, 9, 27, 30, то3, I23

Eskimo, 9I

free of ice, I 5

patrol fleet, I5, I6, I8
Bering Strait, 6, 8

Eskimo,
"Bering's Voyages," I7

Bertholf, Ellsworth P., captain, I7, I8

Besyazykov, Boris, Aleut, 7I, 83, 89

"Big Land," name of the Four Volcanic Islands, i I Billings, J., traveler, 8, I27

Binding materials for harpoons and throwing lances, 53

Birch bark, 89

Bird-bones, 32, 36, 47 on Attu, 25

-dart, $84,85,86$

decoration, 93

Birket-Smith, Kaj, author, I24

Bison, 6

Blacksmith's art, II 9

Blades, stone, retouching, 7 I

"Blood-channels" on weapons, $8 \mathrm{I}$

Blubber of sea-mammals, ro9

Blue-fox farm, 40

"Blut-bzw. Giftrinnen," 82

Boas, Franz, 7, 8, 57, 8I, 9I, I I6, I24 data of, of men in America and Siberia, 7

Boats, primitive, I0 3 harpoon described by, 54

Bodies in cave on Atka, 47

Body-wrappings, 47

Bogdanovich, C. I., Geologist VI, 6, I I4, I24

Bogoras, Waldemar, author, 4, 7, 8, 4I, 57, I 24

Bogoslof Island, I6, I I3

Bolshanin, Mr., custom-house officer, I4

Bone arrows, passim

aw1, 28, 3I, 84, 9I, 92

back-scratcher, $89,9 \mathrm{I}$

belt, $54,55,83,88$

club, $28,87,88$

flakes, 70

at Agla'gax', 7I

Nani'kax', 7I

Ukix, 7 I

for chipping edges of stone implements smooth, 70, 7I

found on Attu, 25

hook for fishing-line, simple, 87 composite, $86,87,89$, I 22

implements, 47, 77, 78, 93

knife, 79, 8I of Siberians, 77

labrets, $3 \mathrm{I}, 96,97,98,99$, I00

lamp, 3I, 76

mouthpiece for a bladder, 90 of seal floats, $9 \mathrm{I}$

needle, 3I, 9I, 92

picks, 82,87 , I2I

plugs to close wounds, 8 I

posts, 33

ring, $54,55,83,88$

scraper, $3 \mathbf{I}$

wedges, $32,90,120$

Bones of birds, 32,36

fish, $32,33,36$

Boomerang, Australian, 77

Botanical division, I

Boulders for breaking echini shells, I03

Bow, 86, I20, I2 I

of Eskimo, 2, I2I

stringing, I2 I

Bowers, St., author, 87, I24 
Brachycephalic head index of the Aleut, i 6

Brass, pieces of, in excavations, 33

Brazil, shell-heaps in, II 7

Breech cloth, 73

Breeches, 99

Bridge, Land, between North America and Eastern

Asia, I I3

British Columbia, I2 Museum, 69, I24

Bristol Bay lamps, 75

Broca's measurement of skulls, i 6

Bronze Age, I03, II9

Brooks, A. H., geologist, I4

Brown, Stanley, author, I4, I7, I I4, I24

Building dwellings, I20

Bulletins of the Imperial Russian Geographical Society, I

Bumpus, Dr. H. C., II

Bureau of American Ethnology, I2

Burial cave on Amlia Island, I22

Atka, 48

$\mathrm{I}^{\prime} \mathrm{lax}, \mathrm{I} 23$

Ka'gam-I'lam, I23

Simichi Island, I22

huts, 30

Ulagan Island, I23

pits, $26,50,52$

places of Aleut, 2I, 33, 42

rock caves, 45,46

urn, 43

types, 45

Caches, 34

Ca'lax', 25

California Academy of Sciences, 44, 102 shell-heaps in, II7

shore-line, II

University of, visit of expedition to, I2

Cannibals, I02

water-line, II7

Canoes, I02

Cape Navarian, I I5

Captain Bay, 37

Carved human face, 94

Carvings of Eskimo, 2

Caserns, dwellings, 32

Cave at Kagam-Ilan, 89 cemeteries, 46

on Attu, 46

Caves on Kanaga Island, I22

Tanaga Island, I22

Celts, stone, 57

Cemeteries, 45,48 cave, 46

Central America, high cultures of, Io

Cephalic index, Aleut, II 5

$$
\text { of Eskimo, I I6 }
$$

Ceremonial masks, II5

Chairs, use of, 43

Chamisso, traveler, 57

Charcoal, Iog

$$
\text { of oaks, II } 7
$$

Cheeks, holes in, 96

Chellean period, 103

Cherkashin, Ivan, Aleut, 33

Chernofski, village, I6

Chess, adopted from Russians, 43

posture in playing, 43

$$
\text { I0 }
$$

Chichagof Bay, 16, 24, 46

arrival of vessel, I6, 24

Chignick Bay, excavations by Dall in, I02

Child, skeleton of, 5I

Childhood, piercing of lips in, 99

Children, sleeping places for, 40

Chipper, bone, 69, 70.

Chirikov, Captain, I2I

Chisel, stone, 62

report of, I2I

Christian conception of death, 43

Chuckchee Peninsula, lamps on the, 75

Chukchee, 3, 8, 6, 57, 75

pottery of, 2

tribe, 4

Church at Unalaska, I4

Chuvantzi, tribe, 3

Ciki'cax', 25

$\mathrm{Ci}^{\prime} \mathrm{knax}^{\mathrm{e}}, 25$

Cimka'yux', 25

Circumpolar elements of culture, 2

Clay, lamps of burned, I22 unbaked, lamp, found by Dall, I22

atthor, 28, 122

vessels and lamps of burned, of Eskimo, I22

Climatic conditions of Aleutian Islands, I9, I2I

Cloth, fur, 47

Clothing of dead, 42

Club, bone, 28, 87, 88

Coast and Geodetic Survey, U. S., IoI

Coats, water-proof, 47

Cod, 25, 32, 33, 38, 47, 107, 108

Coffins, $4 \mathrm{I}$

Commander Islands, II2, II4. (See Kommandorski Islands)

Communication, inland, on the Aleutian Islands, I9

Compartments for dead in dwellings, 49

Composite bone fish-hooks, $86,87,89$, I22

Contributions to North American Ethnology, I02

Cooking-lodges, 40

over lamps, I 22

Copper Island, distance between Attu and, II2

Cormorants, 25

Corpse, arrangement, 42

Corpses kept in dwellings, 4I mummified, 44

Costume, kayak-man's, 99, I00, I22

Cottoidae, 25

Coxe, William, traveler, $\mathrm{I} 24$

Crater Islands, 30

Craters, 44

Cro-Magnon race, the Algonkin Indians originated from, 9

Cultural and physical affinities of Northern Palæasiatics, 7 connections of Aleut, II 5

Culture, history of, I Io of Central America, Io

Eskimo, 2

Mexico, Io

the Aleut, 48, II9

tribes of North Pacific Coast of North

America, 2

-periods, Dall's characterization of, I03

periods of, I02

traits, I22

Cumberland Gulf, Eskimo of, 75 
Curio hunters, $2 \mathrm{I}$

Curvature in bone implements, 82

Curved bone implements, 77

Cu'six', 25

Custom-house officer at Unalaska, I4

Czaplicka, M. A., author, 3, I24

Daggers, grooves on, 83

Dall, W. H., 8, 2I, 38, 39, 43, 44, 45, 48, 49, 59, 75, 89, 96, 98, І00, Іог, 102, 103, 105, 106, І07, I08, ІІо, ІІ2, ІІ4, II5, ІІ7, І20, І22, I 23, I 24

calculations, II 7

conclusion, by author, IO2

description of strata, 38

hypothesis, I03

skeletons found by, ror

theory in which author agrees, II 3

work on Aleutians, 2I

Dancing, festivals, houses for, 34 masks, II5

Danish archaeologists, II 9

"Kjökkenmöddinger," I08, I I7

shell-heaps, I I7

Dawkins, Boyd W., 9, I25

Dawson, G. M., 6, I I 5, I25

Dead, clothing of, 42

disposal, 4I, 42, 49, II 5

fear of, 4I

infants kept by mothers, 42

interpretation of manner of fixing, 43

lay at full length, IOI

lying on backs, 43

mode of burying, $4 \mathrm{I}$

Death, Christian conception, 43

Dechelette, J., author, 55, 69, I25

Decoration, aquatic animals engraved, 93 birds engraved, 93

figures of animals engraved, 93 of implements, 93

de Mortillet, M., author, 69

Department of Commerce and Labor, II, I5, I8

Depths as given by Suvoroff, II2

Devotions of relatives, 4 I

Diet, echini as, to6

fish as, 33

Digging of pits, 22

Diluvial animals, II4

man in North America, 5

South America, 5

Dirks, Mr., merchant, I4

Disintegration of human bones, 47

Disposal of dead, method, 4I, 42, 43, 44

Dixon, Roland B., author, I23, I25

Dog-breeding of Eskimo, 2 team from Valdez to Nome, I3

Dogs, driving, I22

Dolichocephaly of Greenland Eskimo, II6

Dora, mail steamer, I2

Dordogne, race of, 9

Drill, 28, го0

Driving dogs, I22

Duckworth, W. L. H., author, I25

Dutch Harbor, I3, I4, 37

Dwellings, II 5

ancient, $2 \mathrm{I}$

building of underground, I20 old, 40
Dwellings, repairing, I08

underground, 23

whale bones as framework, 28

Dyakonov, Nikifor, Aleut, 40

Ear ornaments, 96

Ears, holes in, 96

Earth hut of Eskimo, 2

in Siberia, 2

Echini, 34, 36, I04

and mollusks, passim

as food, I06

shells of, 32, 35, I04

Echinus layer, I03

period, I03

tissues of, I06

Eider, Pacific, 25

Elk, 6

Elliott, Henry W., author, I25

Elymus, wild barley, 2I

Embalming, manner of, 42

of Aleut, 44

England, expedition in, II

Eolithic man, a conjecture, I I3 period, I03

Eskimo, 3, 9I, I I5, I2I, I23

a division of American race, 8

bone spears, 8.I

cephalic index of, II 6

culture of, 2

dialects, Aleut language in relation to, I

in Alaska, 8

\section{America, 2}

comparative studies, 3

Indians, Palæasiatics, ethnological connection between, 7

journey for soapstone, 57

lamps of, 75

natives, 42

southwestern, 76

migration to America from Siberia, hypothesis, 8

of America, III

Baffin Land, 57

Bering Sea, 9I, Io0

Greenland, 8

Labrador, 8

origin of, 9

stock to which Aleut belong, 8

Ethnographic description of Aleutian Islands, I9

Ethnological connection between Palæasiatics, Indians and Eskimo, 7

Division of the Kamchatka expedition, 2, I I

Rumianzev Museum in Moscow, 3I

Ethnology Division of the U. S. National Museum, 75

Europe, fossil remains of man in, 9 immigrants from, 4

in Pleistocene period, 6

kitchen middens in, II7

passing from neolithic period to Bronze Age, I03

European archaeologists, 69, 72

countries, shell heaps in, I I7

Europeans, II7

Evans, John, author, 69, I25

Evolution, cradle of, 9 
Excavation, number days worked, 23

$$
\begin{aligned}
& \text { of ancient Aleut village sites, } 2 \text { I } \\
& \text { pits, } 22 \\
& \text { on Ama'knax', } 37 \\
& \text { Atka, 26 } \\
& \text { Attu, 24 } \\
& \text { Ukna'dax', } 40 \\
& \text { Umnak, 29 } \\
& \text { time taken, } 22
\end{aligned}
$$

Excavations, number of, 22

Examination of sites, 22

Expedition, Aleut-Kamchatka, 53

Island, 49

organization and personnel, I

Explorers, earlier, III

Eyes, Mongoloid, i 6

Face painting, I22 -width, II6

Facial bones of Labrador Eskimo, iı6

Fairbanks, mines of, 13

Faralon, freighter, I3

Fat in soapstone lamp, 57 wreck of, I3

Felsite, red, 59

Festivals, dancing, houses for, 34

Fewkes, J. W., author, I25

Field work, time required, 22

Finch, rosy, 25

Fir trees from Sitka, 49

Fire, driftwood, 73 -making implements, 74 use of, 100, 103, 109

Fish bones, 32, 33, 34, 36 on Attu, 25

for diet, 33

-bone layer, Io7

-hook, 3 I

composite, $86,87,89$, 9I, I22 simple, 87

spear, 82 sinkers, still in use, 67

Fishing, Kamchadal methods of, 2 -line, bone-hook for, $87,88,89,122$ period, r02, 103, 107, 110

Fjords, Scandinavian, I2

Flaker, bone, 69, 70, 71

Florida, shell-heaps in, II7

Flounder, I08

Foley, Daniel P., senior captain, I8

Food consumed raw or roasted, I22 cooking vessels, 23

echini as, Io6

man's, on the plains, I07

manner of securing, 107

of prehistoric man, I08

-storage pit, 33

Footwear, 73

Fossil bones from South America, 5 remains of ancient man in Europe, 9

Fossils, Pleistocene, not found on the Aleutian Islands, II4

Fox bones, 46

farm, blue-, $4^{0}$

Foxes, hunting, 33, 46

Foy, W., Germa11 ethnologist, II9, I25

France, shell-heaps in, II7 stone implements in, 69
Freezing and thawing of ground, 123

Fresh water, 33

Fried meat, 73

fish, not in Aleut lakes, II4

Friedmann, M., author, 5, I25

Frying-pans, 28, 93, 109, I22

Fur clothing of Eskimo, 2, 47

Geographical Society, Russian, I

Geological basis for considering the Aleutian Islands as a land bridge, II3

data of Alaska and Siberia, 6

expedition of Professor Jaggar, I8 period, of sinking of the sea-bottom, II4 survey, U. S., I4, I5

Geology division of the Kamchatka expedition, I of Aleutian Islands not well known, Ir3

Geometric ornamentation, 93

German archaeologists, II

Gidley, J. W., author, 6, I25

Gilyak, skin boats unknown to, II2 tribe, 3

Glass beads, 33

Golder, F. A., author, I7, I2I, I25

Goltzef Bay, 46

Gordon, G. B., author, I25

Gorodtzov, W. A., archeologist, 69, I25

Government elementary school, Unalaska, I4

Grammar of Aleut language, II 5

Grasses, 2I, 46

Gray, N., Alaska Commercial Co. agent, I3

Greek Catholic Church in Unalaska, I4

Greenland, Eskimo of, 8

show a dolichocephalic index, lamps of, 75

Grewingk, C., geologist, I I3, I25

Grinding stone implements, 72

Grooves on swords, daggers, knives, etc., 83

Grube, W., author, 3, I25

Guillemot, 25

Gull, Pacific, 25

Haake, F. J., captain, I6, I8

Haddon, A. C., ethnologist, 6, II 3,. I25 statement of Aleutian Islands, II3

Haiko (Oncorhynchus lagocephalus), I07

Hala'ca village, $26,28,29$

Halibut, 25, 32, 33, 38, 47, 89, 107

Hammers, stone, 68,69 , I02, I20

Hani'kax ${ }^{e}$ a shaman, I22

Harman, Mr., Unalaska, I4

Harpoon, I I 5 determination of, 53

heads of Magdalenian epochs, 55 of Eskimo, 2

simple and compound or toggle-headed, 53 specimen on Umnak Island, 54 with two foreshafts, 54

Harris, G. D., author, I25

Harvard University, Peabody Museum, I2I

Hawaiian Volcano Observatory, I4

Hawkes, E. W., author, I25

Headpiece for a drill, , Ioo

Heating living rooms, 35

Hematite worn by hunters as amulet, 59

Henning, Captain, 44, 45, I23

Herring, 108 
Heye Foundation Museum, I2I

Heye, G. G., author, 87, I25

Hiding-places for women and children, 34

High Asia, 8

Hindustan, 43

Hodge, F. W., ethnologist, I25

Hoernes, M., author, 55, I25

Hoffman, W. J., author, I25

Hog Island, 40, 49

Hogs at Ukna'dax', 40

Hoikoh, fish, I07

Holmes, W. H., author, I2, 57, 69, 70, I25

Holy Russian Synod, I3

Hook, fish, 3I

Hooks for catching ice-blocks, I2I

Hornstone schist, 57

Horse-tail, plant, for polishing implements, 72,77

Hottentot, tribe, 43

Hough, W., ethnologist, 57, 75, 76, I25

Houses for festivals, dancing, 34

Hřdlicka, A., arthropologist, 5, I0, I16, I25

Hudson Bay, II5

Human bones disintegrated, 47

face, carved, 94

figure, symbolic representation of, as decoration, 93

remains in kitchen middens, $4 \mathrm{I}$

Hunter's belt, 74 clothes, I00

Hunters, 23, 109

lamps used by, 73

primitive, 77

wear hematite as amulet, 59

Yukaghir, 77

Hunting aquatic mammals, I2I

foxes and seals, 33,46

implements, I09

land animals, I2I

of Aleut, I2I

period of Dall, I02, I03, IIo

sea mammals, 9I

wild reindeer, bears, and land animals, I2 I

Hyperborean or Arctic races, 3

Ice-picks as spears, 79

-pillars in cave of Goltzef Bay, 46

-scoops, I2I

-scraper, I2I

Icelandic bridge, remnant of former, 6

Ilax, burial cave on, I23

Iliuliuk Bay, I3, 37

Immanuel, Fr., author, 6, I25

Immigration of Polynesians in southern America, 6

Implements, 47

and lamps, polished, I20
bent, $8 \mathrm{I}$
decoration of, 93
development of, I04
for fire-making, 74
hunting, I09
manufacture of, 67
of wood, 53
painting of, 94
pattern of, 93
serpentine for making, 59
stone and bone, I 22
$\quad$ grinding, 72
in France, 69

Index of age of village sites, 2I

Indian, Eskimo, Palæ-asiatics, Ethnological connection between, 7

Museum of American, v, Ioo, I2I

North American, 4I

tribes, cephalic index of, $\mathrm{II} 6$

types, II 6 .

Indians, II5, II6, I22, I23

and Palæ-asiatics, mythologies of, 7 of America, mythologies of, 2

Tananah, 08

Infants, dead, kept by mothers, 42

Inostrantzev, A. A., geologist, I08, I25

Inside Passage, trip to Alaska through, I2

International Congress of Americanists in London, I

Interpreter, Aleut, I8

Inuit, Yukon, roo

Ireland, shell-heaps in, II7

Iron Age, II9

ax, 33

fish-hooks, American, 89

Negroes of Africa knew art of smelting, II9

Ivan Cherkashin, Aleut, 33

Ivanovsky, A., anthropologist, I, II6, I25

Ivory, 89

walrus tusk, 77 , I00

Jacobs, William, senior captain, $\mathbf{1 6}, \mathbf{I 7}, \mathbf{I} 8$

Jaggar, T. A., Jr., geologist, I2, I4, I8, II3, II4, I25

Japan, III

Japanese junks, Aleutian islands peopled by, II2 schooners, i 6

Jaw of whale, 28

Jesup North Pacific Expedition, 2, 3, 4, 6, 9, Io

Jochelson, Waldemar, 7, 4I, 42, 93, I26

Mrs. Waldemar, v, 22

Journey to the Aleutians, II

Juneau, passage to, I2, I3

Ka'gam-I'lan, burial cave on, I23 cave, 89

Island, I7, 45

mummies in cave on, 123

Kamchadal lamps, 76

methods of fishing, 2

mythologies of, 2

skin boats unknown to, II2

tribe, 77, II I

Kamchatka, I I2, I I4

Expedition, Ethnological Division of, r, 2, 3 , I I

volcanoes, I

Kamensky, P. P., sculptor, $3 \mathbf{I}$

Kanaga Island, sites and burial caves on, I22

Kayak, man's costume, I22

Keller, K., author, 9, I26

Keta (Oncorhynchus lagocephalus), I07

Kettles of steatite (soapstone), 57, 73

Khoroshoff, Peter, Aleut, I23

Khudyakoff, Yegor, Aleut, I22

Killer's tooth, $7 \mathbf{I}$

Killing reindeer, manner of, 8I

Kitchen, 34

middens, 2 I

American, II

antiquity of, II7

human remains in, $4 \mathrm{I}$

refuse of Aleut, I08 
Kixsin Island, 48

Klaprot, traveler, 8

Knife, bone, 79, 8I of walrus tusk, 79 stone, 93

Knipovich, N. M., Professor, v, 99

Knives, 39, 49 grooves on, 83 of African tribes, 77 polishing, 73 stone, $61,62,63,64,65$, I20 woman's tailoring, 63, 64

Knyrko, O. W., slides for testing minerals, made by, 56

Kodiak Island, I3, I4, I2I lamps, 57,75

Kolyma, Russian military transport, 18

Komandorsky Islands, coloning, I I I

Komarov, Wladimir L., Professor, v, I, I26

Kondratyeff, W. I., artist, v

Konrady, S. A., mining engineer, I

Koryak lamps, 76 tribe, 2,3

Kotzebue, O., traveler, 57, I26

Krasheninnikoff, H., author, 4I, I I 8, 126

Kremer, Hans, author, 9

Krœber, A. L., Professor, 12, 54, I26 harpoon described by, 54

Krug, E. W., mining engineer, I

Kurilians, tribe, II I

Kuzmin-Karavayef, B., captain, I8

Kyska Island, excavations on, ro2

Labrador, Eskimo of, 8

Labret, bone, 3I, 96, 97 marble, 3I, 57, 96, 97

Labrets, 96, 97, II 5, I22

Ladoga Sea, I08

Lake, salt-water, 39, II 4

Lamp, 28, 74, I22

bone, $3 \mathrm{I}, 76$

material, soapstone, 57

Lamps and implements, polished, I20

crescentic, I2I

for light, 73

warming, 73

manufacture of, 75

of Alaska, 75

Aleut, 75

Arctic region, 76

Asiatic Eskimo, 57

Bristol Bay, 75

burned clay, I22

Chukchee, 57, 75

Eastern Siberia, 75

Greenland, 75

Kamchadal, 76

Kodiak, 57, 75

Koryak, 76

Mackenzie River, 75

Northern Eskimo, 75

Point Barrow, 75

St. Lawrence River, 75

sandstone, 57

unbaked clay, 28, I22

shaping, 75

steatite for, 57

stone, 28, 3I, 32, 35, 74, 75, 76

and bone, 73, 109
Lamps, type, 75

used by hunters, 73

wick, 73

Lance, throwing, $3 \mathrm{I}, 83,85$ war, 92

Lancehead, 49

Lances, II 5

Langsdorff, von G. H., traveler, I26

Language of Aleut belongs to Eskimo stock, II 5

Lastova Bay, 23, 24, I05, I07

Lathyrus maritimus (wild pea), 2 I

Laugerie Haute, France, a palaeolithic station, 83

Lava andesitic, 56, 59 rhyolitic, 59

Leaders of expedition, I

Leather thongs, 53

Lee, Captain, I4

Lehmann-Nitsche, R., author, 5, I26

Lemon juice, I06

Leti, schooner, 17

Light, lamps for, 73

Linguistic connections of Aleut, II5

Lip, piercing in childhood, 98, 99

Lips, holes in, 96 perforation of adult, 99

Listchuk, P. S., artist, v

Littoral period of Dall, I02, 103, 106, II7

Living rooms, heating, 35

Louisiana, shell-heaps in, II7

Lupins, 2 I

Luschan, Felix von, Professor, 9, I0, II9, I26

Lütke, Th., traveler, I26

Lynx, II7

MacCurdy, G. G., archeologist, 83, 108, I26

Mackenzie River, lamps of, 75

Magdalenian epoch, harpoon heads of, 55 period, 9

Makushin volcano, 57

Malay-Mongolian-Caucasian, origin of American race, 4

Mammoth, from Asia to America, 6 tusk on St. Paul Island, I 4 tusks and teeth found on Unalaska in I8or, II 4

Man, migrated from Asia to America, 6 pseudo-ancient remains in South America, 5

Manufacture of bone and wooden objects, I20 implements, 67

lamps, 75

and kettles of steatite, 57

Mammalian layer of Dall, I02, I03

Map of Atka Island, 27

Ama'knax' Island, 37

Umnak Island, 30

Marble as material for artifacts, 26, 56, 57

labrets, 3I, 57, 96, 97

Marguerites, $2 \mathrm{I}$

Mason, O. T., author, I26

Masks, 47 harpoon described by, 54

ceremonial and dancing, II5 painted wooden, Ioo

Massachusetts Institute of Technology, I4

Mats and baskets made of grass, 46

Meal, echini, sufficient for a, ro6

Meat, fried, 73

Medicine men, Aleut, 93

Menton caves, palaeolithic finds in, ro8 
Mershenin, Michael, Aleut, 123

Metal vessels, 89

Meteorological condition of the Aleutians, 19, 20 division, I

Method of digging by author, 22 fishing of Kamcliadal, 2

Northwestern Indians, 2

Methodist Mission Home for boys and girls in Unalaska, I4

Mexico, high cultures of, Io

Migration from Old World to New, 9 of American race from Asia, 7

Eskimo, 8, 9

Mineralogical Museum of Academy of Sciences, Petrograd, 56

Minerals, determination of, by Obrucheff, v, 55 slides made by Knyrko, 56

Miocene period of Tertiary age, 6

Missionaries, Russian, 4I

Mollusks, 25, 32, 34, 46, 47 shell heaps of, I02

Mongol tribes of Asia, Io

Mongolia, remains in, Io

Mongolian-Malayan races, Indians as descendants of, 4

Mongolians, I I6

Mongoloid eyes, II6 traits of Eskimo, 8, I I6

Moorehead, W. K., author, I26

Mortillet, A. de, author, 69,126

Moscow, Rumiantzeff Museum, 26, 3I, 50, 59

Mousterian flint weapons, I20

Mouthpiece, bone, of seal floats, 9I, 99

Mouthpieces, ivory, for bladdered harpoons, 95

Mummies on $\mathrm{Ka}^{\prime}$ gam-I'lan, I7, 45, I23

Mummified corpses, 44 dead suspended in caves, 45,49

Mummifying of dead, method, 42, 43, 44

Murdoch, John, author, 3, 54, 95, 96,126

Museum of American Indian, 87, I00, I2I, I25

Musk-ox 6

Müller, F. R., author, 3

Mythologies of Indians and Palæ-asiatics, 7 Siberian Koryak and Kamshadal and

Myths, study of Aleut, I5 Indians of America, 2

Nani'kax', bone flakes at, 7I pits at 23,24 village site, $29,50,100,109$

Nansen, Fridtjof, I26

Nasal cartilage, holes in, 96,98

Nassonov, N. V., professor, 7

Natural features of Aleutian Islands, I9

Natxu'kax' village site, 57, 93

Natykin Bay, 40

Nazan Bay, I7, 27, I22

Necklace of salmon vertebrae, I08

Needles, bone, 3I

Negroes of Africa knew art of smelting iron, II9

Nelson, E. W., harpoon described by, 54 traveler, 3, 54, 9I, 95, 97, I00, 126

Nelson, N. C., archaeologist, 126

Neolithic age, 72, I03, I20 shell-heaps in, II7

period, I03, I08 in Scandinavia, 6

Neo-Siberians, 3, 4

Nerka (Oncorhynchus lycaodon), I08
Net sinkers, I Io

Nets, 107

stone, I02

New World, shells heaps in, II7

New York, arrival of expedition, I I plans for transportation made in, 14

Nikolskoye village on Umnak Island, I7, 29, 33, 35

Nome, in winter, reached from Valdez, by dog-teams, I3

North America, Indians of, 2 no remains of Tertiary or Diluvial man have been discovered in, 5

American archaeology by Dixon, I23 Commercial Company, I3, I4, 37 Indian, 4I

Pacific Coast of North America, culture of tribes of, 2

Nose-pendants, 98, 99

Nutxa'kax' village site, $29,30,33,5$ I

Nyuman, Mr., I4

Obermaier, H., author, 55, 82, I27

Obrucheff, W. A., professor, v, 55, 56

Observatory of the Aleut 23

Octopus, catching, 106

Okhotsk, district, I7

Old World, Stone Age of, 69

Onkilon, dwellers of the Arctic, 8

Ookhtomsky, D. E., ethnologist, 76, I27

Orchids, 2I

Organization and personnel of the expedition, I

Origin of Aleut, theory, III, II5

Ornamentation, geometric, 93, I2I of weapons, 92

Ornaments of ear, 96 realistic, I2I

Osborn, Henry Fairfield, professor, palaeontologist, 9, I I, I27

Ox, wild, I I7

Pacific eider, 25

gull, 25

Ocean, 12, 30

Polynesians in, 6

right whale, 39

Pain, B. H., author, 125 , I27

Paint, material, 59 traces of red, 39

Painting of face, 96, I22 implements, 94

skins, I Io

Paints, use of II 5

Palæasiatic languages, 3 tribes, 4,8 , I0 culture of, 2

Palæasiatics, III, I I6 and Indians, 8 cultural and physical affinities, 7

Indians and Eskimo, ethnological connection, 7,8 investigation by the Jesup Expedition, 4 physical type, 7

the term, 3

Palaeoethnologists, I07

Palaeolithic art, 108 period, $42,72,108$ of Western Europe, implements of 55 station at Laugerie Haute, France, 83 
Palaeo-Siberians, 3, 4

Pallas, P. S., traveler, II2, 127

Patagonia, shell-heaps in, II7

Patkanoff, S. K., author, III, I27

Patrol fleet of Bering Sea, I5

Pavloff, P. P., artist, v

Peabody Museum, v, 83, I2I

Penis bone, sea otter's, as flaker, 70, 7I, 72, 78

Perry, revenue cutter, I6, I8

Personnel and organization of the expedition, I

Peschel, O., ethnologist, 3, 127

Peshenkoff, Yegor, Aleut, I23

Petrel, 25

Petrified shells of the Tertiary Period, II4

Petrograd, 22, 56

Petropavlovsk, Kamchatka, 18

Philadelphia, University Museum of, v, I2 I

Physical traits of Aleut, II6, I22

$$
\text { the Kamchadal, } 2
$$

Picks, bone, 82, 121

type of Palæ-asiatics, 7

Pictographic art of Eskimo, 2

Pike, I08

$$
\text { writing of Yukaghir, } 2
$$

Pinart, A. L., ethnologist, 21, I01, 127

Pit in Hala'ca, layers, etc., 29

Pits at Agla'gax village, 32

Nani'kax', 24

Nutxa'kax', contents, etc., 33

Sin village, 26

Tanaxta'xax', contents, 39

Uglu'dax', contents, 35

U'kix', contents, etc., 34

Umnak, contents, 32

Xata'cxan, contents, 38

burial, 26

digging, 22

on Umnak, contents, etc., 30

refuse in, 33

size and contents of, $25,26,28,33$

Plants, Asia as place of origin of cultivation of, 9

Pleistocene fossils not found on Aleutian islands, II4 period, bones belonging to, 5 of Alaska, 6, II3

Siberia, 6

Pliocene period of Tertiary age, 6

Plutonic rocks, II3

Point Barrow, Eskimo of, 75

$$
\text { lamps of, } 75
$$

Poison-channels (Giftrinnen) of grooved spears, 82

Polished knives, 73 stone implements and lamps, r2o

Polishing implements with horse-tail, 72 material, 59

Polygenetic theory of man's origin, 5

Polynesia, immigrants from, 4

Polynesians in Pacific, 6 southern America, immigration of, 6

Population of Aleut settlements, II9

Porphyry, kaoline, 57

Port Möller, Alaska, I02, I23

Portugal, shell-heaps in, II7

Post, bone, 33

-Pliocene period of Aleutian Islands, I I4

Posture in playing chess, 43

$$
\text { of dead, I0I }
$$

the Aleut, 43

Potatoes, Aleut plant, 35
Pottery, Aleut, of unbaked clay, 28, I22

Eskimo, of burned clay, I22

making, loss of, 89

of the Chukchee, 2

Prehistoric man, food of, I08

Preparations for the journey, II

Pre-Russian period, II5

Preuss, Th., ethnologist, I27

Pribilof Islands, I I, I3, I5, I8, 106

Brown's statement of, II4

freight for, I5

lessees of, I3

Proceedings, International Congress of Americanists, I

Prokopyeff, Philaret, Aleut chief of Attu, 74, I22

Prosoff, Michael, Aleut of Attu, I22

Pseudo-ancient remains of man in South America, 5

Puffins, 25, 47

Pulp cavity of bone, 79,83

Pumice, 59

Quaternary period, 6

Quinan, Johnston H., captain, I7, I8

Radloff, L., author, 3, I27

Rafters, whale-bones as, 32

Rafts, 102, I03

Rau, Charles, author, 127

Raven beaks as amulets, 47 mythical, 2

Reasons for investigation of the Aleut, 2

Realistic carvings of Eskimo, 2, 9

Koryak, 2

Recent time, separation of America from Asia in, 6

Red felsite, 59

ocher, 59

Refuse in pits, 33

of ancient habitations, 21

Reindeer appeared in America, 6

breeding, 2

hunting, I2I

killing for food, 8I

manner of killing, 8I

purchase of, at Okhotsk, I7

Religious attitude to animals hunted, I 8

concepts of the Aleut, 4I

significance of hematite, 59

Retouching stone blades, 7 I implements, $7 \mathrm{I}$

Revenue Cutter Service, I7 use of, 15

cutters, assistance of, I8 at Unalaska, I5

Rhyolitic lava, 59

Riaboushinsky Brothers, v

Ring, bone, 83

$$
\text { F. P., I, 53, } 54
$$

Rink, Mr., author, 8

Rissov, Nicholas, priest, 14

Rivière, Mr., to8

Rock caves as burial places, 45 structure near Bering Strait, 6

Rocks of Aleutian Islands, II 3 plutonic, II3 volcanic, 37

Roe of echini as food, Io6

Rookeries of sea-mammals as hunting places, I22

Rooms for sleeping, 34

Root-digger, 3I 
Rosy finch (Leucosticte tephrocotis), 25

Rotted wood as indicative of age of burial place, 52

Rumiantzeff Museum in Moscow, 26, 50, 59

Russia, visit of Captain Bertholf to, I7

Russian Academy of Sciences, 3 ambassador in Washington, I I

American Company, 40 conquerors, II 9

custom of burying, 4I

ethnologist, Prince Ookhtomsky, 76

Geographical Society, I, 2, II

geologist Inostrantzev, I08

Home for Aleut boys, I4

influence at Sitka, I2

on Aleuts, 21

of head measurements, I I5

invaders, 23, IIO

missionaries, 4I

priest, Shayeshnikov, I3

skeleton, 52

Synod, Holy, I3

Russians, 73, 89, I09

Aleut, discovered by, I I

at Agla'gax', 32

chess from, 43

influence the Aleut type, II6

of Yukon, 98

on Umnak, 30

Saikoff, P., Captain, II2

St. George Island, I I4

St. Lawrence River, lamps of, 75

St. Paul Island, I8, 40

mammoth-tusk found on, II

St. Vladimir, ship, the visit to Aleutian Islands, I I2

Salmon, 107, 108

Aleut lived on, in summer, II8

annual spawning migration, 23

Salt-water lake, 39

Sama'lga Island, 30, 57, I23

Sandstone lamps, 57

San Francisco, I3

arrival of expedition in, II visit to, 12

San Miguel Island, California, 87

Sa'nnax', excavations by Dall on, 102

Santa Clara, I2

passengers, 13

Sarana Bay, Attu Island, 7, I6, 23, 24, I07

Sarytcheff, G., traveler, I27

Sauer, Martin, traveler, I27

Scandinavia, Neolithic period, 6

Scandinavian fjords, i2

navigators, 9

Scientific results of Ethnological section of the Riaboushinsky expedition of the Imperial Russian Geographical Society, etc., I

Scharf, R. F., author, 6, I27

Schiefner, A., author, 3

Schist, 57

Science, weekly magazine, 7

Scientific members, I work in Aleutians, I8

Schloss, Mr., I2

Schmidt, Emil, author, I27

Peter J., zoologist, I

School, Government elementary, Unalaska, I4
Scotland, Azilian stage in, 6

Schrenk, Leopold von, 3, 4, 8, II, I27

Schiefner, A., author, I27

Schroter, Mr., manager of North American Commercial Co., Dutch harbor, I4

Schwalbe, G., author, I28

Scraper, bone, for dressing guts, 3I, 78

Scrapers, 78, i Io

Scratcher, back, 89, 9I

Sculpins, Io7

Sea-birds, bones of, I03

depth of, II4

hunting of Eskimo, 2

-lion, 47

bones of, 28

tooth of, 89,93

mammal bones, 46

mammals, $23,25,32,34,36,38$, I2I

hunting, $9 \mathrm{I}$

-otter, hunting by Captain Applegate, I4

-otters, I5, 47 on Attu, 25

-urchin period, I03 -urchins, 25 shells, 36, 104, 105, 106, I07

Seal, 28, 36

at Attu, 25

-bones, 46

fisheries, studies by Suvoroff, II2

-guts, skirt of, IOO

hunting, 46

Seals, 47

on Attu, 25

Seattle, city, I2, I3, I8

Sedge-grass, I9

Seines, I07

Semenov-Tyan-Shansky, P. P., president Russian Geographical Society, I

Semitic languages, 4

Sentry, 23

Serpentine for making implements, 57,59

Severtzoff, M., zoologist, 7

Seward, Peninsula, 6, I3, I 23 village on Kenai Peninsula, I2, I3

Sewing clothing, i Io

Shaft straightner, 97

Shark, I07

Shayeshnikov, Mr., I3, I4

Sheep from High Asia migrated to America, 7 mountain, 6

Shelagskoi, Cape, 8

Shelikhof Strait, I3

Shell-heap period, Aleut, I20

-heaps in various countries, II7 depth of, I02, II 7 , I 8

Shells of Litorina period, II7 sea-urchin, 36, 105

Shepetin, Mark, Aleut, 30, 33

Shipwrecks, no migrations effected by accidental, I I3

Shirt, water-proof, Ioo

Shokalsky, J. M., Lieutenant-general, I

Shore-line of California, II7

Shovel, bone, 78,88

Shumagin Islands, excavations by, I5, I02

Siberia, 4, 4I
Cape Navarin in, I I5 geological data of, 6 lamps of Eastern, 75 
Siberia, northeastern, diggings in, I23

remains in, to

$$
\text { tribes of, } 3
$$

travel of Captain Bertholf, I7

Siberian Americanoid tribes, reëmigration from America to Asia, 7

and American tribes, 3

bone implements, 77 spears, 8I

culture, II5

Eskimo show a mesocepnalic index, II6

Koryak, mythologies of, 2

natives, 2 , 42, II I

reindeer, I7

sheep, 8

tribes, 89

tundra, I 9

Sibiriakoff, Innocent, banker, 2

Sick people warming over stone lamps, 73

Siguan Island, 57

Simichi Island, sites and burial cave on, I22

Sin, ancient village, Attu, 24, 26, 46

Sinew as material for lines, 53

Sinkers, stone, 39,66 , г1

Sitka, fir trees from, 49

former capital of Russian-American territory, I2

Sivtzeff, L. I., assistant priest, vi

Skeletal remains, 29

Skeleton, $36,38,40$

$$
\text { in North Amerika, } 5
$$

found by Dall, Ior

fragment, 33

in Pit, 6, 26

of child, $5 \mathrm{I}$

Russian, 52

warriors, 52

postures, 50

Skeletons found in large pits, 49 on Atka, 48

Skin boats, $15,22,29,45,96$, I 5, I 22 of Eskimo, 2 unknown to Aino, Gilyak, and Kamchadal, I 2

$$
\text { -color, II6 }
$$

Skinner, Alanson, author, I27

Skins of sea mammals, 47

Skirt of seal-guts, I0o

Skull in pit, 28

Skulls, dolichocephaly of, iा6

excavated, 79, II 5

measurement of, II5

of killed sea animal thrown into sea, II 8 on Atka, 47

Virchow's measurement of, I 6

Slate, 56, 57 tailoring-knife of, $62,63,64,120$

Slates found on Unalaska, I 3

Sledges, I22

Sleeping-places, 46

$$
\text { rooms, } 34
$$

$$
\text { for children, } 40
$$

Small Sitkin island, II 4

Smith, Harlan I., archa eologist, I27

Smoking craters still found, II4

Snegireff, Leonty, Aleut, I23

Snow-beaters, I2I

goggles, I2I

knives, I2I
Snow-shoes, I2I

of Eskimo, 2

shovels, I2I

Soapstone as lamp material, 57 bartering of, 57

kettles, 73

Social organization of Eskimo tribes, 2

Palæ-asiatics, 2

Sollas, W. J., author, 6, 9, II2, I27

Solovyov, Unalaska founded by, I3

Solutrian flint weapons, I20

Somatical connections of Aleut, I I5

South America, fossil bones from, 5 pseudo-ancient remains of man in, 5 remains of Tertiary and Diluvial

South Carolina, 43 man, 5

Spear, 77,83

Eskimo bone, 8I

fishing, $3 \mathrm{I}$, IIO

found at Atxa'lax', 85

Spears, from ice-picks, 79

Spence, Doctor, Unalaska, I4

Spiritual culture of the Kamchadal, 2 traits of Aleut, I22

Splitting $\log s, 32,37$, I IO, I20

Squatting, women while working, 43

Steatite for lamps, 57

Steensby, H. P., author, II2, II3, I27

Stefansson, V., traveler, 8, I27

Stein, F., author, II4, I27

Steinmann, G., author, 5, I27

Steller, G. W., traveler, I27

Sternberg, L. J., author, I I2, I28

Stomachs or bladders of reindeer, seal, white whale, or walrus for carrying water or seal oil, 9I

Stone adzes, 58, 62, 72, I20

Age, 21, 35, I09, II9 objects, I20 of the Old World, 69 man in Europe, 82

and bone lamps, Iog weapons, 43

axes, 58, 72, I20

blades, retouching, $7 \mathrm{I}$

disk, 65,67

drill point, 67

hammers, I02, I20

implements, 47 grinding, 72 retouching, 69, $7 \mathrm{I}$ polishing, 72,73

knives, passim

lamp, 3I, 32, 35, 72, 73, 75, 76, I20

lamps carried by hunters, 48

net-sinkers, I02

tool for chipping, 3I

Stools, use of, 43

Stoppers for bladders and stomachs, 9I

Storage places for edible roots, 35

Strata, Dall's description of, 38 , ilo

in excavations, $27,29,31,32,34,36,38,39,40$, 48, 103, I05, I07, I08, IIO, II7, II 8

Suess, Ed., geologist, I9, II3, I28

Superbrachycephalic index, Aleut acquired a, II6

Surgery, stone implements for, 6o, 6r

Sushkin, Peter P., professor, 7

Suvoroff, Professor, II2, I28

Swalbe, G., author, 5, I28 
Swords, grooves on, 83

Symbolical ornamentations on implements, 93

Tahoma, revenue cutter, 16 , 17 , I8

Tailored fur clothing, Eskimo, 2

$$
\text { in Siberia, } 2
$$

Tailoring-knife, slate, $62,63,64$, I20

Ta'naga Island, sites and burial caves on, I22

Ta'nam-Añuna', island, III

Tananah Indians, 98

Tanaxta'xax', village site, $37,39,49,52$

Temperature, mean, on the Aleutians, 19,20

Tent-frame, Yukaghir, 32

Tents, temporary, of hunters, 74

Terpug, fish (Hexagrammus), 25

Tertiary man in North America, 5

$$
\text { Period, II } 3
$$

South America, 5

Thalbitzer, William, traveler, 8, I28

Thawing and freezing of ground, 123

Thomas, Cyrus, author, I28

Thread used in fastening hunting implements, 53

Throwing-board, I I5, I2I

-darts, I22

-lance or spear, 31, 53, 55, 60, 6I, 94, I09

-lances, on skeleton, burial of a warrior, 50 still in use, 67

weapons, 92,93

for drilling, 93

Tibet, remains of a more ancient population in, Io

Time needed to form strata of echini, ro6 required for field work by the author, 22 to form mound of kitchen refuse, 103

Tlingit, tribe, II6, I23

Tool for chipping stone, 3 I

Transbaikalia, Hrdlička's travel over, Io

Transportation at Unalaska, I4 without animals, 22

Traveling in Aleutian Islands, I8

Treasury Department, permission to travel on revenue cutters, I5

Trees, absence of growing, 59, I07, I20

$$
\text { fir, from Sitka, } 49
$$

Tsimshian, Indians, I 6

Tufted puffin, 25

Turner, L. M., author, 54, I28 harpoon described by, 54

Turnips, Aleut plant, 35

Types, variety in of Asiatics and American races, 6

Uglu'dax:, 29, 35, 73, 89, т03

fresh water at, 35

pits at, contents, 35

site, 5 I

strata of pits at, 36

Uhle, Max, author, I28

U'kix', 23, 29, 69

bone flakes at, 71

pits at, 34

site, 50

village, 33,49

Ukna'dax', hogs at, 40

Island, excavations on, 40

site, age of, 40

Ulagan Island, burial cave on, I23

Umnak Island, I5, I6, 33, 47, 49, 50, 5I, 57, I07, I2I, I23 arrival at $\mathrm{I} 8$

excavations by Dall, I02
Umnak Island, fresh water on, 30

harpoon specimen on, 54

map of, 30

pits on, contents, etc., 30,32

temperature, I9

travel by foot, 22

Unalaska, I2, I3, I7, I8, 22, 37, 39, 4I, 44, I23

description of life in, I3

excavation by Dall, I02

Harbor, I5

mammoth tusk and teeth found cn, in I80r, I I4

population of, I4

reception at, I3

revenue cutters at, 16

village, clfief of, 18

Underground dwellings, 23

Unga Island, 13, ror

Unimak Pass, II5

United States Coast and Geodetic Survey, 2I, IOI

Government, permission to work on Aleutian Islands, II

National Museum, 44, I2I

Ethnological Division, 75

Signal Service recorder at Unalaska, I4

Treasury Department, application for use of vessels, II

University Museum of Philadelphia, v, I2I

Ural-Altaic group of languages, 3,4 -Altaians, 3

Urile quill, 89

Uriles, 25,47

Urn burial, 43

Valdez, village, I3

Vessels, metal, 89

of burned clay, Eskimo, I22

Village sites, mode of examining, 22

Villages, location, 23

on open isthmuses, II8

Virchow, Rudolf, professor, 8, I 16 , I28

Virchow's measurement of Eskimo skulls, II6

Vix, author, 128

Vladivostock, i8

Vlassov, W. A., meteorologist, I

Volcanic chain in Alaska, I8 origin of Aleutians, to rocks, 37 tuff, 59

Volcano of Makuskin, I3

Volcanoes, Kamchatka, I

von Luschan, Felix, professor, 9, 10, I19, 126

Wagner, Miss, mail clerk, I4

Walcott, Charles D., Secretary of Smithsonian Institution, II

Walrus tusk, ivory, 77, 100 knife of, 79

War lances, 80, 82, 85, 86, 92, 94, 95

Wardle, H. Newell, author, I28

Warming lamps, 73

Warrior, burial of, 50

Warriors, Aleut, 28 skeletons of, 52

Warshavsky, A. I., artist, v

Washing skeletal bones, 4I 


\section{INDEX.}

Washington, Anthropological Society of, I 16 visit of expedition to, I I

Water, fresh, 33, 39 at Uglu'dax', 35 on Umnak, 30

-line of California, II7 -proof shirt, I00

Weapons, 53

$$
\text { ornamentation of, } 92
$$$$
\text { stone and bone, passim }
$$

Weather conditions on the Aleutian Islands, 23

Weckerly, C. A., artist, v

Weather Bureau, U. S., I4

Wedges, bone, 32, 37, I I0, I20

Weniaminoff, J., missionary and author, 37, 38, 46, 57, III, II 4, I 28

finds mammoth-tusk on St. Paul Island, II4

Weniaminoff's grammar, Aleut language in the light of, I

theory of the Mongolian origin of the Aleut, II I

Whale, $25,36,38,40$, I03, I09

bones, $32,38,47,48,50$, I09

as posts, i Io

framework of dwellings, 28

jaw, 28, 32, 40, II7, I20

stone carving, $3 \mathrm{I}$

Whalers at Unalaska, I5

Whetstone, 3I, 49

Wick of lamps, 73, I2I
Wild barley (Elymus), 2 I

ox, II 7

pea (Lathyrus maritimus), 2I

Wildcat, II 7

Wilson, L., author, I28

Thomas, author, 69,128

Wissler, Clark, author, II, II6, I28

Women did not accompany hunters, II3

Wood, adze for working in, 73

Wooden handles, bone flakers fitted with, 7 I implements, 53

objects, 47

Woody Island, I2I

Wounds, bone plugs to close, 8I

Wrangel, F. von, traveler, 8, III, I28

Writers on prehistoric archaeology, 55

Xata'cxan village site, $37,38,49$

Yachmemev, A. M., Aleut chief, vi, I8

Yakut expedition of I895, 2, 4

Yale University, Peabody Museum, 83

Yarrow, H. C., author, 4I, I28

Yenissei Ostyak, 3

Yermiloff, Cyril, Aleut chief, I23

Yukaghir hunters, 77

tent-frame, 32

tribe, 3, 4I, 42, 93

Yukon Inuit, I00

River, I3

Russians of, 98 



